\title{
Methane Hydrate Production from Alaskan Permafrost Final Report
}

October 1, 2001 to January 31, 2005

by

Thomas E. Williams (Maurer Technology Inc.)

Keith Millheim (Anadarko Petroleum Corp.)

Bill Liddell (Anadarko Petroleum Corp.)

March 2005

DE-FC26-01NT41331

Maurer Technology Inc.

13135 South Dairy Ashford, Suite 800

Sugar Land, TX 77478

Anadarko Petroleum Corp.

1201 Lake Robbins Drive

The Woodlands, TX 77380 


\section{Disclaimer}

This report was prepared as an account of work sponsored by an agency of the United States Government. Neither the United States Government nor any agency thereof, nor any of their employees, makes any warranty, express or implied, or assumes any legal liability or responsibility for the accuracy, completeness, or usefulness of any information, apparatus, product, or process disclosed, or represents that its use would not infringe privately owned rights. Reference herein to any specific commercial product, process, or service by trade name, trademark, manufacturer, or otherwise does not necessarily constitute or imply its endorsement, recommendation, or favoring by the United States Government or any agency thereof. The views and opinions of authors expressed herein do not necessarily state or reflect those of the United States Government or any agency thereof. 


\section{Abstract}

Natural-gas hydrates have been encountered beneath the permafrost and considered a nuisance by the oil and gas industry for years. Oil-field engineers working in Russia, Canada and the USA have documented numerous drilling problems, including kicks and uncontrolled gas releases, in Arctic regions. Information has been generated in laboratory studies pertaining to the extent, volume, chemistry and phase behavior of gas hydrates. Scientists studying hydrates agree that the potential is great-on the North Slope of Alaska alone, it has been estimated at 590 TCF. However, little information has been obtained on physical samples taken from actual rock containing hydrates.

This gas-hydrate project is a cost-shared partnership between Maurer Technology, Anadarko Petroleum, Noble Corporation, and the U.S. Department of Energy's Methane Hydrate R\&D program. The purpose of the project is to build on previous and ongoing R\&D in the area of onshore hydrate deposition to help identify, quantify and predict production potential for hydrates located on the North Slope of Alaska.

As part of the project work scope, team members drilled and cored the HOT ICE No. 1 on Anadarko leases beginning in January 2003 and completed in March 2004. Due to scheduling constraints imposed by the Arctic drilling season, operations at the site were suspended between April 21, 2003 and January 30, 2004. An on-site core analysis laboratory was designed, constructed and used for determining physical characteristics of frozen core immediately after it was retrieved from the well. The well was drilled from a new and innovative Anadarko Arctic Platform that has a greatly reduced footprint and environmental impact. Final efforts of the project were to correlate geology, geophysics, logs, and drilling and production data and provide this information to scientists for future hydrate operations.

Unfortunately, no gas hydrates were encountered in this well; however, a wealth of information was generated and is contained in the project reports. Documenting the results of this effort is key to extracting lessons learned and maximizing industry's benefits for future hydrate exploitation. In addition to this Final Report, several companion Topical Reports were published. These are available from the DOE and on the project's web site.

\section{Project Topical Reports:}

1. "Hydrate Core Drilling Tests"

2. "Drilling and Coring Operations"

3. "Logging Operations"

4. "Core and Fluid Analysis"

5. "3D Vertical Seismic Profile Survey"

6. "Hydrate Reservoir Characterization and Modeling" 


\section{Table of Contents}

Disclaimer ................................................................................................................................

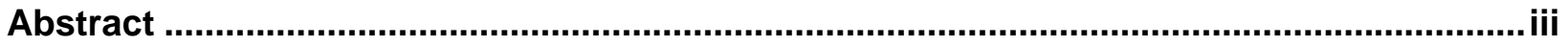

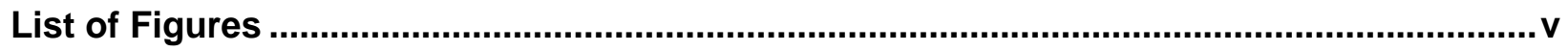

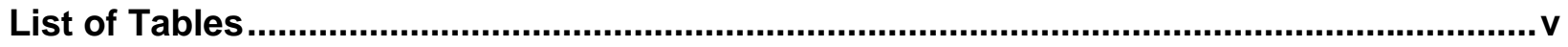

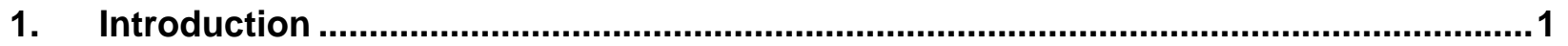

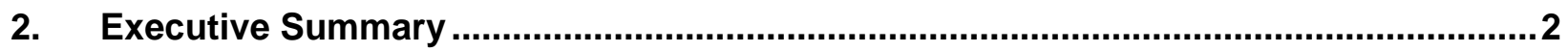

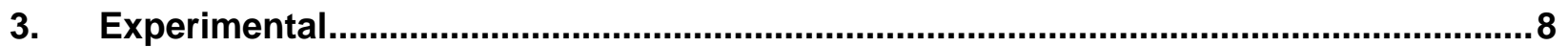

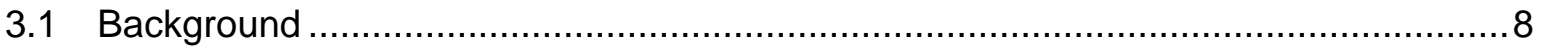

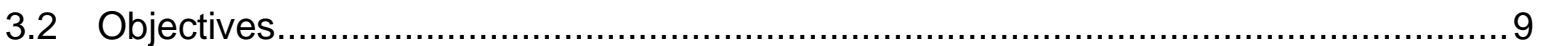

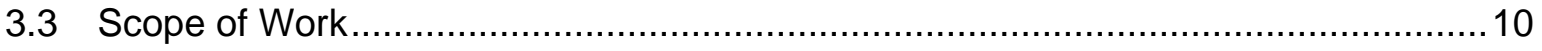

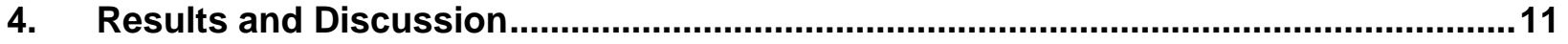

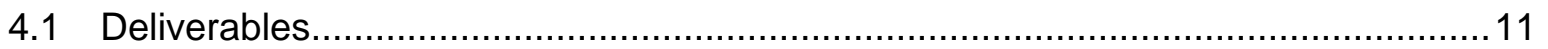

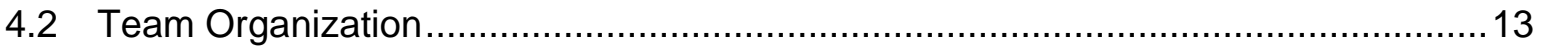

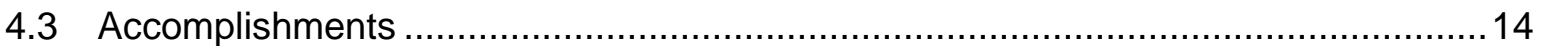

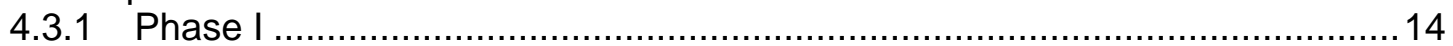

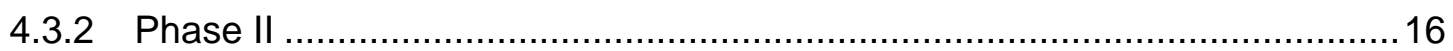

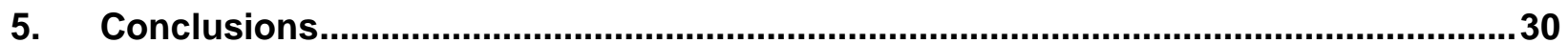

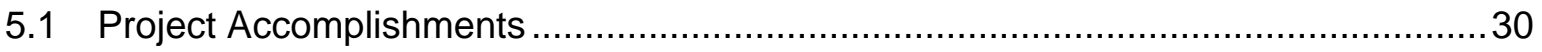

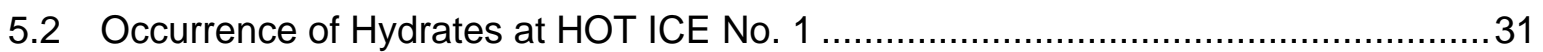

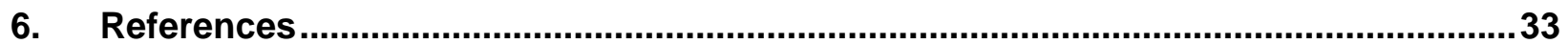

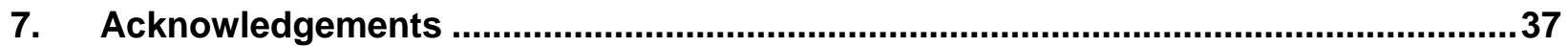

Appendix A: Post-Well Analysis

Appendix B: Draft Completion Procedures

Appendix C: Draft Well Test Procedures

Appendix D: $\quad$ Fundamental and Applied Research of Gas Production from North Slope Hydrate Deposits

Appendix E: HOT ICE No. 1 Site/Rig Photos

Appendix F: Project Presentations at AAPG Hedberg Research Conference, "Natural Gas Hydrates: Energy Resource Potential and Associated Geologic Hazards," on September 12-16, 2004 in Vancouver, BC, Canada. 


\section{List of Figures}

Figure 1. Arctic Platform during Summer ............................................................. 4

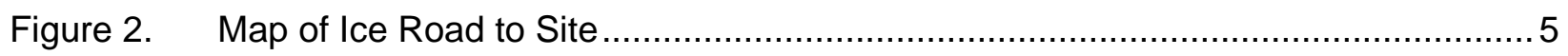

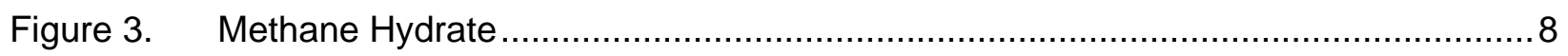

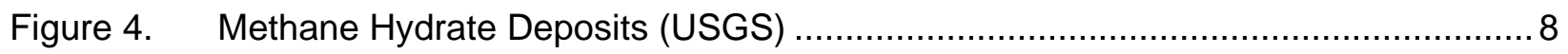

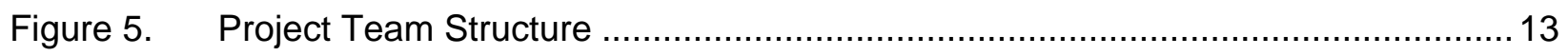

Figure 6. Map of North Slope Showing Location of HOT ICE No. 1 ............................... 15

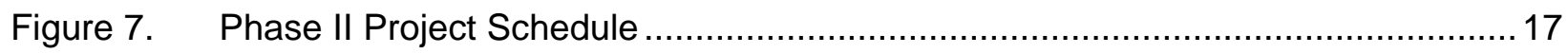

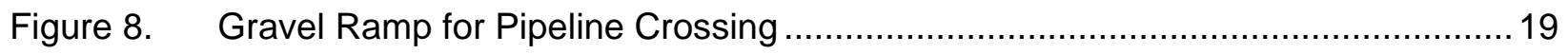

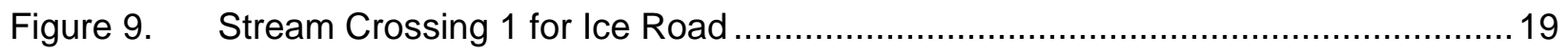

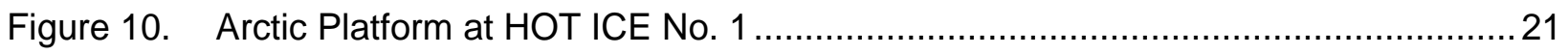

Figure 11. Final Stage of Platform Removal and Site Remediation ............................... 21

Figure 12. Mobile Core Laboratory at HOT ICE No. 1 Site ............................................. 23

Figure 13. Members of Project Team after Donation of Mobile Core Laboratory to

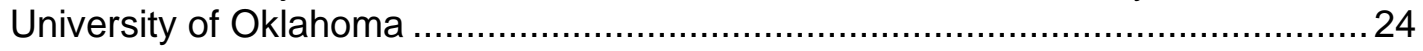

Figure 14. Distribution for Total Free Gas and Hydrate Reserves in Cirque/Tarn Area ..........27

\section{List of Tables}

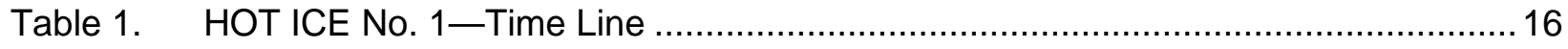

Table 2. $\quad$ HOT ICE Location Winter 2004 Access ........................................................ 18 


\section{Introduction}

The purpose of this project is to plan, design and implement a program that will safely and economically drill/core and produce natural gas from Arctic hydrates. The project team has given special attention to documenting project activities including planning, operations and lessons learned to assist in future hydrate research and field operations. This information will be valuable in making an objective technical and economic assessment of this promising natural gas reservoir potential.

On February 7, 2004, the HOT ICE No. 1 well (HOT ICE = High Output Technology Innovatively Chasing Energy) reached the planned depth of $2300 \mathrm{ft}$, about $300 \mathrm{ft}$ below the zone where temperature and pressure conditions would theoretically permit hydrates to exist. Although significant gas shows were encountered in highly porous sandstones, no methane hydrates were found. The continuous coring rig used in the project proved to be a safe and efficient drilling system, with $93 \%$ of the core recovered.

This project used a special purpose on-site laboratory to analyze cores as drilling progressed. Real-time data and images were transmitted from the rig over the internet, which reduced the number of engineers and scientists required to oversee the project. Additionally, the well was drilled from a special purpose-built Arctic platform. A massive 3D VSP seismic survey was also conducted to investigate lateral variations of the potential hydrate reservoir. 


\section{Executive Summary}

\section{Objectives and Scope of Work}

The objectives of this project were to analyze existing geological and geophysical data and obtain new field data required to predict occurrences of gas hydrates; to test the best methods and tools for drilling and recovering hydrates; and to plan, design, and implement a program to safely and economically drill and produce gas from hydrates in Alaska.

The Overall Scope of Work was to:

1. Evaluate geological and geophysical data that aid in delineation of hydrate prospects

2. Evaluate existing best technology to drill, complete and produce gas hydrates

3. Develop a plan to drill, core, test and instrument hydrate wells in Northern Alaska

4. Characterize the resource through geophysics, logging, engineering and geological core and fluids analysis

5. Test and monitor gas production from hydrate wells for one year

6. Quantify models/simulators with data for estimating ultimate recovery potential

7. Learn how to identify favorable stratigraphic intervals that enhance methane production

8. Assess commercial viability of developing this resource and develop a long-term production plan

9. Provide real hydrate core samples for laboratory testing

10. Develop and test physical and chemical methods to stabilize hydrate wellbores and improve core recovery

11. Step outside the well-known Prudhoe Bay/Kuparuk River area to further delineate hydrate deposits in Alaska

12. Report results to the DOE and transfer technology and lessons learned to the Industry

\section{Phase II Participants}

Maurer Technology Inc. - Performed project coordination, project management and testing of coring tools and techniques at the Drilling Research Center. Served as Prime Contractor with the DOE.

Anadarko Petroleum Corporation - Served as project manager for the design, construction, and operation of the Arctic Drilling Platform, mobile core laboratory, and field coring operations. Secured well location and permitting.

Noble Engineering and Development - Provided personnel and real-time data collection and transmitted digital data and video to project participants located off-site as well as well-site drilling personnel. 
University of Alaska (Anchorage) - Provided support studies on geology, tundra, and disposal of produced water.

University of Oklahoma - Assisted with testing the core system and in development of the purpose-built mobile core laboratory.

Lawrence Berkeley National Laboratory (LBNL) - Performed reservoir modeling used for well test planning and onsite portable $\mathrm{X}$-ray scanner with wellsite operator.

Sandia National Laboratories - Provided downhole mud pressure and temperature recording tool.

Pacific Northwest National Laboratory (PNL) - Provided portable infrared scanner.

United States Geological Survey (USGS) - Provided synthetic core for drilling tests, phase behavior model for hydrates, pressure vessels for hydrate core storage and technical advice. Modeled hydrate preservation and dissociation. Provided personnel for coal core and analysis.

Schlumberger Oilfield Services - Provided CMR equipment used in mobile core laboratory and two onsite analysts; and well-logging services.

Paulsson Geophysical Services - Performed vertical seismic profiling.

Advisory Board - Craig Woolard (University of Alaska, Anchorage); Steve Bartz (Schlumberger); Steve Kirby (USGS); Tim Collette (USGS); Theresa Imm (Arctic Slope Regional Commission); C. Sondergeld (University of Oklahoma); Richard Miller (University of Kansas); and David Young (Baker Hughes INTEQ)

\section{Previous Accomplishments}

- Design and construction of Anadarko's Mobile Core Laboratory completed in August 2002. This highly capable laboratory permits cores to be maintained and analyzed at a reduced temperature and in close proximity to the drill site.

- Operational and logistics planning, geology and geophysics analysis, and site selection completed and environmental and operations permits obtained by the end of December 2002.

- Anadarko's Arctic Platform was installed on site in February 2003. Technology tested here could help achieve three goals independent of this project:

o allow operators to work outside present operations season on the North Slope

o provide access to remote areas where water to build ice roads is scarce and steep grades make it difficult to set or supply a drilling rig

o reduce environmental impact of a well location on the tundra

- $\quad$ Arctic Platform topside facilities were set during March 2003.

- HOT ICE No. 1 Well was spudded on March 31, 2003. 
- Well was cored, logged and cased to the base of the permafrost during April 2003.

- The Arctic Platform fully met expectations for very low environmental impact as it remained in place through a summer season, and was successfully removed with no adverse impact to the surrounding site.

- Drilling operations resumed on January 30, 2004.

- Well successfully reactivated and cored to $2300 \mathrm{ft}$ with $93 \%$ core recovery.

- Well was logged and a massive 3D vertical seismic profile (VSP) survey conducted.

- Geological models were calibrated.

- Phase I Final Report and a Topical Report were completed to document the effort and transfer knowledge to the industry.

The HOT ICE No. 1 well is located approximately 20 miles south of the Kuparuk River oil field center and about 40 miles southwest of Prudhoe Bay. Based on evidence from nearby offsets in the Cirque and Tarn gas-hydrate accumulations, hydrates were expected to be found in sands near the base of the permafrost. The well was spudded on March 31, 2003, and was continuously cored from a depth of $107 \mathrm{ft}$ to $2300 \mathrm{ft}$ (RKB) with core recovery of 93\%. The base of the permafrost was crossed at about $1250 \mathrm{ft}$.

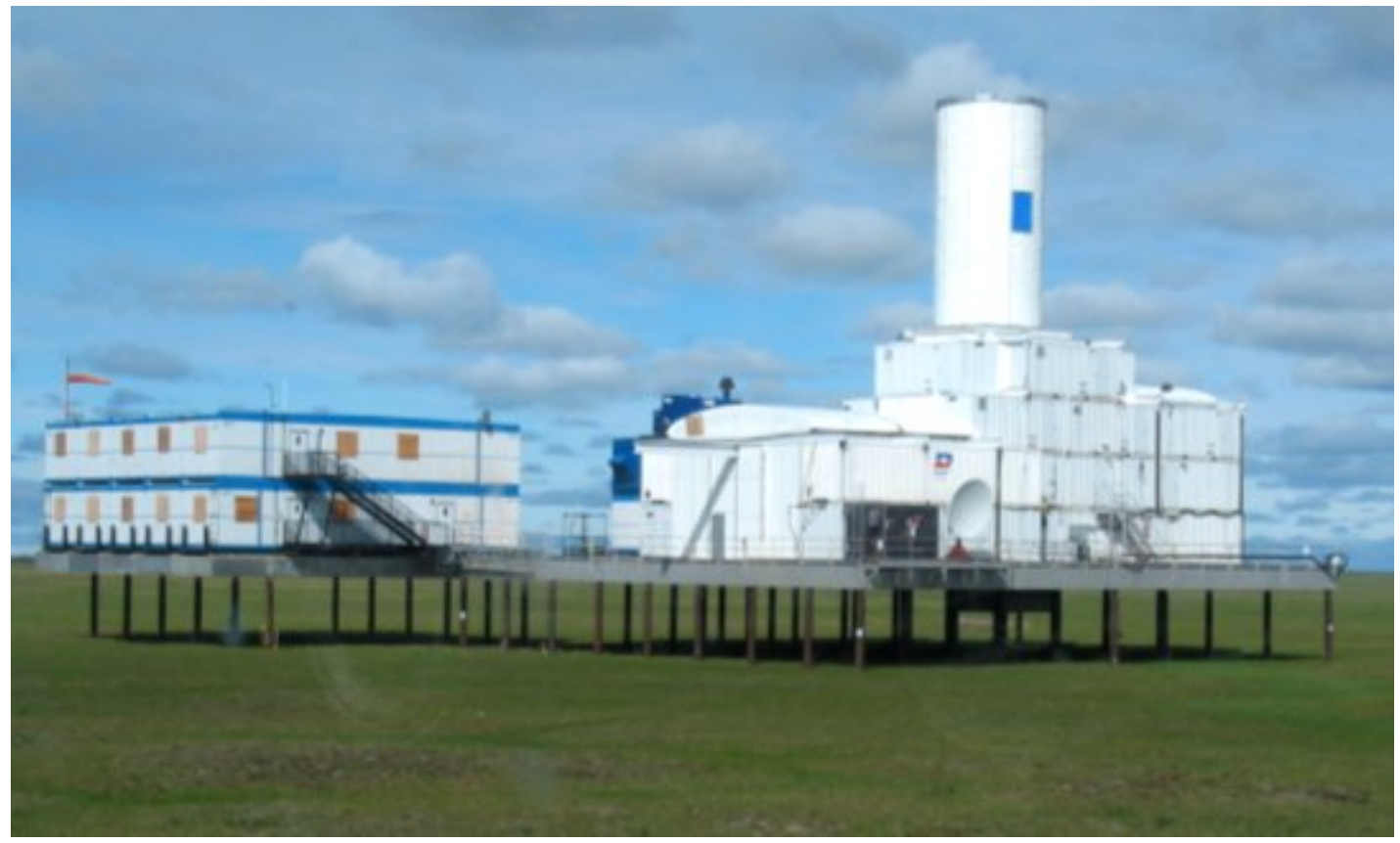

Figure 1. Arctic Platform during Summer

\section{Recent Activities}

Operations on the HOT ICE No. 1 well were suspended after the first drilling season on April 21, 2003 due to the end of the Arctic drilling season (Figure 1). Drilling operations were resumed on 
January 30, 2004 at the opening of the conventional operations season. For this second drilling season, an ice road was constructed from an existing road to west of the well location (Figure 2).

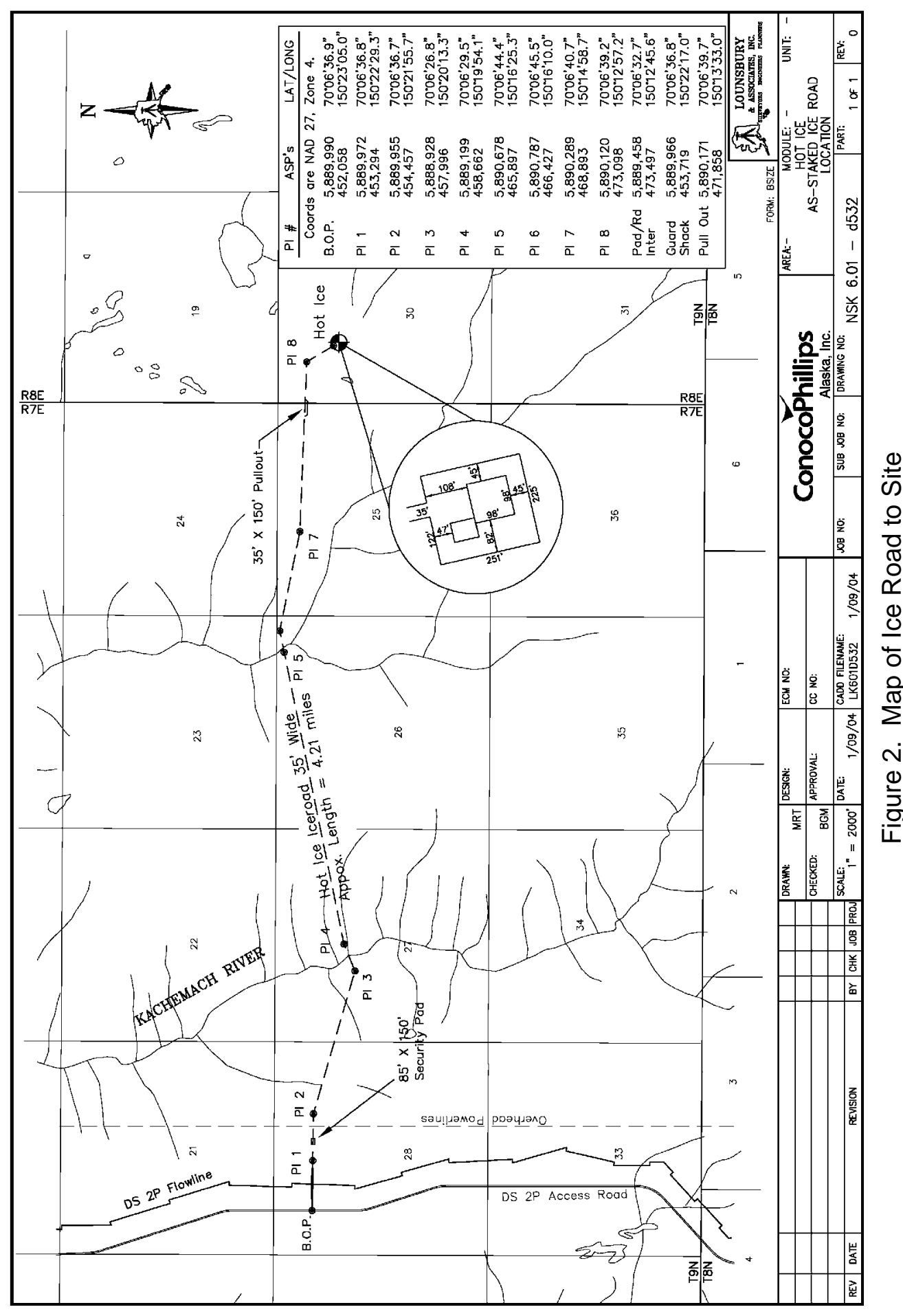

The HOT ICE No. 1 well was cored with a wireline-retrievable coring system using drilling mud that had been chilled to $23^{\circ} \mathrm{F}\left(-5^{\circ} \mathrm{C}\right)$ to preserve the 3.3 -inch $(8.5-\mathrm{cm})$ core and to prevent any hydrate from dissociating during core recovery. The mobile core laboratory was employed to 
immediately perform measurements on both whole core and 1-inch plugs taken from the whole core, while maintaining that temperature. Measurements on the whole core included: core gamma log, infrared temperature, velocity measurement, geologic description and white light photographs, high-resolution CT scan (using equipment from LBNL), and a nuclear magnetic resonance measurement (Schlumberger CMR tool) on a portion of each section of core. Measurements on core plugs included: bulk volume, grain density, helium porosity and permeability at confining stress, $\mathrm{P}$ and $\mathrm{S}$ wave velocity, resistivity, and thermal conductivity. For hydrate samples, the NMR system (Schlumberger CMR tool) would have been used to determine the fluid volume in the sample at various steps in the dissociation process, while released gas volumes and composition are also recorded.

The well was suspended after the first season due to unseasonably warm conditions that prevented transport of heavy loads over the tundra. Soon thereafter, the mobile core laboratory and collected core were moved to Deadhorse, Alaska, where core analysis was continued. The laboratory was then shipped to Tulsa, Oklahoma where repairs and upgrades were made by the University of Oklahoma. The laboratory was shipped back to the location in January 2004. After the well was completed and the equipment demobilized, the core was provided to the University of Alaska and the mobile laboratory was donated to the University of Oklahoma, where it is now available for other research projects.

As mentioned, drilling operations were resumed during January 2004, and the well was successfully cored to $2300 \mathrm{ft}$ with $93 \%$ core recovery on February 7,2004 . The well was then logged and a massive VSP survey conducted. Casing was set directly above the West Sak formation. Gas-bearing sands were encountered in highly porous sandstones that were situated within the hydrate-stability zone. These sands were areally extensive and stratigraphically equivalent to sand units in offset wells. Total depth was reached at $2300 \mathrm{ft}$, which was approximately $300 \mathrm{ft}$ below the gas-hydrate stability zone. A localized temperature model was developed for predicting the base of the hydrate stability zone. This model was verified by well results and used to determine the TD of the well. The well was logged, a VSP run and, because no hydrates were encountered, planned completion and testing programs (see Appendices $\mathbf{B}$ and $\mathbf{C}$ ) were not implemented.

A complete set of core, well log, production and downhole pressure and temperature data has been provided for use in evaluating the hydrate reservoir's quality and to determine potential for production from Arctic hydrate intervals. These data are now available for incorporating into hydrate reservoir models to test possible scenarios for producing methane from hydrates in similar settings.

Drilling operations at the HOT ICE No. 1 well marked the first test of Anadarko's Arctic Platform. The primary platform consists of 16 light-weight aluminum modules fitted together and mounted on steel legs $12 \mathrm{ft}$ above ground. The platform is large enough to contain a coring rig, auxiliary equipment, mud tanks, and the mobile core analysis laboratory. Another five modules form an adjacent platform with living quarters for up to 40 people. An IADC/SPE paper (Kadaster and Millheim, 2004) was presented to the industry on March 2, 2004. 
This report is the Final Report for Phase II. Several companion Topical Reports were compiled for detailed documentation of project activities in various areas. These include:

1. "Hydrate Core Drilling Tests"

2. "Drilling and Coring Operations"

3. "Logging Operations"

4. "Core and Fluid Analysis"

5. "3D Vertical Seismic Profile Survey"

6. "Hydrate Reservoir Characterization and Modeling"

The latest information on operations, geology, and geophysics was presented to the industry at the AAPG Hedberg Research Conference, "Natural Gas Hydrates: Energy Resource Potential and Associated Geologic Hazards," on September 12-16, 2004 in Vancouver, BC, Canada. These presentations, summarized in Appendix F, are:

1. "Integration of VSP Seismic Data with Core and Well Log Data to Investigate Lateral Variations of Potential Hydrate-Bearing Sands, Alaska North Slope," by Donn McGuire, Steve Runyon, Tom Williams, and Richard Sigal.

2. "Characterization of Potential Hydrate Bearing Reservoirs in the Ugnu and West Sak Formations of Alaska's North Slope," by Richard Sigal, C. Rai, Carl H. Sondergeld, William J. Ebanks, William D. Zogg, and Robert L. Kleinberg.

3. "HOT ICE Well No. 1-Well Planning, Operations and Results of the First Dedicated Gas Hydrate Well in the Alaskan Arctic," by Tom Williams, Bill Liddell, Ali Kadaster, and Tom Thompson. 


\section{Experimental}

\subsection{Background}

Natural-gas hydrates (Figure 3) beneath the permafrost have been encountered by the oil and gas industry for years. Numerous drilling problems, including gas kicks and uncontrolled gas releases, have been well documented in the Arctic regions by Russian, USA and Canadian engineers. There has been a significant volume of scientific information generated in laboratory studies over the past decade as to the extent, volume, chemistry and phase behavior of gas hydrates. However, virtually all of this information was obtained on hydrate samples created in the laboratory, not samples from the field.

Discovery of large accumulations around the world (Figure 4) confirmed that gas hydrates may represent a significant energy source. Publications (Makogon and others) on the Messoyakhi gas-hydrate production in Siberia (which has produced since 1965), clearly document that the potential for gas-hydrate production exists. Several studies have also addressed the potential for gas hydrates in the permafrost regions of North America. Results from the Mallik Hydrate, Mackenzie Delta Northwest Territories, Canada wells drilled by JAPEX, JNOC and GSC,

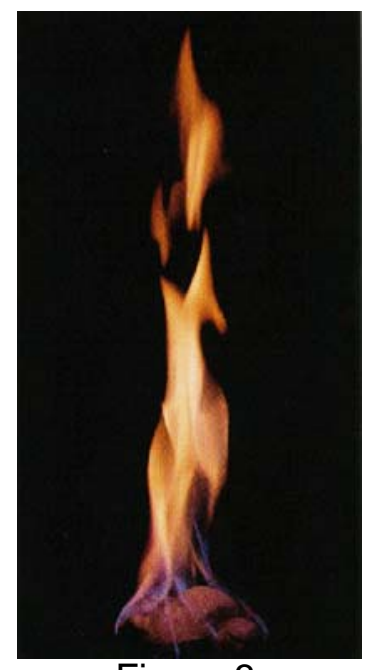

Figure 3.

Methane Hydrate provide a significant amount of useful background information. The USGS made sizeable contributions to the Mallik project, as well as many other investigations on gas hydrates in the USA (especially Alaska), and has much information on the presence and behavior of hydrates.

This knowledge is being applied around the world for environmentally sound development of this resource. The present project work represents the first attempt to drill, core and monitor hydrate wells in the USA. Specific objectives of this effort were to obtain field data required to verify geological, geophysical and geochemical models of hydrates and to plan, design and implement a program to safely and economically drill and produce gas from Arctic hydrates.

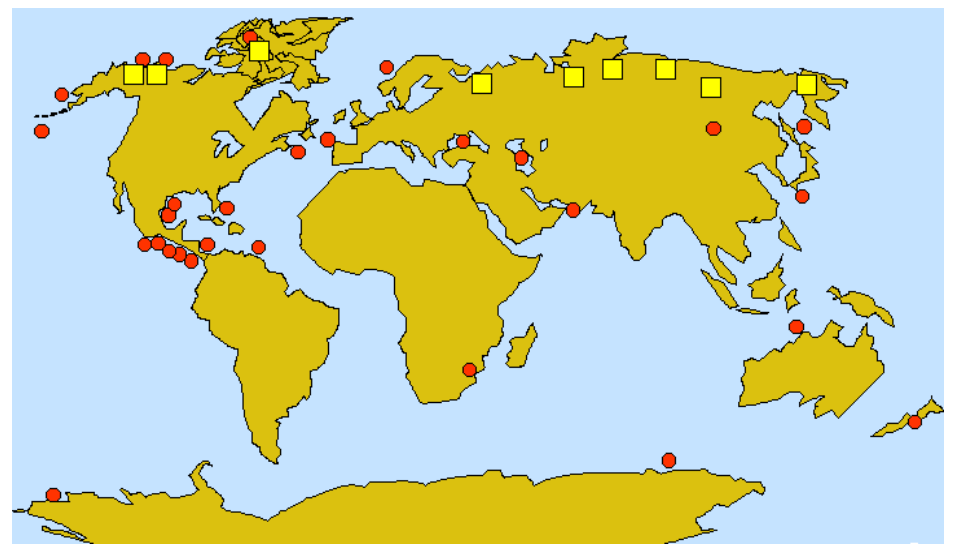

Figure 4. Methane Hydrate Deposits (USGS)

North America's emphasis on utilizing clean-burning natural gas for power generation has increased demand for gas and resulted in higher gas prices. A number of forecasts, including the NPC Study on Natural Gas (2000), indicate higher demand with prices in the range of $\$ 4$ to $\$ 8 /$ mcf. This is sufficiently high to allow investments in sources previously deemed uneconomic. The projected US demand for natural gas may grow to nearly 30 TCF by the end of the decade. This demand, particularly on the West Coast of the US, strongly suggests that a proposed Alaska Natural Gas Pipeline may now be economically feasible. This pending pipeline should 
provide a commercial market for natural gas, thereby allowing necessary investments in new technology to develop and market the hydrate resource.

Team member Anadarko Petroleum is one of the largest independent oil and gas exploration and production companies in the world, with proved reserves of 7.7 TCF of gas and $1.2 \mathrm{BBO}$ of crude oil, condensate and NGL's (approximately 2.5 BBOE). Domestically, it has operations in Texas, Louisiana, the Mid-Continent and Rocky Mountains, Alaska and the Gulf of Mexico. Anadarko is also one of the most active drillers in North America, and is balancing its current exploration and production programs by investing in developing new gas resources in North America, including areas where the risks and potential rewards are high with the application of advanced technology. It is now one of the largest leaseholders in Alaska, with an ongoing program of exploratory drilling and seismic studies. Anadarko's Alaska holdings number about 2 million net acres; some of which may hold potential for commercial production from hydrates. Anadarko also has extensive holdings in the Mackenzie Delta region of the Northwest Territories of Canada, which also may have potential for hydrates. Thus, Anadarko is very interested in seeing this resource become commercially viable.

With the amount of information on hydrates now available and the potential of developing this huge resource, this project was clearly scientifically and economically viable at this time. The best resources and ideas from around the world were used to implement the technology in the field. Thorough planning of the project hydrate well allowed avoiding some of the problems encountered in previous gas-hydrate drilling projects.

This project has provided valuable information to the DOE, industry, and research community to identify key barriers and problems related to gas-hydrate exploration and production. This information will be useful in developing innovative, cost-effective methods to overcome these barriers. An Advisory Board was formed for planning well operations. It included Teresa Imm (Arctic Slope Regional Corp.), Craig Woolard (University of Alaska Anchorage), Steve Kirby (USGS), Steve Bartz (Schlumberger), Timothy Colette (USGS), David Young (Baker Hughes INTEQ), Rick Miller (Kansas Geological Survey) and Carl Sondergeld (University of Oklahoma).

\subsection{Objectives}

Objectives of this gas-hydrate project were to:

1. Analyze existing geological and geophysical data and obtain new field data required to predict hydrate occurrences

2. Test the best methods and tools for drilling and recovering hydrates

3. Plan, design, and implement a program to safely and economically drill and produce gas from hydrates 


\subsection{Scope of Work}

The overall scope of work for this project was to:

1. Evaluate geological and geophysical data that aid in delineation of hydrate prospects

2. Evaluate existing best technology to drill, complete and produce gas hydrates

3. Develop a plan to drill, core, test and instrument a gas-hydrate well in Northern Alaska

4. Characterize the resource through geophysics, logging, engineering and geological core and fluids analysis

5. Test and then monitor gas production from the hydrate wells for an extended period of time

6. Quantify models/simulators with data for estimating ultimate recovery potential

7. Learn how to identify favorable stratigraphic intervals that enhance methane production

8. Assess commercial viability of developing this resource and ultimately develop a long-term production plan

9. Provide real hydrate core samples for laboratory testing

10. Develop and test physical and chemical methods to stabilize hydrate wellbores and improve core recovery

11. Step outside the well-known Prudhoe Bay/Kuparuk River area to further delineate hydrate deposits in Alaska

12. Report results to the DOE and transfer technology to the Industry 


\section{Results and Discussion}

\subsection{Deliverables}

During Phase I, an effective plan was developed for drilling new hydrate wells in Alaska. This included geological and geophysical assessment, site selection, and developing well plans.

In separate reports, the team provided DOE with the following deliverables during Phase I:

- Digital map of well locations

- Well log correlation sections

- Seismic maps and sections showing stratigraphic and lithologic units within gas hydrate stability zone

- Reservoir modeling report

- Well data for control wells used for site selection

- Site selection plan

- Testing and analytical procedures (Topical Report)

- Well plan

- Permit application

- NEPA requirements

Additional Phase I achievements beyond the original contract obligations were also delivered. These included:

- Topical reports from University of Oklahoma and the Drilling Research Center on hydrate core apparatus and testing (see Topical Report-"Hydrate Core Drilling Tests")

- Support of other DOE hydrate projects including the Westport Core Handling Manual

- Three reports from the University of Alaska Anchorage:

1. Geological Research of Well Records

2. Fundamental and Applied Research on Water Generated during Production of Gas Hydrates (see Appendix D)

3. Permafrost Foundations and Their Suitability as Tundra Platform Legs (see Topical Report-“Drilling and Coring Operations")

- USGS report on dissociation of hydrates at elevated pressures (see Topical Report"Core and Fluid Analysis")

- LBNL report on hydrate preservation in cores (see Topical Report-“Core and Fluid Analysis") 
- Arctic platform video

- National Press Release and Conference in Washington, DC

- First-ever North Slope coal cores provided to the USGS for coalbed methane study (see Topical Report-"Core and Fluid Analysis")

- New equipment for measuring hydrates

Phase II achievements encompassed drilling/coring a new hydrate well—HOT ICE No. 1.

- The well was cored to $2300 \mathrm{ft}$ with $93 \%$ of core recovered successfully.

- A geologic model was developed and quantified to predict the potential hydrate-bearing strata.

- A continuous coring rig proved to be a safe and efficient drilling system.

- The ability to characterize whole core on site was demonstrated using a mobile core laboratory. Tools developed for making hydrate-specific measurements were tested on gas-bearing sands and permafrost.

- Petrophysical measurements were quickly performed on site.

- A state-of-the-sate CT scanner from Lawrence Berkeley was used to analyze whole cores on site.

- The USGS collected and analyzed coal cores in real time.

- A massive 3D VSP was designed and conducted. The data were processed and are presented in the Topical Report-"3D Vertical Seismic Profile Survey."

- Viability of the concept of extending the drilling season on the North Slope of Alaska by using a low impact platform was demonstrated.

- Live data feed from the North Slope to Houston and other areas was demonstrated during the project.

Specific Phase II Deliverables (as listed in the Statement of Work) include:

1. Drilling and Coring Operations (Topical Report) (Task 9.2)

2. Logging Operations (Topical Report) (Task 10.0)

3. Core and Fluid Analysis (Topical Report) (Task 11.0)

4. 3D Vertical Seismic Profile Survey (Topical Report) (Task 12.0)

5. Proposed Well Completion Report (Appendix B) (Task 13.0)

6. Proposed Well Testing Report (Appendix C) (Task 15.0)

7. Hydrate Reservoir Characterization and Modeling (Topical Report) (Tasks 17, 18, \&19)

8. Economic Projections and a Production Options Report (see Section 4.3) (Task 20.0) 
9. Post-Well Analysis Report (see Appendix A) (Task 21.0)

10. Technical Publications Summarizing Project Findings (see Section 6) (All Tasks)

11. Final Report Summarizing Project Findings (the present report) (All Tasks)

\subsection{Team Organization}

Team organization is summarized in Figure 5.

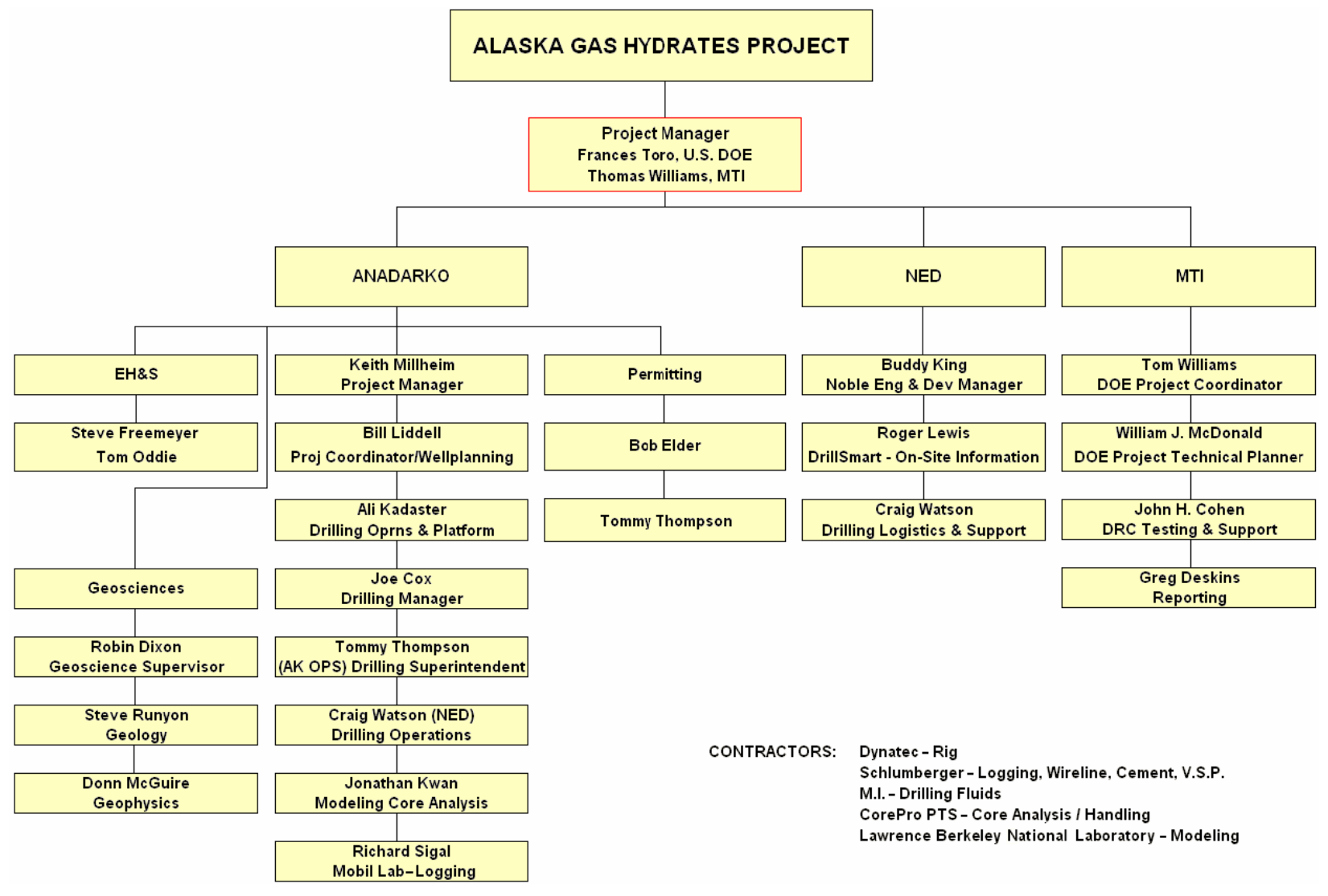

Figure 5. Project Team Structure 


\subsection{Accomplishments}

\subsubsection{Phase I}

Phase I (Tasks 1-7) was completed.

\section{Phase I Task Activities that Continued into Phase II}

A "lessons learned" workshop was held at Anadarko's office in the Woodlands on June 12-17, 2003. Each activity and task were reviewed and a budget revision was completed. Cost of the unanticipated demobilization and stand-by fees significantly increased the cost of the project.

\section{Subtask 4.2 - Permitting}

Permitting was completed; however, revisions for remobilization prior to the normal drilling season (due to freezing of the permafrost) were required. The platform did not move due to thawing during the summer of 2003. Three wells were initially permitted, named HOT ICE No. 1 , 2 and 3 (HOT ICE = High Output Technology Innovatively Chasing Energy). Following the Anadarko Geological and Geophysical assessment and the Site Selection task, the best location was selected in November and final permitting activity focused on the location for HOT ICE no. 1. With the addition of the Arctic Platform, new permitting activities and costs have been required. Meetings with and inspections by State and Federal regulators continued. Results included a number of positive reports complimentary of the operation.

The permit application was provided to the DOE.

A map showing the location of the site is presented in Figure 6.

\section{Task 7.0 - Posting Data on Existing Web Sites}

Maurer Technology constructed an Internet web site for hydrate project updates:

http://www.maurertechnology.com/Engr/RDprojects/HydratesHome.asp

It is also linked to the NETL hydrate web site. The project web site was used to display presentations, progress highlights and photos. This site was updated regularly during the project to make results available to the R\&D community. Information about the project continues to be exchanged with other hydrate research organizations and meetings. Press releases were issued, and the energy press contacted Maurer and Anadarko for progress updates and information about the project. A number articles and papers have appeared in Petroleum New Alaska, Hart's E\&P, World Oil, IADC/SPE and others. These articles and publications are listed in the project bibliography in Section 6 . 

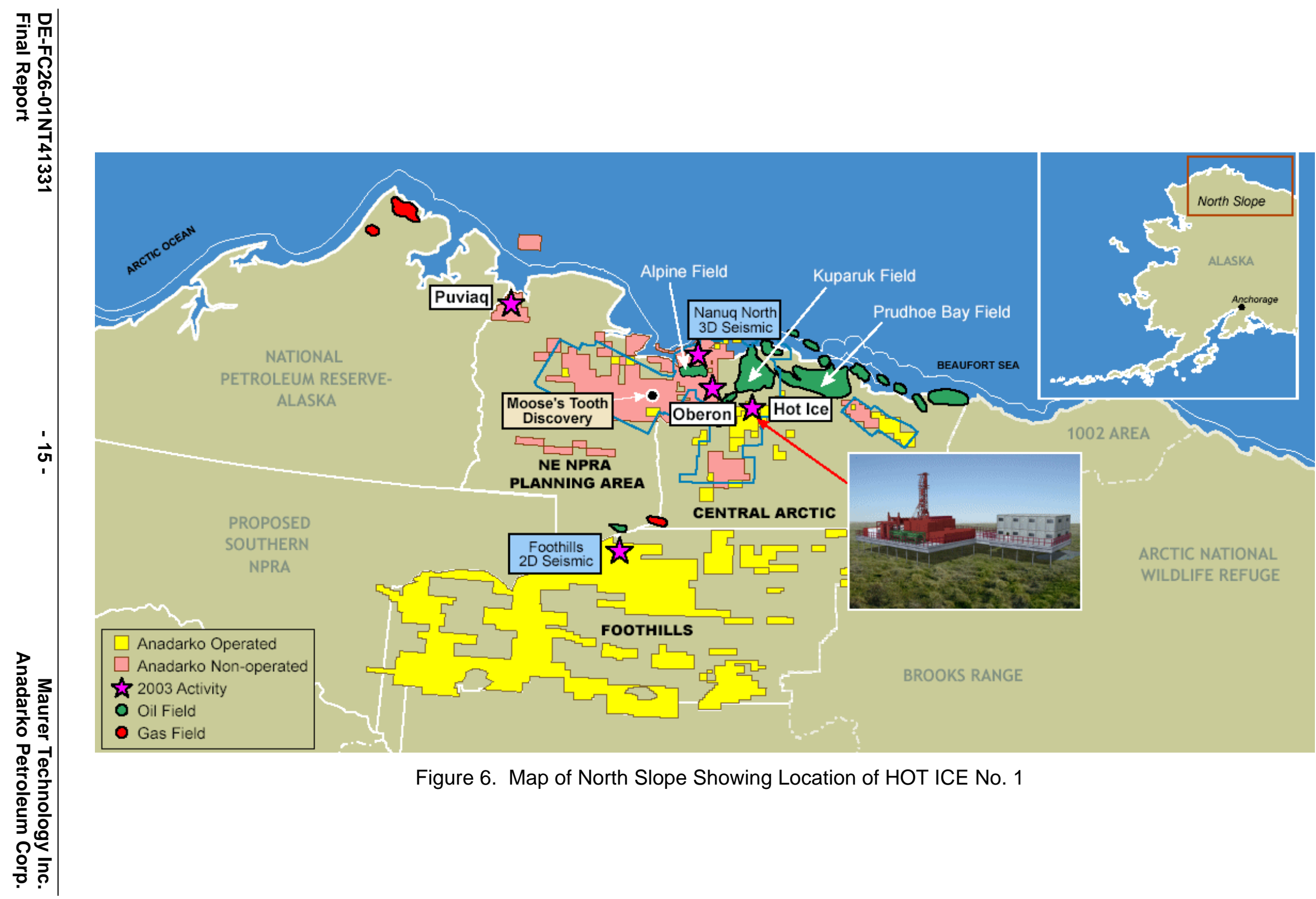

Figure 6. Map of North Slope Showing Location of HOT ICE No. 1 


\subsubsection{Phase II}

Phase II is complete including Tasks 8-22. The overall objective of Phase II was to test exploitation techniques developed in Phase I by drilling/coring and completing the well, and then performing a battery of well tests and logs. Because no gas hydrates were encountered, the completing and testing tasks of the well were not conducted. Draft procedures for completing and testing were prepared, however (see Appendices B and C). Tasks to accomplish these objectives are described below. The schedule for Phase II is shown in Figure 7 and Table 1.

Table 1. HOT ICE No. 1-Time Line

\begin{tabular}{|c|c|c|c|c|}
\hline ID & Task Name & Duration & Start & Finish \\
\hline 1 & Tundra Opening (Actual) & 0 days & $1 / 9 / 2004$ & $1 / 9 / 2004$ \\
\hline 2 & Open Deadhorse w/ key Personnel & 4 days & $1 / 7 / 2004$ & $1 / 11 / 2004$ \\
\hline 3 & HOT ICE Project Resumption & 67 days & $1 / 12 / 2004$ & $3 / 19 / 2004$ \\
\hline 4 & Mobilization & 10 days & $1 / 12 / 2004$ & $1 / 22 / 2004$ \\
\hline 5 & Build 4-mile Ice Road From Meltwater & 10 days & $1 / 12 / 2004$ & $1 / 22 / 2004$ \\
\hline 6 & Deadhorse Office Officially Open & 0 days & $1 / 12 / 2004$ & $1 / 12 / 2004$ \\
\hline 7 & Prep HOT ICE No. 1 Camp & 4 days & $1 / 18 / 2004$ & $1 / 22 / 2004$ \\
\hline 8 & MOB Crews to Deadhorse & 0 day & $1 / 20 / 2004$ & $1 / 20 / 2004$ \\
\hline 9 & Training \& Pre-Spud Mtg in Deadhorse & 3 days & $1 / 18 / 2004$ & $1 / 21 / 2004$ \\
\hline 10 & Rig Up \& Preparation for Spud & 12 days & $1 / 18 / 2004$ & $1 / 30 / 2004$ \\
\hline 11 & RU Electrical & 6 days & $1 / 18 / 2004$ & $1 / 24 / 2004$ \\
\hline 12 & RU Plumbing & 2 days & $1 / 19 / 2004$ & $1 / 21 / 2004$ \\
\hline 13 & RU Communications & 1 day & $1 / 22 / 2004$ & $1 / 23 / 2004$ \\
\hline 14 & Haul Fuel and Fluids & 5 days & $1 / 21 / 2004$ & $1 / 26 / 2004$ \\
\hline 15 & RU Rig and Support Equipment & 5 days & $1 / 21 / 2004$ & $1 / 26 / 2004$ \\
\hline 16 & Set up \& RU Lab & 3 days & $1 / 23 / 2004$ & $1 / 26 / 2004$ \\
\hline 17 & RU Instrumentation & 6 days & $1 / 24 / 2004$ & $1 / 30 / 2004$ \\
\hline 18 & Test BOP & 1 day & $1 / 28 / 2004$ & $1 / 29 / 2004$ \\
\hline 19 & Drilling \& Coring Operations & 17 days & $1 / 29 / 2004$ & $2 / 15 / 2004$ \\
\hline 20 & RIH w/BHA, DO Ice Plugs \& Displace Hole & 1 day & $1 / 29 / 2004$ & $1 / 30 / 2004$ \\
\hline 21 & Test Casing, DO Shoe \& 20', FIT/LOT & 1 day & $1 / 30 / 2004$ & $1 / 31 / 2004$ \\
\hline 22 & Core 1425 ' to $2300 '$ & 7 days & $1 / 31 / 2004$ & $2 / 7 / 2004$ \\
\hline 23 & TOH, Test BOP, TIH, C\&C & 1 days & $2 / 6 / 2004$ & $2 / 7 / 2004$ \\
\hline 24 & C\&C, TOH \& RU Loggers & 1 day & $2 / 7 / 2004$ & $2 / 8 / 2004$ \\
\hline 25 & OH Log & 1 day & $2 / 8 / 2004$ & $2 / 9 / 2004$ \\
\hline 26 & Wiper Trip & 1 day & $2 / 9 / 2004$ & $2 / 10 / 2004$ \\
\hline 27 & VSP & 5 days & $2 / 10 / 2004$ & $2 / 15 / 2004$ \\
\hline 28 & Abandonment \& Demobilization & 25 days & $2 / 15 / 2004$ & $3 / 11 / 2004$ \\
\hline 29 & Test BOP & 1 day & $2 / 15 / 2004$ & $2 / 16 / 2004$ \\
\hline 30 & P\&A/ L/D CHD 134 \& Set Packer \& Plugs & 1 day & $2 / 16 / 2004$ & $2 / 17 / 2004$ \\
\hline 31 & Rig Down \& Demob. Rig Topside & 10 days & $2 / 17 / 2004$ & $2 / 27 / 2004$ \\
\hline 32 & Rig Down \& Demob. Rig Platform & 2 days & $2 / 27 / 2004$ & $2 / 29 / 2004$ \\
\hline 33 & Remove Rig Platform Legs & 3 days & $2 / 29 / 2004$ & $3 / 3 / 2004$ \\
\hline 34 & Rig Down Camp & 2 days & $3 / 3 / 2004$ & $3 / 5 / 2004$ \\
\hline 35 & Remove Camp Platform \& Legs & 2 days & $3 / 5 / 2004$ & $3 / 7 / 2004$ \\
\hline 36 & Remediate Site & 4 days & $3 / 7 / 2004$ & $3 / 11 / 2004$ \\
\hline 37 & Wrap up at Deadhorse & 19 days & $2 / 29 / 2004$ & $3 / 19 / 2004$ \\
\hline 38 & Wash Bay Operations & 12 days & $2 / 29 / 2004$ & $3 / 12 / 2004$ \\
\hline 39 & Long-term Storage & 7 days & $3 / 7 / 2004$ & $3 / 14 / 2004$ \\
\hline 40 & Inventory & 17 days & $3 / 2 / 2004$ & $3 / 19 / 2004$ \\
\hline 41 & HOT ICE Field Operations Complete & 0 days & $3 / 19 / 2004$ & $3 / 19 / 2004$ \\
\hline
\end{tabular}


Methane Hydrate Production from Alaskan Permafrost PHASE II

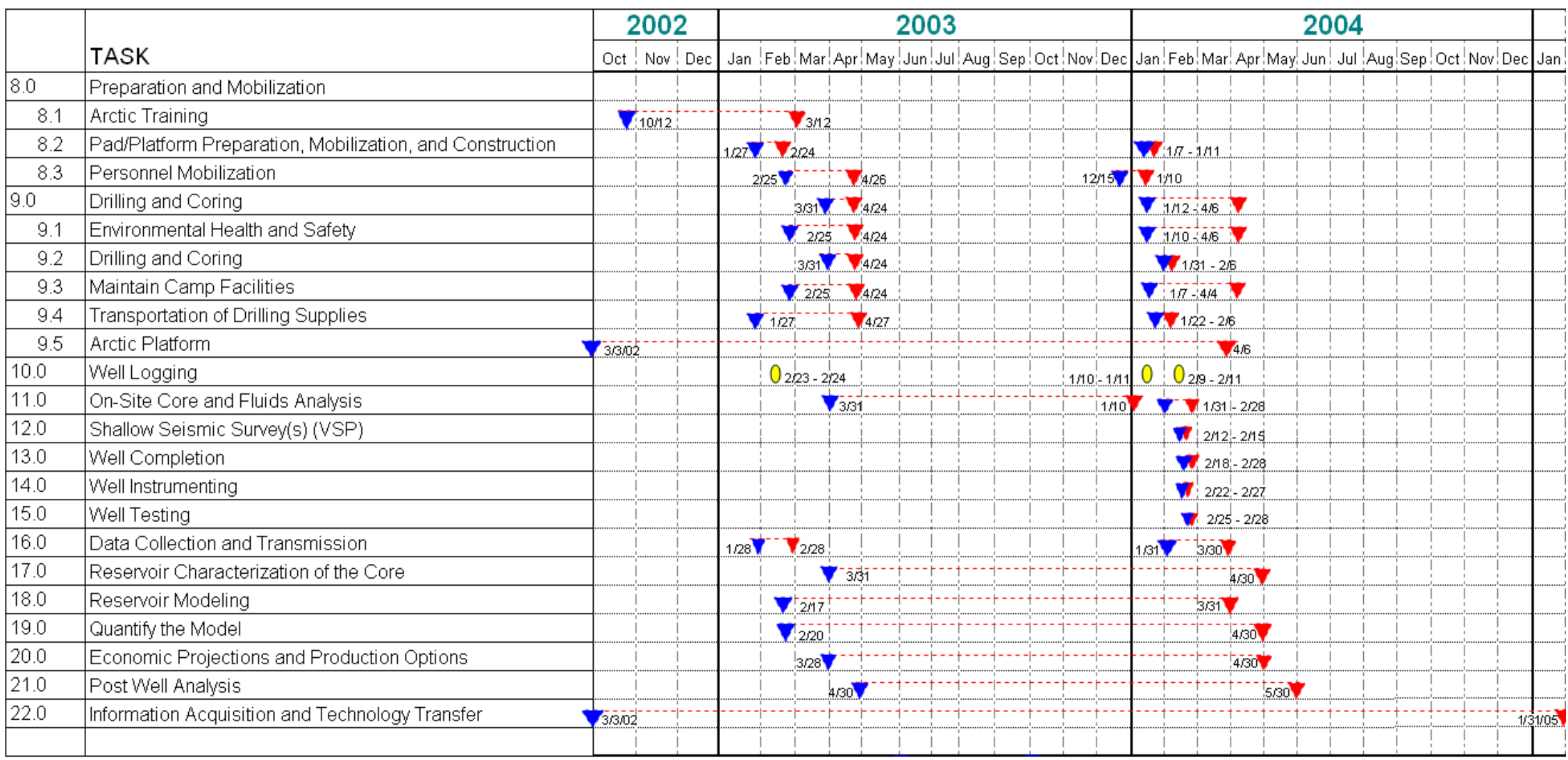

Figure 7. Phase II Project Schedule 


\section{Task 8.0 - Preparation and Mobilization}

\section{Subtask 8.1 - Arctic Training}

The required training was conducted for personnel who were to work on the North Slope overnight in support of this project. Training courses included: First Aid, Respiratory, FIT Test, $\mathrm{H}_{2} \mathrm{~S}$ Training, NSTC Training, Hazcom/Hazwoper, PPE, Alaska Safety Handbook, Arctic Survival, Bear Awareness, NPRA Training, and Fire Extinguisher Training. Refresher training and updated certifications were provided for the 2004 drilling season.

\section{Subtask 8.2 - Pad/Platform Preparation, Mobilization, and Construction}

Permits were issued, and the Arctic platform was installed at the well location in February 2003. The project team mobilized the drill platform equipment to the well location, using an existing gravel road and a staging area at the end of the road. The permits allowed the platform to remain during the summer months. An ice road was permitted and utilized for access during operations in 2004.

Phase 2 of the drilling operation incorporated an ice road (Table 2 and Figure 2) instead of making use of Rolligons.

Table 2. HOT ICE Location Winter 2004 Access

\begin{tabular}{|l|c|c|l|}
\hline Point Name & Lat (WGS 84) & Long (WGS 84) & Comments \\
\hline 001 & 70.10992 & 150.38774 & Road Alignment \\
\hline 002 & 70.11032 & 150.38779 & Road Alignment \\
\hline 003 & 70.10943 & 150.38774 & Road Alignment \\
\hline HI Start & 70.10991 & 150.38741 & Beginning of Ice Road Alignment off road \\
\hline PL-X-1 & 70.10997 & 150.38255 & Pipeline crossing \\
\hline 004 & 70.10959 & 150.37146 & \\
\hline 005 & 70.11026 & 150.37123 & Power line alignment \\
\hline HI PI-03-1 & 70.10712 & 150.34009 & Point of Intercept \\
\hline HI X-03-1 & 70.10763 & 150.33920 & Steam Crossing 1 \\
\hline HI X-03-2 & 70.11195 & 150.27660 & Stream Crossing 2 \\
\hline HI-1 & 70.10836 & 150.21756 & HOT ICE No. 1 Platform location (West Side) \\
\hline
\end{tabular}

The three pipelines at the single pipeline crossing are protected by casings and $7 \mathrm{ft}$ of coarse gravel. The gravel ramp on each side is shown in Figure 8. 


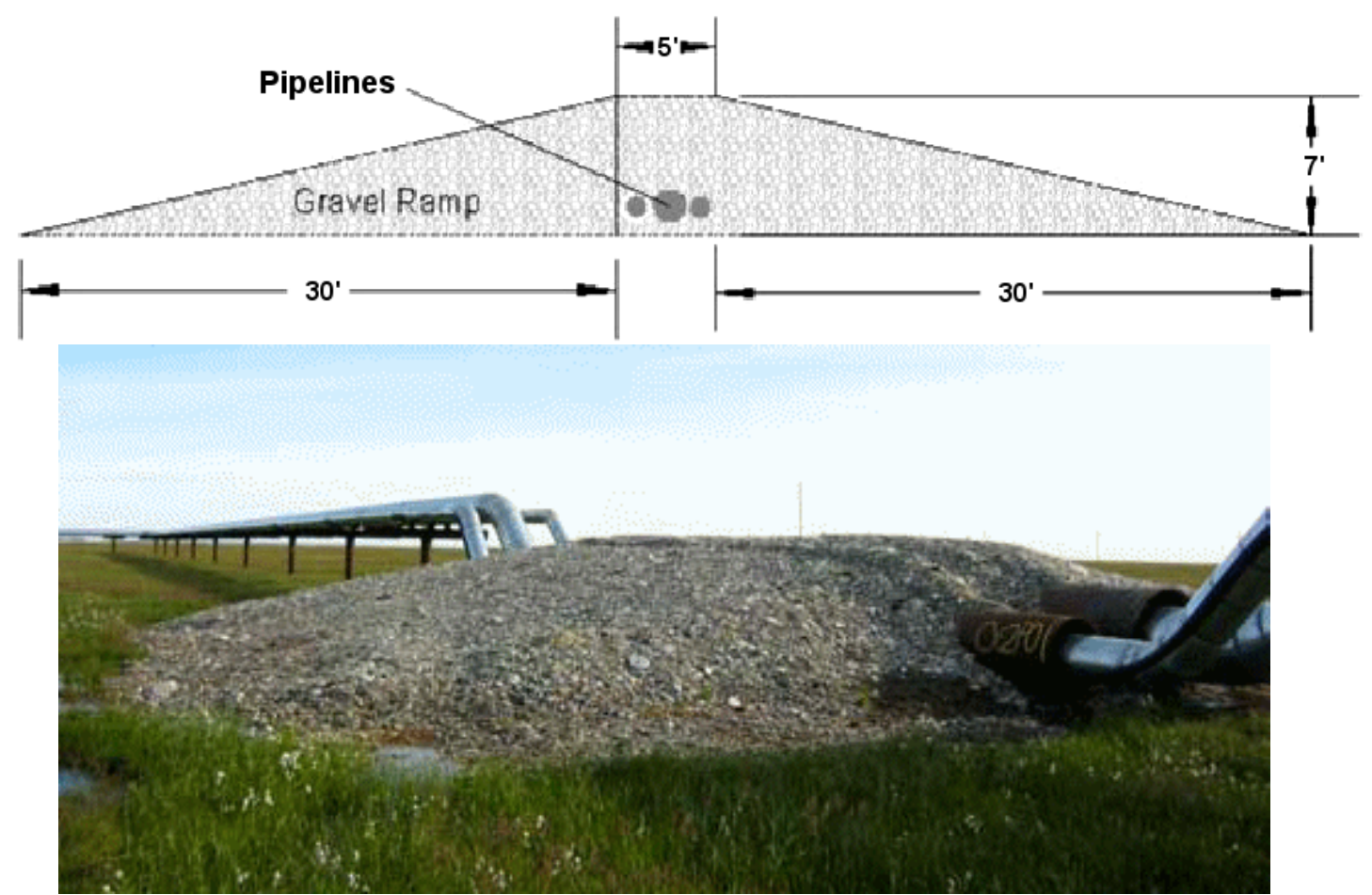

Figure 8. Gravel Ramp for Pipeline Crossing

The site for one of the stream crossings is shown in Figure 9.

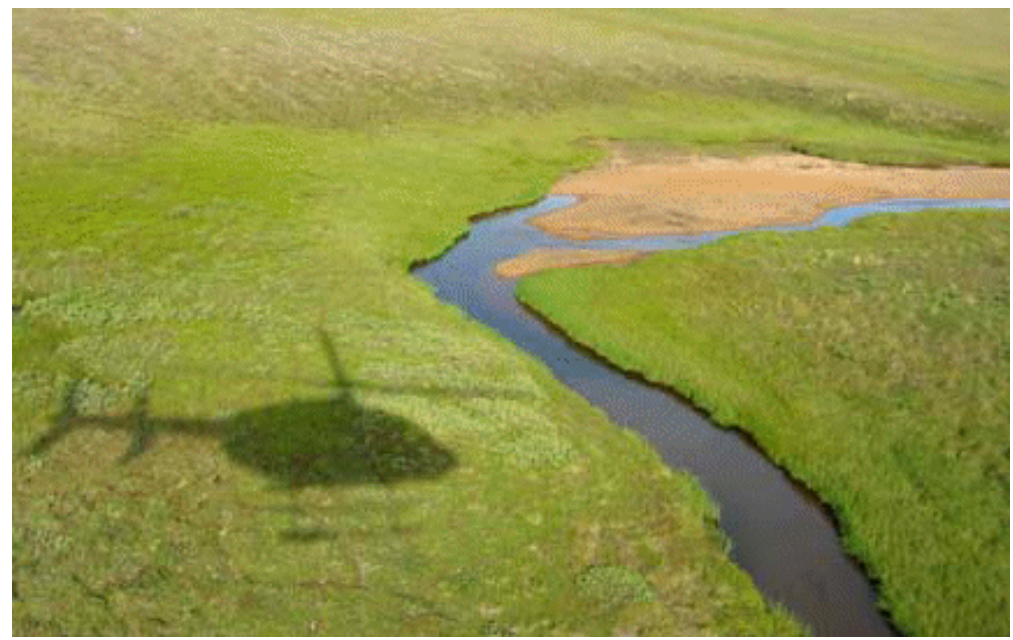

Figure 9. Stream Crossing 1 for Ice Road

\section{Subtask 8.3 - Personnel Mobilization}

The team made provision to transport all project personnel to and from the well site. This included transport of camp crew, catering staff, maintenance crew, rig crew, laboratory crew, logging crew, cementing crew, mud crew, and supervisory personnel. 


\section{Task 9.0 - Drilling and Coring}

The team winterized the drill rig and mobilized it to Deadhorse and then to the well location. We drilled and cored the HOT ICE No. 1 well from the Arctic platform.

\section{Subtask 9.1 - Environmental Health and Safety}

The project team monitored and responded to environmental health and safety concerns, including monitoring and manifesting waste, in order to ensure compliance with regulations specified in permits.

\section{Subtask 9.2 - Drilling and Coring}

The project team drilled the HOT ICE No. 1 well from the Arctic platform constructed in Subtask 8.2. We used chilled drilling fluids and monitored the downhole temperature and inclination using a tool provided by Sandia National Laboratories. Noble Engineering and Development's Drill Smart System was used to allow engineers to monitor and view drilling operations live from Houston. Owing to unseasonably warm weather, the team was unable to complete the drilling program as originally scheduled during the Spring of 2003. We resumed and completed drilling operations during the Winter 2004 drilling season.

A detailed summary of Task 9.2 activities is provided in the Topical Report-"Drilling and Coring Operations."

\section{Subtask 9.3 - Maintain Camp Facilities}

The team provided camp facilities to house and feed the crews rotating on a 12/12 shift schedule.

\section{Subtask 9.4 - Transportation of Drilling Supplies}

During the 2003 season, no ice road was used. Transportation of personnel, equipment, and supplies was via Rolligons and helicopter. By contrast, the team constructed an ice road during the Winter 2004 season to facilitate the mobilization of equipment, supplies, and personnel to the HOT ICE No. 1 Site to complete the drilling and coring operations. Equipment was also removed by ice road after operations were complete.

\section{Subtask 9.5 - Arctic Platform}

The Anadarko Arctic Platform was constructed and tested in Houston, Texas. Tests of platform leg strength are described in the Topical Report-"Drilling and Coring Operations." The structure is made of lightweight aluminum. It was mobilized to the base camp in January 2003, and inspected prior to mobilization to the well location in February (Figure 10). The legs were tested and put on location as soon as the freeze period began in January. A video of the transportation and construction was provided to the DOE. Legs were installed into the tundra permafrost and frozen into place. The platform can be mobilized by either helicopter and/or Rolligon from the base camp and assembled at the well location. Environmental monitoring equipment was also installed. 


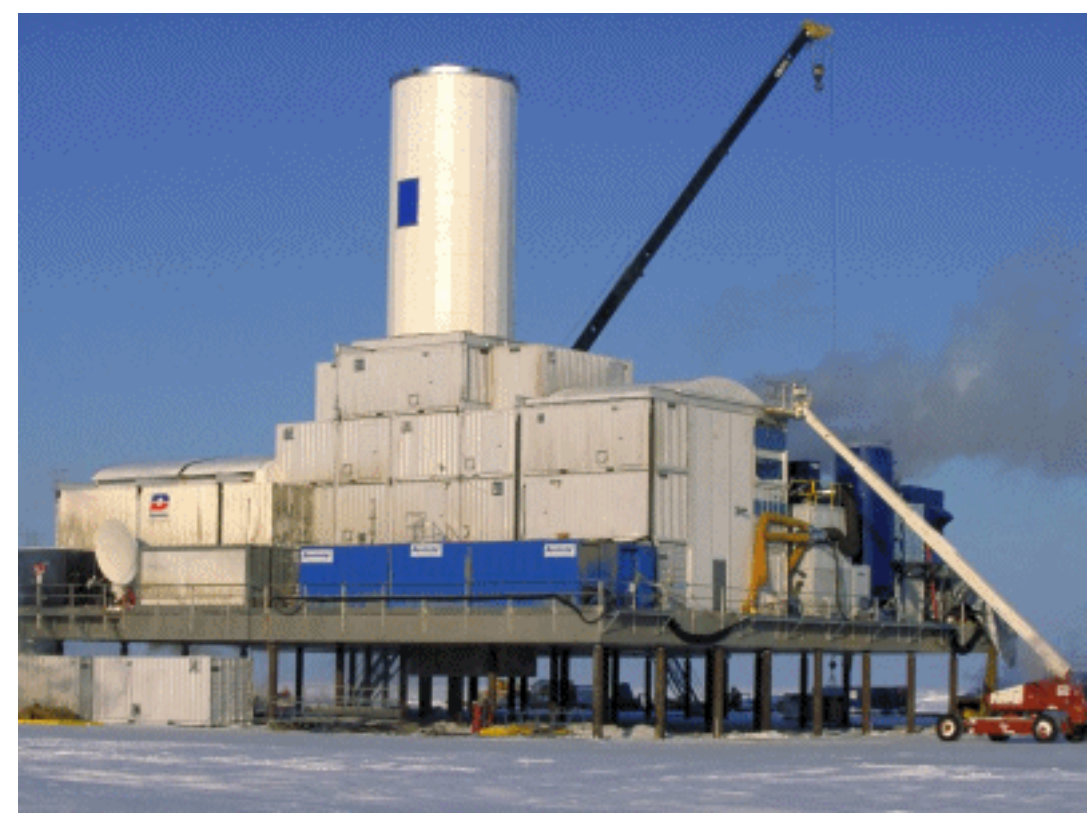

Figure 10. Arctic Platform at HOT ICE No. 1

The platform drilling area is $100 \times 100 \mathrm{ft}$, and the base camp is $62.5 \times 50 \mathrm{ft}$ on an adjacent platform. The rig, equipment and base camp were installed on the platform by Rolligon and two cranes. After completion of drilling and completion operations, the equipment was demobilized. There was no adverse environmental impact at the drill site (Figure 11). The entire platform was demobilized to Dead Horse. The platform was thoroughly inspected by a third party and a post-analysis study was conducted with recommendations on future operations.

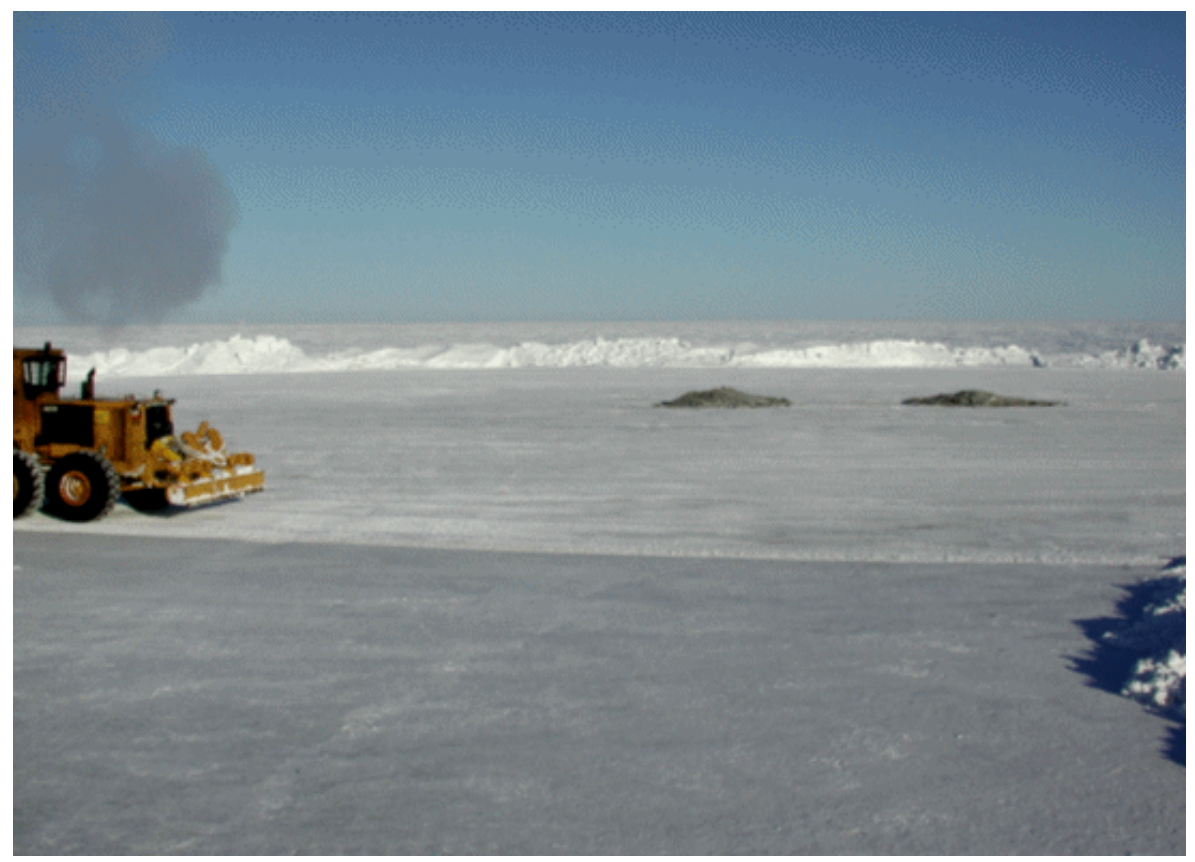

Figure 11. Final Stage of Platform Removal and Site Remediation 


\section{Task 10.0 - Well Logging}

The team ran a suite of logs in the well to characterize gas hydrate-bearing intervals, including the following: (1) electrical resistivity (dual induction), (2) spontaneous potential, (3) caliper, (4) acoustic transit-time, (5) neutron porosity, (6) density, and (7) nuclear magnetic resonance. Logging operations are described in the Topical Report-“"Logging Operations."

Core data were used to calibrate and quantify log information. A report on NMR log measurements of core taken during the 2003 drilling season is presented in the Topical Report- "Core and Fluid Analysis."

\section{Task 11.0 - On-Site Core and Fluids Analysis}

The project team analyzed core and fluids using a specially constructed mobile core laboratory, staffed by trained laboratory technicians. Core was received in the cold module, where it was photographed and assessed for the presence of hydrates. One-inch plugs were removed from the core, and these plugs were measured for porosity, permeability, compressional and shear wave velocity, resistivity, thermal conductivity, and NMR with specialized equipment specifically designed for making these hydrate core measurements, including a Schlumberger CMR tool. All of these measurements were made under controlled pressure and temperature. Core measurements are summarized in the Topical Report-_Core and Fluid Analysis."

Because no hydrates were encountered, no hydrate dissociation testing was conducted, although the procedures and equipment are described in project reports. Laboratory technicians assisted in preparing core for additional testing at other locations. Results of core and fluids handling procedures were provided for the DOE-funded Westport Hydrate Core Handling Manual. The results of the analysis were incorporated in Tasks 17, 18, 19 and 20.

\section{Subtask 11.1 - Mobile Laboratory Repair and Upgrade}

During both the 2003 and 2004 coring seasons, a special mobile core laboratory (Figure 12) was employed to immediately perform measurements on both whole core and 1-inch plugs taken from the whole core, while maintaining temperature. Anadarko, in cooperation with Rock Properties Resources, designed the mobile core laboratory which was operated on the drilling site. Rock Properties Resources constructed the laboratory as well as provided critical support throughout the project. Resulting from the effort was a state-of-the-art, winterized, mobile core characterization laboratory capable of measuring large volume of core in a cost-effective manner in arctic conditions. This effort represents the first comprehensive on-site gas hydrate analytical laboratory of its kind to be deployed in the Arctic. 


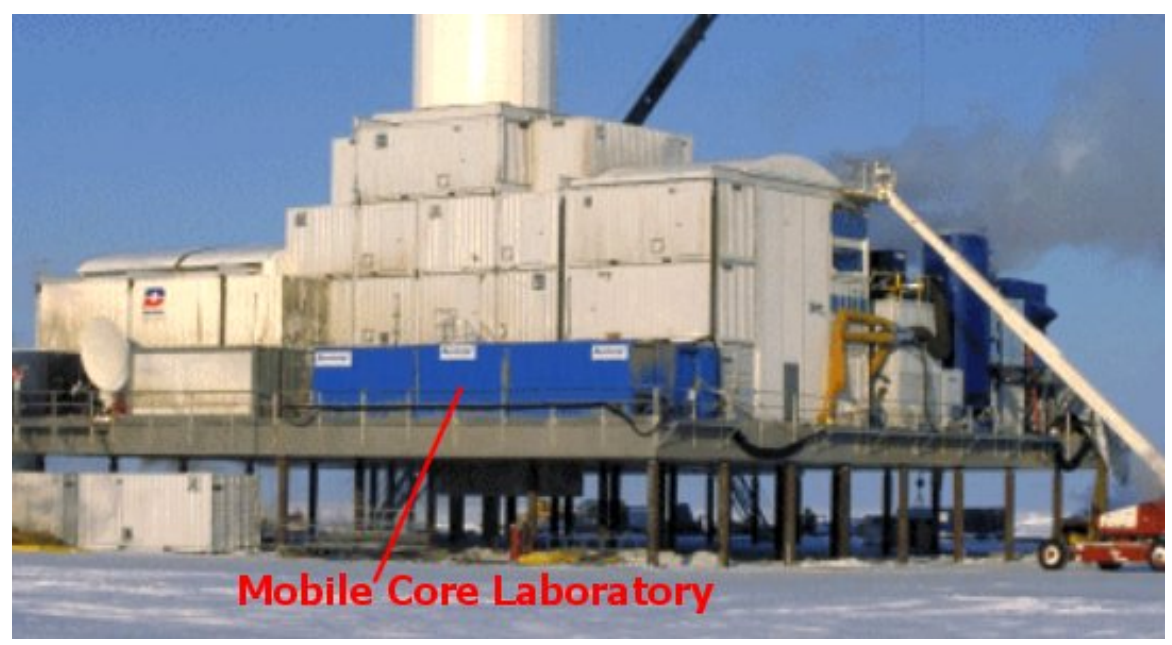

Figure 12. Mobile Core Laboratory at HOT ICE No. 1 Site

The team repaired and upgraded the mobile core laboratory in Tulsa during the summer and fall of 2003 specifically to: (1) redesign the pressure and cooling system for the NMR spectrometer, in order to achieve significantly lower temperature capability required for analysis of hydrate samples; (2) improve insulation for the velocity-thermal conductivityresistivity measurement system; (3) configure the NMR and VCR systems with capability to allow positive pore pressures of methane for hydrate stability; and (4) develop a central database for managing and storing all data measured in the mobile core laboratory.

Regarding the use of the LBNL CT on site:

1. We partitioned one end of a 20-ft Conex with a separate door to the outside for the X-ray room.

2. There was a heater located in the room or an electrical outlet to add a portable heater.

3. The x-ray room is adjacent to the station where the core will be cut to 3-ft lengths.

4. Core sections were taken outside and then into the x-ray room.

5. The x-ray machine can be started in a temperature-controlled environment.

6. During shipment, the machine can be subjected to ambient temperatures of as low as $-40^{\circ} \mathrm{F}$ (unless special measures are taken).

The x-ray scanner is certified to be "cabinet safe." This means that any personnel can be near it for normal operation, and the user does not need to be fitted with a dosimeter. Only a certified "system maintainer" can use tools to perform maintenance and has the ability to modify or override interlock safety features. This authority is granted from our EH\&S department, and Victor was the system maintainer.

Regarding operation: the machine needs to be "tuned" to the samples that are collected. This means that adjustments must be made to both x-ray voltage and current depending on the density and composition of the samples. There may also be adjustments to the camera behind the image intensifier. It is hard to predict how often and when this task should be performed. Since dual-energy scanning was performed, both hard and soft x- 
ray energies needed to be periodically readjusted depending on the collected core density and composition.

LBNL modified the machine so that it will hold a 3-ft piece of core. Four-ft long core holders were constructed since the extra space at the top of the core holder will be empty, preventing concern about core length. The quick scan will be performed in about 2 to 3 minutes from the time the sample in the sample holder is placed in the $x$-ray unit, to when it can be removed from the $\mathrm{x}$-ray unit. A more detailed full 3-D CT characterization will take about 12 minutes for the entire 3-ft length. A shorter interval (i.e., 4 inches) can be scanned in full 3-D mode in about 2 minutes. Three to five core holders were provided so that one can be loaded, while another one is being cleaned or prepped and a third can be in the scanner.

Results of the CT measurements are described in detail in the Topical Report-"Core and Fluid Analysis."

At the conclusion of the HOT ICE field operations, Anadarko donated the mobile core laboratory to the University of Oklahoma (Figure 13). Shown in the photo (left to right) are Susan Howes (APC), Doug Hazlet (APC), Bill Liddell (APC), Julie Struble (APC), Tom Williams (MTI), Richard Sigal (OU), Carl Sondergeld (OU), Dean Oliver (OU), Chandra Rai (OU), Brad Johnson (APC).

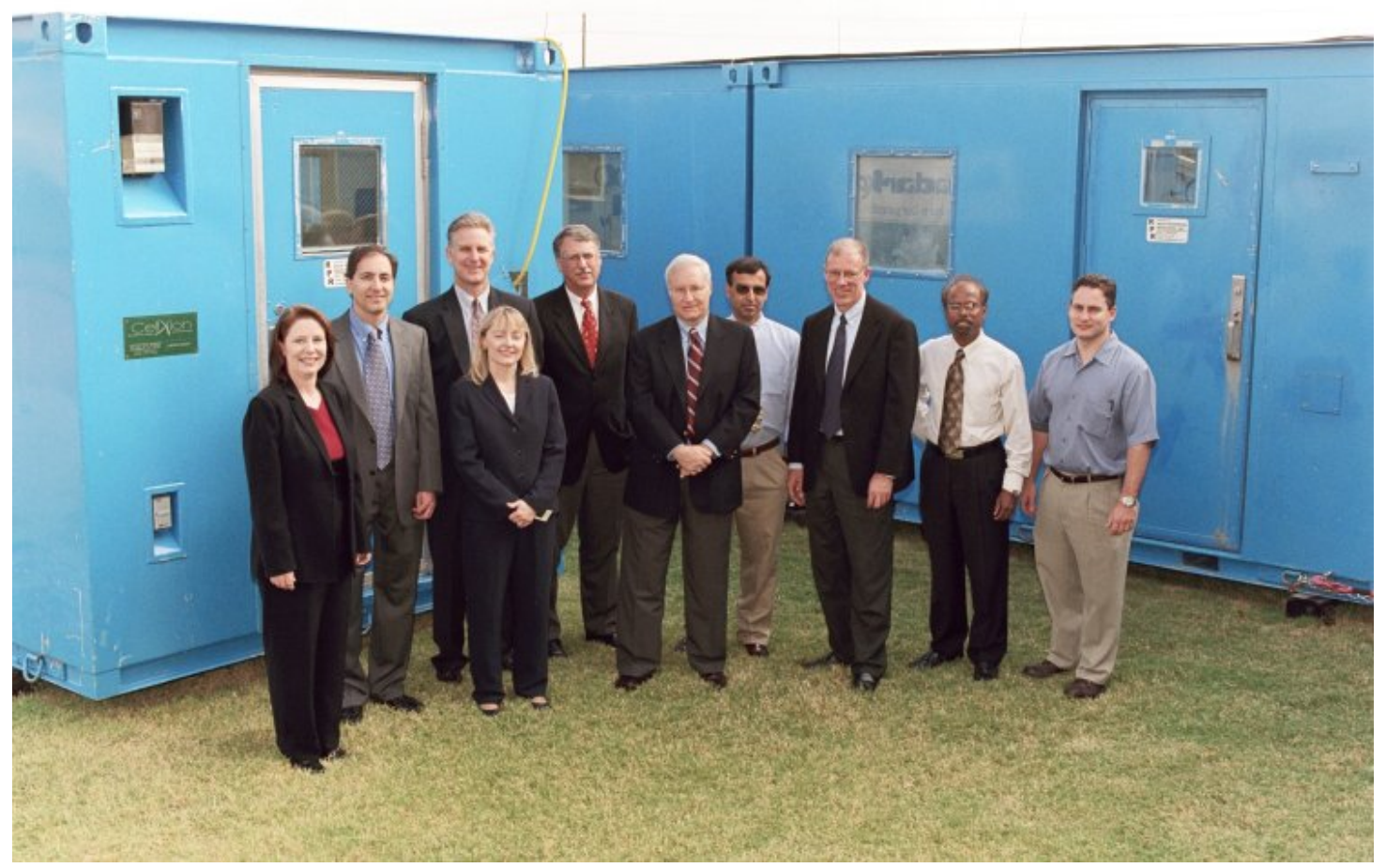

Figure 13. Members of Project Team after Donation of Mobile Core Laboratory to University of Oklahoma

\section{Task 12.0 - Shallow Seismic Survey(s)}

After the well was logged, a 3D vertical seismic profile (VSP) was conducted to calibrate the shallow geologic section with seismic data and to investigate techniques to better resolve lateral 
subsurface variations of hydrate-bearing strata. Paulsson Geophysical Services, Inc. deployed their 80 level $3 \mathrm{C}$ clamped borehole seismic receiver array in the wellbore to record samples every $25 \mathrm{ft}$. The surface vibrators successively occupied 800 different offset positions arranged around the wellbore. This technique generated a 3D image of the subsurface. Correlations of these seismic data with cores, logging, and other well data were generated. This task included additional fabrication of receiver cables, rental of field vibrators and recording equipment and associated personnel.

This work is described in detail in the Topical Report-"3D Vertical Seismic Profile Survey."

\section{Task $13.0-$ Well Completion}

Because no gas hydrates were encountered, the project team did not complete the well. Completion procedures were developed based on experiences in similar wells. Draft Completion Procedures are presented in Appendix B.

The completion for this well was designed to try to address all issues that were identified with producing hydrates at this location. Based on rig capacity, the largest production casing that can be used below the permafrost is $4 \frac{1}{2} 2$ inch. The location would not be accessible by ice roads during production testing. All equipment would need to be transported by rolligon or helicopter. As a result, size and weight of the equipment needs to be minimized. Completion and testing equipment need to be simple and require minimum support. With environmental regulations and cost constraints, the base plan will conclude testing before tundra closure occurs. There was also potential for formation sand production. Freeze protection also has to be incorporated into the completion design, since potential for forming hydrates or ice will exist.

\section{Task $14.0-$ Well Instrumenting}

Because no hydrates were encountered, the pressure and temperature gauge and a surface sensor to provide monitoring capabilities were acquired and tested, but not installed.

\section{Task 15.0 - Well Testing}

There was no well testing, although a comprehensive (draft) well testing plan was developed by the team and is presented in Appendix $\mathbf{C}$. Water and gas samples were collected to determine their composition. The well was plugged and abandoned according to State regulations.

\section{Task 16.0 - Data Collection and Transmission}

The project team performed laboratory work on fluids captured during operations. Results were transmitted daily via email.

\section{Task 17.0 - Reservoir Characterization of the Core}

The team characterized the reservoir, based on analyses of fluids, geology, engineering, logs, geophysics, and rock physics. All these data were analyzed and the results presented in the Topical Report-_Hydrate Reservoir Characterization and Modeling." These data were provided to Lawrence Berkeley National Laboratory for incorporation into their well simulator. 


\section{Task 18.0 - Reservoir Modeling}

The team provided information developed in reservoir characterization efforts to Lawrence Berkeley National Laboratory to be used to quantify their hydrate simulator. LBNL's advanced simulator system is based on EOSHYDR2, a new module for the TOUGH2 general-purpose simulator for multi-component, multiphase fluid and heat flow and transport in the subsurface environment. Reservoir simulation during this phase of the project was focused on considering production schemes, both short and long term, for hydrate production on the North Slope based on all the reservoir characterization data obtained. Depressurization, injection and thermal methods are some of the production processes considered with the simulation.

Results of LBNL's simulation studies are summarized in the Topical Report-"Hydrate Reservoir Characterization and Modeling."

\section{Task 19.0 - Quantify the Model}

This task was to be conducted in parallel with Tasks 17 and 18. The reservoir model used would need to be continuously refined as well test data were acquired. This effort is required for making projections. Models were enhanced iteratively to incorporate dynamic production data during the well test period. (See Topical Report-"Hydrate Reservoir Characterization and Modeling," Appendix B-"Numerical Simulation Studies Related to the HOT ICE No. 1 Well," George J. Moridis, 2004.)

\section{Task 20.0 - Economic Projections and Production Options}

The project team prepared economic projections and production options (see below). Information from other gas-hydrate projects was reviewed and included in our recommendations. Model-based estimates and production options were developed. If it was determined that a significant volume of gas production from hydrates were technically possible, an economic analysis was to be conducted.

Prior to beginning the project, the team developed an estimate of potential reserves. Below are estimates used to calculate a distribution of the potential reserves of the free gas portion and hydrate-bearing rock for the entire area that was being assessed:

\begin{tabular}{|c|c|c|c|c|c|c|c|}
\hline \multicolumn{8}{|c|}{$\begin{array}{l}\text { Stochastic Reserve Determination } \\
\text { August } 2,2002\end{array}$} \\
\hline & $\begin{array}{l}\text { Min } \\
100\end{array}$ & $\begin{array}{c}\text { Most } \\
\text { Likely } \\
150\end{array}$ & $\begin{array}{c}\text { Max } \\
200\end{array}$ & & & & \\
\hline \multirow[t]{2}{*}{ Hydrate Portion } & & & & Free Gas Portion & & & \\
\hline & Min & $\begin{array}{l}\text { Most } \\
\text { Likely }\end{array}$ & $\operatorname{Max}$ & & Min & Most Likely & $\operatorname{Max}$ \\
\hline Number of sections Hydrate & 90 & 140 & 195 & Number of sections free gas & 40 & 145 & 330 \\
\hline $\begin{array}{l}\text { Hydrate Thickness (ft) } \\
\text { Vol (ft3) }\end{array}$ & 50 & 75 & 100 & $\begin{array}{l}\text { Sand Thickness } \\
\text { Vol (ft3) }\end{array}$ & & & \\
\hline Porosity (\%) & $20 \%$ & $30 \%$ & $35 \%$ & Porosity (\%) & $20 \%$ & $30 \%$ & $35 \%$ \\
\hline Hydrate Saturation (\%) & $50 \%$ & $75 \%$ & $85 \%$ & Gas Saturation (\%) & $70 \%$ & $75 \%$ & $80 \%$ \\
\hline Pore Volume of Hydrates ( $\mathrm{ft} 3$ ) & & & & Pore Volume of Gas & & & \\
\hline Hydrate FVF & 142 & 165 & 187 & $\mathrm{Bg}$ & 80 & 100 & 120 \\
\hline
\end{tabular}


Distribution of the potential gas accumulation is shown in Figure 14. Mean gas volume for $\sim 140$ sections of leases was 17.1 TCF gas in place. This estimate does not imply that this gas would be commercial and has no bearing on productivity of the accumulation.

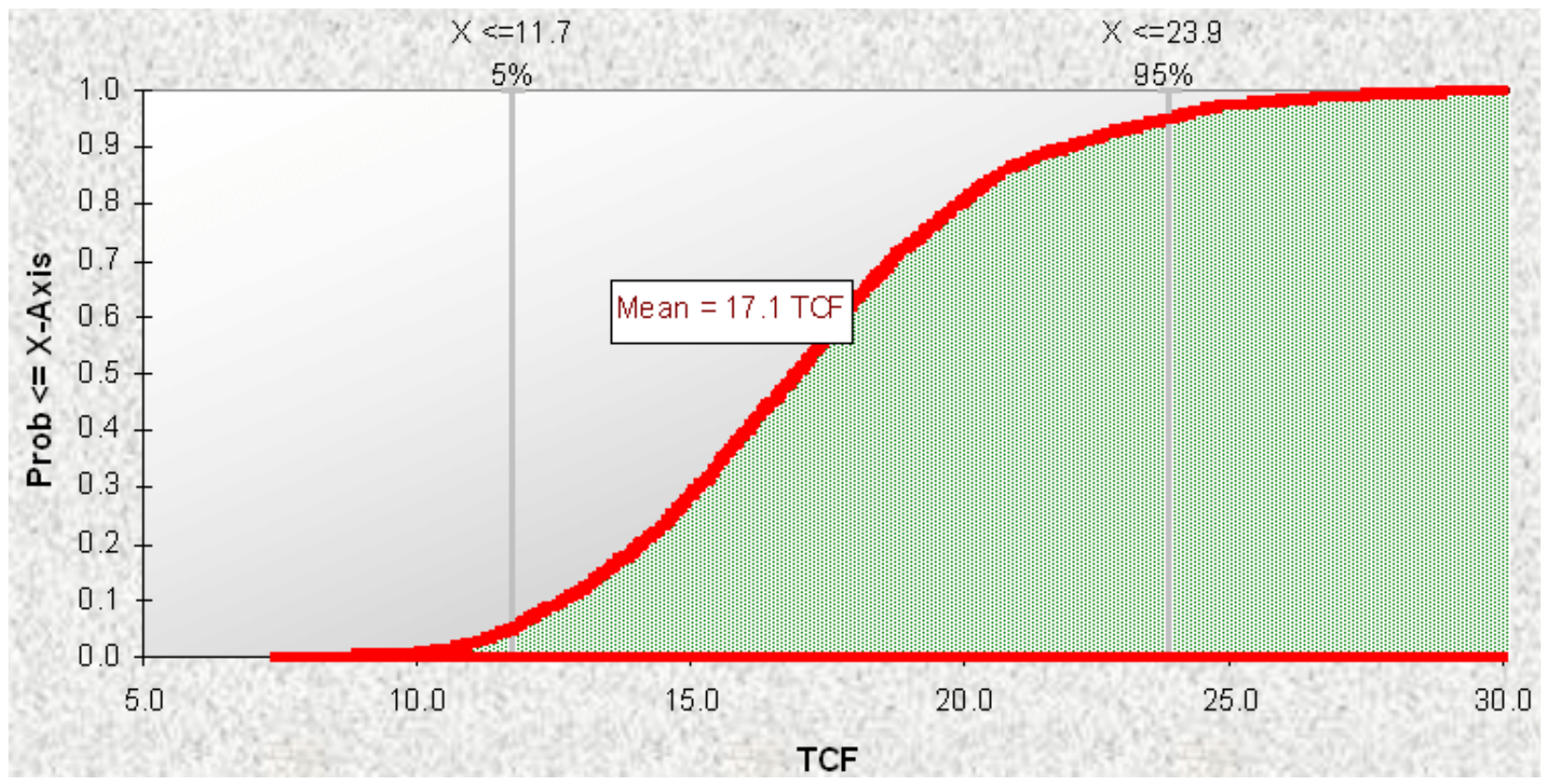

Figure 14. Distribution for Total Free Gas and Hydrate Reserves in Cirque/Tarn Area

Which production options were considered depended on the location of the free gas relative to the hydrate accumulation. To effectively produce hydrates, the consensus was that a free gas leg needed to be located adjacent to the hydrate interval. To the extent that this occurred, we believed that the free gas could be produced similar to a coalbed methane accumulation by drilling several wells in an area in "pods" and producing them until pressure and/or rate began to drop below a pre-determined level. This pod would then be shut in and another pod produced, thereby allowing the hydrates to dissociate into the free gas leg. After pod production dropped below the threshold, production would be returned to the first pod of wells.

\section{Task 21.0 - Post-Well Analysis}

This task includes a lessons-learned report based on past operations, and was designed to help planning operations on other areas of the North Slope of Alaska. The report was to include a budget for an additional well and an extended well test based on the information generated from Phase II activities, if appropriate. The production test plan would help determine the producibility of hydrate deposits. These plans will be valuable for future hydrate operations, even if this project is not extended into Phase III.

The Post-Well Analysis report was prepared and is presented in Appendix A.

\section{Task 22.0 - Information Acquisition and Technology Transfer}

The project team gave high priority to communicating and exchanging information with experts in the field of hydrate well drilling, coring, and testing, including Advisory Board members, to stay abreast of the latest technology and preferred methodologies. Results of the field tests 
were well documented and transferred to the industry via several Topical Reports, the project's web page, technical papers and presentations.

\section{Subtask 22.1 - Information Acquisition}

The team identified and networked with other experts in the field of hydrate well drilling, coring, testing, and analysis to gain insights into the latest methodologies and technologies. The team followed the latest developments related to hydrate wells by meeting with experts in the scientific and drilling communities.

\section{Subtask 22.2 - Technology Transfer}

The hydrate project team documented project results and transferred the new information and technology to the industry via web site postings, meetings, workshops, and several technical papers. Several presentations and poster sessions were presented at the AAPG Hedberg Conference in September, 2004. The team also used the NED Drill Smart system to allow well activities to be viewed by scientists, engineers, and DOE project managers who were not present at the well site during drilling/coring operations.

\section{DELIVERABLES}

Periodic, topical, and final reports were submitted in accordance with the DOE's Reporting Requirements Checklist. In addition, the project team submitted the following:

\section{Phase I}

1. Digital map of all well locations in and adjacent to project area (Task 2.1)

2. Well log correlation sections showing lithologic and stratigraphic units that fall within the gas hydrate stability zone in and adjacent to the project area (Task 2.1)

3. Seismic maps and sections showing extent of stratigraphic and lithologic units that fall within the gas hydrate stability zone in and adjacent to the project lease area (Task 2.2)

4. Reservoir modeling report for proposed site (Task 3.0)

5. Well Data for individual control wells used for site selection (Tasks $2.1 \& 4.1$ )

6. Site Selection Plan (Task 4.1)

7. Testing and analytical procedures report (Task 5.0)

8. Well plan(s) (Task 6.0)

9. Permit application (Task 4.2) 


\section{Phase II}

1. Drilling and Coring Operations (Topical Report) (Task 9.2)

2. Logging Operations (Topical Report) (Task 10.0)

3. Core and Fluid Analysis (Topical Report) (Task 11.0)

4. Bibliography of Publications by Project Personnel (see Section 6)

5. 3D Vertical Seismic Profile Survey (Topical Report) (Task 12.0)

6. Well Completion Report (see Appendix B) (Task 13.0)

7. Well Testing Report (see Appendix C) (Task 15.0)

8. Hydrate Reservoir Characterization and Modeling (Topical Report) (Tasks 17, 18, 19)

9. Economic Projections and a Production Options Report (above under Task 20)

10. Post-Well Analysis Report (see Appendix A)

11. Technical Publications Summarizing Project Findings (see Section 6 and Appendix F) (All Tasks)

12. Final Report Summarizing Project Findings (the present report) (All Tasks)

In addition to the required reports, the team submitted informal status reports directly to the COR. These included short descriptions of successes, problems, advances or other general project status information.

A four-day internal workshop was conducted prior to the project review meeting with the DOE, during which a briefing of the program results was presented at the Anadarko facility in the Woodlands, Texas on May 13, 2004. 


\section{Conclusions}

\subsection{Project Accomplishments}

A number of significant accomplishments were achieved during this project:

1. The geologic model used to predict potential hydrate-bearing strata was proven correct.

- Gas-bearing sands were encountered in highly porous sandstones that were situated within the hydrate stability zone (HSZ). These sands are areally extensive and are stratigraphically equivalent (by correlation) to sand units present in offset wells.

- A localized temperature model was developed for predicting the base of the HSZ. This model was verified by well results and used to determine the total depth of the well.

2. The continuous coring rig proved to be a safe and efficient drilling system.

- The team demonstrated the ability to recover frozen core (permafrost).

- $\quad 93 \%$ of attempted continuous core was recovered.

3. The project team demonstrated the ability to characterize whole core on site using a mobile core laboratory uniquely equipped for hydrate evaluation.

- Tools were developed for hydrate-specific measurements to analyze dissociation of water and methane.

- Petrophysical measurements were performed quickly on site.

- A state-of-the-art CAT scan tool supplied by Lawrence Berkeley National Laboratory was used to analyze whole core.

- The USGS collected and analyzed in real time coal cores taken on the North Slope.

4. The project team designed and recorded a massive 3D vertical seismic profile (VSP).

- The VSP recorded shallow seismic data with 3D perspective using dense spacing of receivers and vibrators.

- Processed data allow investigation of lateral variations of potential hydrate reservoirs.

5. The project team demonstrated the concept of extending the drilling season on the North Slope of Alaska by using a low-impact platform design.

- The modular platform remained in place during the summer and appears to have had no adverse impact on wildlife. 
- At the conclusion of drilling and completion operations, the equipment was demobilized as designed. After clean-up, there was no adverse environmental impact at the drill site.

6. The project team transmitted live data from the North Slope to Houston and Washington D.C. during the project.

- The capability to transmit live data from the well site reduced the number of onsite scientists required to oversee the project.

\subsection{Occurrence of Hydrates at HOT ICE No. 1}

The primary objective of this project was to determine how to successfully explore and produce gas hydrates on the North Slope of Alaska. The HOT ICE No. 1 well was continuously cored to a depth of $2300 \mathrm{ft}$. The well reached its planned total depth on February 7, 2004, approximately $300 \mathrm{ft}$ below the theoretical base of the hydrate-stability zone (HSZ). No gas hydrates were encountered. This was a surprise and disappointment to the Anadarko/Maurer/Noble team since the geological model successfully predicted porous sands containing natural gas within the HSZ.

The HOT ICE well encountered several relatively thin zones with the characteristics of hydrates (high velocity and resistivity indicated on well logs, coupled with gas shows on the mud logs) that were determined to be highly cemented sands. The existence of similar zones in offset wells examined during the planning phase now raises questions about the presence of hydrates in this area.

In larger sand packages structurally up-dip from the HOT ICE location, offset wells have been documented to contain hydrates. Also, several wells located structurally down-dip have exhibited mud log gas shows in these same sand zones. Rather than hydrates, the HOT ICE well encountered free gas and water in the HSZ. This raises questions about what other variables are involved in the formation of methane hydrates in porous sand.

An assessment to address these issues will continue in developing possible recommendations to enhance future exploration efforts. Steps taken to assist in that effort included:

1. Processing and interpreting the high-resolution $3 D$ VSP

2. Performing reservoir characterization to correlate the VSP/core/well log data

3. Providing available data to engineers and scientists for use in hydrate modeling and for future hydrate reservoir evaluation activities

Continuous core was recovered throughout the HSZ. It had been predicted before drilling began that the location would have significant sands in the HSZ and gas in the system. As no shallow seismic data were available, and the cost of acquiring such data was too expensive, it was not known if any traditional hydrocarbon traps existed. Hydrates were established as existing in wells to the northwest in sands that would be cut by HOT ICE. Core showed in the HSZ (as predicted) good high-porosity, high-permeability reservoir sands, and gas shows on the mud log. Despite this, no hydrates were recovered in this well.

Modeling of hydrate dissociation indicates that, if significant hydrates were cored, they would not completely dissociate before reaching the surface. There was no evidence on well logs for 
hydrates existing in-situ. Information on formation brine extracted from samples and resistivity measurements showed it to be somewhat less saline than seawater; therefore, there is no reason to believe that the HSZ had been incorrectly calculated. Experience at HOT ICE No. 1 further establishes what was already clear from earlier studies: even in very good reservoir rocks, more is required beyond correct thermodynamic conditions and gas in the system to produce a hydrate reservoir.

Numerous wells drilled on the North Slope of Alaska have reported drilling through hydrates. Hydrates were definitely recovered at the Northwest Eileen Well 2. Thus, there is no question that hydrates exist at some locations on the North Slope. It is also clear that they are not everywhere. The question then becomes: What is the nature of the geographic distribution? The most optimistic model is that they exist as continuous sheet-like deposits. For this case, detection of hydrates in isolated wells can be used to contour the existence of hydrates between the wells. At the other extreme, the most conservative model states that hydrates only exist where there were shallow gas reservoirs before temperatures cooled a few million years ago. The first model makes hydrates a very large potential resource, the second at best a marginal one. Wells in which hydrates have been detected or inferred from well logs were generally drilled based on the expected existence of a deeper trap containing oil. Such traps often imply the existence of traps in shallower formations. For such a scenario, drilled wells form a biased set, not a random sampling of shallow formations.

It is well known that hydrate plugs can form in pipelines. In addition, hydrates seem to form on the ocean floor without the presence of traditional traps. These observations show that, given a sufficient methane flux and proper temperature/pressure conditions, hydrates are a self-trapping system. It would follow that, if no trapped gas already exists, the size of the gas flux through the system is probably a critical parameter. Lack of hydrates at HOT ICE No. 1 implies that this critical flux was not achieved there. One question then arises: Does or did a large enough gas flux exist in some areas on the North Slope? If so, sheet-like accumulations should exist.

If gas fluxes everywhere on the Slope are below the critical value, a traditional trapping mechanism seems to be necessary. Under these conditions, fields could still be larger than the gas volume the trap can hold. This is because after trapped gas is converted to hydrate it could act as a seed reservoir that grows by converting gas passing by into hydrate. It is therefore essential to obtain quantitative bounds on the gas flux passing through North Slope reservoirs in the last few million years. 


\section{References}

\section{Project Bibliography}

\section{Magazines and Newspapers (longer articles only)}

Antosh, Nelson, 2003: "New Drilling Rig in Tundra Faces Chilling Challenges," Houston Chronicle, February 21.

Bradbury, John, 2003: "Drilling in the Freezer," Hart's E\&P, August.

Bradner, Tim, 2004: "Hydrate project nets data, lacks hydrates," Alaska Oil \& Gas Reporter, May 4.

Bradner, Tim, 2003: "Anadarko Suspends Gas Hydrate Drilling Until Fall," Alaska Oil \& Gas Reporter, May 6.

Bradner, Tim, 2003: "The Woodlands, Texas-Based Oil Firm Suspends Alaska Gas Hydrate Drilling," Alaska Oil \& Gas Reporter, May 5.

Jones, Patricia, 2003: "Tapping Hot Ice," Petroleum News, Volume 8/15, April 13.

Moritis, Guntis, 2003, "Seeking Flammable Ice," Oil and Gas Journal, Volume 101/21; May 26.

Nelson, Kristen, 2003: “Arctic Platform in Place," Petroleum News Alaska, April 6.

Nelson, Kristen, 2002: "Hot Ice Project: Anadarko to Core Hydrate Well South of Kuparuk Unit," Petroleum News Alaska, November 10.

Perin, Monica, 2003: "Firms Warm up to the 'Ice that Burns'," Houston Business Journal, January 27.

Schempf, F. Jay, 2004: "Arctic Platform to Resume Drilling This Month," The Rig Zone News, article id=10337, January 9.

Snyder, Robert E., 2003: "Innovative Arctic Platform. (Drilling Advances)," World Oil, May.

Staff, 2003: "Anadarko Petroleum Corp. Debuts New Arctic Drilling Platform," Anchorage Daily News, Alaska, April 10.

\section{Technical Articles and Presentations by Project Team}

Aleshire, Lynn and Zubeck, Hannele, 2003: "Permafrost Foundations and Their Suitability as Tundra Platform Legs," University of Alaska Anchorage, School of Engineering, February 10.

Anadarko Staff, 2002: "Environmental Evaluation Report for the HOT ICE Prospect," submitted to the State of Alaska, September. 
Barker, Charles E., 2003: "Coalbed Methane Studies at Hot Ice \#1 Gas Hydrate Well; First Report," US Geological Survey, Denver, April.

Barker, Charles E., Clough, James G. and Roberts, Stephen B., Clark, Arthur and Fisk, Bob, 2003: "Physical Limitations on Coalbed Gas Content of Low Rank Coals, North Slope, Alaska: An Apparent Widespread Depletion of Coalbed Gas in Permafrost," US Geological Survey, Alaska Division of Geological and Geophysical Surveys, and Bureau of Land Management, presented at $18^{\text {th }}$ International Low-Rank Fuels Symposium, Billings, Montana, June 24-26.

Circone, S., Stern, L.A., and Kirby, S.H., 2003: "The Role of Water in Hydrate Dissociation," J. Phys. Chem. B., (submitted).

Cohen, John and Williams, Thomas, 2002: "Hydrate Core Drilling Tests," Topical Report by Maurer Technology Inc., November.

Ebanks, W.J. and Zogg, W.D., 2003: "Coring for Methane-Hydrate in Shallow Sands of the Sagavanirktok Formation North Slope, Alaska - Phase I: Progress and Geologic Description," PTS Labs and Corpro, June.

Friefeld, B.M., Kneafsey, T.J., Tomutsa, L., Stern, L.A., and Kirby, S.H., 2002: "Use of Computed X-Ray Tomographic Data for Analyzing the Thermodynamics of a Dissociating Porous Sand/Hydrate Mixture," Proceedings of the 4th International Conference on Gas Hydrates, Yokohama Japan, 2002, pp. 750-755.

Kadaster, Ali G. and Keith K. Millheim, 2004: "Onshore Mobile Platform: A Modular Platform for Drilling and Production Operations in Remote and Environmentally Sensitive Areas," SPE 87140 presented at IADC/SPE Drilling Conference held in Dallas, Texas, 2-4 March.

Kirby, Stephen H., Circone, Susan and Stern, Laura A., 2003: "Dissociation Rates of Methane Hydrate at Elevated Pressures and of a Quartz Sand-Methane Hydrate Mixture at 0.1 MPa," US Geological Survey, Menlo Park, March 5.

Liddell, Bill, 2002: "Project Overview of Methane Hydrate from Alaska Permafrost," presented to University of Oklahoma Graduate Student Seminar, Norman, Oklahoma, November 1.

Liddell, Bill, 2002: "Alaska Hydrate Project Overview," presented to Canadian Society of Petroleum Geologists, Calgary, AB, Canada, November 6.

McGuire, D., Runyon, S., Williams, T., Paulsson, B., Goertz, A. and Karrenbach, M., 2004: "Gas Hydrate Exploration with 3D VSP Technology, North Slope, Alaska," presented at SEG $74^{\text {th }}$ Annual Meeting, Denver, October 11-15.

McGuire, D., Runyon, S., Williams, T. and Sigal, R, 2004: "Integration of VSP Seismic Data with Core and Well Log Data to Investigate Lateral Variations of Potential Hydrate-Bearing Sands, Alaska North Slope," presented at AAPG Hedberg Research Conference, Vancouver, BC, Canada, September 12-16.

Millheim, Keith, 2002: "Methane Hydrate Production from Alaska Permafrost," presented at AAPG Hydrate Meeting, Houston, Texas, March 12. 
Millheim, Keith and Kadaster, Ali, 2005: "Anadarko HOT ICE No. 1 Well: Planning, Permitting and Drilling Operations for a Dedicated Gas Hydrate Exploration Well in the Alaskan Arctic," to be presented at 2005 SPE/IADC Drilling Conference \& Exhibition, Amsterdam, The Netherlands, February 23-25.

Millheim, Keith, Kwan, Jonathan and Maurer, Bill, 2002: "A Field Oriented Natural Gas Hydrate Research Project for the Alaska North Slope - Resource Evaluation and Possible Testing," presented at ACS National Meeting, Orlando, Florida, April 9.

Millheim, Keith, Kwan, Jonathan, Maurer, Bill, McDonald, Bill, and Williams, Tom, 2004: "The First Hydrate Experimental Well in Alaska-A Joint US DOE and Industry Effort," (invited paper to the book Advances in the Studies of Gas Hydrates to be published by Kluwer Academic/Plenum Publishers in 2004).

Moridis, George J., 2003: "FY2002 Studies—Hydrate Preservation in Cores (LBNL)," Lawrence Berkeley National Laboratory, Earth Sciences Division.

Moridis, George J., 2003: "FY2003 Studies-Scoping Analyses of Gas Production from Hydrates," Lawrence Berkeley National Laboratory, Earth Sciences Division.

Newsham, Kent, 2003: "Recalculation of Base of Hydrate Stability Zone," Anadarko Petroleum Corporation, June.

Newsham, Kent, Sigal, Richard, Kleinberb, Robert, and Kwan, Jonathan, 2004: "Using Diffusivity Calculation and Regional Temperature Profile to Determine the Base of Permafrost in a Hydrate Field Experiment," (invited paper to the book Advances in the Studies of Gas Hydrates to be published by Kluwer Academic/Plenum Publishers in 2004).

Ross, Z., Crossen, K. and Munk, L., 2002: "Geologic Research of Well Records and Stratigraphy of the North Slope Region near Kuparuk, Alaska," University of Alaska Anchorage, November 25.

Sigal, R.F., Rai, C., Sondergeld, C.H., Ebanks, W.J., Zogg, W.D., and Kleinberg, R.L., 2004: "Characterization of Potential Hydrate Bearing Reservoirs in the Ugnu and West Sak Formations of Alaska's North Slope," presented at AAPG Hedberg Research Conference, Vancouver, BC, Canada, September 12-16.

Sigal, Richard and Runyon, Steve, 2003: "Interim Report on HOT ICE \#1 Coring, Core Analysis, and Logging Program," Anadarko Petroleum Corporation, May.

Stern, L.A., Circone, S., Kirby, S.H., and Durham, W.B., 2002: "New Insights into the Phenomenon of Anomalous or 'Self' Preservation of Gas Hydrates," Proceedings of the 4th International Conference on Gas Hydrates, Yokohama Japan, 2002, pp. 673-677.

Stern, L.A., Circone, S., Kirby, S.H., and Durham, W.B., 2003: "Temperature, Pressure, and Compositional Effects on Anomalous or 'Self' Preservation of Gas Hydrates," Can. Journal of Physics, 81 (1-2), pp. 271-283.

Tomutsa, L., Freifeld, B., Kneafsey, T., and Stern, L., 2002: "X-ray Computed Tomography Observation of Methane Hydrate Dissociation," Proceedings of the SPE Gas Technology Symposium, Calgary 2002 , paper SPE 75533. 
Williams, T.E., Liddell, B.V., Kadaster, A. and Thompson, T., 2004: "HOT ICE Well No. 1 - Well Planning, Operations and Results of the First Dedicated Gas Hydrate Well in the Alaskan Arctic," presented at AAPG Hedberg Research Conference, Vancouver, BC, Canada, September 12-16.

Williams, T.E., Liddell, B.V., and Sigal, R., 2003: "Methane Hydrate Production from Alaska Permafrost," presented at Methane Hydrate R\&D Conference, Westminster, CO, September 29.

Williams, Thomas E., 2002: "Project Review - Methane Hydrate Production from Alaskan Permafrost," Methane Hydrate Conference, Washington DC, August 28.

Williams, Thomas E., 2002: "Project Review - Methane Hydrate Production from Alaskan Permafrost," Methane Interagency R\&D Conf., Washington DC, March 21.

Williams, Thomas E., 2003: "Methane Hydrate Production - Application of Arctic Hydrate Research to Deep Water," presented at American Association of Drilling Engineers, Deep Water Quarterly Forum, Houston, Texas, February 11.

Woolard, C.R., Schnabel, W., Munk, L. and Hines, M., 2003: "Fundamental and Applied Research on Water Generated During the Production of Gas Hydrates (Phase 1)," University of Alaska Anchorage, February 17.

Woolard, Craig R., 2002: "Fire and Ice: Gas Hydrates in the Last Frontier," presented at University of Alaska Anchorage, October 8. 


\section{Acknowledgements}

The project team acknowledges the many important contributors to this project:

$>$ University of Oklahoma

$>$ Craig Woodard and the University of Alaska, Anchorage

$>$ Steve Kirby and Tim Collett with the United States Geological Survey

$>$ Robert Kleinberg and Doug Griffin with Schlumberger

$>$ Berry Freifeld and George Moridis with Lawrence Berkeley National Laboratory

> Pacific Northwest National Laboratory

$>$ Sandia National Laboratories

$>$ Ocean Drilling Program, JOI—Frank Rack

> Anadarko Petroleum Corp. Team-Tommy Thompson, Ali Kadaster, Donn McGuire, Steve Runyon, Richard Sigal, Bill Liddell and Jonathon Kwan

> Paulsson Geophysical Services, PGS Onshore

Frances Toro and John Rogers with DOE NETL 


\title{
"Methane Hydrate Production from Alaskan Permafrost" \\ Post-Well Analysis - \\ HOT ICE No. 1 Gas-Hydrate Well
}

\begin{abstract}
By
Bill Liddell, Ali Kadaster, Donn McGuire, Richard Sigal, Steve Runyon, Tommy Thompson, Keith Millheim, Mike Globe and Kent Newsham - Anadarko Petroleum Corp.

Thomas Williams and Greg Deskins - Maurer Technology Inc.
\end{abstract}

\section{Contents}

Introduction

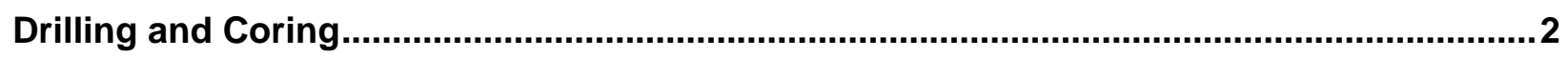

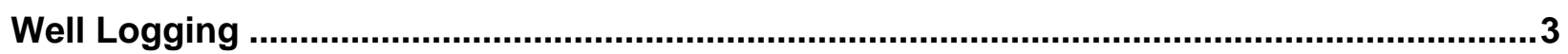

On-Site Core and Fluid Analysis .................................................................................. 4

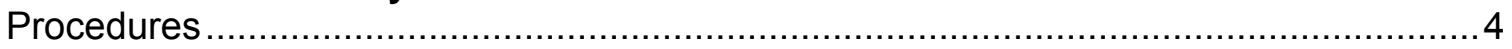

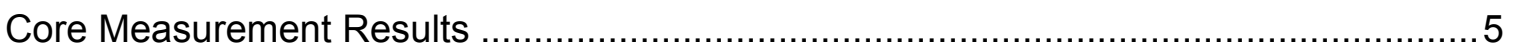

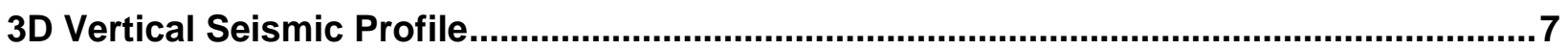

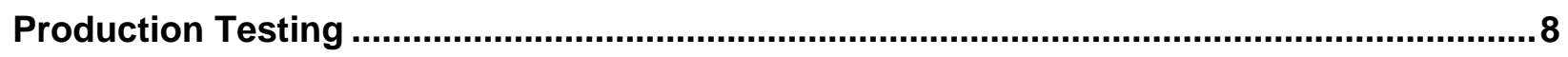

Predicting the Occurrence of Hydrates .............................................................................. 9

Lessons Learned ............................................................................................................ 10

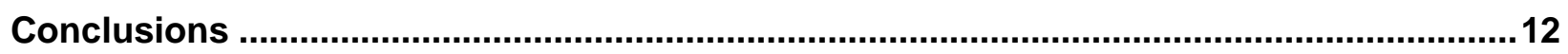

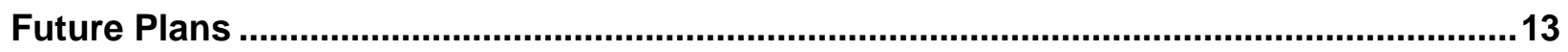

\section{Introduction}

This gas-hydrate project is a cost-shared partnership between Maurer Technology Inc., Anadarko Petroleum Corp., Noble Corp., and the U.S. Department of Energy's Methane Hydrate R\&D program. The overall goal is to build on previous and ongoing R\&D in the area of onshore hydrate deposition to help identify, quantify and predict production potential for hydrates located on the North Slope of Alaska. Important project objectives include the documentation of project planning, field operations and lessons learned to assist in future hydrate research and field operations and to contribute to an objective technical and economic assessment of this natural gas potential.

On February 7, 2004, the well was drilled to total depth of $2300 \mathrm{ft}$, about $300 \mathrm{ft}$ below the zone where temperature and pressure conditions would theoretically permit hydrates to exist. The well was drilled from a special purpose-built arctic platform. A continuous coring rig was used in the project and proved to be a safe and efficient drilling system, with $93 \%$ of the core recovered. 
Unfortunately, although significant gas shows were encountered in highly porous sandstones, no methane hydrates were found.

Other operational highlights include the project team's use of a specially designed on-site laboratory to help analyze hydrate and rock cores. Live data and images were transmitted during field operations from the rig over the internet, which reduced the number of engineers and scientists required to oversee the project. A massive 3D VSP seismic survey was also conducted to investigate lateral variations of the potential hydrate reservoir.

As mentioned, documentation of lessons learned during the project was a key goal. Technical results, successes and failures for the HOT ICE project are discussed in the sections below.

\section{Drilling and Coring}

The work scope for this project included drilling and coring the HOT ICE No. 1 gas-hydrate well on Anadarko leases during the winter drilling seasons in 2003 and 2004 . During the first season (January 28 to April 30, 2003) the well was spudded and drilled to a depth of $1403 \mathrm{ft}(428 \mathrm{~m})$. Due to the onset of unseasonably warm weather, work was then suspended for the season. The platform was shut down and left in position throughout the summer. Operations at the site were continued after the tundra was re-opened the following winter. Between January 12, 2004 and March 19, 2004, the well was drilled and cored to a final depth of $2300 \mathrm{ft}(701 \mathrm{~m})$.

Daily drilling reports were completed by personnel at the rig consistently during the 2003 and 2004 operations seasons. The team monitored and responded to environmental health and safety concerns, including monitoring and manifesting waste, to ensure compliance with regulations specified in permits. The safety record was excellent during the entire operation.

The team drilled the well from an innovative Arctic Platform. The team used chilled drilling fluids to maintain cores as close to in-situ conditions as possible, and monitored downhole temperature and inclination using a tool provided by Sandia National Laboratory. The team used Noble Engineering and Development's DrillSmart ${ }^{\mathrm{TM}}$ system to allow engineers to monitor and view drilling operations live from their offices in Anchorage and Houston.

Anadarko's Arctic Platform (Figure 1) is constructed of lightweight aluminum and was designed as a zero-discharge facility. It was mobilized to the base camp and inspected in January 2003, prior to mobilization to the well location in February. The legs were tested and put on location as soon as

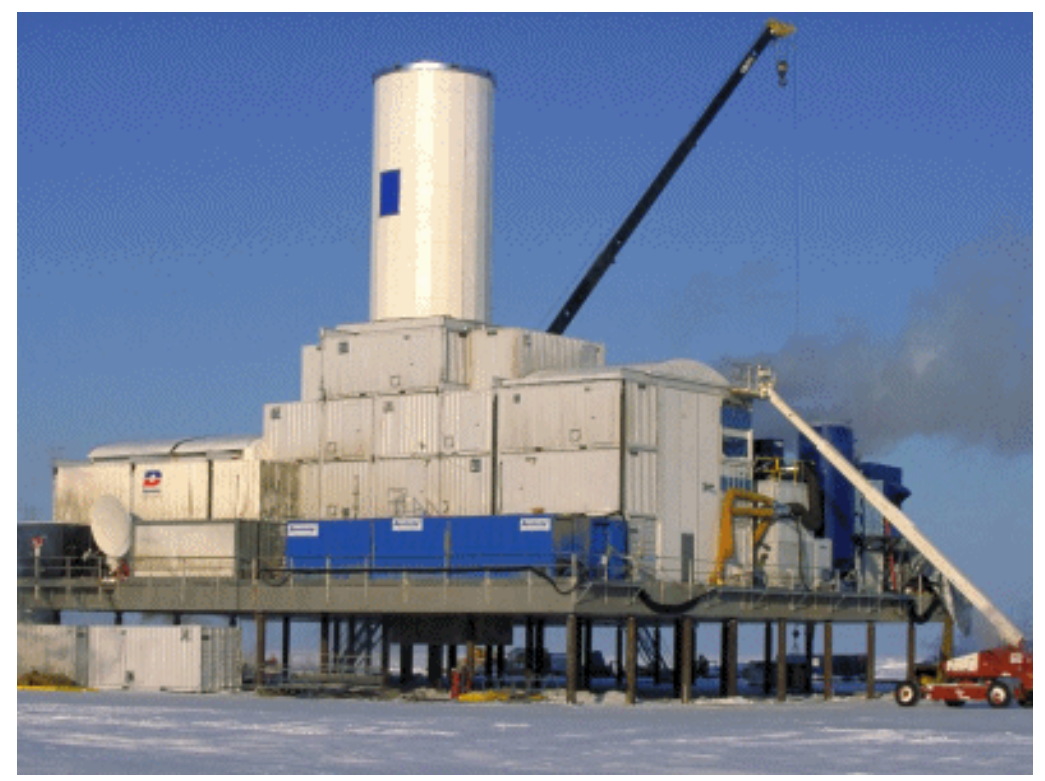

Figure 1. Onshore Arctic Platform

the freeze period began in January. A video of rig transportation and construction was provided to the DOE. Legs were installed into the tundra permafrost and frozen into place. The platform 
can be mobilized by helicopter and/or Rolligon from the base camp and assembled at the well location. Environmental monitoring equipment was also installed on the rig.

The platform drilling area is $100 \times 100 \mathrm{ft}(30.5 \times 30.5 \mathrm{~m})$ and the base camp is $62.5 \times 50 \mathrm{ft}(19.1$ $x 15.2 \mathrm{~m}$ ) on an adjacent platform. The rig, equipment and base camp were installed onto the platform by two cranes. At the conclusion of drilling and completion operations, the equipment was demobilized successfully as designed. After clean-up, there were no adverse environmental impacts at the HOT ICE drill site. The entire platform was demobilized to Dead Horse, Alaska. It was thoroughly inspected by a third party and a post-analysis study was conducted with recommendations on future operations.

For the first drilling season (during 2003), a road was not constructed to the site. The team used special trucks, helicopters and Rolligons to transport the rig, platform, personnel, equipment and supplies that were used in the drilling operations, including drilling fluids and mud. For the winter 2004 season, the team constructed a new ice road to facilitate mobilization of equipment, supplies, and personnel to the site to complete drilling and coring operations.

Drilling and coring operations are described in detail in the project Topical Report - Drilling and Coring Operations.

\section{Well Logging}

During the first drilling season (in 2003) the well was spudded and drilled to a depth of $1403 \mathrm{ft}$. Open-hole logging was conducted on April 15-16, 2003. Work was then suspended for the season. Operations at the site were continued the following season. After final depth was achieved, open-hole logging was conducted February 8-9, 2004.

The project team ran a suite of logs in the well to characterize gas hydrate-bearing intervals, including: (1) electrical resistivity (dual induction), (2) spontaneous potential, (3) caliper, (4) acoustic transit time, (5) neutron porosity, (6) density, and (7) nuclear magnetic resonance. Core data were used to calibrate and quantify log information.

During logging operations in the 2004 season, the wellbore contained water-based mud with a measured density of $9.6 \mathrm{ppg}\left(1150 \mathrm{~kg} / \mathrm{m}^{3}\right)$, and a resistivity of $0.05 \mathrm{Ohm}-\mathrm{m}$ at $62^{\circ} \mathrm{F}\left(17^{\circ} \mathrm{C}\right)$. Bit size used for this section of the well was $57 / 8$ inches. The borehole was generally in gauge, with hole size rarely exceeding 6.5 inches. Well log data were generally of good quality. However, invasion of the high-conductivity mud did affect the induction-based resistivity measurements. This was particularly noticeable in the profile of the array resistivity measurements in sediments above $1900 \mathrm{ft}(579 \mathrm{~m})$. Although conductive mud is not generally a favorable environment for induction-based electrical logging, the relatively small wellbore in this well should have mitigated any unfavorable borehole signal.

The interval from 1400-2250 ft (427-686 m) was evaluated using a Baker Atlas petrophysical analysis package. Clay volume was computed using a Hodges-Lehmann average of clay volumes computed from the density/neutron cross-plot and gamma-ray techniques. Effective porosity was computed using the clay-corrected density/neutron cross-plot technique, based on an assumed $2.65 \mathrm{~g} / \mathrm{cc}$ matrix density. Effective water saturation was calculated using the modified Simandoux equation.

Results of the evaluation indicate that there is likely a gas-saturated, porous and permeable sandstone in the interval 1460-1510 ft (445-460 m). In this interval, porosity of the sandstone 
beds ranges from $21 \%$ to $33 \%$, and water saturation from $15 \%$ to $50 \%$ depending on reservoir quality. There are interbedded zones with very low resistivities through this interval that most likely are associated with clay-rich beds, but remain unexplained. One of these low-resistivity beds occurs at the base of the sand interval at 1506-1508 ft $(459.0-459.6 \mathrm{~m})$, and could be associated with a gas/water contact.

Logging operations are described in detail in the project Topical Report - Logging Operations.

\section{On-Site Core and Fluid Analysis}

The project team analyzed core and fluids using a specially constructed mobile core laboratory (Figure 2) staffed by trained technicians. Core was received in the cold module immediately after retrieval from the well. There it was photographed and assessed for the presence of hydrates. One-inch plugs were removed from the core, and these plugs were measured for porosity, permeability, compressional and shear wave velocity, resistivity, thermal conductivity, and NMR with equipment specifically designed for these hydrate core measurements, including a Schlumberger CMR tool. Because no hydrates were encountered, hydrate dissociation testing was not conducted. All core measurements were conducted under controlled pressures and temperatures.

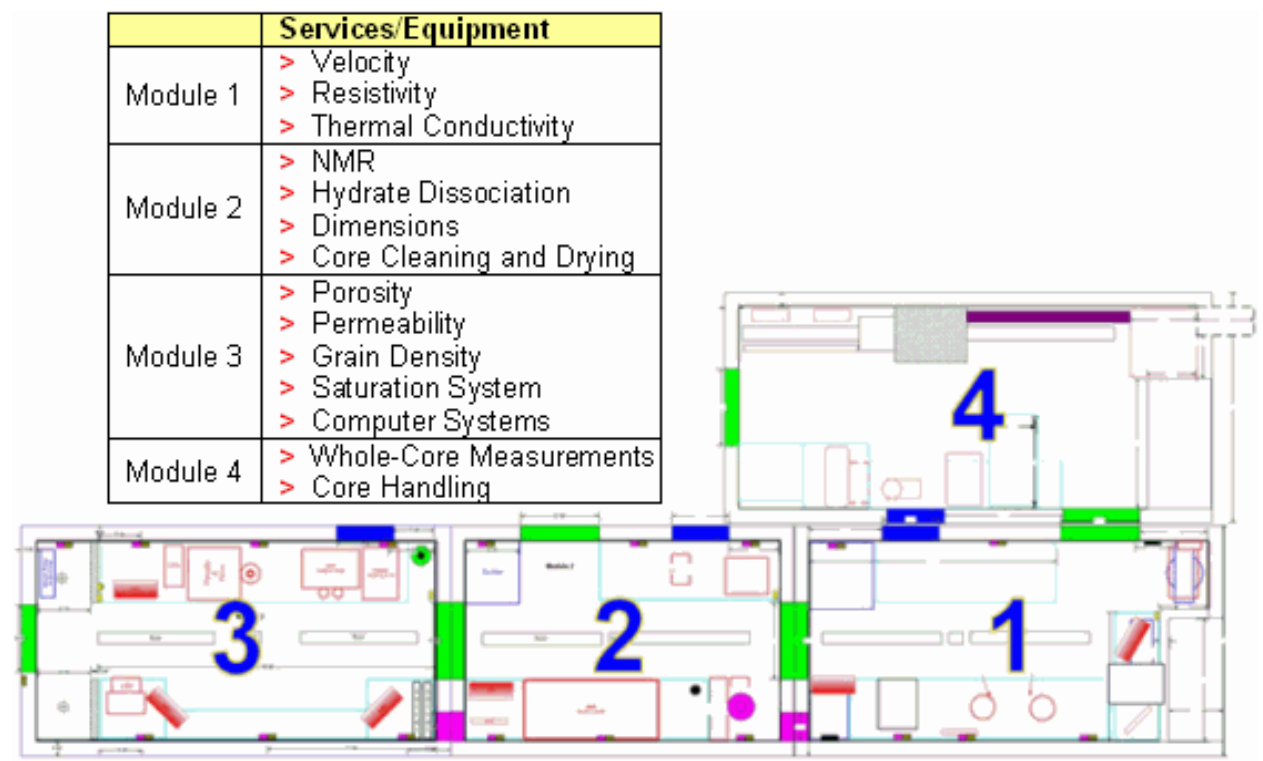

Figure 2. Design of Mobile Core Laboratory used for On-Site Analysis

\section{Procedures}

The well was drilled from surface to a measured depth of $2300 \mathrm{ft}(701 \mathrm{~m})$. There was almost complete core recovery from the bottom of surface casing $(107 \mathrm{ft} ; 33 \mathrm{~m})$ to total depth. Based on the team's best estimate of the bottom of the methane hydrate stability zone, core was recovered over the zone's complete range. Approximately $580 \mathrm{ft}(177 \mathrm{~m})$ of porous, mostly frozen sandstone and $155 \mathrm{ft}(47 \mathrm{~m})$ of conglomerate were recovered in the Ugnu Formation and $215 \mathrm{ft}(66 \mathrm{~m})$ of porous sandstone were recovered in the West Sak Formation. There were gas shows in the bottom part of the Ugnu and throughout the West Sak. No hydrate-bearing zones 
were identified either in recovered core or on well logs. The base of the permafrost was determined to be near $1260 \mathrm{ft}(384 \mathrm{~m})$.

The whole core was described by well-site geologists as soon as it was extracted from the wireline-retrievable core barrel. A graphic lithology log was produced from the description. During 2003 operations, a CMR logging tool located in the mobile laboratory was used to make NMR measurements on a 6-inch section from each 40-inch $(102 \mathrm{~cm})$ core segment. This measurement provided an estimate of the amount of unfrozen brine in the "frozen rocks" from the permafrost section. The median value for unfrozen porosity in the permafrost zone was 0.051 . For rocks in this section, this translates to about $13 \%$ of the pore space being filled with unfrozen brine.

One-inch plugs were cut from all rock intervals that were of potential reservoir quality as identified by the well-site geologists, whether these were from above or below the base of the permafrost. Several plugs were cut for thick sand sections. Later, the plugs were cleaned and dried. Next, porosity, permeability, and grain density were measured on each plug. Other procedures performed on the plugs followed two paths, depending on whether they came from the permafrost zone or from a deeper section. For samples from the permafrost zone, velocity and resistivity was measured on samples as they were recovered at subfreezing temperatures. NMR measurements were made on a few frozen plugs, on thawed plugs, and on some resaturated samples. For samples taken from unfrozen formations, the complete suite of measurements was performed after cleaning and drying.

\section{Core Measurement Results}

A thick section of sandstones, mudstones, coals and conglomerates was cored continuously during the 2003 program, from 107-1400 ft (33-427 m) (Figure 3). At this depth the well was temporarily suspended because the spring thaw had begun early on the North Slope. Surface protective casing was set at this point, just below the base of the ice-bearing permafrost. No hydrate-bearing sediment had been encountered at the suspension of coring.

Sediments cored during 2004 (1403-2300 ft; 428-701 $\mathrm{m}$ ) are not as variable in character as those encountered during 2003. This reduction in variability, the overall more fine-grained texture of the sediments, and the common occurrence of layers of shell fragments and whole bivalve shells indicate deposition of these sediments in shallow marine shelf environments.
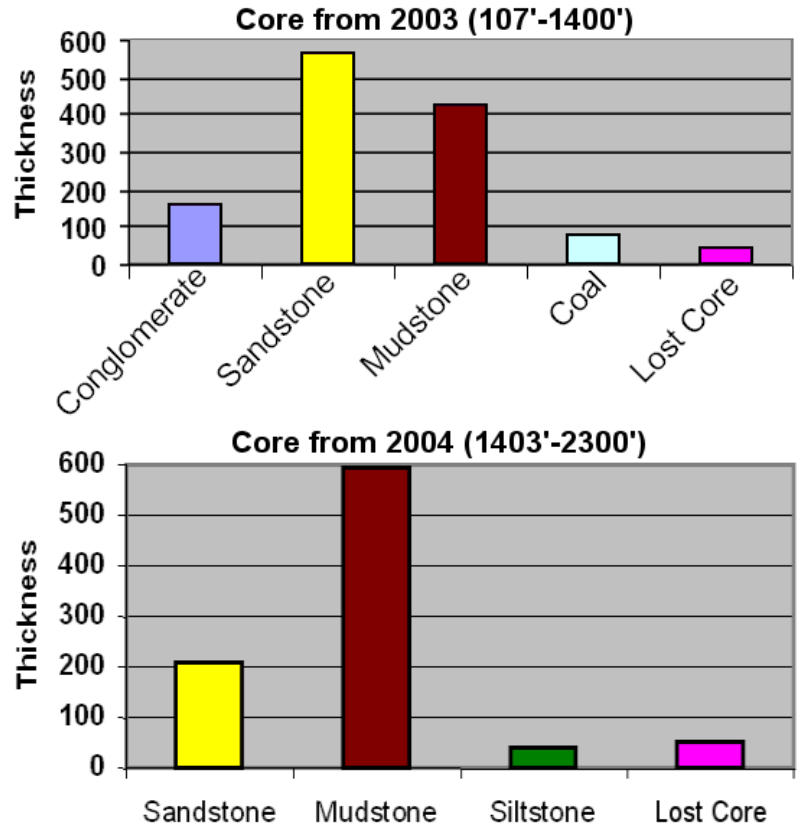

Figure 3. HOT ICE Lithology

With the exception of the deepest sands in the West Sak and some anomalous thin, tight zones, all sands recovered are unconsolidated with high porosity and high permeability. At 800 psi (5.5 MPa), Ugnu sands have an average porosity of $39.3 \%$ and geometrical mean permeability of 3.7 Darcys. Average grain density is $2.64 \mathrm{~g} / \mathrm{cc}$. West Sak sands have an average porosity of $35.5 \%$, geometrical mean permeability of 0.3 Darcy, and average grain density of $2.70 \mathrm{~g} / \mathrm{cc}$. 
There were several 1-2 ft intervals of carbonate-cemented sandstone recovered from the West Sak. These intervals have porosities of only a few percent and very low permeability. On a well log they appear as resistive with a high sonic velocity. In shallow sections of other wells these are usually the only logs available. Given the presence of gas in HOT ICE No. 1, if resistivity, sonic and mud logs had been the only logs available, tight sand zones may have been interpreted as containing hydrates. Although this finding does not imply that all previously mapped hydrate zones are merely tight sands, it does add a note of caution to the practice of interpreting the presence of hydrates from old well logs.

Velocity data from the Ugnu section are consistent with high-porosity sand with most of its pore space filled with ice. Median compressional velocity at 800 psi (5.5 MPa) confining stress is $3864 \mathrm{~m} / \mathrm{sec}$. Median shear velocity is $2185 \mathrm{~m} / \mathrm{sec}$. Compressional velocity is $75 \%$ of the maximum theoretical velocity for a mixture of quartz with $39.6 \%$ ice. Median shear velocity is $66 \%$ of maximum velocity. These values are consistent with ice acting as part of the frame and probably to some extent as a cementing agent.

West Sak velocities (from unconsolidated unfrozen samples) were much slower than frozen Ugnu samples. The median $V_{p}$ was $2000 \mathrm{~m} / \mathrm{sec}$ and median $V_{s} 1000 \mathrm{~m} / \mathrm{sec}$. Sands and shales have similar velocities.

Ugnu sample resistivities were measured on the native-state samples. If assumptions are made regarding the percentage of unfrozen brine in the samples, salinity of the brine before freezing can be estimated from the data. The percentage of unfrozen brine found in this way is consistent with values obtained from core CMR measurements. The median pre-freezing salinity of the brine is $7100 \mathrm{ppm}$.

Most West Sak sand samples were resaturated with a $3 \% \mathrm{KCl}$ solution after drying in a lowtemperature vacuum oven. Resistivity was then measured and fit to a standard Archie's Law relationship. The median value of $m$ (Archie's cementation exponent) for the unconsolidated sands was 1.94. Two sand samples were measured in their recovered state. These measurements provided an estimate of pore fluid salinity. Pore fluid in the West Sak appears to have a salinity less than about one-third that of ocean water. This is consistent with salinity measured on a water sample extracted from the core at the bottom of the Ugnu.

NMR measurements on plugs in the Ugnu raise some interesting (and as of yet unanswered) questions. There are significant differences between measurements of thawed samples and those of after resaturation. No completely satisfactory model has been found to explain these differences. Observed relaxation times for samples are somewhat faster than usually observed for rocks with such high permeability. Finally, NMR measurements do not provide a good estimate of permeability. Modeling of NMR response of the frozen samples from the unfrozen samples shows that the ice restructured the pore geometry so that what appeared as a single pore in the unfrozen rock appears as multiple smaller pores in the frozen NMR spectrum.

NMR measurements on West Sak samples are more nearly what would be expected from past experience. A very good permeability estimator could be developed from the NMR data. Possibly due to trace minerals in the West Sak rocks, the formula differs from the default formula by a factor of three, so that West Sak samples appear have a relaxation rate 1.7 times that of samples used to develop the default formula.

In summary, the methane hydrate stability zone below the HOT ICE No. 1 location includes thick sections of sandstone and conglomerate which would make excellent reservoir rocks for hydrates and below the permafrost zone shallow gas. The Ugnu formation comprises a more 
sand-rich section than does the West Sak formation, and the Ugnu sands when cleaned and dried are slightly more porous and significantly more permeable than the West Sak.

Core and fluid analyses are described in detail in the project Topical Report - Core and Fluid Analysis.

\section{D Vertical Seismic Profile}

After the well was logged, a 3D vertical seismic profile (VSP) (Figure 4) was recorded to calibrate the shallow geologic section with seismic data and to investigate techniques to better resolve lateral subsurface variations of potential hydrate-bearing strata. Paulsson Geophysical Services, Inc. was contracted to deploy their 80 level $3 \mathrm{C}$ clamped borehole seismic receiver array in the wellbore to record samples every $25 \mathrm{ft}$. Seismic vibrators were successively positioned at 1185 different surface positions in a circular array around the wellbore. This technique created a 3D image of the subsurface. Correlations were generated of these seismic data with cores, logging, and other well data.
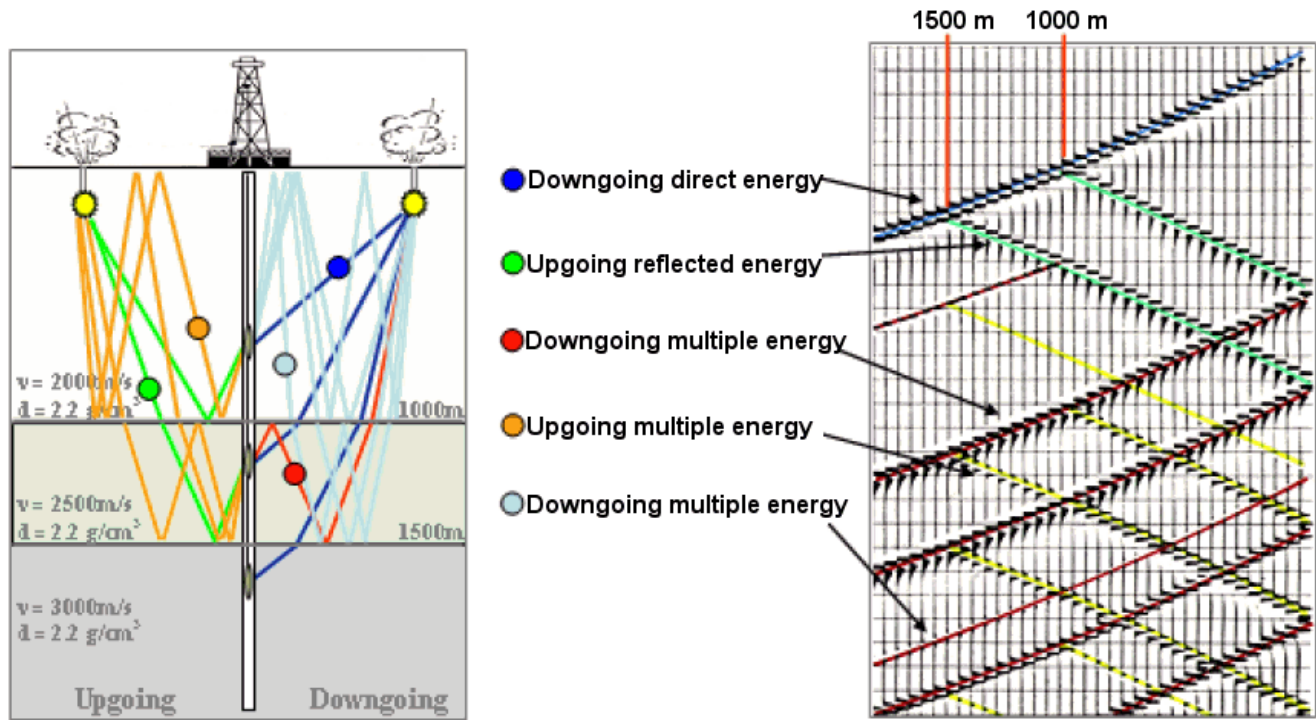

Figure 4. Vertical Seismic Profile Survey

The well did not encounter hydrates in the reservoir sands; however, brine-saturated sands containing methane were encountered within the hydrate-stability zone. Synthetic seismograms created from well log data were in agreement with reflectivity data measured by the 3D VSP survey. Modeled synthetic seismograms indicated a detectable seismic response would be expected in the presence of hydrate-bearing sands. Such a response was detected in the 3D VSP data at locations up-dip to the west of the wellbore. As seen in Figure 5, the amplitude display on the geologic marker plane at the top of Sand A shows little or no amplitude strength at the well location (yellow). To the west, amplitudes are strong peaks (blue). This amplitude variation is the same response seen in the synthetic seismograms when the in-situ case is substituted for a hydrate-bearing case. Therefore, the change in amplitude may indicate the presence of methane hydrates in Sand A only a few hundred feet west and up-dip of the wellbore.

Results of this analysis suggest that the presence of hydrate-bearing strata may not be related as simply to thickness of the hydrate stability zone as previously thought. Geological complications of reservoir facies distribution within fluvial-deltaic environments will require 
sophisticated detection technologies to assess the locations of recoverable volumes of methane contained in hydrates. High-resolution surface seismic data and more rigorous well log data analysis offer the best near-term potential.

The 3D VSP successfully imaged the volume surrounding the HOT ICE No. 1 well consisting of a sequence of deltaic fluvial deposits. Anticipated resolution could be met with the average dominant frequency of the processed data to reach between $110-130 \mathrm{~Hz}$.

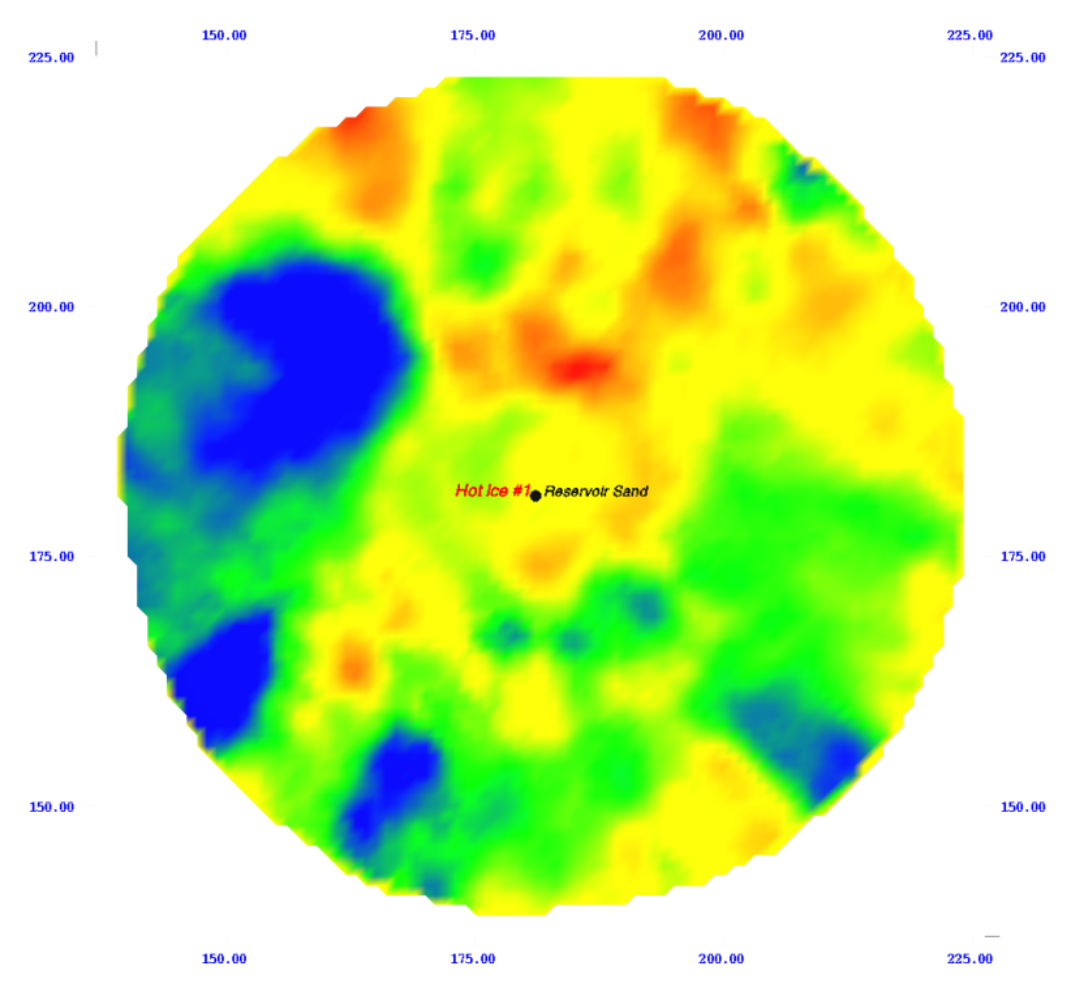

Figure 5. VSP Amplitude Data Displayed on a Seismic Marker at top of Sand A

Since HOT ICE No. 1 had no producible volumes of methane hydrate, one of the goals was to map a potential hydrate-bearing horizon into the surrounding volume and investigate the reflective properties for evidence of hydrates. This proved to be a difficult task, mainly because gas hydrates generally produce only weak AVO (amplitude variation with offset) anomalies. This task could not be accomplished since AVO/AVA studies would have to be carried out in the depth domain for a 3D VSP survey and (although being developed) P/GSI does not currently have a suitable true-amplitude prestack migration algorithm for this purpose.

3D VSP operations and analysis are described in detail in the project Topical Report - 3D Vertical Seismic Profile Survey.

\section{Production Testing}

Since the HOT ICE No. 1 did not encounter any hydrates, no production testing was performed. A comprehensive (draft) well-testing plan was developed by the project team and is presented in Appendix $\mathbf{C}$ of the Final Report. Water and gas samples were collected to determine their composition. Production scenarios were developed by Lawrence Berkeley National Laboratories in their modeling efforts (see project Topical Report - Hydrate Reservoir Characterization 
and Modeling - Appendix B: "Numerical Simulation Studies Related to the Hot Ice No. 1 Well"). Results indicated zones adjacent to free gas hold the best promise for production. The team's design was planned for this case.

At the end of operations, the well was plugged and abandoned according to State regulations.

\section{Predicting the Occurrence of Hydrates}

The primary objective of this project was to determine how to successfully explore for and produce gas hydrates on the North Slope of Alaska. The well reached its planned total depth approximately $300 \mathrm{ft}(91 \mathrm{~m})$ below the theoretical base of the hydrate stability zone (HSZ). No gas hydrates were encountered. This was a surprise and disappointment to the team since the geological model successfully predicted porous sands containing natural gas within the HSZ.

The well encountered several relatively thin zones with the characteristics of hydrates (high velocity and resistivity indicated on well logs, coupled with gas shows on mud logs) that were determined to be highly cemented sands. The team noted the existence of similar zones in offset wells during the planning phase. This observation now raises questions about the presence of hydrates in this area.

In larger sand packages structurally up-dip from the HOT ICE location, offset wells have been documented to contain hydrates. Also, several wells located structurally down-dip have exhibited mud log gas shows in these same sand zones. Rather than hydrates, the HOT ICE well encountered free gas and water in the HSZ. This raises questions about what other variables are involved in the formation of methane hydrates in porous sand.

An assessment to address these issues will continue in developing possible recommendations to enhance future exploration efforts. Steps taken to assist in that effort included:

1. Processing and interpreting the high-resolution 3D VSP data

2. Performing reservoir characterization to correlate VSP/core/well log data

3. Providing available data to engineers and scientists for use in hydrate modeling and for future hydrate reservoir evaluation activities

Operators have reported encountering hydrates in numerous wells drilled on the North Slope of Alaska. There is no question that hydrates exist at some locations on the North Slope. The most optimistic model is that they exist as continuous sheet-like deposits. For this case, detection of hydrates in isolated wells can be used to infer the existence of hydrates between the wells. At the other extreme, the most conservative model states that hydrates only exist where there were shallow gas reservoirs before temperatures cooled a few million years ago. The first model indicates that hydrates comprise a very large potential resource, the second a marginal resource at best. Wells in which hydrates have been detected or inferred from well logs were generally drilled based on the expected existence of a deeper trap containing oil. Such traps often imply the existence of traps in shallower formations. For such a scenario, drilled wells form a biased set, not a random sampling of shallow formations.

It is well known that hydrate plugs can form in pipelines. In addition, hydrates seem to form on the ocean floor without the presence of traditional hydrocarbon traps. These observations show that, given a sufficient methane flux and proper temperature/pressure conditions, hydrates are a self-trapping system. It would follow that, if no trapped gas already exists, the size of the gas flux through the system is probably a critical parameter. Lack of hydrates at HOT ICE No. 1 
implies that this critical flux was not achieved there. One question then arises: Does or did a large enough gas flux exist in some areas on the North Slope? If so, sheet-like accumulations should exist.

If gas fluxes everywhere on the Slope are below the critical value, a traditional trapping mechanism seems to be necessary. Under these conditions, fields could still be larger than the gas volume the trap can hold. This is because after trapped gas is converted to hydrate it could act as a seed reservoir that grows by converting gas passing by into hydrate. It is therefore essential to obtain quantitative bounds on the gas flux passing through North Slope reservoirs in the last few million years.

\section{Lessons Learned}

This project provided valuable information to the DOE, industry, and research community to identify key barriers and problems related to gas-hydrate exploration and production. This information will be useful in developing innovative, cost-effective methods to overcome these barriers. The most noteworthy successes and lessons are listed below.

1. The special Onshore Drilling Platform (first of its kind) functioned as designed:

$>$ Transported across tundra by trucks and Rolligons with no impact on the tundra

$>$ Assembled on site and left in place loaded with equipment throughout two Arctic drilling seasons

$>$ All required equipment was successfully installed on platform

$>$ For future operations, connexes can be coupled directly without external bracing

$>$ Operations on the platform were successfully reactivated after being shut down for eight months for the summer season with no damage to the tundra under/around the platform.

$>$ Negligible movement of legs throughout life of project (maximum recorded movement $=0.48$ inches)

$>$ Removed and transported topsides and platform to storage as planned. Fifty of 51 legs removed by heating; one cut off below grade.

$>$ The platform proved to be an excellent option for gas-hydrate drilling and testing, because it allows extended evaluation and testing of the reservoir. Proper evaluation of a gas hydrate reservoir cannot be accomplished if limited to the short drilling season on the North Slope.

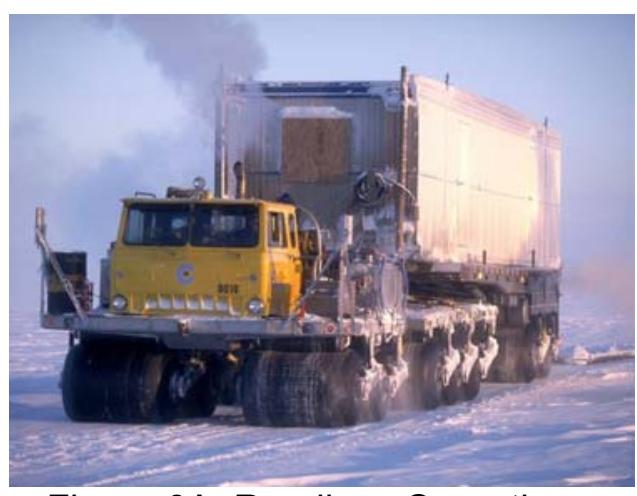

Figure 6A. Roadless Operations

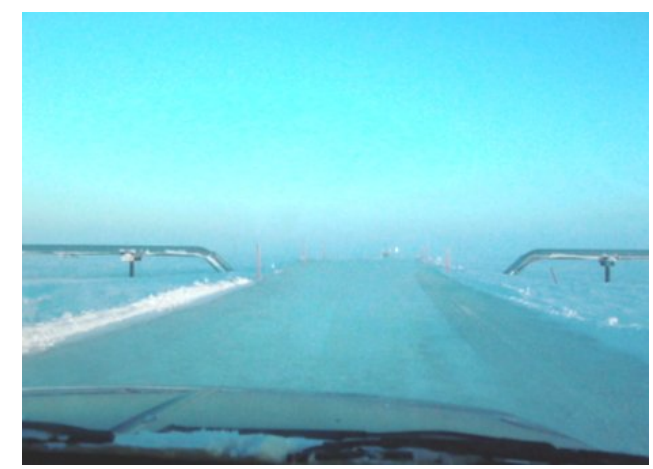

Figure 6B. Ice Road The platform will accommodate multiple wells and could also be an excellent production platform. However, the extra set-up time and expense required for 
the platform on an exploration site will somewhat reduce total available drilling time. This should be considered for exploration wells.

2. Transportation to site

$>$ Proved the concept of "roadless" operation in 2003 (Figure 6). Ice trails and ice work areas were used to eliminate repetitive low impact environmental stress from low impact vehicles/Rolligons and tracked vehicles

$>$ The ability was demonstrated to haul heavier loads by Rolligons without negative impact. While they offer excellent protection of the tundra and save considerable time in not having to construct ice roads, the limited number of Rolligons on the North slope cause this to be an expensive option.

$>$ In 2004 season, the team saved operating costs by building four miles of ice road to access the well site.

3. Project was conducted with an excellent safety and environmental record. No losttime injuries were recorded with

$>+100,000$ man-hours on site

$>$ Over 150 different vendors used

4. Various drilling and equipment problems that resulted in operational downtime were solved.

\begin{tabular}{|l|l|}
\hline \multicolumn{1}{|c|}{ Problems } & \multicolumn{1}{c|}{ Solutions } \\
\hline Foaming of mud & Modifications to circulating systems and equipment \\
\hline Mud temperature control & $\begin{array}{l}\text { Refined regulation of feed mud; solids control; rebuilt the chiller } \\
\text { system }\end{array}$ \\
\hline Solids control & $\begin{array}{l}\text { Used finer mesh screens, operated centrifuges judiciously } \\
\text { without causing foaming problems }\end{array}$ \\
\hline Freezing of mud system & $\begin{array}{l}\text { Modified mud chemistry; lowered freeze point of mud in 2004; } \\
\text { installed better insulation of mud transfer lines }\end{array}$ \\
\hline
\end{tabular}

5. Continuously cored $80-2300 \mathrm{ft}(24-701 \mathrm{~m})$ (that is, below base of hydrate-stability zone) with 93\% core recovery.

6. Obtained good quality core at high recovery rates.

7. Demonstrated continuous coring of permafrost with chilled drilling fluid.

8. Successfully cored target hydrate reservoir (although no hydrates were encountered).

9. Evaluated other coring systems, including pressure coring systems.

10. Increased core diameter from original plans to minimize hydrate dissociation.

11. Split-barrel stainless-steel liners were found to work very well.

12. Mobile core laboratory performed very well as designed and allowed successful on-site core analysis in real time. 
13. Ability was demonstrated to quickly make petrophysical measurements on core plugs at reservoir conditions.

14. Successfully demonstrated remote monitoring and access to ongoing operations from anywhere at any time.

15. Successful use of a rotating head while coring.

16. Developed a custom slim-hole dynamic well-control model. (This is now part of a Maurer software program and is applicable for any slim-hole managed-pressure drilling application including gas hydrates, shallow gas or coal gas.)

17. Proved downhole CMR (combinable magnetic resonance) as effective as surface CMR in 2003 operations (surface CMR was not available in 2004).

18. On-site computed tomography (CT) scan performed on all core by Lawrence Berkeley National Laboratory as an excellent nondestructive evaluation tool.

19. Real-time coal desorption tests performed on coal core samples by USGS in 2003. Contrary to prediction, no coal found in 2004 drilling.

20. Successfully obtained open-hole logs throughout the wellbore.

21. Conducted pilot test of zero discharge for camp operations (further refinement is required for future operations).

22. Evaluated Lawrence Berkeley National Laboratory's hydrate software models.

23. Conducted the first shallow massive vertical seismic profile (VSP) on the North Slope of Alaska.

\section{Conclusions}

There is no proven way to accurately predict and assess gas hydrate in sediments without drilling wells. Future work and research should be conducted to develop cost-effective ways to explore for gas hydrates. Even after a gas hydrate well is discovered, it is unlikely the areal extend of the hydrate zone can be determined. The industry needs to improve its understanding of thermodynamic behavior of gas in hydrate-stability zones.

DOE should consider funding a high-resolution VSP survey adjacent to known gas hydrates. DOE should also strongly encourage future Arctic hydrate projects to take advantage of the specialized equipment and on-site laboratory developed for this project, which is now located at Oklahoma University. On the Hot Ice project, there was much support and cooperation from a number of organizations and companies. This collaboration is necessary to improve characterization and to make more accurate assessments of hydrates and hydrate behavior in sediments.

Hydrate coring tools, core holders and other equipment should be shared as much as possible between projects to save costs and prevent different teams from reinventing tools and equipment that are sufficient. It is important to note that the greater the number of new experimental tools and technologies attempted on exploration projects, the greater the 
complexity (and complications) of the project. Future projects should carefully prioritize what is necessary and limit the temptation to try too many new "bells and whistles" in a single effort.

Adding the USGS to the HOT ICE project to take coal cores was a good decision, and there may be sufficient synergy in coal and coalbed methane exploration to collaborate on shallow exploration technologies on the North Slope.

It is very expensive and potentially cost-prohibitive to operate on the North Slope without taking advantage of existing infrastructure, personnel, equipment, service providers, roads, accommodations and transportation. While there are significant differences between conventional oil/gas operations and gas hydrates, the oil/gas service infrastructure, expertise and personnel highly experienced in North Slope operations are critical for these operations.

In hindsight, the first HOT ICE well should not have been continuously cored, but rather drilled as fast as possible from an ice pad. A second well could then have been cored and evaluated if the first well had encountered gas hydrates. The Arctic platform would be an outstanding technological tool for coring and testing hydrates. Extensive testing and planning of everything from fluids, equipment, rigs and on-site personnel prior to operations proved to be an excellent investment. The team's decision to utilize Noble's real-time data transmission system was also a good investment that should be considered for future operations.

\section{Future Plans}

If the HOT ICE No. 1 well had encountered hydrates, the project team planned to develop a budget for an additional well(s) and an extended well test based on the information generated from the Phase II drilling activities. The production test plan would help determine the producibility of hydrate deposits. The Arctic platform would have been an excellent component in this phase.

Currently, the project team does not have plans to continue an assessment of the hydrate potential on the North Slope of Alaska until gas can be commercialized. A gas pipeline from the North Slope to existing pipeline infrastructure (as well as space in the line) is required for gas exploration and production. Additionally, the economics of this type of endeavor must be considered. It is apparent that high-GOR oil wells that are currently producing in known areas of the region will be the first ones to sell gas and can absorb a much higher tariff than new wells. Because development costs must be competitive, realistically, it might require several years to be competitive with existing producers.

The team is convinced that a thorough assessment of the potential of gas hydrates will be an important requirement before any operating company will consider developing exploration plans for this resource. 


\section{Appendix B: Draft Completion Procedures \\ HOT ICE No. 1 Well}

\section{Completion Challenges}

The completion for this well was designed to try to address all issues that have been identified with producing hydrates at this location. Based on rig capacity, the largest production casing that can be used below the permafrost has an OD of $4 \frac{1}{2}$ inches. This will have a drift diameter of approximately 4 inches. The location will not be accessible by ice roads during production testing. All equipment will be transported by Rolligon or helicopter. As a result, size and weight of the equipment needs to be minimized. Completion and testing equipment need to be simple and require minimum support. With environmental regulations and cost constraints, the base plan will conclude testing before tundra closure occurs. The original plan was to not incorporate artificial lift in the base plan. There was also potential for formation sand production. Freeze protection has to be incorporated into the completion design. The fact that the well produces fresh water and predominately methane creates the possibility of forming hydrates or ice in both the tubing and tubing/casing annulus. Potential for having hydrate or freezing problems is greatest during shut-in periods.

\section{Completion Base Plan}

There will be a number of uncertainties until we pull core from the well. We plan to perforate one hydrate interval after cementing $4 \frac{1}{2}$ inch casing. The base case is to produce one well completed in a single hydrate interval using a tubing string, packer and permanent downhole pressure/temperature gauges. Water and gas will be produced into the tubing string. We will have the capability to swab the well to reduce bottomhole producing pressure. The well will be set up so that it can be shut in downhole by setting a plug in a profile to reduce wellbore storage volume. The well will be equipped with two electronic bottomhole pressure gauges and one temperature gauge near the perforations. A heat strip will be attached to the tubing string to prevent fresh produced water from refreezing across from permafrost when the well is shut in.

The base completion plan is to perforate one interval that is located at a depth with a reservoir temperature greater than $32^{\circ} \mathrm{F}$. After the completion is run, production facilities consisting of a two-phase vertical separator with gas and water measurement in winterized enclosures will be hooked up.

A heater cable will be used to keep water in the production tubing from freezing. It is anticipated that produced water will have a low salinity. Undisturbed surface temperature is approximately $12^{\circ} \mathrm{F}$. As a result, there is a high probability that there will be a problem with water freezing or hydrate formation inside the tubing, if heat is not added. The heater cable is basically a flat ESP cable that is shorted above the packer. Electrical current flowing through the cable results in the generation of heat. The majority of the heat generated is transferred to the production tubing. Modeling results predicted that the heater cable would keep temperature of fluid inside the tubing above $50^{\circ} \mathrm{F}$. 
A heater cable should eliminate problems with water freezing, but adds other completion challenges. Using a heater cable requires use of wellhead penetration. There is not enough room in a standard wellhead for $4 \frac{1}{2}$ inch casing to have a high amperage penetration. To solve this problem, two additional casing spools will be used to allow the electrical penetrator. The top two joints of casing will be $5 \frac{1}{2}$ inch so that there is enough room for the splices and the pigtail connection. With the heater cable and standard 2-3/8 inch EUE tubing, there is very little clearance inside of $4 \frac{1}{2}$ inch casing. The weight of $4 \frac{1}{2}$ inch was reduced to 9.5 pounds per foot to give the largest possible internal diameter. This results in a clearance of slightly more than 0.25 in. between the heater cable over the coupling and drift of the $4 \frac{1}{2}$ inch casing. This is especially tight since Range 1 tubulars (15-24 ft/joint) will be utilized for this project since a continuous coring rig is being used to run the completion equipment. 2-3/8 inch NU (10rd) tubing will be used in place of 2-3/8 inch EUE (8rd) tubing to increase the clearance by approximately 0.20 inch at each connection.

The well will be set up so that bottomhole pressure and temperature measurements can be made from surface. Because of the large cost to come back and plug the well in an isolated Arctic environment, it is planned to plug the well at the end of the production test. This will also minimize the need to mobilize equipment at a later time to the well and reduce environmental impact.

\section{Completion Procedure}

NOTE: The completion procedure will not be finalized until the completion interval is selected after the well has been logged.

NOTE: All connections below the packer will be 2-3/8" EUE 8rd special clearance couplings, except for the sand screen. All connections above the packer will be 2-3/8" NU 10rd special clearance couplings, unless noted otherwise. All tubulars are 4.6-4.7\#/ft, L-80 unless noted otherwise.

Cement plug was bumped with $9.3 \mathrm{ppg} \mathrm{KCl}$ completion fluid $+\mathrm{X}$ bbl of diesel and $4 \frac{1}{2} 2^{\text {" casing }}$ was landed with mandrel hanger.

1. ND BOP Stack and install the tubing head per FMC procedure 2.XX. This will involve installation of reducer bushing and 11" $5 \mathrm{k} \times 7-1 / 16$ " $5 \mathrm{k}$ tubing head.

2. Install a 7-1/16" $5 \mathrm{~K} \times 11$ " $5 \mathrm{~K}$ DSA on top of the tubing head. NU 11" $5 \mathrm{~K}$ Double Ram preventor (blind rams and 2-3/8" rams) +11 " $5 \mathrm{~K}$ Annular preventer. Test BOP stack to 5000 psi per FMC procedure 2.12. Note: APC will need to provide one joint of 31/2" IF drillpipe.or a 31/2" crossover to our drillpipe. Install short bowl protector per FMC procedure 2.13 , if we are anticipating drilling out cement.

3. Move in 2-3/8" NUE production tubing. Remove thread protectors and visually inspect boxes and pins. Have TIW valve made up to appropriate crossovers and available on rig floor. RIH with 3-7/8" mill + casing scraper + bit sub on 2-3/8" NUE production tubing with special clearance couplings. Dope entire pin of connection lightly and evenly; do not dope boxes. Tubing should be made up using MU torque values on Tubular Data Sheet. RIH so that bit is $50 \mathrm{ft}$ below bottom perforation. Circulate hole with $9.3 \mathrm{ppg} \mathrm{KCl}$ completion fluid until clean returns are seen. $\mathrm{POOH}$ with mill and scraper. Install thread protectors and lay down tubing. Remove short bowl protector if installed in step 2. 
4. RU Schlumberger Wireline Unit on rolligon. $\mathrm{RU}$ on 11 " $5 \mathrm{~K}$ flange on top of annular preventer. No pack-off will be used for this step. RIH w/ Gamma ray, CCL and 3.85" Gauge Ring to $50 \mathrm{ft}$ below bottom perforation. Log from $50 \mathrm{ft}$ below bottom perforation up to $50 \mathrm{ft}$ above the top of the permafrost. Correlate to openhole logs. $\mathrm{POOH}$.

5. TCP gun assembly will be run with a pack-off on top of annular preventer. Radio silence is not required with this perforating system. MU TCP assembly on wireline setting tool (assembly may need to be modified by adding an additional 4-ft pump joint to make sure that the packer is not set in a collar). Rabbit all joints while lifting joints to rig floor. Verify that TIW valve is made up to appropriate crossovers and available on the rig floor.
a) Bull plug
b) 2-7/8" tubing conveyed perforating guns with 6 JSPF, 60 phasing (HSD-WL-DP $2906 \mathrm{PJ}, \mathrm{HMX}$ charges, perforated interval to be determined)
c) $10 \mathrm{ft} 2-7 / 8$ " blank gun (spacer assembly)
d) Firing head with dual hydraulic firing heads (firing pressure will be approximately 2500 psi over hydrostatic pressure) and 2-3/8" SXAR gun drop assembly
e) Solid collar
f) $\quad 4 \mathrm{ft} \times 2-3 / 8$ " SC EUE pup joint
g) $\quad 4 \mathrm{ft} \times 2-3 / 8$ " SC EUE pup joint
h) X-over 2-3/8" seal-lock HT box x 2-3/8" EUE SC pin
i) Baker 2-3/8" Excluder 2000 sand screen 2-3/8" seal-lock HT box x pin
j) X-over 2-3/8" EUE SC box x 2-3/8" seal-lock HT pin
k) SLB type "D" NO-GO style profile nipple with 1.562" polished bore made out of 9CR- $1 \mathrm{MO}$ with 2-3/8" 4.7\#/ft EUE SC box x pin
I) $\quad 4 \mathrm{ft} \times 2-3 / 8$ " SC EUE pup joint
m) $\quad 4 \mathrm{ft} \times 2-3 / 8$ " SC EUE pup joint
n) Baker 24-23 F-1 Permanent production packer, $10 \mathrm{ft}$ seal bore extension, bottom cross over to 2-3/8" EUE 8rd pin
0) Schlumberger wireline setting tool with slow burn charge

Note components d, e, f (SLB) g, h, i, j, k, I (Baker) and m, n (Baker) will be made up in the shop by the indicated company prior to bringing out to the platform.

6. Correlate to CCL run in step 4, set packer on wireline with perf guns across hydrate interval. POOH. RD Schlumberger wireline unit. Move Schlumberger wireline unit against container. RU Bell nipple.

7. Pick up Baker 21-23 "GBH" locator seal assy with 70 durometer seals and $6 \mathrm{ft} 2-3 / 8$ " NU 10 RD pup joint. Run one joint of 2-3/8" NU 10RD tubing with special clearance (SC) couplings.

8. Make up Promore gauges. Gauge sub will have $6 \mathrm{ft} 2-3 / 8$ " NU 10RD handling subs on top and bottom. Prep to run the electric cable for the Promore gauges and \#8 heater cable. Attach gauge cable to Promore gauge and verify electrical connection. Run one joint of 23/8" NU 10RD tubing. Termination block should be installed on the heater cable prior to arriving on location. Termination block at end of heater cable should be approximately 25 $\mathrm{ft}$ above Promore gauge. Guides will be placed on top of heater cable and banded every 3 $\mathrm{ft}( \pm)$. Promore gauge cable should be banded to outside of heater cable guide per attached drawing. Be careful with slips to make sure that heater cable and gauge cable are not damaged when setting the slips. 
9. MU SLB 2-3/8" DS NO-GO 9Cr-1MO nipple with 1.875" ID with $6 \mathrm{ft} 2-3 / 8$ " NU handling subs top and bottom (made up by Baker). Note the profile will have 2-3/8" NU coupling instead of 2-3/8" NU special clearance coupling. This will still have a clearance of more than 0.4". Run remaining 2-3/8" NU 10RD SC production tubing banding heater cable and Promore cable every $3 \mathrm{ft}( \pm)$ per procedure.

10. Note when weight indicator shows seal assembly locator bottoms out on packer. Do not set down more than 10,000 lb on seal assembly. Pick up on tubing so that seals are $5 \mathrm{ft}$ below the top of packer. Pressure up on tubing to 100 psi (using BOP test pump). Note: the perforating guns have dual hydraulic firing heads that are set at an absolute pressure of x psi (2000 psi over hydrostatic @ pay depth). Be extremely careful not to put more than 100 psi on the tubing. PU on tubing and note when seals come out of seal bore by monitoring the tubing and annulus pressure.

11. PU and space out so that seals will be $x \mathrm{ft}$ into the seal bore extension when hanger is landed. Pick up tubing hanger and landing joint (see FMC running procedure 2.14). Hanger will have $15 \mathrm{ft}$ tubing subs made up on top and bottom before being taken to platform. Connect lower pigtail assembly to penetrator. Splice heater cable to lower pig tail assembly. Splice Promore gauge cable to $1 / 4$ " line that will go through tubing hanger. Test continuity of heat trace line and Promore gauge line. Lower tubing assy until seals are $2 \mathrm{ft}$ above packer. Align hanger so that gauge line, heater cable and wing from the tree will have proper orientation.

12. Install TIW valve on top of landing joint. Connect line from rig pump to top of TIW valve. Pump tubing capacity $+3.0 \mathrm{bbl}$ of diesel down tubing at a maximum rate of $1 \mathrm{bpm}$. Tubing pressure should be approximately $x$ psi at the end of displacement (300 psi at $2500 \mathrm{ft}$ ). Shut tubing valve.

13. Sting seals into packer, land tubing and lock down hanger.

14. Test annulus to 1000 psig, confirm that tubing is open so that pressure inside tubing will not build up if there is communication between tubing and casing. Remove landing joint.

15. Install 2" ISA 100 BPV in tubing hanger.

16. ND BOP's. Note: Use caution when nippling down the BOP to prevent damaging penetrator or gauge line. NU tubing head assembly. Install surface pigtail to wellhead penetrator for downhole heat trace. Connect surface TECH wire to Promore HPHT surface pack-off. Test continuity of heat trace line and Promore gauge line. Install tree consisting of two 2-1/16" 5000 \# master valves, cross with one blind flange, 2-1/16" swab valve and 3-1/8" wing valve and blind flange. Hook up downhole gauge to Provision surface unit. Start recording pressure and temperature every minute. Remove 2" ISA 100 BPV. Install 2" ISA 100 tree testing plug. Remove blind flange from 3-1/8" wing valve.

17. Make sure that wing valve is closed. RU on 2-3/8" EUE threads on inside of tree cap. Pressure test wellhead to wing valve to 200 psi, verify that the tree test plug is holding by checking the BHP gauge reading. Increase test pressure to 4000 psi and observe pressure for 15 minutes. Remove 2" ISA 100 tree test plug. Install Halliburton 3-1/8" surface safety valve $+3-1 / 8$ " choke downstream of 3-1/8" wing valve. 
18. Connect surface pigtail connector to junction box and set step-down voltage on transformer so that it will not exceed 160 Amps during a cold start. Voltage setting will be determined by the length of heater cable installed and cannot be determined until completion interval is selected. Downhole heater cable needs to be turned on initial voltage for at least 30 minutes. This will heat up cable and cause resistance to increase. Using higher voltage initially could result in exceeding amperage rating of penetrator. Supply power to downhole heat trace. After 2 hours it may be necessary to increase voltage after heater cable has heated up to maximize the temperature in the annulus.

19. Monitor casing pressure every 6 hours. 
Well Name:

Field:

Legals:

Status:

\section{Proposed Completion}

Hot Ice \#1

Wildcat

Anadarko-Maurer Hydrate project with DOE

Proposed Completion - Short term test with permanent gauges
18-Feb-03

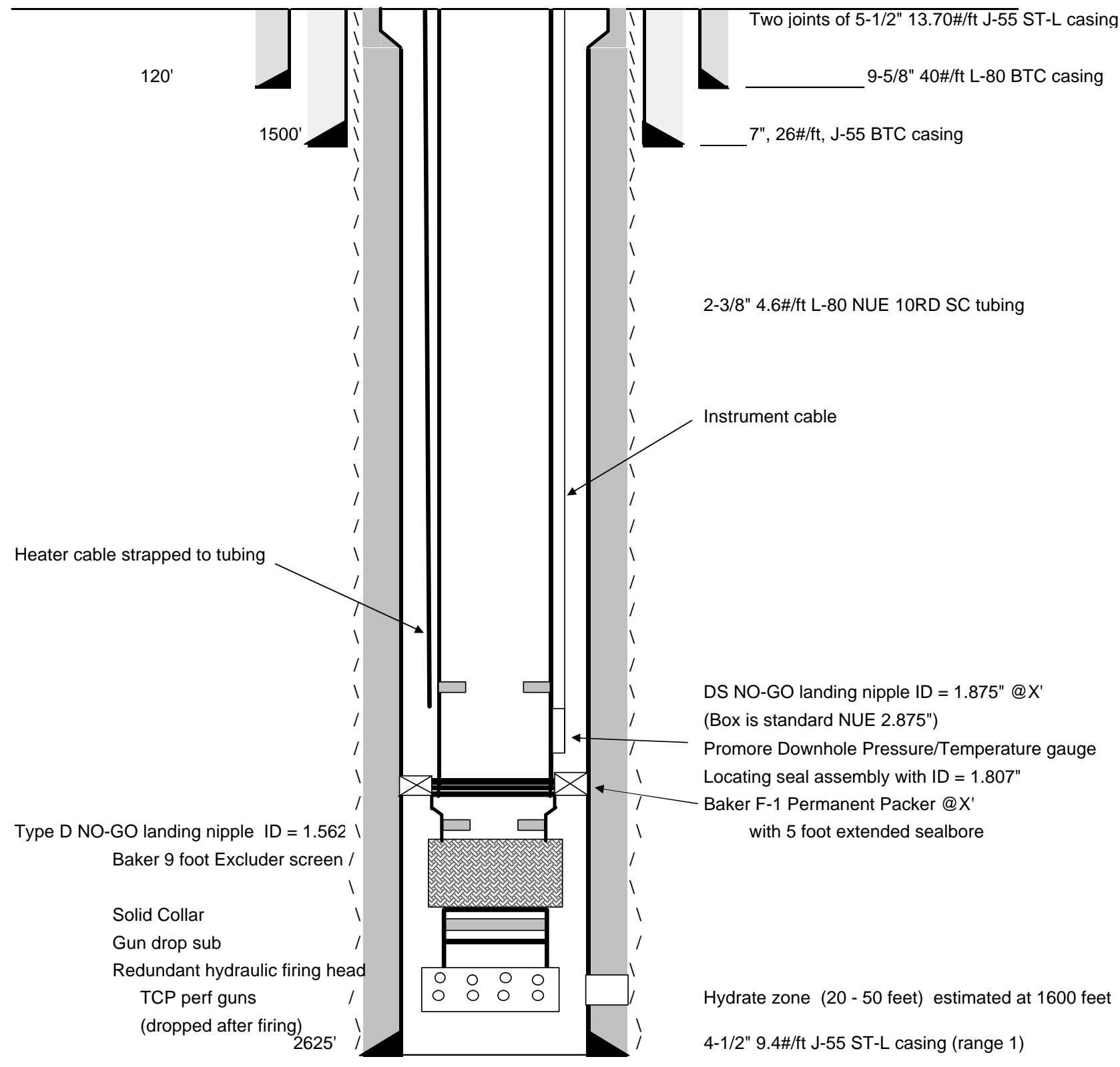


Well Name:

Field:

Legals:

Status:

\section{Proposed Suspension}

Hot Ice \#1

Wildcat

Anadarko-Maurer Hydrate project with DOE

Proposed Suspension - Short term test with permanent gauges
16-Jan-03

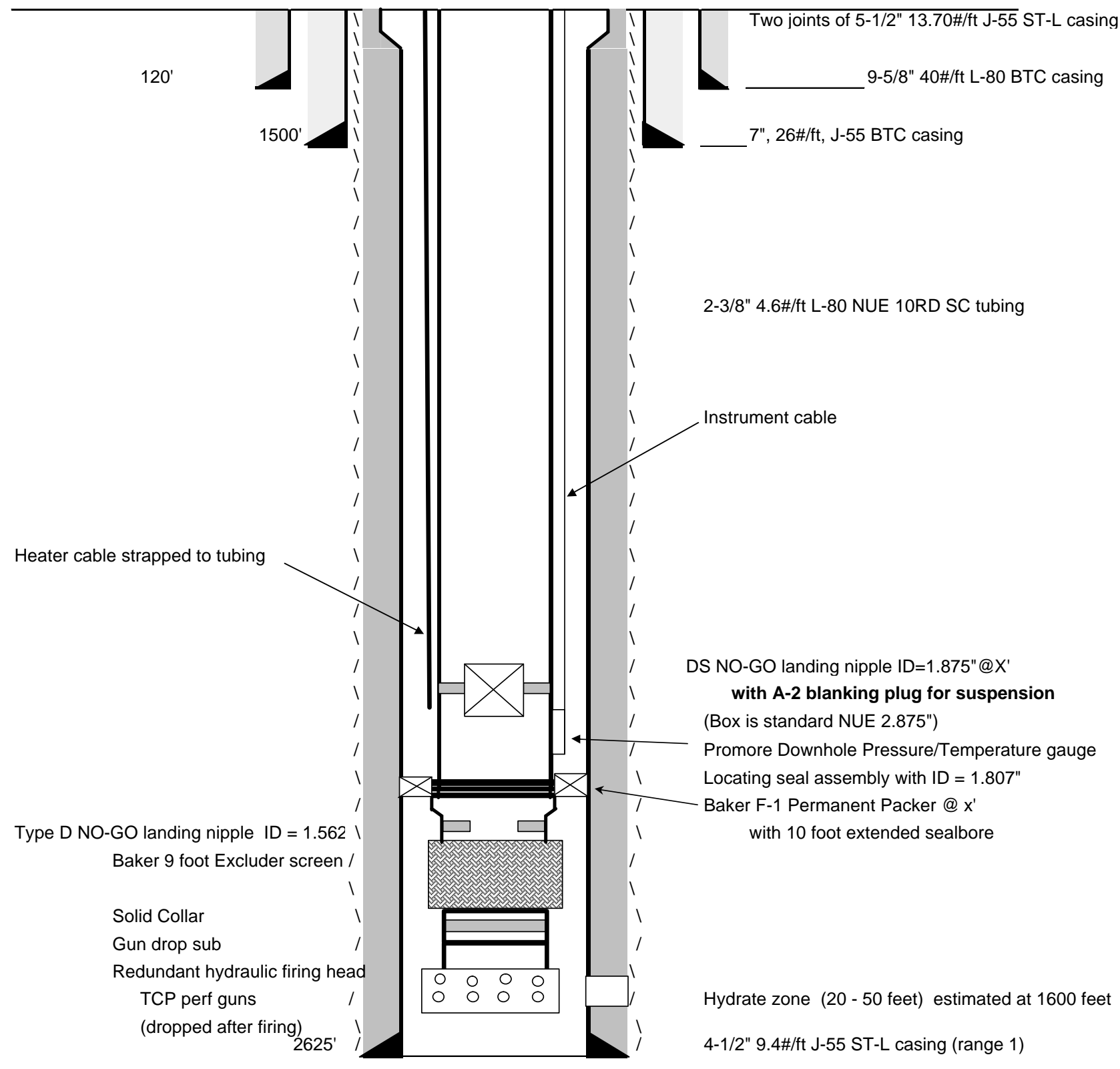




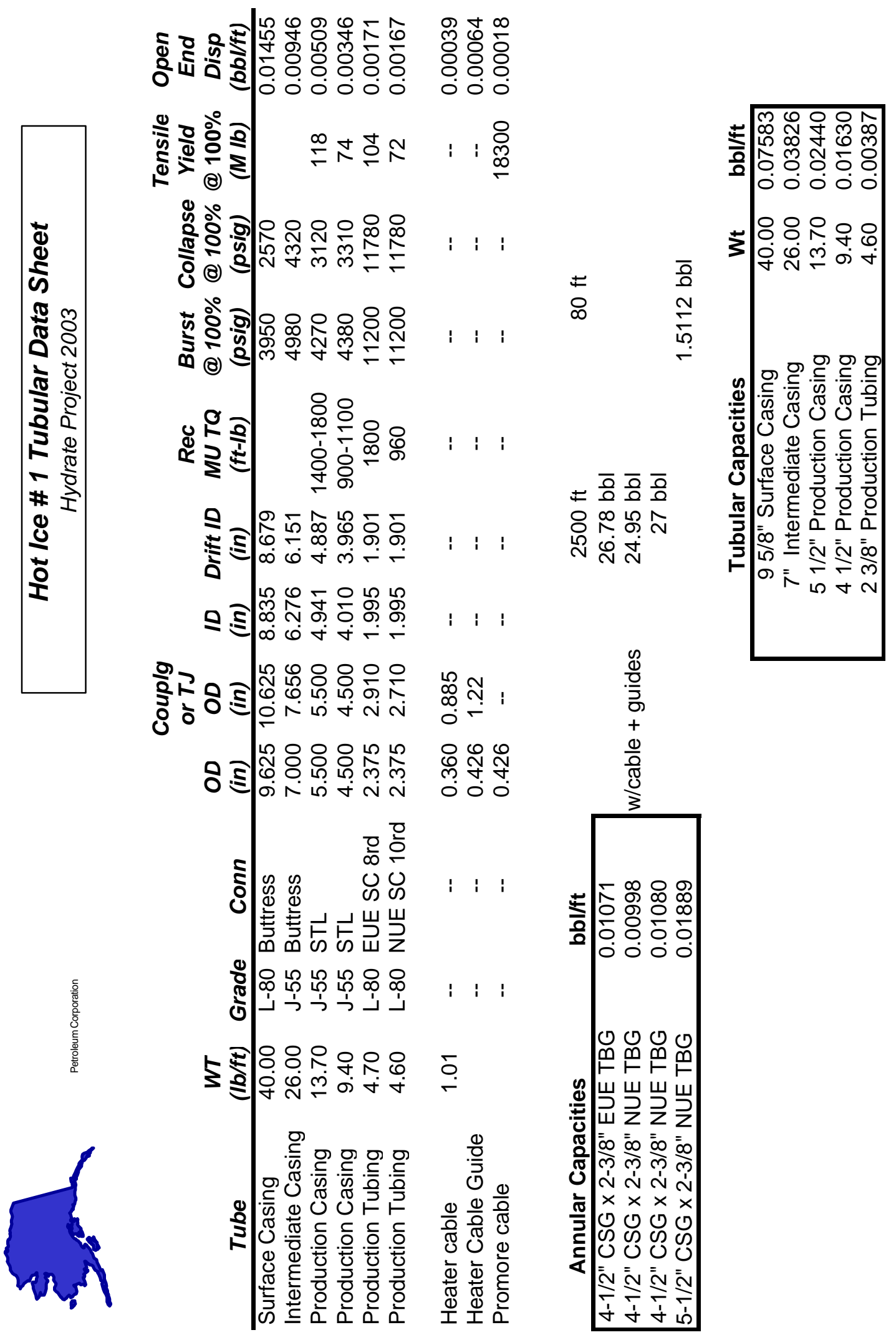




\section{Appendix C: Draft Test Procedures \\ HOT ICE No. 1 Well}

Well Name: Hot lce No. 1

AOGCC Permit No.:

BLM Lease No.:

API No.:

AFE: 26495

Red text indicates estimated values

Unless specified, all depths are measured (RKB) referenced to GR/CCL

Corr Logs: Tie-in log will be the GR/CCL

Depth Control: Correlation log

RKB Elev: ?' = ?' + ?'

Top of Platform Elev: ?' MSL

Ground Level Elev: ?'MSL

Perforations: $\quad 1600^{\prime}-1620^{\prime}$ (TBD) TCP Charges 6 spf 60 deg phase

Packer Top: 1550 ' (TBD)

Reservoir Pressure: $\quad$ Estimated 700 psi (TBD)

Well Status: Completion has been run as shown on attached well schematic. No perforating has been done.

Note Promore Gauge at 1500' (TBD)

2-3/8" x 4-1/2" annulus freeze protected to 200' with diesel

Objectives: 1) Perform operations without any accidents or spills

2) Test Hydrate interval for flow rate potential, gas composition, and reservoir pressure

3) Obtain quality pressure data during flow and shut-in periods

4) Obtain quality fluid samples for laboratory analysis

5) Suspend the well by setting a plug in production tubing 


\section{Test Procedure}

\section{Complete Rig Up of Test Equipment}

1. Confirm that a copy of Anadarko Hot Ice No. 1 Air Permit is on location.

2. Conduct pre-job safety meeting.

3. Confirm that power to downhole heat trace has been turned on.

4. Rig up secondary containment around separator. RU surface test equipment according to attached equipment layout. Pressure test lines to flare and liquid lines downstream of separator to heated fluid tank to 100 psia with air for 15 minutes.

5. Rig up a line from the mud pump into a tee on the flowline with an isolation valve. (This will allow the well to be killed if required during the well test without changing the lines.) Ensure master valves are closed. Wing valve, surface safety valve and choke should be open. Fill surface lines with heated diesel. Test from wellhead to separator outlet valves to 200 psi. Check bottomhole pressure gauge and make sure that the master valves are holding. Increase test pressure to 400 psi. Check BHP to verify that master valves are holding prior to increasing test pressure above 400 psi. Shut valve upstream of the separator, and pressure test from wellhead to separator inlet to 1500 psi with heated diesel for 15 minutes. Shut Halliburton 3-1/8" surface safety valve. Bleed off pressure downstream of the SSV and observe pressure on wellhead to verify that the SSV will hold pressure. Note: tree should have been tested after installation to 4000 psi up through the wing valve.

6. Complete heat trace and insulation of all surface test lines.

7. Purge lines with nitrogen.

\section{Perforate: TCP Guns}

NOTE: Promore surface readout gauges will be run in place with the completion.

8. Obtain a hot work permit for flaring/venting prior to conducting safety meeting.

9. Conduct pre-job safety meeting.

10. Check annular pressure. Rig up steel line on top of crown valve. Verify that wing valve, surface safety valve and choke are closed. Separator bypass valve should be open to tank to relieve any pressure if the wing and SSV leak. Shut crown valve and pressure test line to 4000 psi using diesel.

11. Increase data-acquisition rate on Promore ProVision data-acquisition unit. Open crown valve. Pressure up on tubing to $2700 \mathrm{psi}$ and hold the pressure for 1 minute. Open wing valve and SSV. Bleed off pressure to tank through separator bypass line by slowly opening choke. Leave separator bypass valve open. Monitor wellhead and bottom-hole pressure gauge to ensure that guns fired. If guns do not fire, close wing valve and pressure up to 4000 psi wellhead pressure, hold pressure for 1 minute then bleed off 
pressure. Shut in separator bypass valve and monitor data header to determine if the surface pressure is increasing.

12. Close the crown valve. RD lines used to pressure up tubing. Determine if there is any pressure on the well. If BHP has not increased, rig-up swabbing equipment per attached swabbing procedure. If BHP is building, install tree cap, pressure gauge and attempt to flow well.

13. Verify that surface safety valve and wing valve are open and then close the choke. Light pilot light on flare. Determine if well will flow to separator by gradually opening the choke. Monitor annulus pressure. If well stops flowing, consult with onsite Anadarko Engineer about rigging up swab equipment. A decision on flaring or venting will be made based on the production rate, wind and other considerations.

14. It is anticipated that the well will be flow/swab tested for 5 days. Length of flowing time will be dependent on how the well responds.

15. At the end of the flow period, use Schlumberger slickline to set a plug to suspend the well. Shut crown valve, remove tree cap or swab equipment. RU slickline lubricator. Pressuretest lubricator to 1000 psi with diesel. Set A-2 plug with CS lock in Schlumberger DS NOGO landing nipple with 1.875" bore @ 1500' to suspend well.

16. Leave well shut in for twice the flow period. If well will be suspended and not plugged, production tubing should be freeze protected. Swab produced fluid from production tubing down below the permafrost. Fill tubing with diesel to prevent formation of hydrates and ice. Install 2" ISA 100 back-pressure valve in tubing hanger. The downhole heat trace can be turned off after production tubing has been freeze protected.

Plug and abandonment procedures to be outlined separately as appropriate.

Prepared by:
D. L. Copeland
Date

Approvals:

\begin{tabular}{ccc}
\hline T. Thompson & & Date \\
\cline { 1 - 1 } & & Date \\
\hline Keith Millheim & & Date
\end{tabular}




\title{
Appendix D: \\ Fundamental and Applied Research on Water Generated During Production of Gas Hydrates (Phase I)
}

\author{
Prepared for

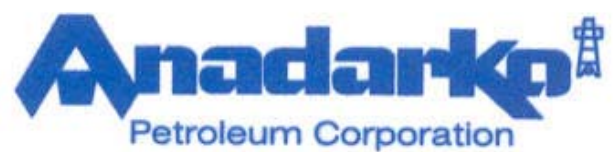 \\ Dr. Keith Millheim \\ Manager, Operations, Technology and Planning \\ By \\ Craig R. Woolard, Associate Professor, School of Engineering \\ William Schnabel, Assistant Professor, School of Engineering \\ LeeAnn Munk, Assistant Professor, Department of Geology \\ Mark Hines, Professor, Department of Biology
}

\section{WAA UNIVERSITY of ALASKA ANCHORAGE}

February 17, 2003 


\section{Executive Summary}

As part of Department of Energy project DE-PS26-01NT41331, Anadarko Petroleum contracted with the University of Alaska Anchorage (UAA) to conduct research projects related to the construction of an on-shore platform, hydrate geology and characteristics and hydrate exploration and production water handling and treatment. This report provides a review of hydrate water production and handling, hydrate geochemistry and hydrate microbiological activity.

A review of the available conceptual and numerical models for hydrate production indicates that significant amounts of water will be generated during the production of hydrate reserves. In most of the production scenarios cited in the literature, it is reasonable to assume that unless the water generated during hydrate dissociation is removed, the relative permeability of the formation to gas flow and the ability to maintain gas production rates will be reduced. The one numerical modeling effort reviewed for this report that explicitly considered the water phase indicates that the single well depressurization production approach will generate water slugs as water is displaced from the formation by expanding gas. Major components of the produced water will be salts and dissolved gases and potentially some sediment. Brine or steam injection production options may require water beyond that provided by hydrate dissociation to meet production demands.

The water generated during gas hydrate dissociation suggests that water handling will be a critical component of the production process. And as such, the infrastructure designed to process water and wastewater will become a more important factor to the success of individual well or field than most conventional oil and gas operations. Under these conditions, the approach used to design and operate water systems may need to be modified from current methods used in the oil and gas industry. A more effective approach would be to design the w/ww infrastructure using a regional approach based on the following three principles. First, the design of w/ww systems at a particular installation should be integrated with the exploration and production activities and consider all water requirements and wastewater generation activities that occur at each site. Second, to increase efficiency and reduce complexity, w/ww systems should be designed on a field wide or region wide basis and not at a site-by-site basis. Finally, the w/ww systems designs should be robust enough to handle a variety of conditions and permit requirements. Membrane technologies represent some of the best systems commercially available to implement this approach.

Understanding the geochemical characteristics of gas hydrates and associated pore waters may lead to enhanced exploration and development techniques. Gas chemistry, pore water salinity, and isotopic composition of gases and water associated with gas hydrates are the current areas of interest related to developing and exploring for gas hydrates. Most of the literature focuses on marine gas hydrates because they have been studied more extensively than terrestrial gas hydrates. However, it is possible that some of the same principles used to understand marine gas hydrates could be related to terrestrial gas hydrates.

The existence and activity of microorganisms in the deep subsurface are important in relation to gas hydrate research since these organisms are responsible for much of the gas formation, their activities affect the distribution and fate of gases, and their populations in strata adjacent to hydrate deposits may be useful as bioindicators of the presence of hydrates. Recent studies have determined that microorganisms are ubiquitous in the deep marine and terrestrial subsurface and that the biomass of these bacteria exceeds the sum of all other biomass on Earth including all marine and terrestrial plants and animals. 
The presence of gas hydrates greatly affects the abundance, composition, and activities of bacterial communities. To date, interactions among hydrates, geochemical conditions, and microbial processes have only been ascertained in oceanic settings. However, it is clear that microbial life influences the formation of hydrates and vice versa. Hydrates that intersect the marine sediment/water interface at methane seeps can support complex animal and microbial communities that are similar in composition to submarine communities at hydrothermal vents. Virtually nothing is known of microbiology of terrestrial hydrates and what types of microbial consortia are present, but it has been suggested that the terrestrial deposits may be comprised of a higher proportion of thermogenic methane than in their marine counterparts, but little is known of these hydrates. Whatever the source, it seems clear that a better understanding of bacterial populations associated with hydrates will prove useful in locating and retrieving hydrate gases since microbial communities seem to respond strongly to the presence of the hydrates or at least to the free gas trapped under them.

Based on the results of the literature review conducted for this report, a number of data gaps were identified that include:

1) Evaluation of water production volume and rate from gas hydrate reserves

2) Analysis of the organic and inorganic composition of hydrate produced water,

3) Quantification of water use and consumption on drilling platforms and possible incorporation of produced waters into platform operations,

4) Evaluation of the use of microbial populations as bioindicators for hydrate deposits,

5) Assessment of core material as a record of past biological activity, and

6) Evaluation of oxygen and hydrogen isotope ratios as indicators of hydrate dissociation rates.

These issues should be considered for further study as a part of the Anadarko gas hydrates research effort. 


\section{Table of Contents}

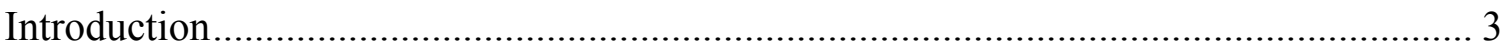

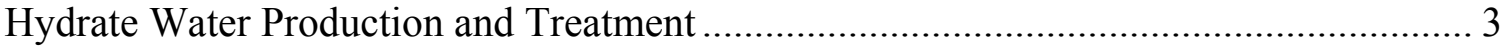

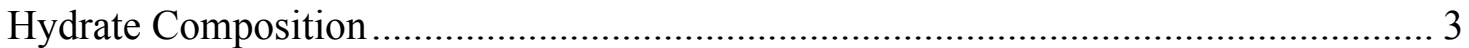

Hydrates in Porous Media................................................................................... 4

Hydrate Production Techniques............................................................................ 8

Water production during depressurization of a single well. ................................ 9

Water Production during the cyclic injection of hot fluids in a single well ............. 12

Water production during depressurization of an associated free gas reservoir ........ 13

Water production during continuous thermal stimulation ................................. 14

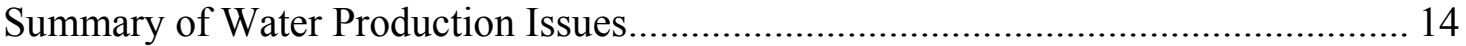

Water and Wastewater Infrastructure Strategies..................................................... 15

Exploration and Production Water Demands and Wastewater Generation .............. 16

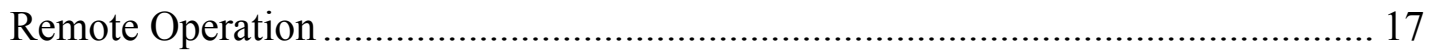

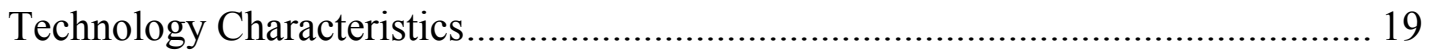

Conceptual Design of Hydrates Water and Wastewater Infrastructure ................... 21

Overview of Membrane Water Treatment Processes ........................................ 21

Conceptual Design of Hydrates Water and Wastewater Infrastructure .................... 33

Overview of Membrane Wastewater Treatment Processes ............................... 33

Produced Water and Wastewater Disposal Options ................................................ 38

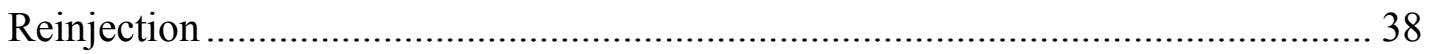

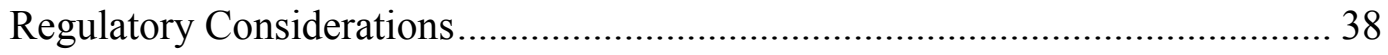

\section{1 of 69}




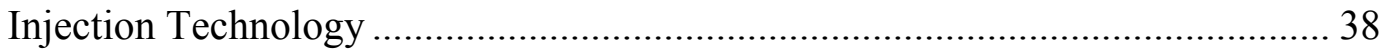

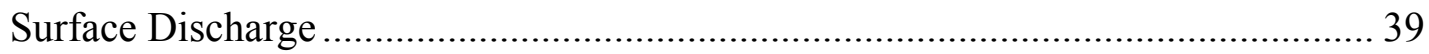

Regulatory Considerations.................................................................................... 40

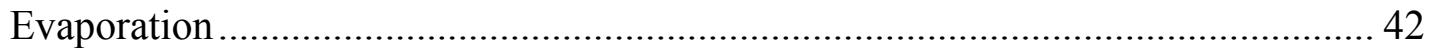

Geochemistry Related to Gas Hydrate Exploration and Development in the North Slope Permafrost Regions, Alaska........................................................................................... 44

Review of geologic setting and occurrence of gas hydrates in the Prudhoe Bay-

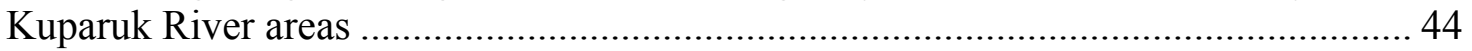

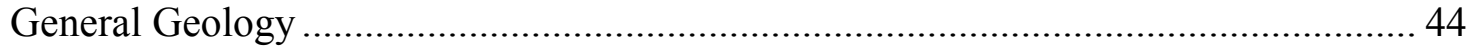

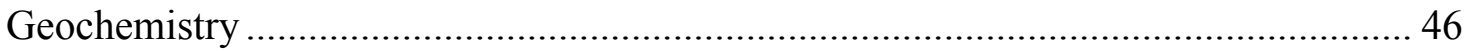

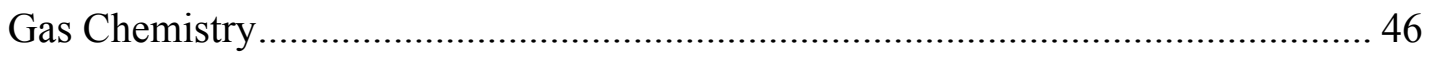

Pore Water Salinity and Isotopic Composition.......................................................... 47

Microbiology of Gas Hydrate Formations ................................................................. 49

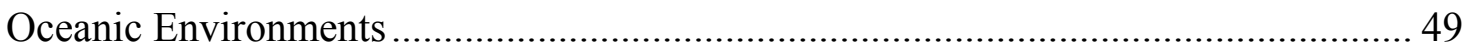

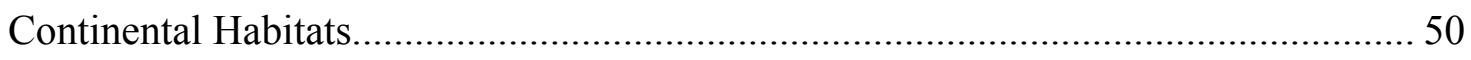

Effects of Hydrates on Microbial Populations ........................................................... 51

Anaerobic Methane Oxidation .................................................................................... 54

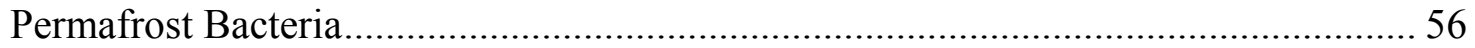

Recommendations for Future Research .................................................................... 58

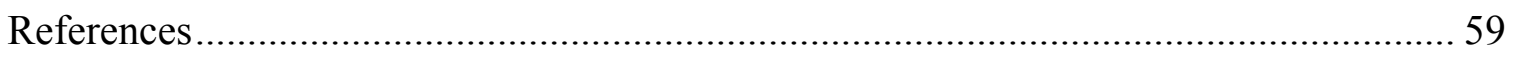

2 of 69 


\section{Introduction}

Anadarko Petroleum Corporation (Anadarko), Maurer Technology and Noble Drilling are conducting a 3-year Department of Energy project (DE-PS26-01NT41331) to drill, core and produce gas from hydrates on Alaska's North Slope. As part of that effort, Anadarko contracted with the University of Alaska Anchorage (UAA) to conduct research projects related to the construction of an on-shore platform, hydrate geology and characteristics and hydrate exploration and production water handling and treatment. This report provides a review of hydrate water production and handling, hydrate geochemistry and hydrate microbiological activity. The report was prepared in accordance with the proposal titled "Fundamental and Applied Research on Water Generated During the Production of Gas Hydrates" approved by Anadarko on June 18, 2002, and comments received from Anadarko during subsequent project meetings.

The report is divided into four main sections. The first section provides a review of the gas hydrate produced water quantity and quality as well as a review of potential treatment infrastructure strategies and options. Gas hydrate geochemistry and microbiology are reviewed in sections two and three, respectively. Finally, the report provides recommendations for future research.

\section{Hydrate Water Production and Treatment}

\section{Hydrate Composition}

Hydrates are ice-like structures that consist of a lattice of hydrogen-bonded water molecules with voids occupied by gas molecules. Many gases can form hydrate structures, but in natural gas hydrates the voids are occupied primarily by methane and propane. Hydrates on the North Slope of Alaska are composed primarily of methane (Collett, Kvenvolden et al. 1990; Collett 1993).

There are two basic types of hydrate structures. An ideal Structure I hydrate is a $1728 \AA^{3}$ unit cell consisting of 46 water molecules with eight voids. These voids include two small dodecahedron voids that can hold gas molecules with a diameter of up to $5.2 \AA$ and six large tetradecahedra voids that con hold gas molecules with a diameter of up to $5.9 \AA$. An ideal Structure II hydrate is a $5268 \AA^{3}$ unit cell containing 136 water molecules and 24 voids. Sixteen of these voids are have a diameter of $4.8 \AA$. The eight remaining voids are somewhat larger with a diameter of approximately $6.9 \AA$. The presence of the gas guest molecules results in an expansion relative to ice of $16 \%$ and $18 \%$ for Structure I and Structure II hydrates (Kuuskraa, Hammershaimb et al. 1983).

\section{3 of 69}


The number of water molecules divided by the number of gas molecules is termed the hydrate number. For an ideal Structure I hydrate, the hydrate number is $46 / 8$ or 5.75. An ideal Structure II hydrate has a water to gas ratio of 136:24 and a hydrate number of 5.67. In naturally occurring hydrates, hydrates numbers range from 6 (95\% void occupancy) to 8 (70\% void occupancy). Hydrates formed at lower pressures tend to have higher hydrate numbers (Kuuskraa, Hammershaimb et al. 1983).

The basic structure defines the relationship between gas and water generated during hydrate production. One cubic foot of an ideal Structure I hydrate completely saturated with methane would yield approximately $179 \mathrm{ft}^{3}$ of methane at $14.7 \mathrm{psia}$ and $60^{\circ} \mathrm{F}$ and $0.78 \mathrm{ft}^{3}$ of water. These values represent the maximum theoretical volumes of gas and water that could be produced during Structure I hydrate dissociation (Kvenvolden 1993).

\section{Hydrates in Porous Media}

Naturally occurring hydrates contain somewhat less favorable ratios of water and gas. The formation temperature and pressure as well as the gas composition, formation porosity and pore water chemistry all influence the composition and extent of a hydrate reserve.

The presence of dissolved solids in the pore water lowers the equilibrium temperature and the capillary forces present in porous media increase the equilibrium pressure at which hydrates form relative to pure water (Collett 1997; Klauda and Sandler 2001). As a result, naturally occurring hydrates occur in only a fraction of the voids present in the porous media. For example, in laboratory experiments conducted with a well sorted natural sand with an average grain size of $0.75 \mathrm{~mm}$, deBoer et al (1985) observed that only $50 \%$ of the available pore space was filled with hydrates. Hydrate saturation values of less than 50\% are often cited in the literature (Kamath, Godbole et al. 1987; Goel, Wiggins et al. 2001). Additionally, not only are the pore spaces in naturally occurring systems often unsaturated with respect to hydrates, but the hydrate structures themselves are often unsaturated with respect to gas. Naturally occurring hydrates range from 6.0 to 8.0 , which correspond to a void occupancy of $95-70 \%$ (Kuuskraa, Hammershaimb et al. 1983; Collett, Bird et al. 1988).

When hydrates form, water molecules are incorporated into the hydrate lattice. Any ions present in the pore water during hydrate formation are excluded. As a result, hydrate formations can contain pore water with elevated salt contents. Increased salt concentration in the pore water will decrease the hydrate formation temperature and eventually inhibit hydrate formation creating hydrate filled pores interspersed with pores filled with saline water exist in a formation. Enrichment of salt concentrations to the solubility limit of approximately $26 \mathrm{wt} \%(260 \mathrm{~g} / \mathrm{L})$ is theoretically possible (Sloan 1990);

\section{4 of 69}


however, field data from the North Slope indicate that pore water salt contents range from 5 to 15 parts per thousand ( 5 to $15 \mathrm{~g} / \mathrm{L}$ ) (Kamath, Godbole et al. 1987).

Several different forms of gas hydrates have been observed in porous media. Massive gas hydrates deposits contain only a small amount (e.g., 5\%) of sediment. In layered hydrate formations, thin lenses of sediment separate hydrate layers. Nodular hydrate formations contain granules of hydrates up to $5 \mathrm{~cm}$ in diameter. Small hydrate inclusions are dispersed throughout the formation in disseminated hydrate formations. Several researchers have proposed that disseminated hydrates can grown into nodules, layers and eventually into to massive hydrate deposits if enough gas, pore water and the proper soil conditions exist (Kuuskraa, Hammershaimb et al. 1983; Sloan 1990).

In their evaluation of hydrate resources in the Prudhoe Bay-Kuparuk River area, (Collett, Bird et al. 1988) identified six laterally continuous sandstone and conglomerate formations that contained hydrates. The porosity of these units was difficult to measure due to a lack of hydrate samples, however, porosities were estimated to range from 22 to $48 \%$. These estimates were consistent with the work of other researchers who measured porosities in the permafrost interval (0-610 m) at Prudhoe Bay of 40-45\% and the estimated porosity of the West Sak sandstones in the 1000-1300 $\mathrm{m}$ interval to range between 25 and 35\% (Collett 1993). Intervals containing hydrates ranged from $3-24 \mathrm{~m}$. Due to the lack of hydrate samples the form of the hydrate deposits (i.e, massive, layered, etc.) from the North Slope is not currently known. Figure 1 provides a schematic representation of hydrates formed in North Slope formations.

As shown schematically in Figure 2, two basic types of hydrate reserve configurations have been reported in the literature. A confined hydrate deposit exists when a hydrate bearing formation is located between two relatively impermeable layers. A hydrate cap on top of a free gas reservoir can also occur. Since the formation of hydrates significantly reduces formation permeability, hydrates can also act as a free gas cap (deBoer, Houbolt et al. 1985; Sloan 1990).

Figure 3 schematically illustrates the multiphase nature of a hydrate deposit before and after dissociation. In the most general case, a total of four phases can be present in the hydrate formation: the solid phase (i.e., the sediment grains), the hydrate phase, a brine phase with an initial salt concentration of $\mathrm{C}_{1}$ and a free gas phase with a initial pressure $\mathrm{P}_{1}$. Gas production requires the dissociation of the hydrate structure creating a threephase system. The solid sediment grain phase volume remains unchanged. An increase in the volume of the brine phase and a reduction in the salt concentration would be expected in the closed system. An increase in the gas phase volume and pressure would also be expected. An example calculation for a hydrate formation where no free gas exists is also shown in Figure 3.

\section{5 of 69}




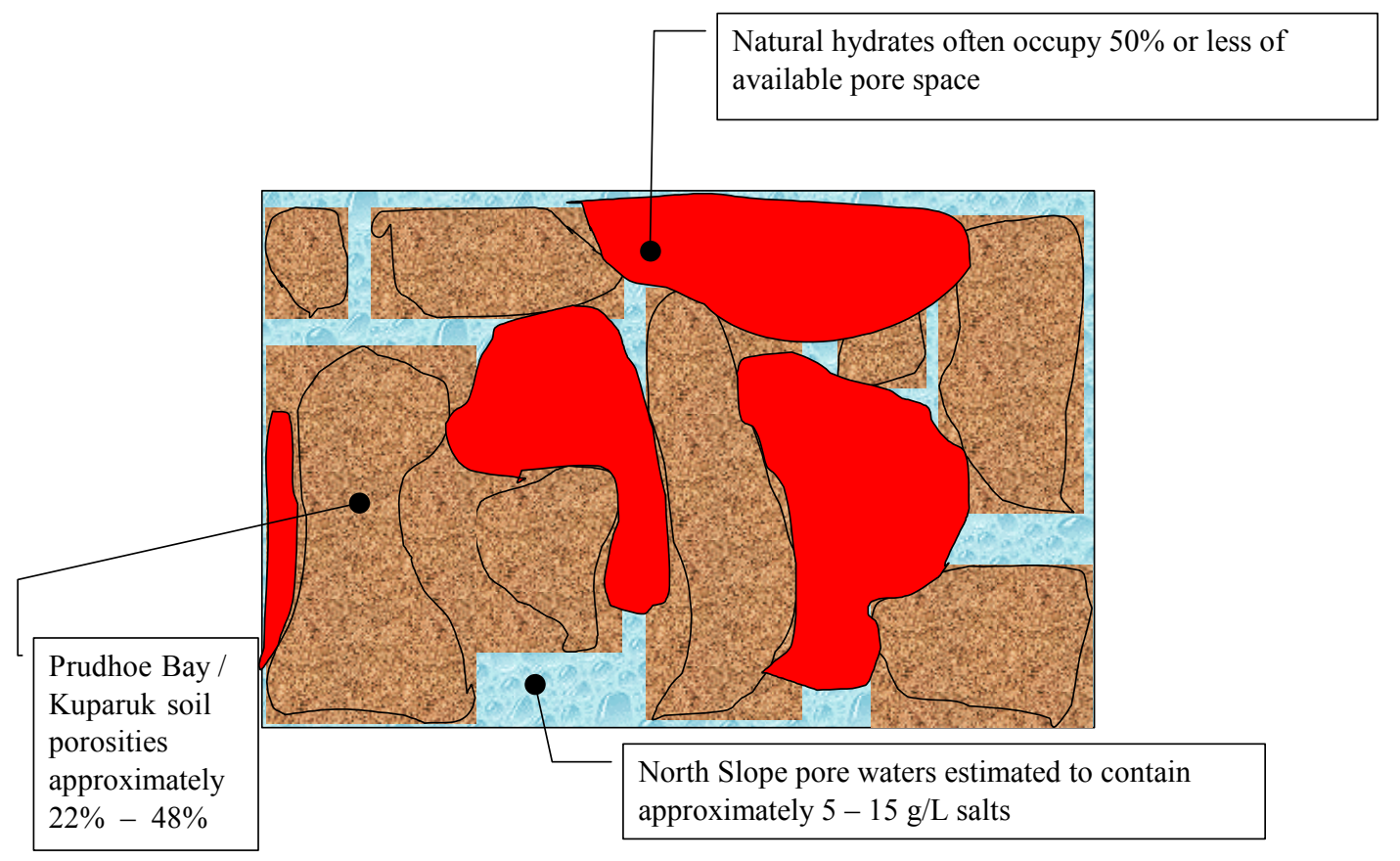

Figure 1 - Schematic of Hydrates in North Slope Porous Media
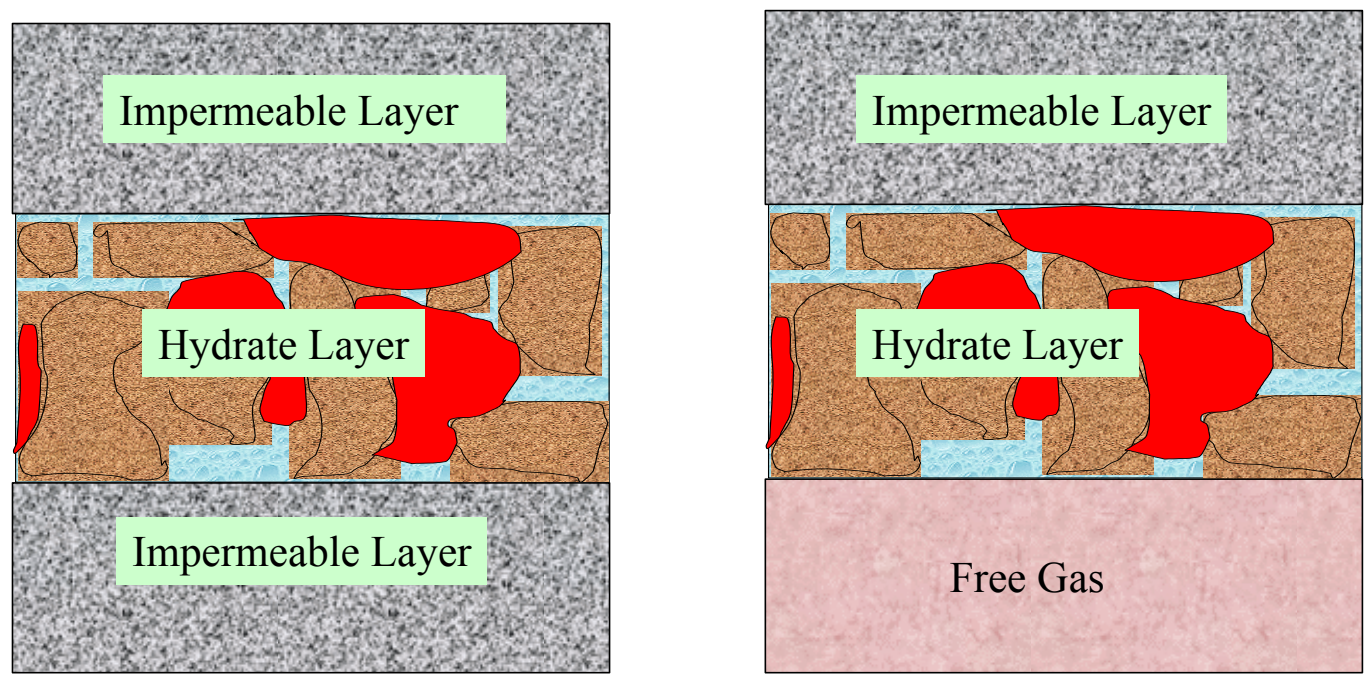

Figure 2 - General Types of Hydrate Reservoirs

\section{6 of 69}




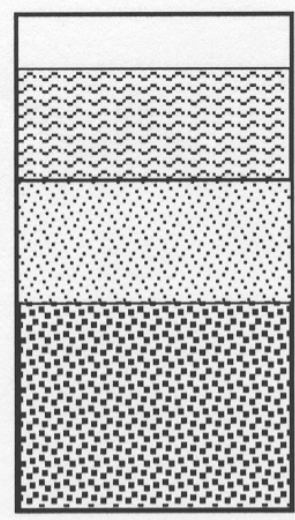

\author{
Gas (P1) \\ Brine $[\mathrm{C} 1]$ \\ Hydrate phase
}

Solid phase

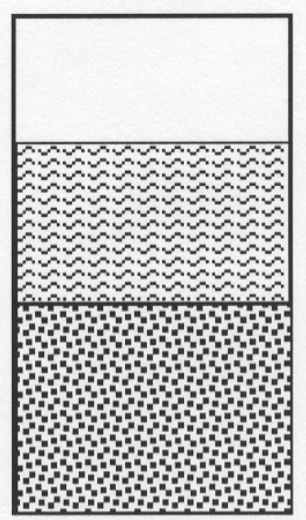

Gas $(\mathrm{P} 2>\mathrm{P} 1)$

Brine $[\mathrm{C} 2<\mathrm{C} 1]$

Solid phase

\section{After Dissociation}

Example (for $1 \mathrm{ft}^{3}$ of formation):

Formation porosity $=30 \%$

Hydrate saturation $=50 \%$

Brine saturation $=50 \%$ at a concentration of $1 \mathrm{wt} . \%(10 \mathrm{~g} / \mathrm{L})$

No free gas

Hydrate number $=6.3$ (90\% occupancy)

Temperature $=2^{\circ} \mathrm{C}$

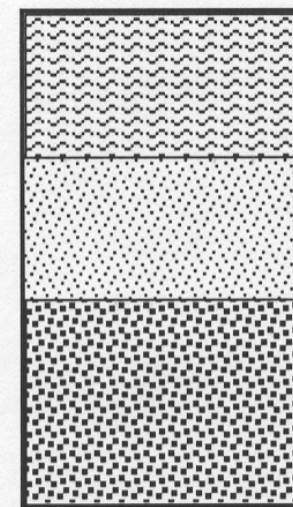

Brine $\left(0.15 \mathrm{ft}^{3}\right.$ at $\left.10 \mathrm{~g} / \mathrm{L}\right)$

Hydrate phase $\left(0.15 \mathrm{ft}^{3}\right)$

Solid phase $\left(0.7 \mathrm{ft}^{3}\right)$

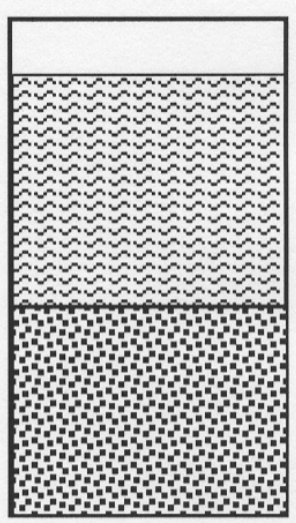

Gas $\left(0.03 \mathrm{ft}^{3}, \Delta \mathrm{P} \approx\right.$ 17,500 psi.)

Brine $(0.27 \mathrm{ft} 3$ at $5.6 \mathrm{~g} / \mathrm{L}$

Solid phase $\left(0.7 \mathrm{ft}^{3}\right)$

Before Dissociation

After Dissociation

Figure 2 - Schematic Representation of the Phases Present in a Hydrate Reservoir Before and After Dissociation. 


\section{Hydrate Production Techniques}

Hydrate dissociation can be accomplished using thermal stimulation, depressurization or the injection of hydrate inhibitors. A number of conceptual models of potential production techniques have been proposed in the literature. These include:

- A single well depressurization model where formation pressure is reduced to stimulate hydrate dissociation. (Kuuskraa, Hammershaimb et al. 1983; Kamath, Mutalik et al. 1991; Yousif, Abass et al. 1991; Goel, Wiggins et al. 2001)

- A single well, cyclic thermal injection model where hot brine or steam is injected into the hydrate formation, hydrates are allowed to dissociate during a "soak" period and then gas and water are produced from the well (Kuuskraa, Hammershaimb et al. 1983).

- Injection of methanol or glycol to lower the hydrate formation temperature (Sira, Patil et al. 1990; Patil 2002)

- A multi-well continuous thermal injection model where two or more interconnected wells are use. Hot brine or steam are injected into one well and gas and water are produced from the other well(s) in the system. Wells are connected by a network of fractures that facilitate gas and water flow (Kuuskraa, Hammershaimb et al. 1983).

- A reservoir depressurization model in which the reservoir pressure in a fracture in the hydrate deposit is maintained at a low value to cause hydrate dissociation (Kuuskraa, Hammershaimb et al. 1983).

- Depressurization of the free gas reservoir located beneath the hydrate cap (Makogon 1981).

- Use of down-hole heaters or the use of electromagnetic heating (Islam 1994; Patil 2002).

Since only depressurization of the free gas reservoir in the Messoiakh field in Western Siberia has been implemented at full scale (Makogon 1981), very limited information on the full-scale application of gas hydrate production approaches is available. Most of the research conducted to date consists of lab scale experiment to evaluate stimulation techniques (Sira, Patil et al. 1990; Kamath, Mutalik et al. 1991; Ershov and Yakushev 1992) and the development of numerical models to simulate thermal stimulation and

\section{8 of 69}


depressurization production techniques (Holder, Angert et al. 1982; Kamath, Holder et al. 1984; Das and Srivastava 1991; Yousif, Abass et al. 1991; Goel, Wiggins et al. 2001).

Unfortunately, most of the hydrate production experiments and numerical models reviewed for this report fail to specifically address the water phase. The models typically assume that the water phase is immobile and will not impact gas production although several researchers agree that this is not a good assumption (Wittebolle and Sego; Sloan 1990; Yousif, Abass et al. 1991). Due to the lack of information on the fate of the water phase during hydrate production, only a conceptual evaluation of the water production issues can be offered at this time.

The volume and flow rate water generated during hydrate production will fundamentally be a function of the hydrate dissociation rate. (Kim, Bishnoi et al. 1987) determined that the intrinsic hydrate dissociation rate is proportional to the hydrate surface area and the difference between the fugacity of gas phase at the equilibrium and the decomposition pressure. Not all of the water liberated during hydrate dissociation will be produced. Formation type (i.e., confined, gas cap, etc.), formation characteristics (i.e., porosity, permeability, hydrate content, residual saturation) will also impact the amount of water produced. Capillary forces exerted by the formation will hold a fraction of the water produced during hydrate dissociation. Only water at saturations above the residual saturation will be mobile. (Makogon 1981) reported that residual water saturation in the Messoiakh field ranged from 29 to $50 \%$. As discussed in the following paragraphs, each production technique would be expected to have unique water production characteristics.

\section{Water production during depressurization of a single well.}

Hydrate production using the depressurization approach using a single well can be accomplished by reducing the pressure in the well bore or formation fracture below the hydrate stability pressure. Figure 4 is a schematic representation of single well depressurization hydrate production.

A previous study (Goel, Wiggins et al. 2001) modeled hydrate dissociation via depressurization by assuming a cylindrical reservoir geometry. Hydrate production created an undissociated hydrate/dissociated gas interface. The position of this interface varied as hydrates dissociated during production. The model assumed a radial flow of fluids and that the water formed during dissociation had no effect on gas flow (i.e., water would not reduce the relative permeability to gas flow). Table 1 summarizes the parameters used in the Goel model. The model was used to generate pressure profiles in the formation for various production times and gas flow rates. Examples of data generated by the Goel model are provided in Figure 5. A large pressure drop is predicted at the undissociated/dissociated hydrate interface with very little change in pressure

\section{9 of 69}


predicted in the dissociated portion of the formation. Gas production rates of 0.5 standard cubic meters per day (SCMD) were predicted from the model.

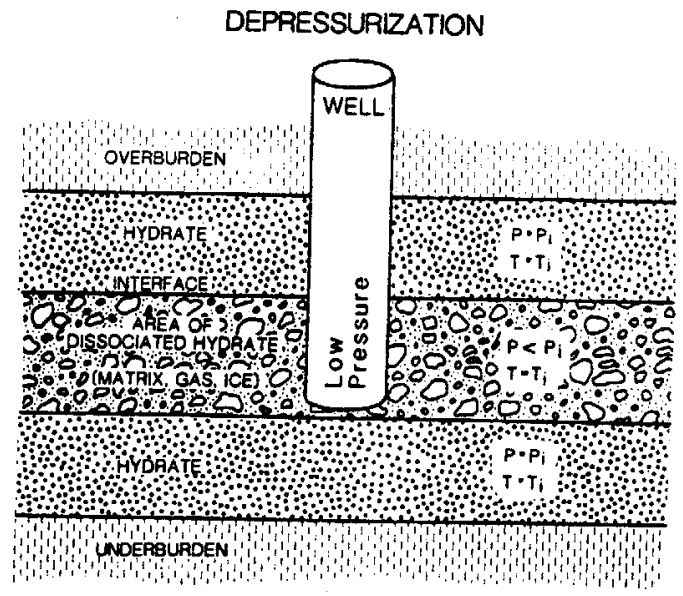

Figure 4 - Schematic Representation of Single-Well Depresssurization Hydrate Production from (Kuuskraa, Hammershaimb et al. 1983)

Table 1 - Hydrate Formation Parameters Used in the (Goel, Wiggins et al. 2001) Model

\begin{tabular}{ll}
\hline Parameter & Value \\
\hline Hydrate reservoir area & $10 \mathrm{acres}$ \\
Hydrate reservoir thickness & $30 \mathrm{~m}$ \\
Porosity & $30 \%$ \\
Hydrate saturation & $20 \%$ \\
Hydrate reservoir temperature and pressure & $56 \mathrm{~atm} / 280 \mathrm{~K}$ \\
Hydrate equilibrium pressure & $54 \mathrm{~atm}$ \\
Hydrate dissociation constant & $124 \mathrm{e}^{(-9400 / \mathrm{T}(\mathrm{K}))} \mathrm{kmol} /\left(\mathrm{s} \mathrm{m}^{2} \mathrm{~Pa}\right)$ \\
Gas viscosity & $1.5 \mathrm{x} 10-5 \mathrm{~Pa} \mathrm{~s}$ \\
Dissociated zone permeability & 0.01 and $10 \mathrm{milldarcy}$
\end{tabular}

\section{0 of 69}




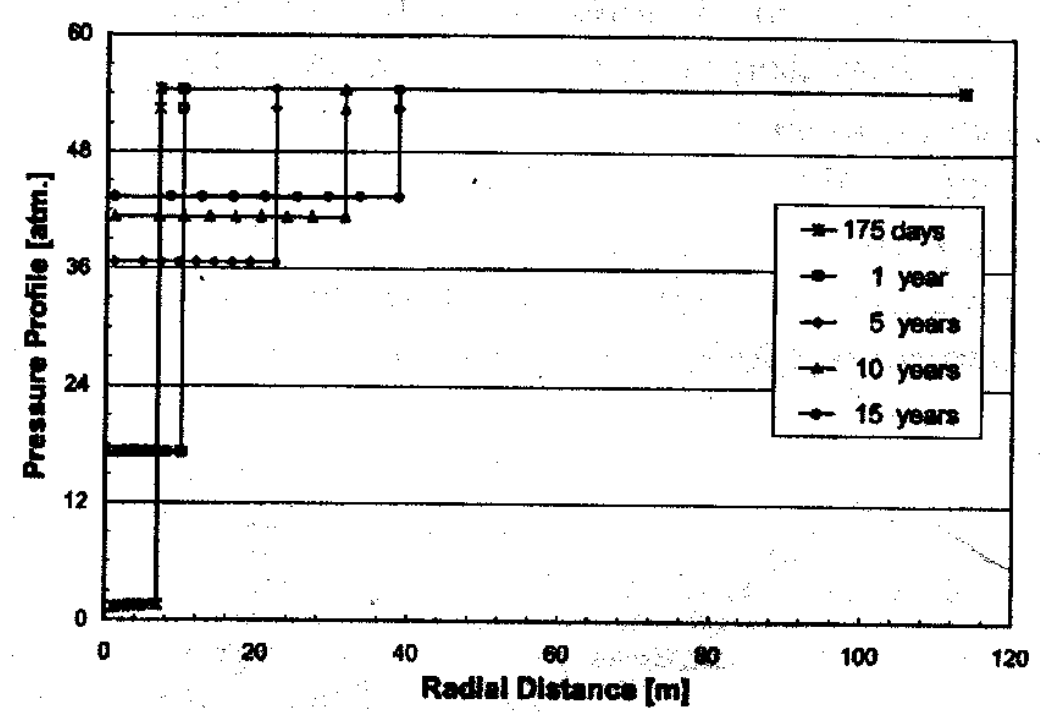

Figure 5 - Formation Pressure Profile Model Results from (Goel, Wiggins et al. 2001)

Yousif et al. (1991) also created a one-dimensional model to simulate the production of gas hydrates using the depressurization approach. This model explicitly addressed the mobile water phase and, as shown in Figure 6, the results indicated that a localized water content maximum would be created in the formation during hydrate production. The expanding gas forces all but the immobile water from the formation near the undissociated hydrate interface creating a water front. In this work, water saturations above approximately $40 \%$ would be mobile and create a produced water flow. These results suggest that dissociated water would reduce the relative permeability of the formation to gas flow and limit the ability to maintain gas production rates. A reduction in the relative permeability of the formation to gas would result in a reduction in gas flow and an increase in pressure that may inhibit hydrate dissociation. Using this production technique, the produced water would have to be removed to maintain hydrate production (Wittebolle 1985).

\section{1 of 69}




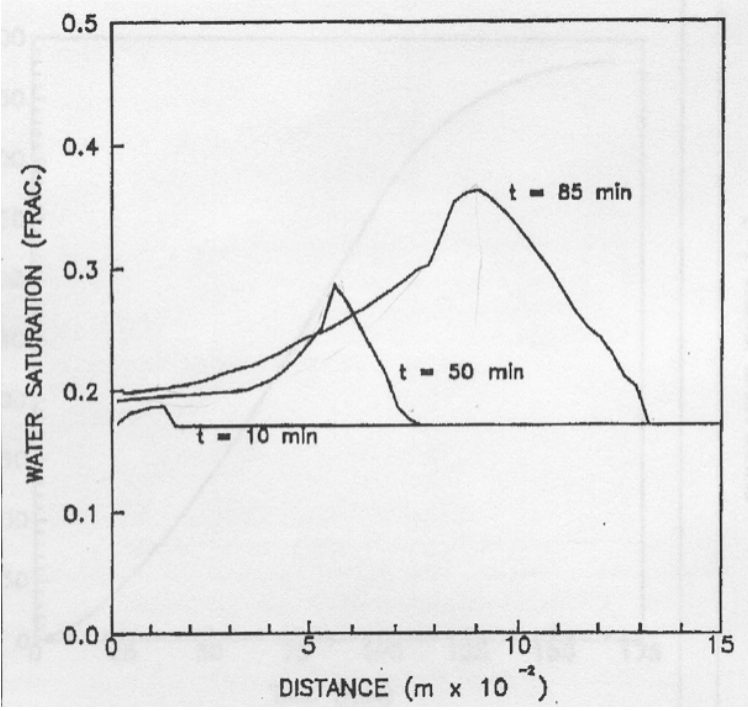

Figure 6 - Water Saturation Predictions from the (Yousif, Abass et al. 1991) Model

\section{Water Production during the cyclic injection of hot fluids in a single well}

Consider the cyclic single well production approach shown schematically in Figure 7 in which hot fluid (steam or brine) is cyclically injected into the hydrate formation to cause dissociation. In this production scenario, the sum of the formation water, the hot fluid (brine or the hot water condensate formed by from injected steam) and the water from dissociation of the hydrates would be present in the formation. In order to force hot fluids to the undissociated hydrate face, the dissociated formation would need to be flooded. At least a portion of this water must be removed if gas is to be produced using this approach to restore permeability to gas flow.

As the radius of dissociated hydrates expands, water will be required to fill the formation. Since the volume of water produced by hydrate dissociation is approximately $22 \%$ less than the volume occupied by the hydrate, additional water will be necessary to flood the formation.

\section{2 of 69}




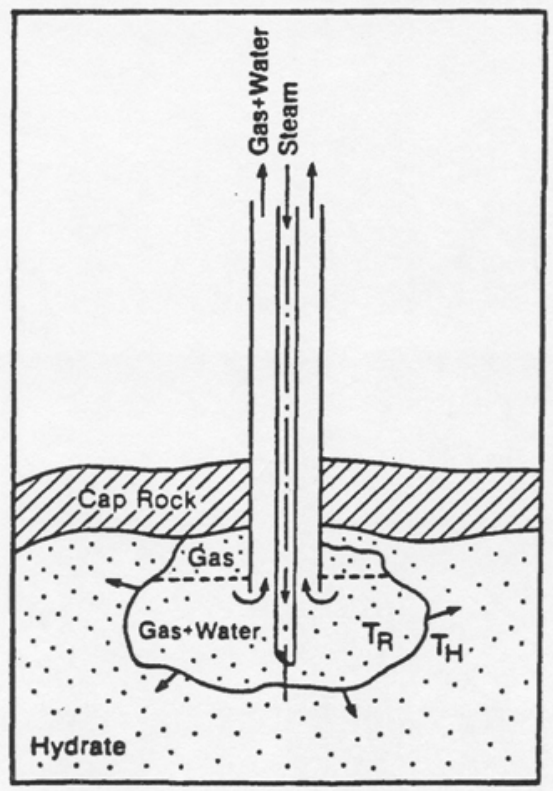

Figure 7 - Schematic Representation of Cyclic Single-Well Hydrate Production Using Injected Steam from (Kuuskraa, Hammershaimb et al. 1983)

In addition, the dissociation of hydrates will add pure water to the formation diluting the brine concentration. (Kamath, Mutalik et al. 1991) conducted laboratory experiments on hydrate dissociation using the brine injection methods. Salinity of the brine used to dissociate the hydrates was reduced by approximately 3 to $5 \%$ as the hydrates dissociated. Since the rate of gas production using the brine injection method is a function of temperature, pressure, brine concentration (as well as temperature, pressure and hydrate dissociation interface area) the continual addition of salts and/or the concentration of the recovered water (if it is to be reinjected) may be required to maintain the brine concentration and gas production rates.

\section{Water production during depressurization of an associated free gas reservoir}

Hydrate dissociation induced by the depressurization of an associated free gas reservoir may represent the best case scenario for the production of hydrate formations. This scenario also represents the case where minimal amount of produced water may be expected. Gas produced from the hydrate formation will be in contact with the water generated during the dissociation of the hydrate and connate water in the free gas formation. As a result, the gas stream should be saturated with water but water generated from the dissociation of hydrates may not load the well bore in this situation.

\section{3 of 69}




\section{Water production during continuous thermal stimulation}

Hydrate production during continuous thermal stimulation with hot brine, hot water or steam would use a combination of injection and recovery wells linked by fractures as shown schematically in Figure 8. Hot fluid would be injected into the fractures causing hydrate dissociation. This water, along with the water generated during the dissociation of the hydrate formation, would be drain from the undissociated hydrate interface. The gas generated during hydrate dissociation may also displace water. Unless it is removed, the water generated during hydrate dissociation would reduce the relative permeability of the formation to gas flow and potentially load the production well.

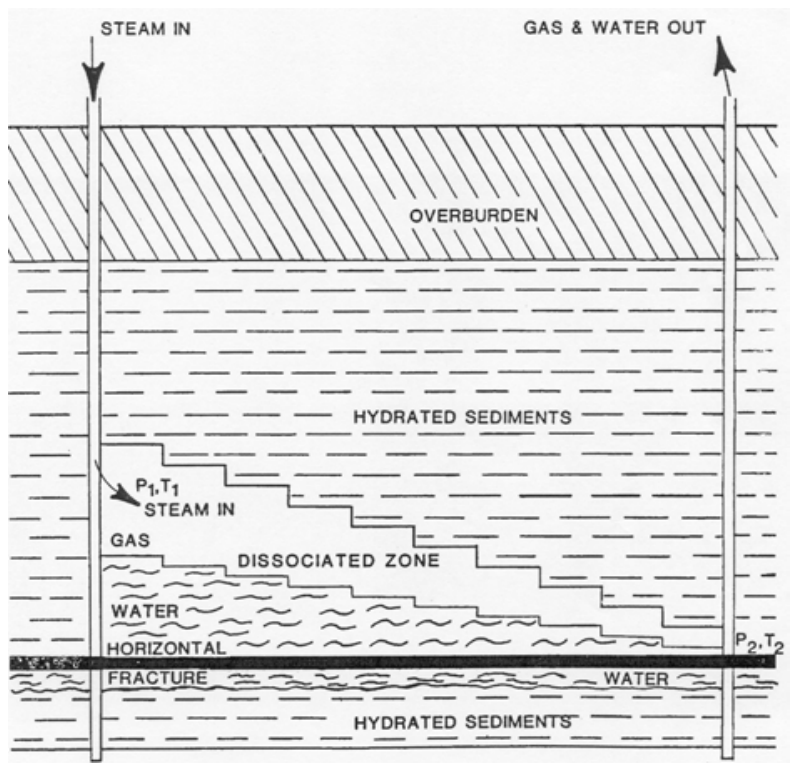

Figure 8- Schematic of Continuous Hydrate Production Using Steam Injection from (Kuuskraa, Hammershaimb et al. 1983)

\section{Summary of Water Production Issues}

A review of the available conceptual and numerical models for hydrate production indicates that significant amounts of water will be generated during the production of hydrate reserves. In most of the production scenarios cited in the literature, it is reasonable to assume that unless the water generated during hydrate dissociation is removed, the relative permeability of the formation to gas flow the ability to maintain gas production rates will be reduced. The one numerical modeling effort reviewed for this report that explicitly considered the water phase indicates that the single well depressurization production approach will generate water slugs as water is displaced from

\section{4 of 69}


the formation by expanding gas. The major components of the produced water will be salts and dissolved gasses and potentially some sediment. Brine or steam injection production options may require water beyond that provided by hydrate dissociation to meet production demands.

\section{Water and Wastewater Infrastructure Strategies}

The water generated during gas hydrate dissociation suggest that water handling will be critical component of the production process. And as such, the infrastructure designed to process water and wastewater will become a more important factor to the success of individual well or field than most conventional oil and gas operations. Under these conditions, the approach used to design and operate water systems may need to be modified from current methods used in the oil and gas industry.

In most oil and gas operations today, the water and wastewater (w/ww) infrastructure is not considered as an integral part of planning process for field development. Water and wastewater systems are often designed separately from the main oil and gas handling facilities by oil-field service providers, term engineering contractors or camp system manufacturers contracted to perform design and construction tasks. Since many of these contractors do not specialize in $\mathrm{w} / \mathrm{ww}$ processes, designs that are not fit for purpose frequently occur. Under the best circumstances, this approach produces designs that meet all the regulatory requirements for a particular installation. However, under almost all circumstances, the design of the w/ww infrastructure is completed on a site-by-site basis which can result in an eclectic collection of treatment technologies, each with its own specific operations and maintenance requirements.

A more effective approach, and one that the increased water generated expected during gas hydrate production may demand, would be to design the w/ww infrastructure using an regional approach based on the following three principals. First, the design of w/ww systems at a particular installation should be integrated with the exploration and production activities and consider all water requirements and wastewater generation activities that occur at each site. Second, to increase efficiency and reduce complexity, w/ww systems should be designed on a field wide or region wide basis and not at a siteby-site basis. Finally, the w/ww systems designs should be robust enough to handle a variety of conditions and permit requirements. Additional information on each of these design principals are provided in the following paragraphs.

\section{5 of 69}




\section{Exploration and Production Water Demands and Wastewater Generation}

Table 2 summarizes the water requirements and wastewater generation anticipated for a hydrates exploration and production platform and the associated water quality requirement (when known).

Table 2 - Summary of Water Demands and Wastewater Generation Activities on Gas Hydrate Exploration and Production Sites.

\begin{tabular}{|c|c|c|}
\hline Water Use & $\begin{array}{l}\text { Quantity and/or } \\
\text { Rate }\end{array}$ & $\begin{array}{l}\text { Required Water } \\
\text { Quality }\end{array}$ \\
\hline $\begin{array}{l}\text { Personal use of potable water } \\
\text { (drinking, personal hygiene, } \\
\text { cooking) }\end{array}$ & $65-70 \mathrm{gal} / \mathrm{capita} /$ day & Potable \\
\hline $\begin{array}{l}\text { Heat Generation and Cooling } \\
\text { (boiler makeup water, steam } \\
\text { generation, cooling water) }\end{array}$ & $\begin{array}{l}\text { Function of types of } \\
\text { system used }\end{array}$ & $\begin{array}{l}\text { Hardness limitation } \\
\text { (to prevent scaling) }\end{array}$ \\
\hline Air Pollution Control Facilities & $\begin{array}{l}\text { Function of type of } \\
\text { systems used }\end{array}$ & $\begin{array}{l}\text { Function of type of } \\
\text { system used }\end{array}$ \\
\hline Drilling Fluids Makeup Water & $\begin{array}{l}\text { Function of drilling } \\
\text { mud used }\end{array}$ & $\begin{array}{l}\text { Function of drilling } \\
\text { muds used }\end{array}$ \\
\hline Washdown Water & Minimal & unknown \\
\hline \multicolumn{3}{|l|}{ Wastewater Generation } \\
\hline $\begin{array}{l}\text { Backwash and concentrate from } \\
\text { water treatment systems }\end{array}$ & $1-5 \mathrm{gal} / \mathrm{cap} /$ day & $\begin{array}{l}\text { Function of water } \\
\text { treatment system } \\
\text { utilized }\end{array}$ \\
\hline $\begin{array}{l}\text { Domestic Wastewater (gray } \\
\text { water from } \\
\text { kitchens/showers/sinks, etc. and } \\
\text { blackwater from toilet facilities) }\end{array}$ & 60-65 gal/cap/day & $\begin{array}{l}\text { Function of location } \\
\text { of discharge (i.e, } \\
\text { injected, surface } \\
\text { discharged, reused, } \\
\text { etc.) }\end{array}$ \\
\hline $\begin{array}{l}\text { Hydrate and connate produced } \\
\text { water }\end{array}$ & $\begin{array}{l}\text { Function of type of } \\
\text { hydrate formation } \\
\text { produced }\end{array}$ & $\begin{array}{l}\text { Unknown, although } \\
\text { flow is not expected } \\
\text { to be uniform (surge } \\
\text { flow is expected }\end{array}$ \\
\hline
\end{tabular}

16 of 69 
Arctic oil field camps typically must provide 65-70 gallons per capita per day of potable water. Most camps have a single plumbing system and as a result, potable water is supplied to all sinks, showers and toilet facilities in the camp. The remaining demands for water are process demands including the formulation of certain drilling fluids, water for heating and cooling system and washdown water used for cleaning process equipment and spaces. Some installations may also use water in the scrubbers used to meet air pollution discharge requirements.

Since most camps are prefabricated modules plumbed with high integrity water distribution and wastewater collection systems, nearly all of the potable water produced is collected as wastewater. Additional wastewater flows (e.g., backwash, concentrate, spent cleaning solutions) can be generated by the water treatment system. However, the largest waste stream will likely be the produced water generated during hydrate production. Although the basic nature of hydrate deposits suggests that the gas and water production rates should be related, good estimates of the volume and rate of water production do not exist.

\section{Remote Operation}

The Alaska Department of Environmental Conservation (ADEC) classifies water and wastewater treatment systems into one of four classes based on complexity (i.e., a class one system would be simple and a class four system complex). ADEC further requires that the supervising operator responsible for a public water or wastewater system be actively supervised each day by an operator with a level of certification equal to or greater than the system classification. Thus a class 4 system would require at least a Level 4 operator to be in compliance. Although the current regulations specify that the supervising operator be on-site during normal working hours, the ADEC does provide a process for evaluating alternate methods of system supervision.

One alternate method to operate water and wastewater systems is to implement a remote operations strategy shown schematically in Figure 9. Using this approach, water and wastewater treatment systems are distributed throughout the region (e.g., the North Slope) each have their own water and wastewater infrastructure. However, rather than have a full crew of operators on-site as is now the practice, a low level operator on-site would be supported by more experienced, higher level operators at a central monitoring and operations and support facility.

This type of approach would result in an overall reduction in the number of high level personnel required to operate the water and wastewater infrastructure. Fewer personnel may reduce operating costs, but as importantly, it will also reduce the need for high level operators that are currently in short supply. A number of rural Alaska communities are

\section{7 of 69}


attempting this remote operations support approach because they cannot find and/or adequately compensate trained operators.

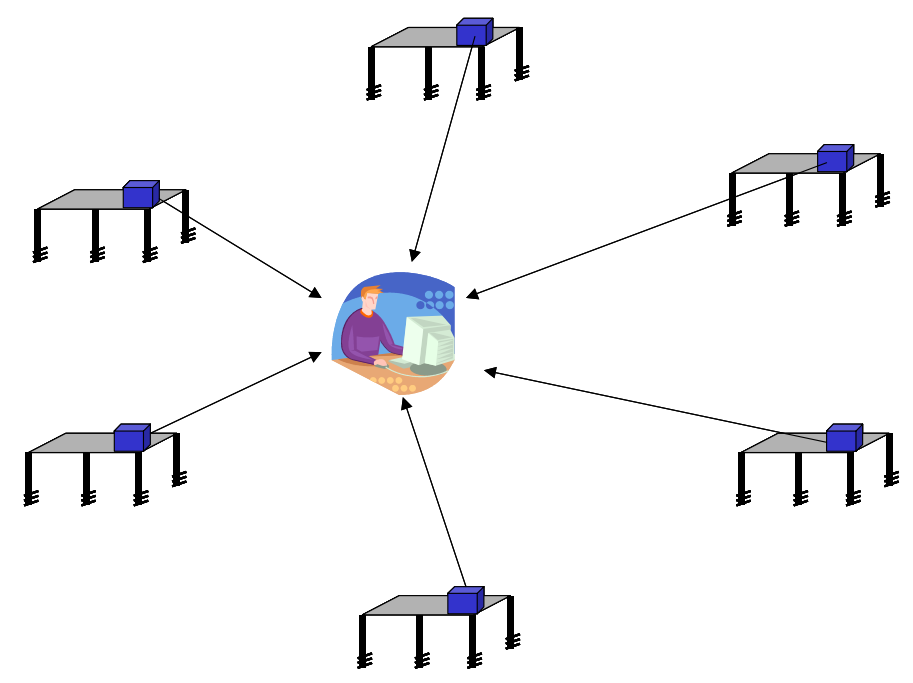

Figure 9 - Distributed Operation of Water and Wastewater Treatment Systems

To implement a remote operations and monitoring strategy, the ADEC and the Governor's Water/Wastewater Advisory Board must convinced that any operations strategy that deviates from that stated in the regulations is adequate to protect public health and the environment and the capital invested in the system. The general framework for the O\&M strategy that must be reviewed and approved by the Board and the ADEC is summarized in Table 3.

\section{8 of 69}


Table 3 - General Framework for a Remote Operations and Maintenance Plan

Framework Elements

Statement of proposed O\&M strategy

Description of the system involved including current classification, O\&M requirements and the status of system compliance with current regulations

Qualifications of the operating personnel including current certification level, work history and job responsibilities

Duration of the proposed O\&M change

For off-site supervising with on-site custodial care strategies include the qualifications and duties of the custodial personnel, the method of communications, the frequency of on-site visitation by supervising personnel and methods of emergency response.

Consequences of system malfunction and/or system failure and the methods of detection, safeguard and response

Compliance plan (if applicable)

\section{Technology Characteristics}

The final principal of an effective water and wastewater infrastructure strategy is to select treatment technologies that are robust enough to provide high performance under a wide variety of conditions yet flexible enough to be readily adaptable to different installations. Table 4 summarizes the major technology requirements required for oil and gas exploration and production operations and the corresponding design features.

One of the most important features for any water and wastewater treatment technology in the oil and gas industry is the flexibility. The normal design process for water and wastewater infrastructure consists of forecasting the design life needs and sizing process tanks and equipment to meet the needs of the installation throughout the design life. Unfortunately, the very nature of oil and gas exploration and production activities makes accurate prediction of water and wastewater flow rates difficult at best. Camp populations predictions are of loose estimates subject to changes in field production capability and economic factors beyond the control of individual project managers. As a result,

\section{9 of 69}


estimates of treatment requirements are, in the author's experience, inherently unstable and subject to change.

Table 4 - Water and Wastewater Technology Requirements and Design Features

Technology Requirement Design Feature

Variable camp population, Uncertain flows Modular, scalable design

(need for flexibility)

Sensitive receiving environments

High quality (tertiary) effluent

Poor source waterwater characteristics

Ability to remove organics and pathogens

Scarcity of qualified operators

Ease of operation. Capable of automated, remote operation

Space limitations

Small foot print

High transportation costs

Limited chemical use, limited sludge production

Many of the conventional technologies commonly used in the oil and gas industry to provide water and wastewater infrastructure are not well suited to match changing demands. Tanks must be sized to accommodate a certain range of flows/demands and significant variations, either above or below the design flow, can result in poor performance. Ideal infrastructure would be flexible enough to provide good performance over a wide range of flows and be easily expandable if additional capacity was required.

Remote, roadless exploration and production installations (i.e., the on-shore platform) will also make small footprint a premium. Systems that can operate with a minimum of tank space and be easily transported and assembled will be necessary.

Finally, wastewater systems should be capable of producing high quality effluent that will maximize the number of potential disposal options (i.e., surface discharge, reinjection, reuse, etc.). Water systems must be able to produce potable water from local sources, which on the North Slope are typically tundra ponds containing high concentrations of natural organic material. For both water and wastewater systems, high

\section{0 of 69}


transportation costs require that the use of chemicals and the production of residuals be minimized to the extent possible.

Membrane technologies represent some of the best available systems commercially available to implement this approach. Selection of one or two membrane technologies capable that meet the criteria in Table 4 and standardization of designs could result in significant savings in permitting construction and operational costs. In the following paragraphs, conceptual designs of water and wastewater treatment systems for hydrate production platforms are presented along with preliminary technical information and cost estimates for these technologies.

\section{Conceptual Design of Hydrates Water and Wastewater Infrastructure}

Figures 10 provides a conceptual layout for an integrated water treatment systems for a gas hydrate production facility. Produced water from the hydrate formation would first pass through a separator to remove any dissolved gasses and entrained sediments.

Depending upon the quality of that water, it may be suitable for use in other processes on pad (e.g., drilling mud makeup water, washdown water, etc.). Hydrate produced water could then be processed through a membrane treatment system to remove colloidal solids and reduce the total dissolved solids content. If necessary, surface water could also be processed through the membrane treatment system.

Several disposal options are possible for permeate and concentrate streams generated by the membrane treatment system. The permeate could be used for potable water uses on the platform and to satisfy other demands for high quality water. Permeate from the membrane system will be of high quality and also may be suitable for surface discharge, a factor which may be important in hydrate production of large amounts of water are generated that cannot be reinjected. The concentrate from the membrane system will be a concentrated brine that could be used to stimulate hydrate production. Other options for this stream include reinjection or evaporation.

\section{Overview of Membrane Water Treatment Processes}

Membrane processes involve the use of species selective membranes for the concentration of dissolved solids into smaller volumes. The utility of membrane systems is related to their mobility and flexibility, as well as their treatment capacity. As described in Figure 11, microfiltration (MF) technology typically provides removal of particles larger than 0.1 to 0.4 microns. Ultrafiltration (UF) technology is a tighter membrane providing removal of macromolecular particles and compounds with a size of 1,000 to 100,000 atomic molecular units (AMU). Nanofiltration (NF) membranes can reject compounds with a size of between 100 and 1,000 AMU and reverse osmosis (RO)

\section{1 of 69}


can reject constituents in the water with less than 100 AMU. Unlike MF and UF however, factors other than molecular size including electrical charge can play a significant role in whether a compound is rejected at the membrane surface in RO and NF systems.

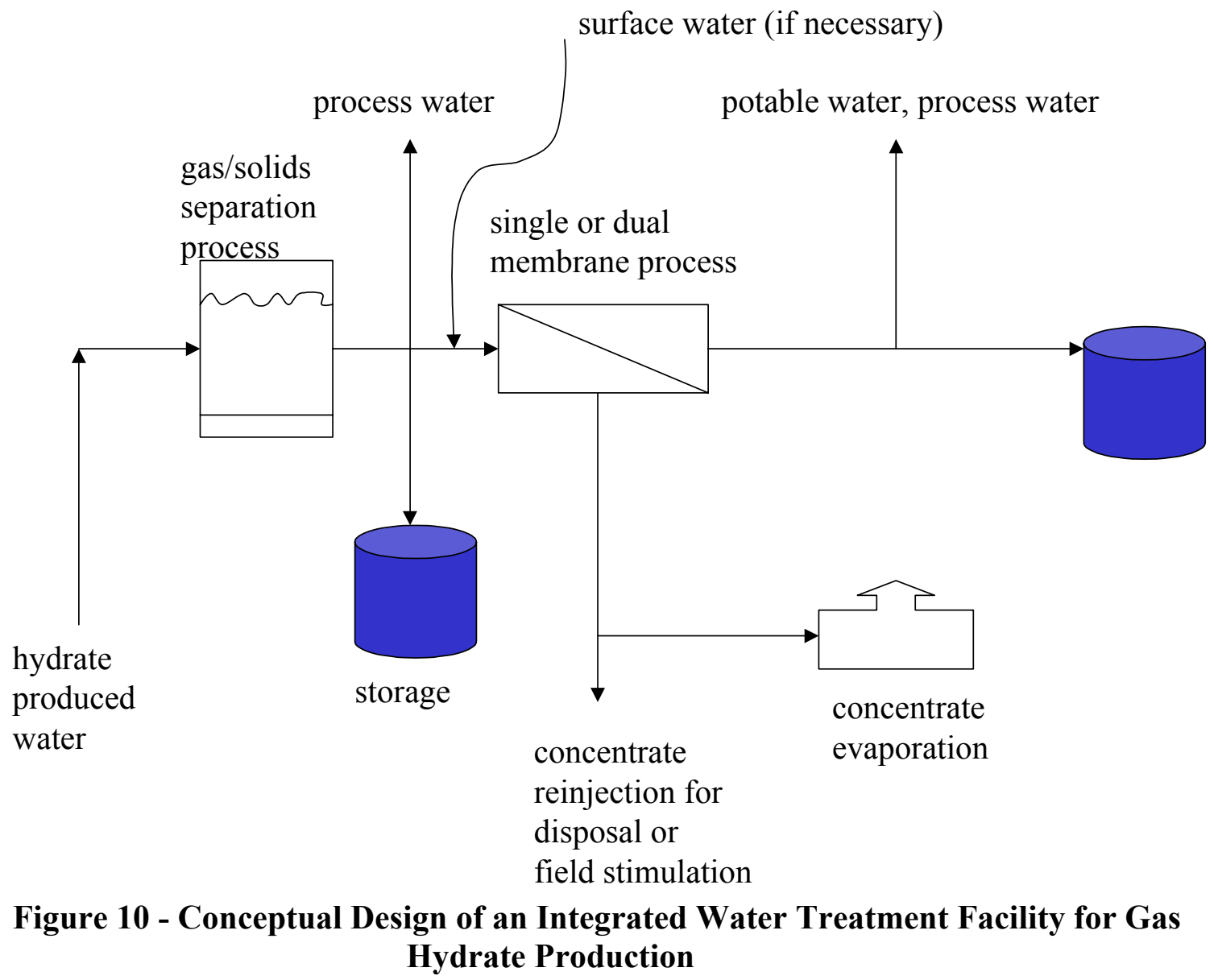

22 of 69 


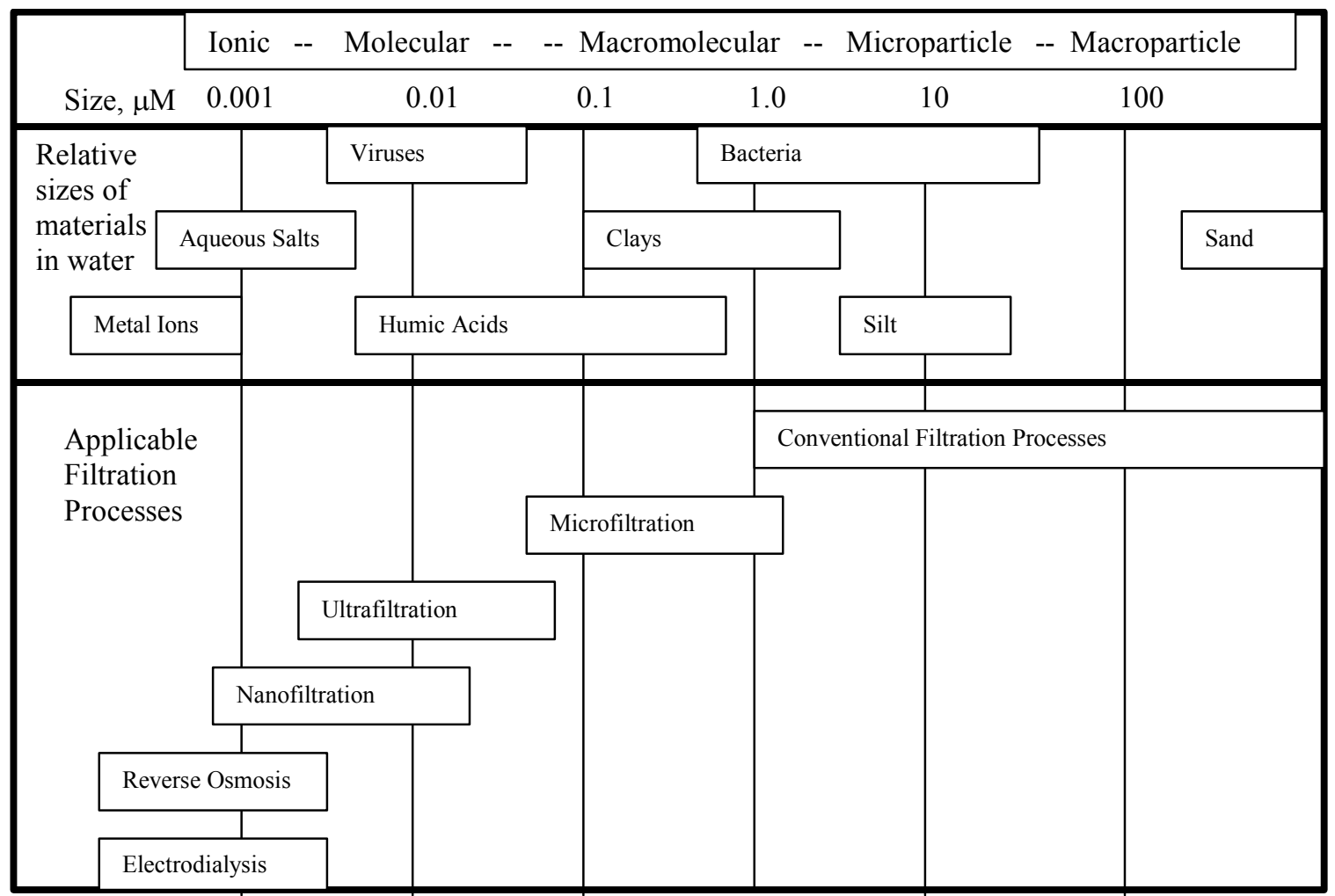

Figure 11 - Membrane Filtration Processes and Relative Sizes of Materials in Water

Since the dissolved inorganic compounds present in hydrate produced water will be typically smaller than the nominal pore size, MF and UF will not effectively reduce the total dissolved solids concentration. NF and RO membranes, however, will reject inorganic ions present in hydrate produced water. Of these two processes, RO membranes remove a higher fraction of the inorganic total dissolved solids. However, NF membranes will remove a fraction of the TDS at a lower operating pressure and can be an appropriate choice when large reductions in TDS are not required.

\section{Types of Commercially Available Membrane Systems}

Two basic types of NF and RO systems are commercially available. Spiral wound nanofiltration systems, as shown schematically in Figure 12, consists of a sandwich of flat sheets of NF membrane material and spacer channel wrapped around a central perforated tube to form a membrane element. These elements are inserted in to a pressure vessel end to end. Individual pressure vessels are then operated in hydraulic arrays configured to produce permeate with a minimum of fouling. Spiral wound construction yields membrane filtration systems with large membrane surface areas relative to the volume of the pressure vessels.

\section{3 of 69}


Spiral wound NF treatment systems will easily foul if supplied with water that is not adequately pretreated to remove particles. As a result, spiral wound nanofilters are typically preceded by one or more pretreatment processes intended to provide removal of colloidal particles. Pretreatment for NF processes include cartridge filtration, direct filtration, or conventional filtration. More recently microfiltration (MF) membrane or ultrafiltration (UF) filtration has been deployed as pretreatment to NF membranes to provide better pretreatment and extend the useful life of NF membranes. The use of both $\mathrm{MF}$ and NF membranes has been termed integrated dual membrane treatment, or $\mathrm{MF} / \mathrm{NF}$ treatment.

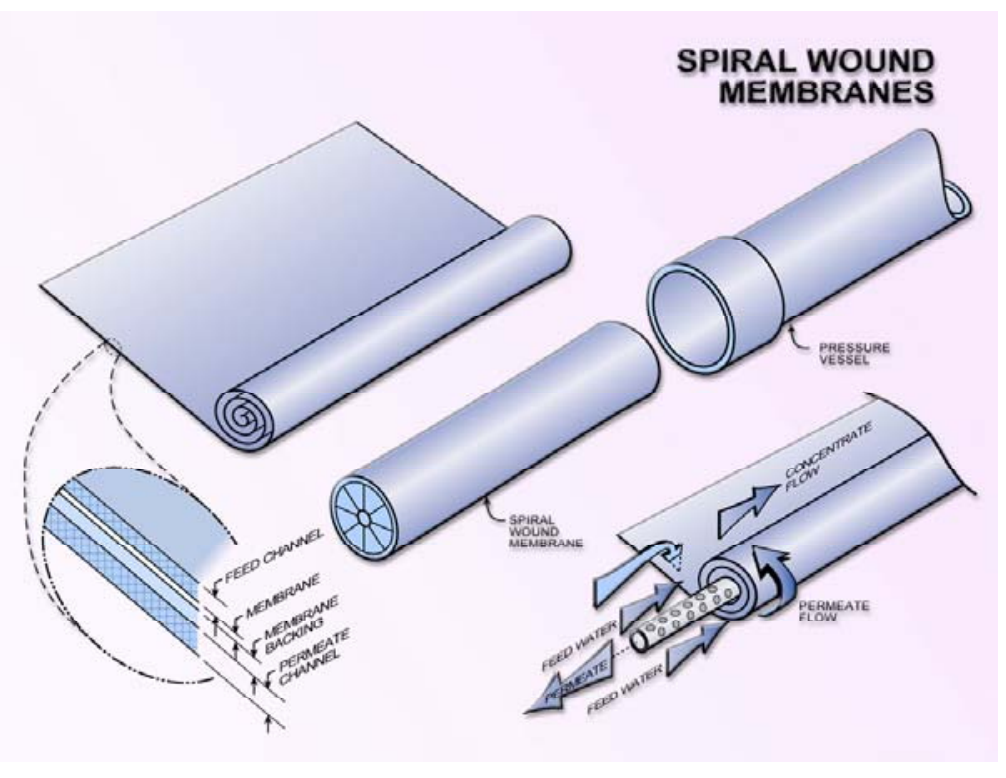

Figure 12 - Spiral Wound Membrane Module Construction

Tubular membranes are the second type of NF configuration used in drinking water treatment. In this type of treatment system, tubular membrane elements which are typically on the order of $1 / 2$ " in diameter are inserted into a pressure vessel to create a membrane module. A cutaway section of a typical tubular membrane module is shown in Figure 13.

In a full-scale tubular membrane NF system, raw water is pumped through the tubular elements. A recirculation pump is typically used to obtain the water pressures and flow rates necessary for the system to operate effectively. Permeate is collected in the module shroud. A small fraction of the concentrate stream is wasted, but the majority is recycled and combined with the raw water stream. Unlike spiral wound systems, tubular membrane systems are not easily fouled by particulates and only limited pretreatment (e.g., a strainer or bag filter) is required for their use. Certain manufacturers also employ 24 of 69 
an automated cleaning process where a foam ball is periodically run through the membrane elements to scour off the foulants that accumulate on the membrane surface. High flow velocities are also maintained through the membrane elements to reduce fouling.

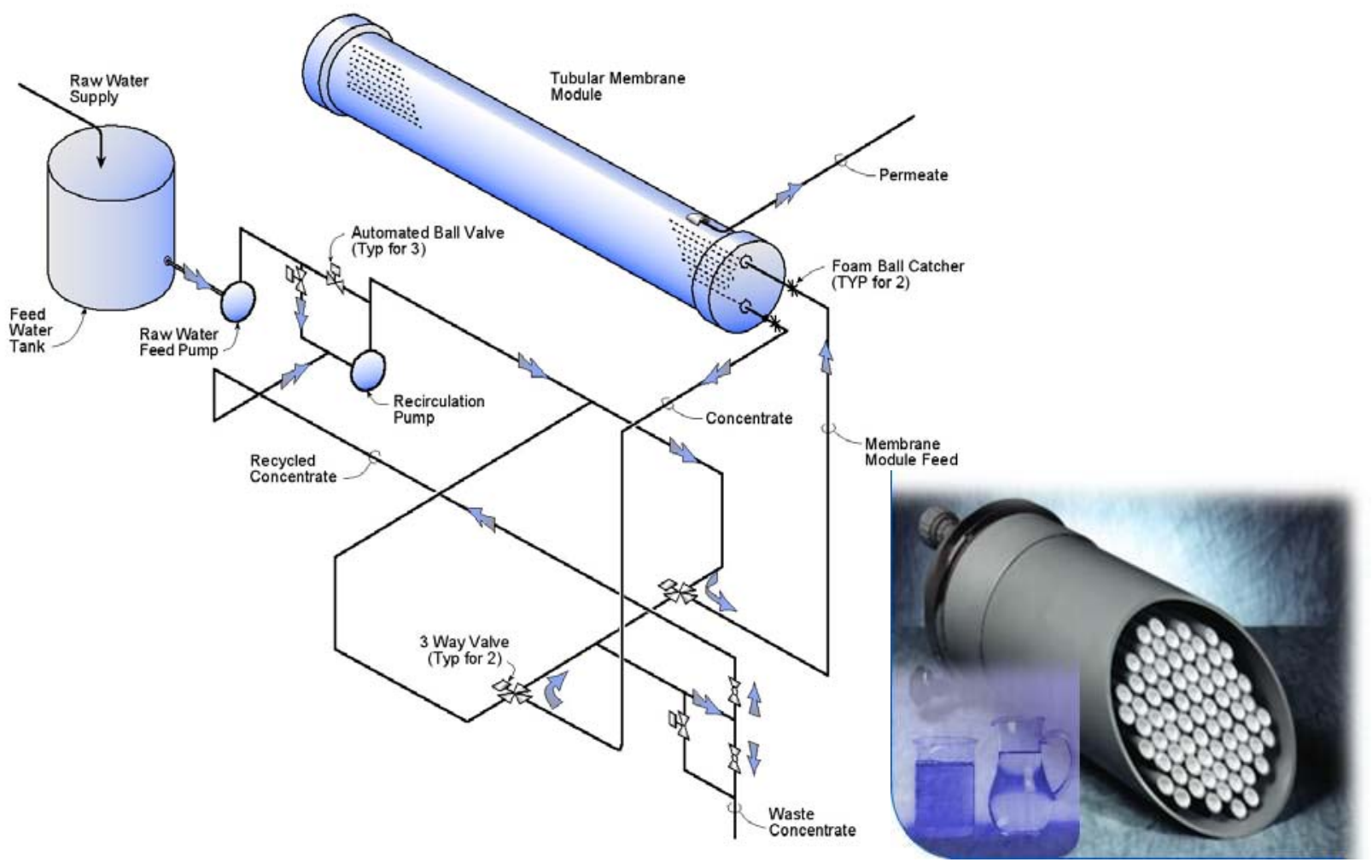

Figure 13- Cutaway section of a Tubular Membrane NF or RO Module (PCI Membrane Systems) and a Schematic of a Tubular Membrane NF or RO System.

The ED process is based upon the premise that most solutes in water are ionic species. Through the application of a direct current across the solution, cations are conveyed towards the anode, while anions migrate towards the cathode. As these ions move through solution, they are routed through charge-specific membranes, and flushed out of the system in concentrated brine solutions. In a fashion similar to the RO process, purified water would be surface applied or employed for beneficial uses, while concentrated brines would be re-injected or subjected to further treatment/disposal. A schematic of a typical ED process is provided in Figure 14.

25 of 69 


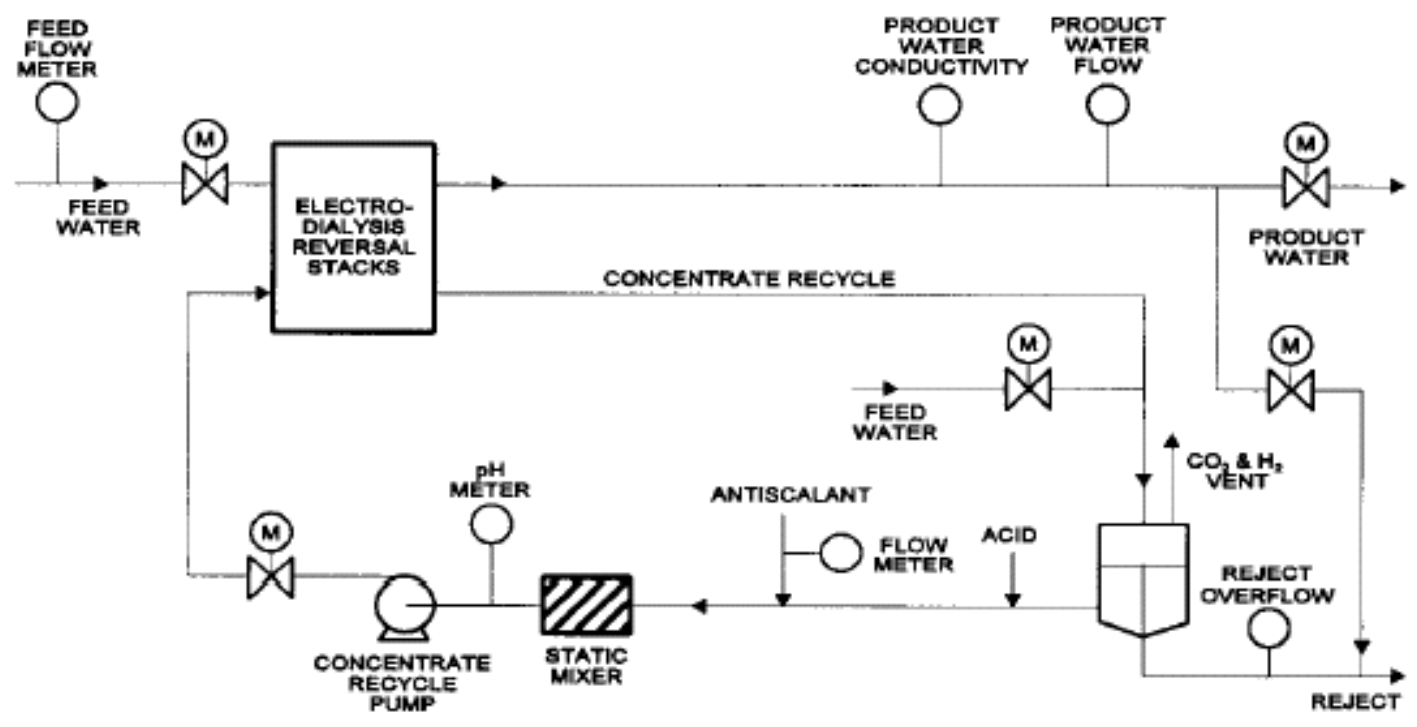

Figure 14 - Schematic of an ED Treatment Process from (Leitz and Boegli 2001)

\section{Use of Membrane Systems for Hydrate Produced Water Treatment}

Since both spiral wound and tubular membranes can effectively remove TDS, selecting the appropriate system depends on a number of factors including:

- Reduction in suspended and dissolved solids required for discharge

- Capital costs of the treatment equipment

- Footprint (which impacts overall building costs)

- Operating costs

- Complexity, redundancy and other factors

Although no membrane systems have been specifically designed for hydrate produced water treatment, reasonable estimates of capital and operations and maintenance costs can be obtained by evaluating drinking water membrane treatment systems. Jones and Woolard (2001) compared the costs of integrated MF/NF and tubular NF system for treating a hypothetical Alaskan drinking water source for system with a capacities ranging from 30,000 to 120,000 gal per day. The cost estimates compiled for this work should be reasonable estimates of costs for treating hydrate produced water with low

\section{6 of 69}


pressure RO or NF membranes. It is important to note that the flux rates assumed by the NF membrane manufactures are approximately 6 gallons per day per square foot (gfd) for both the tubular and spiral wound membranes (see Table 2). This is a relatively low flux rate that could be met in a hydrate produced water RO or NF system.

Table 5 - Membrane System Design Parameters and Scope of Supply

\begin{tabular}{|c|c|}
\hline \multicolumn{2}{|c|}{ Hollow Fiber MF Equipment } \\
\hline $\begin{array}{l}\text { Approximate MF Flux Rate } \\
\text { Membrane } \\
\text { Module Surface Area } \\
\text { Membrane Nominal Pore Size } \\
\text { MF Recovery }\end{array}$ & $\begin{array}{l}20 \text { gfd } \\
\text { Hollow Fiber PVDF } \\
538 \text { sf } \\
0.1 \text { micron } \\
96 \text { percent }\end{array}$ \\
\hline \multicolumn{2}{|c|}{ Sprial Wound NF or RO Equipment } \\
\hline $\begin{array}{l}\text { Approximate NF Flux Rate } \\
\text { Membrane } \\
\text { Hydraulic Array } \\
\text { NF System Overall Recovery } \\
\text { Membrane Element Size } \\
\text { Individual Membrane Element Area }\end{array}$ & $\begin{array}{l}6.1 \text { gfd } \\
\text { Composite Polyamide } \\
\text { Single Pass with Recycle } \\
85 \text { percent } \\
8 \times 40 \text { inch } \\
350 \text { sf }\end{array}$ \\
\hline \multicolumn{2}{|c|}{ Tubular NF or RO Equipment } \\
\hline $\begin{array}{l}\text { Approximate Flux Rate } \\
\text { Membrane } \\
\text { Hydraulic Array } \\
\text { NF System Overall Recovery } \\
\text { Individual Membrane Module Area }\end{array}$ & $\begin{array}{l}6 \text { gfd } \\
\text { Tubular Polyamide } \\
\text { Single Pass with Recycle } \\
80-90 \text { percent } \\
115 \text { sf }\end{array}$ \\
\hline
\end{tabular}

\section{7 of 69}




\begin{tabular}{|l|l|}
\hline \multicolumn{1}{|c|}{ MF Equipment Scope of Supply } & \multicolumn{1}{|c|}{ Spiral Woun Membrane Equipment Scope of Supply } \\
Backwashable Strainer & 8-inch Pressure Vessels \\
Feed Water Tank & 8-inch x 40-inch membrane elements \\
Feed Pump & NF Feed Pump \\
Membrane Modules & Stainless Steel High Pressure Piping, Valves and Fittings \\
Membrane Skid & PVC Schedule 80 Low Pressure Piping \\
Valve Assembly Block & PLC Process Controller \\
Integrity Test System & Flow, Pressure, Temperature, Conductivity Instruments \\
Reverse Flow (RF) Pump & Modem Process Monitoring Capability \\
Compressed Air System & Automatic Concentrate Flushing System \\
Interconnecting Piping for Furnished Equipment & Chemical Dosing System for Scale Inhibitor \\
Process Instrumentation and Controls & CIP System Components \\
Variable Frequency Drives for RF and Feed Pumps & Start Up Assistance and Training \\
Filtrate Turbidimeter & \\
Clean in Place System & \\
Chemical Dosing Pumps for CIP & \\
Spent Cleaning Solution Neutralizing System & \\
Start Up Assistance and Training & \\
\hline
\end{tabular}

Table 6 summarizes the budgetary equipment capital costs for the integrated MF/NF and tubular NF systems. It is important to note that these are costs for the membrane treatment skids only. These data indicate that tubular membrane systems exceed the cost of an integrated MF/NF system for the range of capacity sizes evaluated for this report, and that the difference increases as increases with design flow. As design flow rates increase, additional membrane area can be added to a spiral wound system in far fewer pressure vessels than with a tubular membrane system, and the capital costs for larger tubular membrane equipment reflect this.

Table 6 - Budgetary Capital Costs for Membrane Skids

\begin{tabular}{|c|c|c|c|c|c|c|c|c|c|c|}
\hline \multirow[b]{3}{*}{$\begin{array}{c}\text { Capacity } \\
\text { (gpd) }\end{array}$} & \multirow{2}{*}{\multicolumn{3}{|c|}{ Tubular NF or RO System }} & \multicolumn{7}{|c|}{ Integrated MF/NF or MF/RO Membrane System } \\
\hline & & & & & MF & & & NF or RO & & \\
\hline & Modules & $\begin{array}{c}\text { Membrane } \\
\text { Area }\left(\mathrm{ft}^{2}\right)\end{array}$ & Capital Cost & Modules & $\begin{array}{c}\text { Membrane } \\
\text { Area }\left(\mathrm{ft}^{2}\right)\end{array}$ & Capital Cost & $\begin{array}{c}\text { Membrane } \\
\text { Elements }\end{array}$ & $\begin{array}{c}\text { Membrane } \\
\text { Area }\left(\mathrm{ft}^{2}\right)\end{array}$ & $\begin{array}{c}\text { Capital } \\
\text { Cost }\end{array}$ & $\begin{array}{l}\text { System Capital } \\
\text { Cost }\end{array}$ \\
\hline 30,000 & 44 & 5,060 & $\$ 320,000$ & 4 & 2153 & $\$ 145,000$ & 7 & 4,900 & $\$ 79,000$ & $\$ 224,000$ \\
\hline 60,000 & 88 & 10,120 & $\$ 464,000$ & 7 & 3766 & $\$ 183,000$ & 21 & 9,800 & $\$ 123,000$ & $\$ 306,000$ \\
\hline 90,000 & 132 & 151,080 & $\$ 604,000$ & 11 & 5918 & $\$ 215,500$ & 28 & 14,700 & $\$ 143,000$ & $\$ 358,500$ \\
\hline 120,000 & 176 & 20,240 & $\$ 742,000$ & 13 & 6994 & $\$ 227,200$ & 36 & 19,600 & $\$ 164,000$ & $\$ 391,200$ \\
\hline
\end{tabular}

\section{8 of 69}


Another factor that is often a significant contribution to overall project capital costs, especially in cold climates, is the size of the structure needed to house the treatment system. To determine the relative areas required for MF/NF systems and tubular membrane systems, preliminary floor plans for both were prepared for the process equipment, and compared for the four system capacities presented above. The assumptions made in the preparation of the floor plans to determine system footprint included:

- Floor space for a strainer was provided for both the MF and tubular NF equipment.

- Interior ceiling height for the process floor was limited to 14 feet.

- MF and spiral wound NF membranes were configured as single skids without parallel redundancy. By contrast, tubular NF membranes were configured with multiple parallel modular stacks all operating in parallel and able to maintain production if one stack were out of service for CIP or maintenance.

- Minimum clearances of 2.5 feet were provided around at least three sides of all membrane skids.

- Four feet of clearance on each end of the spiral wound membrane skid was provided on each end for loading and unloading membrane elements. By contrast, an overhead door was provided on one end of the building for removal and replacement of the 12-foot long tubular membrane modules.

- Common clean in place (CIP) equipment including chemical solution tank, tank heater, circulation pump, solution flow meter, and micron filter would be used for both the MF and NF or RO equipment in the dual membrane system configuration.

- Floor space for control panels with a minimum of 36 inches clearance at the front of the panel was provided for each membrane skid.

- An MF backwash surge tank was included to prevent sewer hydraulic overload.

- For the MF/NF alternative, floor space was included for the membrane skids, air compressors, feed pumps, reverse flow pump, raw water break tank, an intermediate break tank for MF filtrate, an MF reverse flow surge tank, and the CIP equipment.

- For the tubular membrane alternative, floor space was included for the membrane module stacks, the recirculation pump, a raw water strainer, system control panel, and CIP equipment.

- No floor space allocations were made for any post treatment chemical addition or chemical storage for fluoridation or chlorination.

\section{9 of 69}


Table 7 summarizes the floor space required for the MF/NF system and the tubular NF system for each of the four capacities considered. The dual membrane MF/NF treatment system occupies a somewhat larger floor area for the 30,000 gpd plant capacity than the tubular NF system. However, for larger capacity systems, the MF/NF system occupies a smaller area due again to the fact that spiral wound membrane elements are more compact in terms of available surface area per unit volume than are the tubular membranes.

\section{Table 7 - Process Equipment Floor Space Requirements}

\begin{tabular}{|ccc|}
\hline $\begin{array}{c}\text { Capacity } \\
\text { (gpd) }\end{array}$ & $\begin{array}{c}\text { MF/NF } \\
\text { Equipment } \\
\text { Floor Space } \\
\text { (sq ft) }\end{array}$ & $\begin{array}{c}\text { Tubular NF } \\
\text { Equipment Floor } \\
\text { Space (sq ft) }\end{array}$ \\
30,000 & 392 & 352 \\
60,000 & 542 & 640 \\
90,000 & 636 & 928 \\
120,000 & 660 & 1,216 \\
\hline
\end{tabular}

Operating costs for the membrane filtration options are the sum of multiple components that include labor, energy, chemicals, and replacement membranes. Factors used to compute these costs are summarized in Table 8 for the MF/NF(or RO) and tubular NF or RO membrane alternatives. The following assumptions were made in estimating system operating costs:

- Labor costs were based on past experience with integrated MF/NF and tubular NF membrane systems and reflect the time required to operate (i.e., make process adjustments, mix chemicals, perform cleaning, monitor process parameters) the treatment system only. Other operator duties like maintaining the disinfection system, performing general housekeeping functions and preparing monthly reports are not included in the labor estimates.

- A power cost of $\$ 0.07$ per $\mathrm{kW}-\mathrm{hr}$ assuming that power is generated on-site using recovered gas.

- Annual membrane replacement costs were calculated assuming a 5-year life. No interest was accrued on money set aside each year for membrane replacement.

\section{0 of 69}


- Operating costs not considered in this comparison include the expenses of repair and replacement of equipment and components, and their associated depreciation costs.

Table 8 - Preliminary Estimates of Operating Costs

\begin{tabular}{|c|c|c|c|c|c|}
\hline \multicolumn{6}{|c|}{ MF/NF or MF/RO Filtration System } \\
\hline $\begin{array}{l}\text { System Capacity } \\
\text { Labor }\end{array}$ & 30,000 & 60,000 & 90,000 & 120,000 & gpd \\
\hline Labor Manhours & 50 & 50 & 50 & \multicolumn{2}{|c|}{$50 \mathrm{hrs} /$ month } \\
\hline Labor Costs Including Benefits & $\$ 50$ & $\$ 50$ & $\$ 50$ & $\$ 50$ & $\$ / h r$ \\
\hline $\begin{array}{l}\text { Annual Labor Cost } \\
\text { Energy }\end{array}$ & $\$ 30,000$ & $\$ 30,000$ & $\$ 30,000$ & $\$ 30,000$ & $\$ / y r$ \\
\hline Energy Used & 5.8 & 11.3 & 17.2 & 21.8 & $\mathrm{~kW}$ \\
\hline Energy Cost & $\$ 0.07$ & $\$ 0.07$ & $\$ 0.07$ & $\$ 0.07$ & $\$ / \mathrm{kWH}$ \\
\hline Annual Energy Cost & $\$ 3,557$ & $\$ 6,929$ & $\$ 10,547$ & $\$ 13,368$ & $\$ / y r$ \\
\hline Chemical Costs & $\$ 6,039$ & $\$ 10,781$ & $\$ 15,617$ & $\$ 23,663$ & $\$ / y r$ \\
\hline Annual Membrane Replacem & $\$ 4,240$ & $\$ 7,980$ & $\$ 12,220$ & $\$ 15,460$ & $\$ / y r$ \\
\hline Total Annual Cost & $\$ 43,836$ & $\$ 55,690$ & $\$ 68,384$ & $\$ 82,491$ & $\$ / y r$ \\
\hline \multicolumn{6}{|c|}{ Tubular NF or RO Filtration System } \\
\hline $\begin{array}{l}\text { System Capacity } \\
\text { Labor }\end{array}$ & 30,000 & 60,000 & 90,000 & 120,000 & gpd \\
\hline Labor Manhours & 15 & 15 & 15 & \multicolumn{2}{|c|}{$15 \mathrm{hrs} / \mathrm{month}$} \\
\hline Labor Costs Including Benefits & $\$ 50$ & $\$ 50$ & $\$ 50$ & $\$ 50$ & $\$ / h r$ \\
\hline $\begin{array}{l}\text { Annual Labor Cost } \\
\text { Energy }\end{array}$ & $\$ 9,000$ & $\$ 9,000$ & $\$ 9,000$ & $\$ 9,000$ & $\$ / y r$ \\
\hline Energy Used & 5.6 & 11.3 & 16.9 & 22.6 & $\mathrm{~kW}$ \\
\hline Energy Cost & $\$ 0.07$ & $\$ 0.07$ & $\$ 0.07$ & $\$ 0.07$ & $\$ / \mathrm{kWH}$ \\
\hline $\begin{array}{l}\text { Annual Energy Cost } \\
\text { Chemicals }\end{array}$ & $\$ 3,434$ & $\$ 6,929$ & $\$ 10,363$ & $\$ 13,858$ & $\$ / y r$ \\
\hline Chemical Costs & $\$ 230$ & $\$ 460$ & $\$ 690$ & $\$ 920$ & $\$ / y r$ \\
\hline Annual Membrane Replacem & $\$ 17,600$ & $\$ 35,200$ & $\$ 52,800$ & $\$ 70,400$ & $\$ / y r$ \\
\hline Total Annual Cost & $\$ 30,264$ & $\$ 51,589$ & $\$ 72,853$ & $\$ 94,178$ & $\$ / y r$ \\
\hline
\end{tabular}

Overall system complexity and redundancy should also be considered when selecting a membrane treatment processes. Larger water systems typically have the resources to effectively operate more complex systems and can handle the added complexity of an integrated membrane process that uses both MF and NF or RO membrane filtration. The tubular NF or RO process uses a single membrane filtration process. There is physically more hardware to maintain with the dual membrane alternative than the single membrane

\section{1 of 69}


alternative, and commensurately more operational labor required to keep the system running.

System complexity will also impact installation costs. Because there is physically more hardware associated with the dual membrane alternative, the costs associated with process piping, mechanical and electrical work required to install the integrated system will likely exceed the costs for a tubular membrane system.

The MF/NF alternatives considered for this analysis were configured with only a single skid for each filtration process. If there is a failure in the performance of an MF module, most MF manufacturers provide for isolating the faulty module and operating with less than full capacity until corrective action is taken. However, if an NF element fails, the faulty equipment cannot be temporarily isolated. By contrast, with tubular NF equipment, a faulty NF module can be isolated, removed from service, and the remainder of the equipment operated until corrective action is taken. If dual NF skids are considered for the $\mathrm{MF} / \mathrm{NF}$ alternative, the capital cost of that alternative would increase.

In summary, capital costs, footprint, operating costs and complexity and redundancy are factors that should be considered when evaluating NF processes. In the analysis conducted to prepare this report:

- Capital equipment costs for MF/NF treatment were lower than for tubular NF treatment over the 30,000 gpd to 120,000 gpd capacity range assuming only a single NF skid is used for the MF/NF alternative.

- Floor space requirements for the tubular NF process equipment were lower for the 30,000 gpd system. The integrated $\mathrm{MF} / \mathrm{NF}$ system required less area for the large capacity systems.

- Operating costs computed as the sum of labor, chemical, energy, and membrane replacement costs are lower for the smaller 30,000 gpd tubular NF system. Somewhere between 30,000 and 60,000 gallons per day capacity, the operating costs become lower for the MF/NF system.

- An integrated $\mathrm{MF} / \mathrm{NF}$ system is typically more complex than a tubular system and as a result, will have additional operation and installation costs relative to a tubular NF system. These costs are offset by the lower capital cost of the integrated $\mathrm{MF} / \mathrm{NF}$ system at higher flow rates.

\section{2 of 69}




\section{Conceptual Design of Hydrates Water and Wastewater Infrastructure}

Figure 15 is a conceptual schematic of a wastewater treatment system for a gas hydrate production platform. Domestic and certain industrial wastes are treated biologically in a membrane bioreactor (MBR) or other appropriate treatment system. Effluent from an MBR would be of a quality that it could be used for certain process applications. Reuse is also an option.

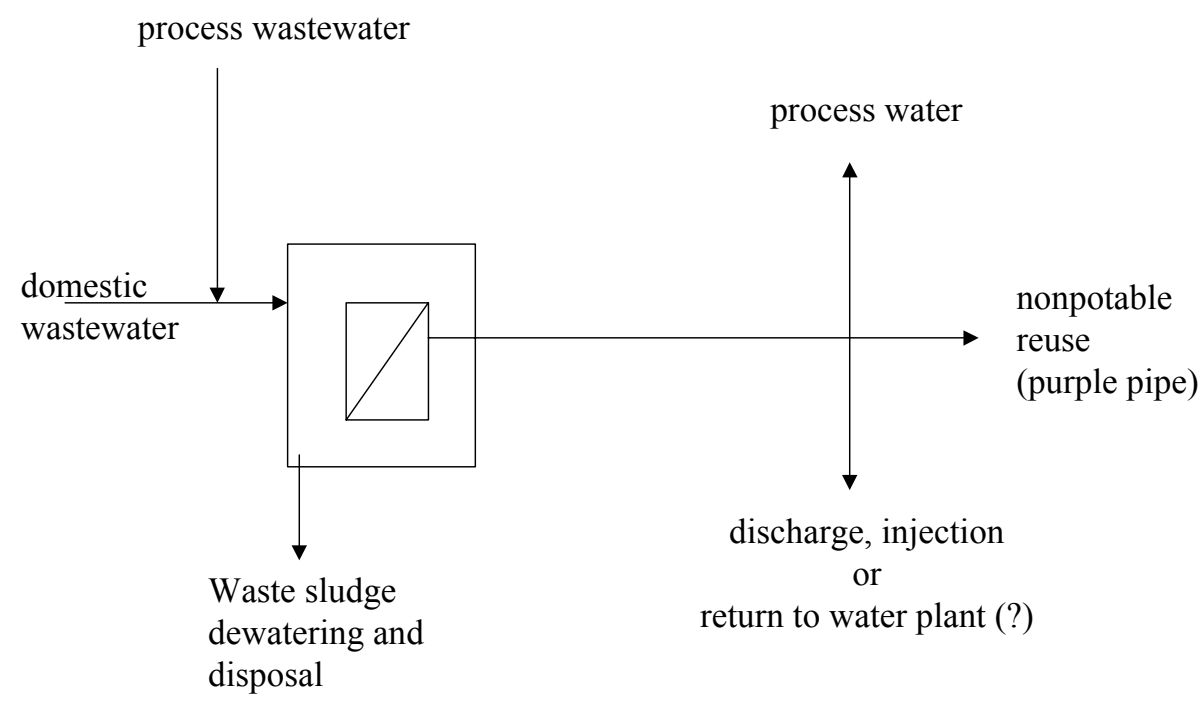

Figure 15 - Conceptual Design of an Integrated Wastewater Treatment System for Gas Hydrate Exploration and Production

\section{Overview of Membrane Wastewater Treatment Processes}

The membrane bioreactor (MBR) wastewater treatment systems are a suspended growth activated sludge treatment process that uses a mixed culture of microorganisms to treat wastewater. The MBR system uses banks of microfiltration (0.085-0.2 micron pore size) membranes suspended in the aeration chamber provide solids separation. Membrane modules eliminate the need for a separate secondary clarifier. These membranes, which resemble large bundles of "spaghetti" or flat sheets, are immersed at the end of the aeration basin. A vacuum is applied that draws treated wastewater through the membrane unit leaving the solids in the aeration basin. An aerator located at the base of each membrane units agitates the membranes and scours the membrane surface to prevents the accumulation of solids on the membrane surface. Several times each hour, the membrane units are backwashed with stored permeate (i.e., treated effluent) or allowed to agitate without vacuum applied to dislodge any accumulated solids. MBR's require only a primary screen for pretreatment. As a result of this positive clarification process the

\section{3 of 69}


system is easily automated and maintained, while providing an extremely consistent tertiary quality reclaimed water

MBR's are extremely compact because biological treatment, clarification and digestion all occur within the same aerated bioreactor. MBR's also typically operate at much higher mixed liquor concentrations (i.e. 12,000 to $15,000 \mathrm{mg} / \mathrm{L}$ ) than the other treatment processes. As a result, the size of the reactor is 3 and 5 times smaller than more conventional treatment processes. The membrane units also provide solids separation that is largely independent of influent flow rate, strength and sludge properties making the system easy to operate and extremely reliable.

The MBR process produces a state-of-the-art treated effluent that exceeds secondary treatment standards. A system with a hydraulic residence time of less than 6 hours has been proven to be able to consistently produce an effluent with less than $5 \mathrm{mg} / \mathrm{L}$ BOD and suspended solids. A several log reduction in fecal coliforms (prior to disinfection) can also be achieved. The membrane modules allow MBR's to operate at long sludge ages that reduce the amount of waste sludge produced, and will significantly reduce the costs associated with hauling sludge. Nutrient removal is possible with minor modifications.

The MBR process requires very little operator attention. Unlike other processes, the physical separation of solids from the final treated effluent is accomplished by the membranes and does not require the operator attention or training necessary for other biological treatment systems. Many MBR plants are operated remotely with only daily local inspection and operator attention every several weeks. Some additional advantages the MBR technology has for oil and gas exploration and production include:

- Ease of operation with highly variable flows: The MBR is also a robust system that is easy to operate under variable wastewater flow conditions without deterioration in effluent quality.

- High quality effluent: The MBR produces an effluent of such quality that if can often be discharged to sensitive receiving environments without further treatment.

- Reduced Size: The use of membrane modules within the reactor reduces the size of the reactor. Small footprint systems require less space at the site and reduce the cost of heating the treatment facility.

\section{4 of 69}


- Packaged Systems: Modular MBR systems can be constructed off-site and delivered as a fully functional, containerized unit ready for connection to the influent and effluent piping and power.

A general process schematic for a typical MBR wastewater treatment system is shown in Figure 16. Screened wastewater is pumped from the primary treatment process directly into the MBR basins for secondary treatment. Treated effluent from the MBR is decanted into an effluent equalization basin and then pumped through a dsinfection system (if necessary) to the final discharge location. Waste sludge produced during biological treatment is pumped to an aerobic digester. Digested sludge is dewatered prior to final disposal. Screenings collected from the rotary drum screen are dewatered and compacted prior to final disposal.

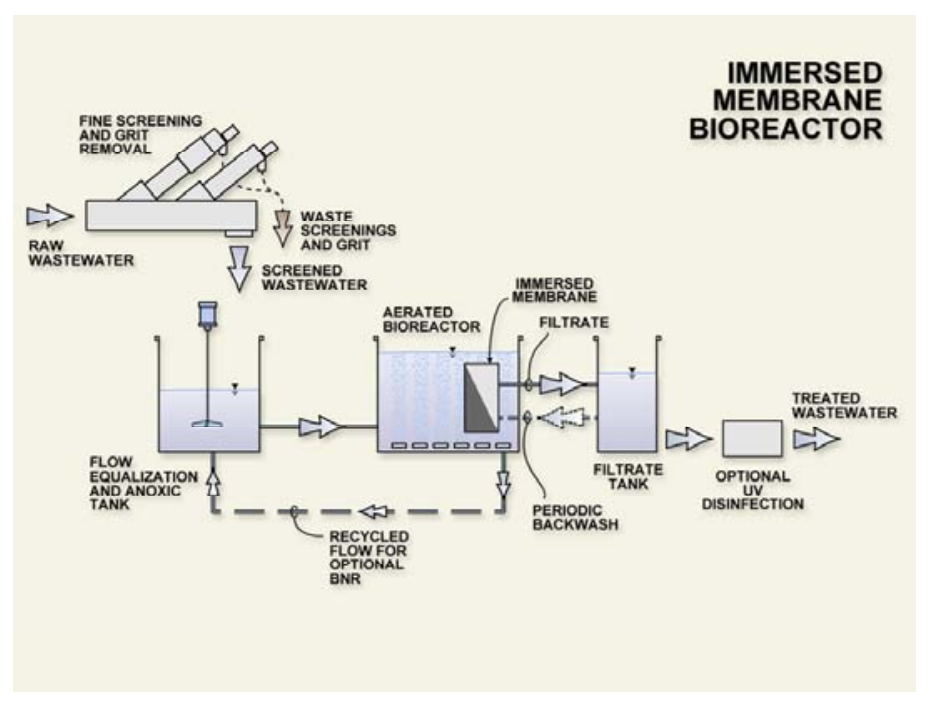

\section{Figure 16 - Flow Schematic for a Typical MBR}

Three types of submersible membranes are commercially available at this time. As shown in Figure 17, immersed hollow several manufacturers provide fiber membranes with either a vertical or horizontal orientation. Kubota, Inc manufactures a system of submersible flat sheet membranes.

Table 9 provides a rough order or magnitude capital cost estimate for a MBR system designed to treat an average daily wastewater flow of 45,000 gallons per day. In addition to the MBR treatment equipment, an equipment cost estimate for a sludge press has also

\section{5 of 69}


been included in the estimate. Note that the costs listed in Table 9 are for equipment only. Additional costs for engineering, construction and startup would also be incurred.

Table 9 - ROM Equipment Cost Estimate for a 45,000 gpd MBR Wastewater Treatment System

\begin{tabular}{|c|c|c|c|c|}
\hline Description & Quantity & Units & Unit Cost & Total Cost \\
\hline Fine Screen & 1 & Each & $\$ 25,000$ & $\$ 25,000$ \\
\hline Sreenings Chute and Hopper & 1 & Each & $\$ 5,000$ & $\$ 5,000$ \\
\hline Sreenings Transfer Pump w/spare & 2 & Each & $\$ 3,000$ & $\$ 6,000$ \\
\hline Equalization Basin (30k gal) & 1 & Each & $\$ 38,000$ & $\$ 38,000$ \\
\hline Blowers & & Each & $\$ 6,000$ & $\$ 12,000$ \\
\hline Level Sensors & & Each & $\$ 5,000$ & $\$ 10,000$ \\
\hline Screened Influent Transfer Pumps & & Each & $\$ 12,000$ & $\$ 24,000$ \\
\hline $\begin{array}{l}\text { MBR Equipment Package (includes } \\
\text { control system, blowers, membranes and } \\
\text { membrane tank(s), process pumps and } \\
\text { associated instrumenation for the MBR } \\
\text { process) }\end{array}$ & & Each & $\$ 500,000$ & $\$ 500,000$ \\
\hline On-Line Suspended Solids Analyzer & & Each & $\$ 5,000$ & $\$ 5,000$ \\
\hline Effluent Holding Basin (4k gal) & & Each & $\$ 8,500$ & $\$ 8,500$ \\
\hline Effluent Transfer Pumps & 2 & Each & $\$ 3,000$ & $\$ 6,000$ \\
\hline Effluent UV & & Each & $\$ 20,000$ & $\$ 20,000$ \\
\hline Effluent Flow Meter & 1 & Each & $\$ 5,500$ & $\$ 5,500$ \\
\hline Sludge Holding Tank (4k gal) & 1 & Each & $\$ 8,500$ & $\$ 8,500$ \\
\hline Sludge Transfer Pump w/spare & 2 & Each & $\$ 3,000$ & $\$ 6,000$ \\
\hline Sludge Decant Pumps & 3 & Each & $\$ 1,500$ & $\$ 4,500$ \\
\hline Sludge Flow Meter & 1 & Each & $\$ 5,500$ & $\$ 5,500$ \\
\hline $\begin{array}{l}\text { Sludge Press and Appurtenances (20- } \\
30 \% \text { dry solids) }\end{array}$ & & $\begin{array}{l}\text { All } \\
\text { Inclusive }\end{array}$ & $\$ 160,000$ & $\$ 160,000$ \\
\hline Refrigerated Samplers & & Each & $\$ 4,000$ & $\$ 8,000$ \\
\hline Drain Pump/Sump & 1 & Each & $\$ 4,000$ & $\$ 4,000$ \\
\hline $\begin{array}{l}\text { Laboratory Equipment (oven, scale, kits, } \\
\text { glassware, misc) }\end{array}$ & & $\begin{array}{l}\text { All } \\
\text { Inclusive }\end{array}$ & $\$ 10,000$ & $\$ 10,000$ \\
\hline TOTAL & & & & $\$ 871,500$ \\
\hline
\end{tabular}

\section{6 of 69}



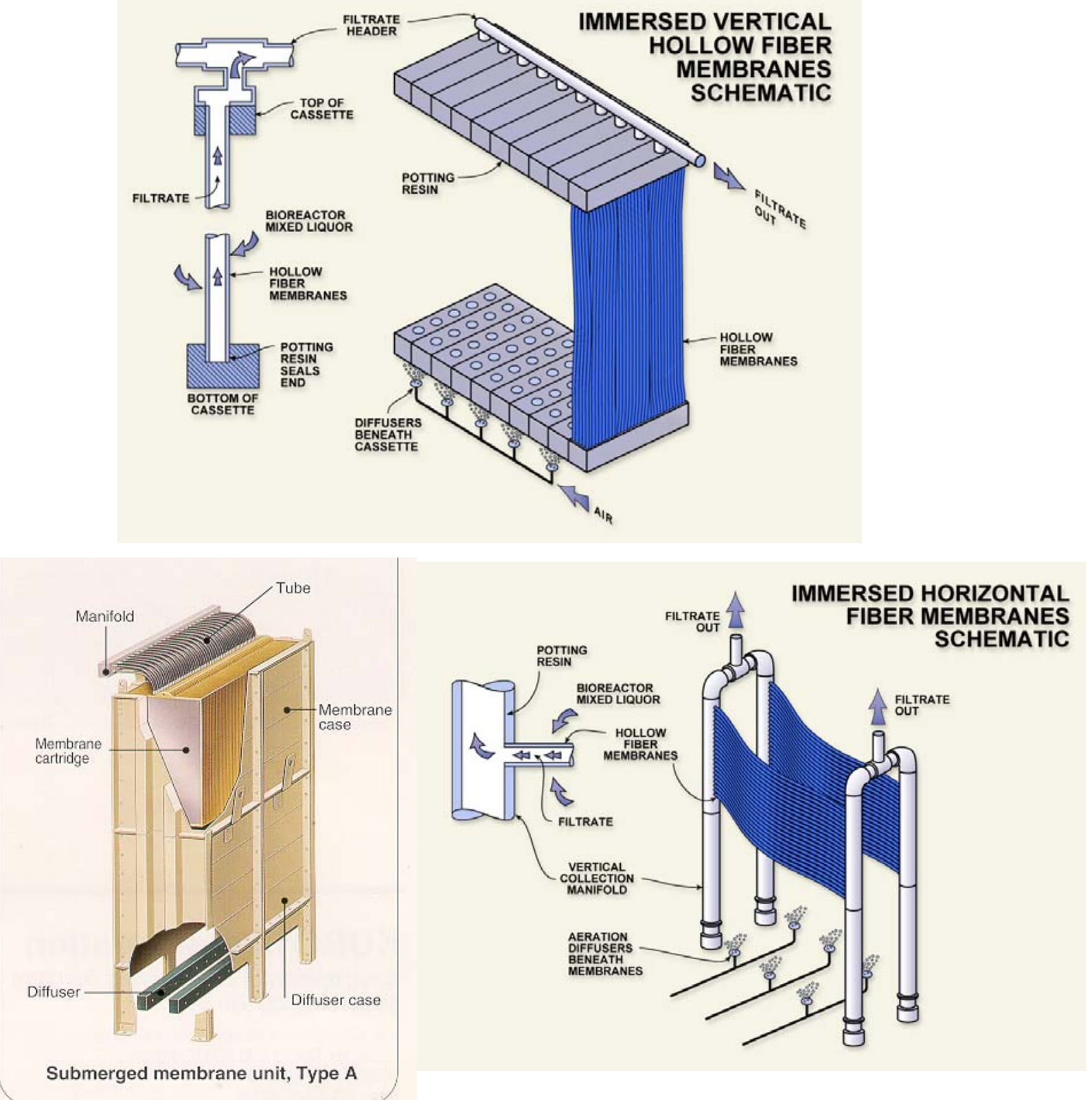

Figure 17 - Types of Membranes Commercially Available for Wastewater Treatment (Zenon, Inc. manufactures vertical immersed hollow fiber membranes. Mitsubishi, Inc. manufactures horizontal hollow fiber membranes, which are sold in the US market through Ionics, Inc. Kubota, Inc. manufactures immersed flat sheet membranes, which are sold in the US market through Enviroquip) 


\section{Produced Water and Wastewater Disposal Options}

There are several potential disposal options for handling the water generated during hydrate production and the effluent from the wastewater treatment facilities. Reinjection of the wastewater and produced water into a separate formation will likely be the preferred option when available. Depending upon the type of reinjection technology used and the characteristics of the injection formation, little to no treatment may be required. In locations where reinjection is not feasible, surface discharge may be an option. Based on the anticipated water quality, treatment of the produced water would be required for surface discharge on the North Slope of Alaska. Finally, evaporation of produced water and wastewater is also an option for locations where neither reinjection nor surface discharge are options. The following sections summarize the technical and regulatory considerations for hydrate produced water disposal.

\section{Reinjection}

In reinjection, water produced during hydrate generation is pumped into a formation isolated from the hydrate-bearing zone. Since produced water from hydrate reserves is anticiapted to contain only dissolved salts and gasses and limited suspended solids, the feasibility of reinjection depend upon the proximity of a suitable formation to the hydrate-bearing strata.

\section{Regulatory Considerations}

Water generated during hydrate production is waste uniquely associated with the production of natural gas from hydrate reserves and as such, it should be classified as an exempt from regulation under Subtitle $\mathrm{C}$ of the Resource Conservation and Recovery Act (RCRA). Reinjection of this produced water would be regulated under the Underground Injection Control program of the Safe Drinking Water Act. Hydrate related produced water could be injected into a Class II D disposal well. Injection of produced water in a Class IID well will require demonstration that the practice will not adversely impact any underground sources of drinking water.

\section{Injection Technology}

Reinjection of produced water can be accomplished using surface reinjection pumps or down hole injection systems. Surface injection pumps require that produced water be lifted to the surface, treated to remove dissolved gasses and suspended solids if necessary, and then reinjected into a separate formation.

\section{8 of 69}


Down hole injection systems utilize pumps located in the production well bore to separate produced water and reinject this fluid into a deeper formation. Down hole technology eliminates the need to lift produced water to the surface and the associated handling costs and environmental issues. Hand et al. (1999), in a technical evaluation of down hole injection technology for the Gas Research Institute, indicated that gas wells that are proximate to the injection zone and have minimal sand production and tendency to scale are good candidates for down-hole injection technology. Down-hole gas/water separation technologies were determined to be economical in wells that generate 25-50 barrels of produced water per day and have produced water disposal costs of more than $\$ 1 /$ barrel.

Hand et al. (1999) evaluated 4 types of down hole pumping equipment. Bypass tools (see Figure 17) allow produced water to flow from the formation and accumulate in the casing-tubing annulus. The pump draws water into the pump chamber during the upstroke, pushes it through the standing valve and into the tubing. The standing valve acts as a check on the pump downstroke preventing the water from draining out of the tube. When sufficient hydrostatic head has accumulated in the tube, the produced water drains into the injection formation by gravity. Bypass tools typically pump between 200 and 400 barrels of water per day.

Modified plunger rod pumps draw water into the pump barrel during the upstroke and then discharge the barrel contents into the disposal formation located below the production zone. Modified plunger pumps typically move between 800 and 1000 barrels of water per day. Electric submersible pumps and progressive cavity pumps can also be located down hole.

\section{Surface Discharge}

In circumstances where produced waters must be surface discharged, the major components of concern will likely be dissolved salts. Consequently treatment technologies to reduce the salt content will constitute the primary unit process in a treatment train.

\section{9 of 69}




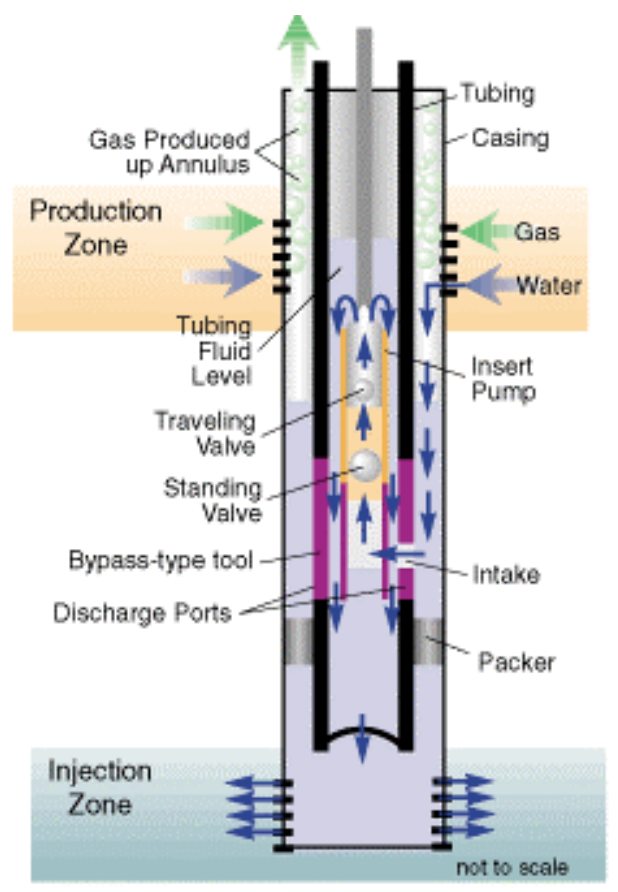

Figure 17 - Schematic of a Down-Hole Bypass Pump (From Hand et al. , 1999)

\section{Regulatory Considerations}

If treated produced water is to be discharged onto the tundra or into North Slope waterbodies, permits will be required from Alaska Department of Natural Resources (DNR), Alaska Department of Fish and Game (ADF\&G), and Alaska Department of Environmental Conservation (ADEC). A DEC official (Kukla 2002) explained that all three agencies will likely grant a discharge permit if the effluent meets the Alaska Water Quality Standards stipulated in 18 AAC 70. Unless a variance is authorized, effluent water will be required to satisfy the most stringent standard applied for water use classes 1(A) and 1(b), water supply and water recreation respectively. The applicable standards and most stringent use classification are listed in Table 2.

The Alaska Water Quality Standards do provide for the utilization of mixing zones, as described in 18 AAC 70.240 through 18 AAC 70.270. Consequently, discharge waters

\section{0 of 69}


could potentially exceed the standards listed above within a freshwater mixing zone, provided an appropriate permit is obtained.

Table 9 - Alaska Water Quality Criteria

\begin{tabular}{|c|c|c|}
\hline Standard & Criteria & Class \\
\hline Dissolved Oxygen & Not less than $7.0 \mathrm{mg} / \mathrm{l}$. & 1(A)iii \\
\hline $\mathrm{pH}$ & $\begin{array}{l}\text { Not less than } 6.5 \text { or greater than } 8.5 . \text { Must not alter } \\
\text { baseline by more than } 0.5 \text { units. }\end{array}$ & 1(A)iii \\
\hline Turbidity & $\begin{array}{l}\text { Not greater than } 5 \text { NTU above baseline when baseline } \\
\text { is } 50 \text { NTU or less. Not greater than } 10 \% \text { above } \\
\text { baseline for baselines greater than } 50 \% \text {, not to exceed } \\
\text { a maximum increase of } 15 \text { NTU. Not greater than } 5 \\
\text { NTU increase in lakes, regardless of baseline. }\end{array}$ & $1(\mathrm{~B}) \mathrm{i}$ \\
\hline Temperature & May not exceed 15 degrees Celcius. & $1(\mathrm{~A}) \mathrm{i}$ \\
\hline $\begin{array}{l}\text { Dissolved Inorganic } \\
\text { Substances }\end{array}$ & $\begin{array}{l}\text { TDS from all sources may not exceed } 500 \mathrm{mg} / \mathrm{l} \text {. } \\
\text { Neither chlorides nor sulfates may exceed } 250 \mathrm{mg} / \mathrm{l} \text {. }\end{array}$ & $1(\mathrm{~A}) \mathrm{i}$ \\
\hline Sediment & $\begin{array}{l}\text { No measurable increase in settleable solids above } \\
\text { baseline conditions, as determined by Imhoff cone } \\
\text { method. }\end{array}$ & $1(\mathrm{~A}) \mathrm{i}$ \\
\hline $\begin{array}{l}\text { Toxic and Other Deleterious } \\
\text { Organic or Inorganic } \\
\text { Substances }\end{array}$ & $\begin{array}{l}\text { Standards may not exceed Alaska Drinking Water } \\
\text { Standards (18 AAC 80), or where those standards do } \\
\text { not exist, EPA Quality Criteria for Water }\end{array}$ & $1(\mathrm{~A}) \mathrm{i}$ \\
\hline Color & $\begin{array}{l}\text { May not exceed } 15 \text { color units or the natural condition, } \\
\text { whichever is greater }\end{array}$ & $1(\mathrm{~A}) \mathrm{i}$ \\
\hline $\begin{array}{l}\text { Petroleum Hydrocarbons, } \\
\text { Oil and Grease }\end{array}$ & $\begin{array}{l}\text { May not cause a visible sheen upon the surface of the } \\
\text { water }\end{array}$ & $1(\mathrm{~A}) \mathrm{i}$ \\
\hline Radioactivity & $\begin{array}{l}\text { May not exceed Alaska Drinking Water Standards (18 } \\
\text { AAC } 80 \text { ): } \\
\text { Gross alpha radioactivity (including }{ }^{226} \mathrm{Ra} \text {, but } \\
\text { excluding } \mathrm{Rn} \text { and } \mathrm{U}): 15 \mathrm{pCi} / \mathrm{l} \text {; Combined }{ }^{226} \mathrm{Ra} \text { and } \\
{ }^{228} \mathrm{Ra}: 5 \mathrm{pCi} / \mathrm{l} ;{ }^{90} \mathrm{Sr}: 8 \mathrm{pCi} / \mathrm{l} \text {; Tritium: } 20,000 \mathrm{pCi} / \mathrm{l} \text {; } \\
\text { Gross beta radioactivity: } 4 \text { mrem. } \\
\text { Also may not exceed standards in } 10 \mathrm{CFR} 20 \text {, or } \\
\text { National Bureau of Standards Handbook } 69 \text {. }\end{array}$ & $1(\mathrm{~A}) \mathrm{i}$ \\
\hline Residues & $\begin{array}{l}\text { May not, alone or in combination with other } \\
\text { substances or wastes, make the water unfit or } \\
\text { unsafe for the use, cause a film, sheen, or discoloration } \\
\text { on the surface of the water or adjoining shorelines, } \\
\text { cause leaching of toxic or deleterious substances, or } \\
\text { cause a sludge, solid, or emulsion to be deposited } \\
\text { beneath or upon the surface of the water, within the } \\
\text { water column, on } \\
\text { the bottom, or upon adjoining shorelines. }\end{array}$ & $1(\mathrm{~A}) \mathrm{i}$ \\
\hline
\end{tabular}

*Table exerpted from 18 AAC 70.020

\section{1 of 69}


If tundra discharge is determined to be a viable disposal option and large-scale disposal is planned, it is possible to petition for inclusion onto the National Pollutant Discharge and Elimination System (NPDES) General Permit for North Slope oil and gas extraction facilities (NPDES Permit \# AKG-31-0000). An EPA official familiar with the permit indicated that although inclusion of tundra discharge is indeed possible, the negotiated standards would likely be similar to the standards stipulated by the Alaska water quality standards (Godsey 2002).

\section{Evaporation}

Evaporation represents a potential mass reduction technique for produced waters and wastewaters at North Slope well sites. The primary benefit of employing evaporation is that it allows for the possibility of near zero waste discharge. Additionally, a clear advantage to evaporation techniques is that the fuel necessary to drive the process can be readily obtained from gas produced at the wellhead.

The quantity of fuel required to evaporate wastewaters (produced, industrial, or domestic) will likely dictate the cost effectiveness of the process. It was stated previously that an ideal Structure I hydrate will produce approximately $0.78 \mathrm{ft}^{3}$ of water per $179 \mathrm{ft}^{3}$ of methane $\left(229 \mathrm{ft}^{3}\right.$ methane $/ \mathrm{ft}^{3}$ water at $\left.60^{\circ} \mathrm{F}\right)$. As the hydrate numbers of naturally occurring hydrates are most often between $6-8$, a natural system will likely produce between $165-220 \mathrm{ft}^{3}$ methane $/ \mathrm{ft}^{3}$ water (assume $189 \mathrm{ft}^{3}$ methane/ $\mathrm{ft}^{3}$ water).

Assuming a 100\% efficient evaporation system, it would require approximately $68 \mathrm{ft}^{3}$ methane $/ \mathrm{ft}^{3}$ water, or $36 \%$ of the total gas produced, to completely evaporate all of the associated hydrate water. Assuming a process efficiency of $70 \%$ (a frequent manufacturer's claim), $98 \mathrm{ft}^{3}$ ( $52 \%$ of total) would be required to totally eliminate the hydrate water from a well producing $189 \mathrm{ft}^{3}$ methane $/ \mathrm{ft}^{3}$ water.

As the amount of methane necessary to evaporate hydrate waters constitutes a large fraction of the methane produced at any given well, evaporation only becomes cost effective if the volume of hydrate waters requiring disposal is significantly less than the theoretical volume of water dissociated during production. If the volume of connate water actually retrieved is less than the amount dissociated, then evaporation could be weighed against re-injection, filtration, or offsite disposal as a treatment option. If, on the other hand, large volumes of connate waters were retrieved, then evaporation could be used in conjunction with membrane systems to reduce the waste volume to a minimum. This multi step waste reduction process could be optimized to maximize cost savings resulting from lower disposal costs of reduced waste volumes.

\section{2 of 69}


Commercial evaporative treatment systems vary considerably by mechanism, design, capacity, and cost.

- Forced air type evaporators (e.g. Synthermic Wastewater Evaporator) are relatively energy efficient, as they rely on atmospheric input to overcome the latent heat of vaporization. Such systems would not likely be effective on the North Slope, however, due to the extremely cold temperatures.

- Steam pipe evaporators (e.g. Landa Water Blaze) force hot gasses through a water filled evaporation chamber. Due to the presence of hot gas bubbles in the liquid, the heat transfer efficiency of these systems is theoretically higher than efficiencies for bottom heated or submersed coil type systems. Although boilertype systems (e.g. steam pipe, bottom heated, or submersed coil) require more energy than forced air evaporators in order to overcome the latent heat of vaporization, boiler systems are less dependant on atmospheric conditions. Corrosion can be a problem in any boiler type system, as the increased temperatures tend to amplify the corrosive effects of the fluids.

- Thermal oxidation systems (e.g. Thermo Oxidizer) subject an atomized flow stream to an open flame, thus vaporizing the stream and elevating the steam temperature to $800-1200{ }^{\circ} \mathrm{C}$. The primary advantage of this type of system is that solids in the influent fluids are reduced to a dry ash. Additionally, dissolved components (e.g. methane, TPH, etc.) are oxidized in the process, thus minimizing hazardous stack emissions. Finally, corrosion is theoretically minimized in these systems compared to boiler systems, as there is no requirement for hot liquid water to be in contact with metal surfaces. The primary disadvantage of such systems is that energy is consumed in raising the temperature of the steam, and consequently these systems require more energy that boiler type systems.

\section{3 of 69}




\section{Geochemistry Related to Gas Hydrate Exploration and Development in the North Slope Permafrost Regions, Alaska}

\section{Review of geologic setting and occurrence of gas hydrates in the Prudhoe Bay-Kuparuk River areas}

The focus of traditional exploration for both petroleum and gas hydrates focuses on subsurface traps and the play concept in sedimentary basins described according to tectonic style (Collett 1993). A play consists of prospects and fields with similar geology (reservoir, cap rock, style of trap). The general concept of a play is to use the characteristics of discovered accumulations to predict similar undiscovered accumulations. However, basing interpretations mainly on tectonic style may be somewhat limiting to the discovery of new play types especially related to methane gas hydrates that exist in the North Slope because little is known about the geologic parameters controlling their distribution(Collett 1993).

Direct evidence for gas hydrates on the North Slope of Alaska comes from a core test and other indirect evidence comes from drilling and open-hole well logs that suggest many gas hydrate layers in the area of Prudhoe Bay and Kuparuk River oil fields(Collett 1993). Other locations including the Mackenzie River Delta and the Arctic Islands have inferred gas hydrates as well(Judge 1988; Judge 1992). The combined data from arctic gas hydrate studies shows that in permafrost regions, gas hydrates may exist between a range of depths of 130 to 2,000 m (Kvenvolden 1993) Global estimates of the amount of natural gas in permafrost related hydrate deposits range from $5.0 \times 10^{2}$ to $1.2 \times 10^{6}$ trillion cubic feet (TCFG) (Kvenvolden 1993).

In the case of the North Slope gas hydrates, two plays have been identified as the Topset play and the Fold Belt play (Collett 1993). Both of these plays are generalized due to the lack of knowledge of the size and distribution of individual gas hydrate accumulations that may exist within each of the plays defined. Collett (1993) defines the Alaska gas hydrate province as an area extending $950 \mathrm{~km}$ from the Chukchi Sea on the west to the Canadian border on the east with a maximum width of $320 \mathrm{~km}$ with a total area of $140,000 \mathrm{~km}^{2}$.

\section{General Geology}

Extensive studies of the geology and petroleum geochemistry of the northern Alaska region have been done by(Lerand 1973; Grantz 1975; Carman 1983; Bird 1987; Gyrc 1988). In summary the sedimentary rocks of northern Alaska are divided into three 44 of 69 
sequences, which indicate major episodes of tectonic development in the region as well as the lithologic characteristics (Collett, 1993). In terms of source area according to Lerand (1973) and application to northern Alaska by Grantz et al. (1975) the three sequences are the Franklinian (Cambrian through Devonian), the Ellesmerian (Mississippian to Lower Cretaceous), and the Brookian (Lower Cretaceous to Holocene).

According to Collett (1993), the only confirmation of natural-gas hydrates in the Alaska gas hydrate province was obtained in 1972 by ARCO and Exxon when a core containing gas hydrates was recovered. Well-log data from an additional 445 Alaska wells were examined for gas hydrate occurrences (Collett, 1993), which showed that gas hydrates occurred in approximately 50 of the surveyed wells. These wells have multiple gas hydrate units that range in thickness from 3 to $31 \mathrm{~m}$. There appear to be six laterally continuous sandstone and conglomerate units to the east of the Kuparuk River production unit and to the west of the Prudhoe Bay production unit. In addition, there is evidence from open-hole logs that a large free-gas accumulation exists downdip below four (C-F) of the hydrate units. The total estimated gas hydrates excluding the associated free gas in the Prudhoe Bay-Kuparuk River is approximately 37 to 44 trillion cubic feet (at STP) (Collett, 1993).

Two gas hydrate plays have been defined for the northern Alaska region; the Topset play and the Fold Belt play. The Topset play consists of stratigraphic traps and sandstone reservoirs of Creatceous and Tertiary age and is indicated structurally as a clinaform sequence on seismic records, which are relatively undeformed rocks that exist north of the Brooks Range fold belt. These rocks are part of the Nanushuk Group and the Sagavanirktok Formation that include marine and nonmarine deltaic sandstone, siltstone, shale, conglomerate, and coal. The methane-hydrate stability zone is up to $1,000 \mathrm{~m}$ within the area of the Prudhoe Bay field and the northern offshore limit of the stability zone corresponds to the $50 \mathrm{~m}$ bathymetric contour. Reservoir rocks consist of sandstone and conglomerate with beds up to $20 \mathrm{~m}$ and may account for up to $75 \%$ of the total gashydrate stability zone. Probable source rocks within the play are immature interbedded deltaic shales and mudstones. Below the stability zone are thermally mature gas sources, which likely contribute to the known gas-hydrate accumulations in the Prudhoe BayKuparuk River area (Collett, 1993). Expected traps are mostly stratigraphic and are related to facies changes, or traps formed against small-displacement normal faults, both of which would provide only fair to poor conventional caps (Collett, 1993).

The Fold Belt play consists of anticlinal traps in Cretaceous and Tertiary sandstone reservoirs in the northern part of the Brooks Range fold belt. This play is sandwiched between the Brooks Range thrust belt to the south and the rocks of the undisturbed deposits of the Topset play. The Chukchi Sea borders on the west and the eastern border extends offshore to the 50-m bathymetric contour in the Beaufort Sea. The eastern part

\section{5 of 69}


of the play exists in rocks of the Sagavanirktok and Canning Formations, Hue Shale, a pebble shale unit, and Kemik Sandstone. The western part of the play includes parts of the Nanushuk Group and Torok Formation. The methane-hydrate stability zone reaches a maxiumum thickness of about $500 \mathrm{~m}$ and only half of the play has appropriate thermal conditions for the existence of gas hydrates. Potential reservoirs are sandstone units of deltaic and shallow-marine environments with expected porosities of 5 to $20 \%$. Source rocks include gas-prone shale units of the Nanushuk Group and the Sagavanirktok, Torok, and Canning Formations. These source rocks range from immature to mature. Fault-cored anticlines related to Brooks Range thrusting form traps in this play and updip stratigraphic pinchouts on the flanks of anticlines may provide traps as well. The shales likely provide fair to good seals, although due to faulting the effectiveness of these seals may be reduced.

\section{Geochemistry}

The four main areas of technological contributions of modern geochemistry to petroleum exploration include 1) petroleum systems and exploration risk, 2) biomarkers, isotopes, and multivariate statistics for genetic oil-oil and oil-source rock correlation, 3) calibrated three-dimensional (3D) basin modeling, and 4) controls on petroleum occurrence and composition related to secondary processes(Peters 2002). These four areas may be applied in some fashion to the exploration of methane gas hydrates since their sources are often related, however, the occurrence of on-shore methane hydrates in the North Slope permafrost regions of Alaska are generally much shallower than petroleum deposits and therefore will likely pose different problems.

Understanding the geochemical characteristics of gas hydrates and associated pore waters may lead to enhanced exploration and development techniques. Gas chemistry, pore water salinity, and isotopic composition of gases and water associated with gas hydrates are the current areas of interest related to developing and exploring for gas hydrates. Most of the literature focuses on marine gas hydrates because they have been studied more extensively than terrestrial gas hydrates. However, it is possible that some of the same principles used to understand marine gas hydrates could be related to terrestrial gas hydrates.

\section{Gas Chemistry}

Analyses of gas hydrates that have been recovered indicate that the gas composition is predominately methane ( $>99 \%$ ) and biogenic. However, gas hydrates may contain mostly thermogenic gas or mixture of thermogenic and biogenic gases. Thermogenic gases generally migrate from deep reservoirs along structurally controlled paths and form gas hydrates within in the appropriate temperature-pressure regime that is controlled

\section{6 of 69}


primarily by the presence of permafrost in the North Slope region. Biogenic gas produced by microbial activity generally forms at more shallow depths. Thermogenic and biogenic gases can be distinguished based on their carbon isotopic compositions. A $\delta^{13} \mathrm{C}$ in methane of -60 per mil or lighter relative to PDB standard suggests microbial formation and $\delta^{13} \mathrm{C}$ heavier than about -50 per mil indicates a thermogenic source(Kvenvolden 1993). This depletion in $\delta^{13}$ occurs as bacteria metabolize $\mathrm{CO}_{2}$ and release $\mathrm{CH}_{4}$ as a product. In marine sedimentary sections from DSDP cores the carbon isotopic composition of $\mathrm{CH}_{4}$ and $\mathrm{CO}_{2}$ increases with depth (ie. ${ }^{12} \mathrm{C}$ is depleted with depth). The range of $\delta^{13} \mathrm{CH}_{4}$ is from -94 permil to -66 permil and that for $\mathrm{CO}_{2}$ is from 25 permil to -4 permil with almost parallel changes(Kvenvolden 1993). Analyses from a corehole (92GSCTAGLU) in the McKenzie River Delta show that that $\delta^{13} \mathrm{C}$ values range from -89.94 to -77.96 per mil indicating a microbial origin (Dallimore and Collett 1995)

\section{Pore Water Salinity and Isotopic Composition}

As gas hydrates form and water molecules crystallize, ions in solution are excluded from the crystal structure through a process referred to as ion exclusion (Ussler and Paull 1995) This results in pore waters associated with gas hydrates becoming concentrated in ion salts. The results from 55 analyses of pore waters from the North Slope region collected between depths of 400 to $2000 \mathrm{~m}$ range in salinity from 0.5 to 19.0 parts per thousand (ppt) (Collett, 1993) with no apparent correlation between depth and salinity. Pore water salinity affects the stability zone of gas hydrates because the presence of salts lowers the freezing temperature of water and therefore shifts the stability to higher pressure and lower temperatures.

During gas hydrate decomposition, pore waters would tend to be diluted as pure water is released from ice in the hydrate phase. Therefore, distinct geochemical gradients may exist during production of gas hydrates, which may establish a chemical model for drilling hydrates because the gradients may depend on the distance to and the amount of gas hydrate rich areas in sediment. The same principle applies to the $\delta^{18} \mathrm{O}$ composition of pore water. As hydrates form ${ }^{18} \mathrm{O}$ is preferentially included in the crystalline structure of the hydrate and therefore the pore waters become depleted in ${ }^{18} \mathrm{O}$. Hence, as the gas hydrates dissociate the pore water becomes progressively enriched in ${ }^{18} \mathrm{O}$. Therefore, another geochemical gradient may be established by the oxygen isotopic composition of the pore water as gas hydrates dissociate. This may also be used as a tool to indicate a relative amount of gas hydrate in a given sedimentary formation or layer. These concepts have been modeled as closed systems and indicate that pore water salinities will increase and become isotopically fractionated during hydrate formation and that during decomposition, the pore waters will be diluted and enriched in ${ }^{18} \mathrm{O}$. However, the oxygen, hydrogen, and carbon fractionation factors in the methane-water-methane gas

\section{7 of 69}


hydrate system are unknown and may lead to complications of applying the models (Ussler and Paull 1995).

\section{8 of 69}




\section{Microbiology of Gas Hydrate Formations}

The existence and activity of microorganisms in the deep subsurface is important in relation to gas hydrate research since these organisms are responsible for much of the gas formation, their activities affect the distribution and fate of gases, and their populations in strata adjacent to hydrate deposits may be useful as bioindicators of the presence of hydrates. Recent studies have determined that microorganisms are ubiquitous in the deep marine and terrestrial subsurface and that the biomass of these bacteria exceeds the sum of all other biomass on Earth including all marine and terrestrial plants and animals (Pedersen 2000). These bacteria are attached to soil and rock matrices and are free living in groundwater (Pedersen 2001; Haveman and Pedersen 2002). To date, boreholes have been drilled that exceed $10,000 \mathrm{~m}$, but living bacteria have been found to depths slightly over 5000 m (Gold 1992; Huber, Huber et al. 1994). Deeper depths are restrictive to life due to intolerable temperatures. The highest temperature at which hyperthermophilic bacteria have been cultured is $\sim 113^{\circ} \mathrm{C}$ (Stetter 1996) and temperature seems to set the ultimate limit for life in the subsurface. However, pore space can also limit the abundance of bacteria since compaction is severe at high pressures and sediment loads (Ingebritsen, Sanford et al. 2000). Since microorganisms are adept at utilizing a variety of energy sources, it is not surprising that they occupy virtually every niche on Earth that does not surpass their extreme limits.

\section{Oceanic Environments}

The sub-sea floor and underlying basement rocks have been studied in increasing detail since 1985 due to the technology afforded by the drilling ship JOIDES Resolution of the Ocean Drilling Program (ODP). Until these studied were initiated, it was thought that that microbial life was restricted to the upper few meters of sediments in the deep sea since early studies failed to detect culturable species (Morita and ZoBell 1955). Microbial life has been found to be abundant in deep-sea sediments and rocks (Wellsbury, Goodman et al. 1997; Fisk, Giovannoni et al. 1998) and these microorganisms appear to be actively involved in the weathering of these rocks (Thorseth, Furnes et al. 1995; Thorseth, Torsvik et al. 1995). Hence, the continued search for microbial life in deep-sea deposits and rocks is a priority of the ODP.

The accumulation of bacterial end products within sediments indicates that bacteria are active throughout the sediment column even when the sediments are hundreds to thousands of meters thick, and these products are direct precursors of bacterially produced methane (Kvenvolden 1995; Kvenvolden 1995). Culturing and molecular studies have demonstrated the abundance and diversity of bacteria within deep layers of deep-sea sediments (Wellsbury, Goodman et al. 2000; Marchesi, Weightman et al. 2001; Inagaki, Sakihama et al. 2002). Bacterial abundance in marine sediments as determined 49 of 69 
primarily by microscopic counts of cells stained with fluorescent DNA dyes were over $10^{6}$ cells $/ \mathrm{cm}^{3}$ at depths exceeding $500 \mathrm{~m}$ below the sediment surface (Cragg, Wimpenny et al. 1990; Cragg, Parkes et al. 1992; Cragg 1994; Cragg and Parkes 1994; Parkes, Cragg et al. 1994; Cragg, Parkes et al. 1996; Wellsbury, Goodman et al. 1997; Cragg, Law et al. 1999; Parkes, Cragg et al. 2000). In addition, other evidence exists that a high biomass of microbial life occurs deep within sediments and that these populations are active including 1) the presence of high molecular weight DNA that can be amplified using molecular techniques (Rochelle, Cragg et al. 1994; Bidle, Kastner et al. 1999; Li, Kato et al. 1999; Vetriani, Jannasch et al. 1999; Lanoil, Sassen et al. 2001; LopezGarcia, LopezLopez et al. 2001; Marchesi, Weightman et al. 2001); 2) rapid growth of bacteria in mixed cultures (Getliff, Fry et al. 1992); 3) isolation of bacteria that are uniquely adapted to the deep-sea environment such as barophiles (Bale, Goodman et al. 1997; Barnes, Bradbrook et al. 1998), and; 4) rapid activities determined by growth and radiotracer techniques (Cragg, Parkes et al. 1992; Parkes, Cragg et al. 1994; Patching and Eardly 1997). In addition, rates of bacterial processes within deep sediment samples vary vertically with mineralogical and geochemical changes, suggesting that the measured activities reflect in situ activities (Cragg, Parkes et al. 1992; Parkes, Bale et al. 1995). Some of these deposits are millions of years old yet still support relatively active bacterial communities (Ingebritsen, Sanford et al. 2000). Bacterial abundance does decrease with depth and with sediment age, but these decreases are far smaller than what would be expected simply due to the age of the deposit, indicating that other sources of energy may be involved.

\section{Continental Habitats}

Less work has been conducted on continental boreholes, but considerable work has appeared including studies using appropriate aseptic technique to isolate subsurface bacteria without surface contamination. Diverse microbial communities exist down to the deepest levels studies ( 3000 m) (Chandler, Li et al. 1997; Crozier, Agapov et al. 1999; Onstott, Phelps et al. 1999). Sediments and soil/rocks become anoxic with depth and much of the microbial communities discovered within these deep regions are comprised of anaerobic communities living at high temperatures and pressures. Cultured species can be salt tolerant and heat loving, and may be either fermenting or respiring species. Metal and sulfate-reducing, acetogenic, autotrophic, and methanogenic bacteria have been isolated among others (Kotelnikova and Pedersen 1998; Onstott, Phelps et al. 1999; Pedersen 2001; Haveman and Pedersen 2002). Deep subsurface bacteria are capable of significant weathering of rocks (Petsch, Eglinton et al. 2001). Presently there are two lines of thought regarding the source of energy for these deep bacteria, the degradation of organic matter originally produced near the surface and transported or buried to depth over time, or the in situ formation of hydrogen or other inorganic energy sources at depth (Gold 1992; Stevens and McKinley 1995; Pedersen 1997; Stevens and 50 of 69 
McKinley 2000). Although it has been shown that hydrogen can be produced from water-granite interactions, the potential for this process to support significant life has been questioned (Anderson, Chapelle et al. 1998). However, recent data have shown that some igneous rocks can support active microbial hydrogen-utilizing methane-forming bacterial communities that lack input of significant electron donors from the surface (Chapelle, ONeill et al. 2002). It has been suggested that deep-sea sediments are able to support bacterial activities through the heat-driven generation of acetic acid from buried organic within the sediments (Wellsbury, Goodman et al. 1997). Hence, recalcitrant organic matter left over from material deposited millennia earlier can be converted to labile organic compounds later due to the heat within deep deposits. It is unknown if this mechanism occurs in continental deposits.

The deep subsurface harbors microbial communities with abilities to conduct a variety of processes including the complete recycling of elements (Krumholz, McKinley et al. 1997; Abdelouas, Nuttall et al. 2000; Fujita, Ferris et al. 2000; Colwell 2001; Fredrickson and Onstott 2001; Grossman and Desrocher 2001; Lovley 2001). Studies of deep sites for the storage of spent nuclear waste have lead to discoveries of active and diverse microbial communities in deep aquifers in the Fennoscandian Shield (Haveman and Pedersen 2002) and the Canadian Shield (Stroes-Gascoyne and Sargent 1998). It was also found that these bacteria are quite active in situ (Pedersen and Ekendahl 1992; Ekendahl and Pedersen 1994; Kotelnikova and Pedersen 1998). Molecular studies determined the vast diversity of bacteria within deep subsurface continental aquifers and rocks (Chandler, Li et al. 1997; Krumholz, McKinley et al. 1997; Chandler, Brockman et al. 1998), and interesting new species have been recovered (Kotelnikova, Macario et al. 1998; Motamedi and Pedersen 1998; Krumholz, Harris et al. 1999). Like marine sediment, pore space is limiting and affects the distribution and activity of subsurface bacteria (Pedersen 2001). The deep subsurface harbors microbial communities with abilities to conduct a variety of processes including the complete recycling of elements (Krumholz, McKinley et al. 1997; Abdelouas, Nuttall et al. 2000; Fujita, Ferris et al. 2000; Colwell 2001; Fredrickson and Onstott 2001; Grossman and Desrocher 2001; Lovley 2001)..

\section{Effects of Hydrates on Microbial Populations}

The presence of gas hydrates greatly affects the abundance, composition, and activities of bacterial communities. To date, interactions among hydrates, geochemical conditions, and microbial processes have only been ascertained in oceanic settings. However, it is clear that microbial life influences the formation of hydrates and vice versa. Hydrates that intersect the marine sediment-water interface at methane seeps can support complex animal and microbial communities that are similar in composition to submarine communities at hydrothermal vents. These seep communities are common in the Gulf of 51 of 69 
Mexico and are fueled by methane and reduced sulfur species (Sassen, MacDonald et al. 1994; Sassen, DeFreitas et al. 1999). However, while hydrates that are located well within sediments do not support rich communities of animals, they do seem to support rich bacterial populations that are often unique compared to bacteria in sediments devoid of methane.

It has been estimated from isotopic studies that much of the methane confined in hydrates in the sea is of microbial rather than thermogenic origin (Galimov and Kvenvolden 1983; Waseda 1998). However, some sites, like those studied in the Gulf of Mexico, have hydrate deposits that are derived from both thermogenic and biogenic methane, and these may be separated (Sassen, Sweet et al. 1999). It has also been suggested that even deposits derived solely from thermogenic methane may contain methane that has been recycled through methanogenic bacteria to yield a redefined microbial isotopic signature (Coleman, Risatti et al. 1981; Sassen, MacDonald et al. 1994; Sassen, DeFreitas et al. 1999).

It is not surprising that studies of microbial communities in hydrate-containing sediments have often focused on methanogenic bacteria and all studies that have searched for methanogens have easily found them. In some cases, unique species of methanogenic bacteria have been discovered in hydrate-containing strata (Hinrichs, DeLong et al. 1999) and these bacteria differ markedly from those found in sediments situated directly above and below the hydrate stability zone (Thomsen, Finster et al. 2001). Isotopic data indicate that the bulk of methane in marine hydrates is from the bacterial reduction of $\mathrm{CO}_{2}$ via $\mathrm{H}_{2}$ oxidation as opposed to the formation of methane from the methanogenic fermentation of acetic acid (Wellsbury, Goodman et al. 1997). The latter process accounts for $67 \%$ of methane in most anaerobic habitats (Conrad 1999), but appears to be of less importance in these deep-sea sediments. It is also possible that methane formed in much deeper sediments moves into hydrate-forming regions. However, to date, data show that methane carbon in hydrates has an isotopic signature similar to $\mathrm{CO}_{2}$ at those depths suggesting that hydrate methane is derived from methane generated within or near the hydrate stability zone (Ingebritsen, Sanford et al. 2000). However, the anaerobic oxidation of methane (discussed in detail below) can be several orders of magnitude more active than the in situ production of methane from $\mathrm{H}_{2} / \mathrm{CO}_{2}$ suggesting that most of the methane was derived from sites well away from the hydrate stability zone (Cragg, Rochelle et al. 1996).

Besides methanogenic bacteria, hydrate deposits also contain large populations of other bacteria typical of active marine sediments, i.e., methane-oxidizers, sulfate reducers, acetogenic bacteria, nitrogen transforming species, sulfur oxidizers, metal reducers, and a suite of fermentative species (Bidle, Kastner et al. 1999; Ingebritsen, Sanford et al. 2000; Lanoil, Sassen et al. 2001). Waseda (1998) suggested that the total organic carbon of

\section{2 of 69}


adjacent sediments needs to be $0.8-2.3 \%$ by weight to supply sufficient methane to create a significant hydrate deposit and hydrate methane is derived from sediment organic carbon. This level of organic carbon is not uncommon even in rather deep sediments in the deep ocean (Berner 1982; Emerson 1987; Waseda 1998).

When the global deep ocean is examined, it is possible to generate a relationship between sediment depth and microbial parameters such as biomass or activity (Wellsbury, Goodman et al. 2000; D'Hondt, Rutherford et al. 2002) in which microbial processes tend to decrease with sediment depth. However, bacterial biomass and activity increase greatly within the hydrate-stability zone. In fact, it is becoming clear that microbial activities increase greatly at the base of hydrate-containing strata (Ingebritsen, Sanford et al. 2000; Wellsbury, Goodman et al. 2000; Lanoil, Sassen et al. 2001). Lanoil et al. (2001) found that bacterial abundance was low within hydrate samples that lacked any noticeable sediment particles, but that these populations contained a relatively diverse bacterial community yet only a few types of methanogenic bacteria. They did find that bacterial populations in sediments adjacent to hydrates were nearly three orders of magnitude more abundant than in the hydrate itself. Wellsbury et al. (2000) conducted a detailed study of the depth distribution of bacterial biomass and several types of microbial activities and found that bacteria were unusually abundant and active in strata immediately below the hydrate-containing region (determined from bottom-simulating reflection data (BSR)). In particular, rates of bacterial growth (from nucleic acid uptake measurements), methane formation, methane oxidation and sulfate reduction peaked just below the BSR. Cell abundances were 10-100 times higher than predicted from average depth distributions indicating the stimulation of bacteria just below the hydrate-stability zone. Hence, this region represents a biogeochemically dynamic zone in which a complete carbon cycle occurs. In addition, ODP sites with the highest amounts of hydrates and underlying free gas supported the largest and most active bacterial populations (Cragg, Parkes et al. 1995; Cragg, Rochelle et al. 1996). It is also interesting that acetic acid concentrations increase to extremely high levels $(>10 \mathrm{mM})$ at and below the hydrate-containing zone in deep-sea sediments and this acetate is oxidized to methane and $\mathrm{CO}_{2}$ (Wellsbury, Goodman et al. 1997; Wellsbury, Goodman et al. 2000). In fact, it their studies, acetate conversion to methane greatly exceeded the rate of methane formation from the oxidation of $\mathrm{H}_{2}$ coupled to $\mathrm{CO}_{2}$ reduction. The elevated rates of microbial activity within these sediments appears to be due to consumption of free gases just below the hydrate zone as opposed to the direct use of hydrate-associated methane (Wellsbury, Goodman et al. 1997; Wellsbury, Goodman et al. 2000; Lanoil, Sassen et al. 2001).

\section{3 of 69}




\section{Anaerobic Methane Oxidation}

One of the mot interesting and perhaps useful discoveries within hydrate-containing sediments is the active rate of anaerobic methane oxidation. Although the oxidation of methane by aerobic bacteria has been studied for decades, it has only been recently that details of the bacterial oxidation of methane in the absence of oxygen have become known. It was proposed nearly 30 years ago that vertical profiles of dissolved methane within marine sediments were due to the consumption of methane at the base of the sulfate reduction zone (Reeburgh 1967; Barnes and Goldberg 1976; Martens and Berner 1977; Reeburgh 1977; Reeburgh and Heggie 1977; Reeburgh 1980; Reeburgh 1982) according to the following reaction:

$$
\mathrm{CH}_{4}+\mathrm{SO}_{4}{ }^{2-} \rightarrow \mathrm{HS}^{-}+\mathrm{HCO}_{3}^{-}+\mathrm{H}_{2} \mathrm{O}
$$

It is well known that methanogenesis and sulfate reduction are mutually exclusive processes in nature since the microorganisms involved compete for the same growth substrates (Martens and Berner 1974). However, methane produced in deeper methanogenic strata does not diffuse to aerobic layer where it is consumed, but rather disappears near the base of the sulfate-containing region immediately above the methane production zone (Reeburgh and Heggie 1977). The fact that the anaerobic oxidation of methane is microbially mediated is supported by tracer experiments using ${ }^{14} \mathrm{C}$-methane (Reeburgh 1980; Iversen and Blackburn 1981) and from stable isotope ratios of methane and $\mathrm{CO}_{2}$ (Blair and Aller 1995; Popp, Sansone et al. 1995). In addition, lipid biomarkers of microbes within the zone of anaerobic methane oxidation tend to be unusually depleted in ${ }^{13} \mathrm{C}$ indicating that these bacteria are consuming isotopically light carbon such as biogenic methane (Hinrichs, DeLong et al. 1999; Orphan, House et al. 2001).

Isotopically light lipids from both sulfate-reducing and methane-producing bacteria have been found (Elvert and Suess 1999; Boetius, Ravenschiag et al. 2000; Elvert, Whiticar et al. 2000; Pancost, Damste et al. 2000; Orphan, Hinrichs et al. 2001). Sulfate-dependent anaerobic methane oxidation probably occurs to some extent in all sediments, especially those that have sufficient sulfate to support the sulfate-reducing partner. Studies noted increased rates of sulfate reduction and degradation of radiolabeled methane occurring in samples collected from the base of the sulfate-containing layers suggesting that methane was a source of energy for this process (Devol and Ahmed 1981; Alperin and Reeburgh 1984; Alperin and Reeburgh 1985; Iversen and Jørgensen 1985; Alperin, Reeburgh et al. 1988; Blair and Aller 1995; Hansen, Finster et al. 1998). Recent studies have demonstrated in vivo the stochiometric reduction of sulfate to sulfide during the oxidation of methane (Nauhaus, Boetius et al. 2002). It appears that anaerobic methane oxidation occurs in freshwater environments too, including lakes and flooded rice paddy soils (Panganiban, Patt et al. 1979; Murase and Kimura 1994; Murase and Kimura 1994), and has been noted in salt lakes as well (Iverson, Oremland et al. 1987).

\section{4 of 69}


Although it has been assumed that sulfate-reducing bacteria were responsible for this anaerobic methane loss, no sulfate reducer has ever been isolated that has this capacity. It was suggested later that the anaerobic oxidation of methane was occurring via a cooperative effort between methane-producing and sulfate-reducing bacteria in which the methanogen acts in reverse and consumes methane followed by a transfer of electrons to a sulfate reducer that then reduces sulfate to sulfide (Hoehler, Alperin et al. 1994). This type of bacterial cooperation termed syntrophy (Biebl and Pfennig 1978) is similar to what has been studied for over 30 years involving interspecies $\mathrm{H}_{2}$ transfer between cooperating bacteria (Bryant, Wolin et al. 1967). However, in classical syntrophy, the methanogenic bacterium accepts $\mathrm{H}_{2}$ from the partner and then reduces $\mathrm{CO}_{2}$ to methane. It appears that methanogenic species involved in syntrophy during anaerobic methane oxidation are consuming methane and donating electrons via some carrier to a sulfate reducer. It was first suggested that the carrier molecule was $\mathrm{H}_{2}$ since reverse methanogenesis could yield the following reaction (Hoehler, Alperin et al. 1994):

$$
\mathrm{CH}_{4}+2 \mathrm{H}_{2} \mathrm{O} \rightarrow \mathrm{CO}_{2}+4 \mathrm{H}_{2}
$$

This reaction, which is endergonic at standard temperature and pressure can be exergonic if the $\mathrm{H}_{2}$ levels are maintained extremely low by the $\mathrm{H}_{2}$-consuming partner, i.e.,:

$$
\mathrm{SO}_{4}{ }^{2-}+4 \mathrm{H}_{2}+2 \mathrm{H}^{+} \rightarrow \mathrm{H}_{2} \mathrm{~S}+4 \mathrm{H}_{2} \mathrm{O}
$$

More recent studies have suggested that this reaction may not be energetically favorable and acetate transfer is more likely (Valentine and Reeburgh 2000). However, additional study of molecules that could potentially shuttle electrons between the methanogen and the sulfate reducer tends to rule out acetate as well and suggests that formate is a more likely shuttle molecule and that the two partners must be in close physical contact with each other for the process to generate sufficient energy for both (Sorensen, Finster et al. 2001). Despite the fact that it seems clear that anaerobic methane oxidation is due to a bacterial partnership, little is known of these organisms

Molecular studies have shown that bacteria, especially methanogenic and sulfatereducing species that are dominant within the methane-oxidizing region in anoxic sediments are distinct compared to species located above or below this region (Hinrichs, DeLong et al. 1999; Orphan, Hinrichs et al. 2001; Orphan, House et al. 2001; Thomsen, Finster et al. 2001). The fact that these physiologic groups dominate further supports the notion that these two bacterial groups are responsible for anaerobic methane oxidation. The finding that they are unique species or even genera suggests that this process is unique and is well designed for bacterial survival when using a low energy yielding reaction in a distinct environment.

\section{5 of 69}


Further studies utilizing molecular probes have investigated micro-colonies of sulfatereducing and methanogenic bacteria that show that the methane-producer (which is actually consuming methane in this instance and is therefore a methanotrophic bacterium) is located in a small group that is surrounded by sulfate-reducers on the outside (Boetius, Ravenschiag et al. 2000; Orphan, Taylor et al. 2000). Secondary ion mass spectrometry in which an ion beam is passed directly through a microbial aggregate demonstrated that the aggregate was extremely depleted in ${ }^{13} \mathrm{C}$, indicative of methane oxidation (Orphan, House et al. 2001). These aggregates have been found in hydrate containing sediments and at the interface between the sulfate reduction and methane production zones in other sediments. Neither species involved has been isolated in culture, but they can be detected easily using molecular probes. The methanotrophic group has a unique ribosomal RNA sequence that tends to be found only in regions exhibiting anaerobic methane oxidation including sediments with gas hydrates.

Virtually nothing is known of microbiology of terrestrial hydrates and what types of microbial consortia are present, but it has been suggested that the terrestrial deposits may be comprised of a higher proportion of thermogenic methane than in their marine counterparts (Collett 1993; Kvenvolden 1995), but little is known of these hydrates. Whatever the source, it seems clear that a better understanding of bacterial populations associated with hydrates will prove useful in locating and retrieving hydrate gases since microbial communities seem to respond strongly to the presence of the hydrates or at least to the free gas trapped under them. Terrestrial sites are most certainly much more complicated than their marine counterparts since they are affected by a myriad of continental processes such as soil formation, tectonic forces and a complicated geology. Marine hydrates are located on or within marine deposits that have been accumulating for millennia. Although these latter deposits may change greatly over time due to physical, geochemical and climate conditions, they are still composed primarily of marine muds that exhibit predictable depth patterns. Continental deposits can be overlain by a variety of rock and soils types and are subject to extensive folding and compression. They are affected by lateral and vertical water movement and can be affected by both freshwaters and brines of varying ionic strengths and compositions. Hence, the microbial biogeochemistry of continental hydrate deposits may vary greatly from marine deposits, but they may also have many similarities. Terrestrial sites can still have significant sulfate contents (Collett 1997) and hydrate-containing regions may harbor stimulated microbial communities such as those responsible for anaerobic methane oxidation and acetate utilization.

\section{Permafrost Bacteria}

High latitude sites also contain tens to hundreds of meters of permafrost and this ice can bisect the hydrate stability zone. The frozen layer can maintain a record of past climate

\section{6 of 69}


events including a frozen record of vegetation and presumably microbial communities. However, prolonged freezing probably selects for bacterial species that are the most resistant to long-term freezing (Friedmann 1994) and do not provide an unequivocal record of past population structure as might be expected from preserved spores or plant parts like pollen. However, permafrost samples have provided cells that are very ancient and do provide insights into past ecosystems (Gilichinsky, Vorobyov et al. 1992; Gilichinsky 1997; Wilson, Braddock et al. 1998). Frozen habitats have been largely ignored until the last few years and techniques for studying processes in permafrost are in their infancy (Finegold 1996). Electron microscopic analysis of permafrost that was up to 3 millions years old revealed the presence of intact, vegetative bacterial cells that were not frozen inside (Vorobyova, Minkovsky et al. 2001). These cells differed from those isolated from surface seasonally unfrozen materials in that they often exhibited surficial capsules that were unusually thick, probably for cell protection. Bacterial enzyme activities commenced immediately after thawing without a lag indicating that these activities were present in situ, and enzymes that are normally thought to be robust in soils were also found to be most active in permafrost (Vorobyova, Minkovsky et al. 2001). Interestingly, in very old permafrost, few bacterial spores are present and fungal biomass is high, but is mostly present as spore (Gounot 2001). Hence, the only cells that are viable in situ are bacterial. This is surprising since soils tend to contain large numbers of spores, yet these tend to disappear in permafrost.

The microbial biomass in permafrost can be quite high with $10^{7}$ to $10^{9}$ cells per gram even in samples that are millions of years old (Gilichinsky and Wagener 1995; Shi, Reeves et al. 1997; Vorobyova, Soina et al. 1997; Rivkina, Gilichinsky et al. 1998; Wilson, Braddock et al. 1998). Both aerobic and anaerobic bacteria are present and viable. Anaerobes tend to dominate in soils that were anoxic prior to freezing and vice versa (Rivkina, Gilichinsky et al. 1998). Although bacterial activity is greatly depressed at cold temperatures, studies have shown that bacteria are viable and metabolizing in samples as low as $-20^{\circ} \mathrm{C}$ (Friedmann, Kappen et al. 1993; Rivkina, Friedmann et al. 2000). It is thought that viable bacteria in ancient permafrost are able to metabolize since even old and highly frozen soil still contains regions of unfrozen water (Ershov 1998). Hence, it is highly likely that deep permafrost like that found in N. Alaska would contain relatively high numbers of viable and metabolizing bacteria. One would expect that this bacterial activity would increase greatly in the deeper regions just below the permafrost layer and especially just below the hydrate stability zone that transects the base of the permafrost.

\section{7 of 69}




\section{Recommendations for Future Research}

1. Due to the lack of full-scale experience with produced water generated during hydrate production, experiments to determine the mass and flow rate of gas and water produced using various production techniques should be conducted once the hydrate well has been completed.

2. Extensive inorganic and organic analysis of the water produced during hydrate drilling and production should be conducted to provide fundamental information on produced water quality and how it can change during hydrate production. Recommended analysis includes major and trace elements, anions, and isotope analyses. The major and trace elements and ions will allow us to establish any geochemical signatures associated with the hydrates as well as provide essential supporting data for understanding the microbial activity. These signatures may include changes in salinity or changes in concentration of other elements that have not yet been investigated. In addition, the chemical composition of the water must be known in order to make any decisions about treatment and ultimate disposal of the water.

3. A careful analysis of all water uses on the hydrate exploration and production platform should be conducted. This analysis should include quantification of the volumes and flowrates and the associated water quality requirements for all processes used on site. The overall water balance generated from this analysis can then be used to develop appropriate strategies for treatment, reuse, reinjection and disposal of water generated on site.

4. Changes in the relative distribution of microbial species can potentially pinpoint the location of hydrate deposits in oceanic settings. This was exemplified by drastic increases in biomass and activity just below the hydrate-containing region. If this is also true in continental deposits then small samples of drilling materials can be investigated to determine the potential for hydrates to occur and perhaps even the size of the deposit in continental settings. Molecular phylogenetic and activity measurements within adjacent strata need to be investigated. These data, in conjunction with the isotopic measurements outlined above, may provide unique markers.

5. The acquisition of a continental core in northern Alaska provides a unique opportunity to investigate ancient bacteria in the Arctic. This would be the first opportunity to examine extremely old permafrost deposits in this manner and, together with geochemical information, could provide unique information on past climate history and the types of microorganisms that existed in the geologic past.

\section{8 of 69}


6. Oxygen and hydrogen isotopes may provide a useful tool in determining the rate of dissociation of hydrates during drilling. If gas hydrates and equilibrium pore water were removed from the subsurface, an initial oxygen and hydrogen isotopic composition from which to measure the relative changes in isotopic composition of pore water as the hydrates dissociate could be obtained. This application may help develop a model of hydrate dissociation that could be applied to other locations where there is potential to drill gas hydrates.

\section{References}

Abdelouas, A., E. H. Nuttall, et al. (2000). "Biological reduction of uranium in groundwater and subsurface soil." Sci. Tot. Environ. 250(1-3): 21-35.

Alperin, J. J., W. S. Reeburgh, et al. (1988). "Carbon and hydrogen isotope fractionation resulting from anaerobic methane oxidation." Global Biogeochem. Cycles 2: 27988.

Alperin, M. J. and W. S. Reeburgh (1984). Geochemical observations supporting anaerobic methane oxidation. Microbial Growth on C-1 Compounds. R. S. Hanson. Washington, D.C., ASM: 282-289.

Alperin, M. J. and W. S. Reeburgh (1985). "Inhibition experiments on anaerobic methane oxidation." Appl. Environ. Microbiol. 50: 940-945.

Anderson, R. T., F. H. Chapelle, et al. (1998). "Evidence against hydrogen-based microbial ecosystems in basalt aquifers." Science 281(5379): 976-977.

Bale, S. J., K. Goodman, et al. (1997). "Desulfovibrio profundus sp. nov., a novel barophilic sulfate-reducing bacterium from deep sediment layers in the Japan Sea." Int. J. Syst. Bacteriol. 47(2): 515-521.

Barnes, R. O. and E. D. Goldberg (1976). "Methane production and consumption in anaerobic marine sediments." Geology 4: 297-300.

Barnes, S. P., S. D. Bradbrook, et al. (1998). "Isolation of sulfate-reducing bacteria from deep sediment layers of the Pacific Ocean." Geomicrobiol. J. 15(2): 67-83.

Berner, R. A. (1982). "Burial of organic carbon and pyrite sulfur in the modern ocean: Its geochemical and environmental significance." Am. J. Sci. 282: 451-473.

Bidle, K. A., M. Kastner, et al. (1999). "A phylogenetic analysis of microbial communities associated with methane hydrate containing marine fluids and sediments in the Cascadia margin (ODP site 892B)." FEMS Microbiol. Ecol. 177: 101-108.

Biebl, H. and N. Pfennig (1978). "Growth yields of green sulfur bacteria in mixed cultures with sulfur and sulfate reducing bacteria." Arch. Microbiol. 117: 9-16.

\section{9 of 69}


Bird, K. J., and Magoon, L.B. (1987). "Petroleum geology of the northern part of the Arctic National Wildlife Refuge, Northeastern Alaska." U.S. Geological Survey Bulletin 1778: $324 \mathrm{p}$.

Blair, N. E. and R. C. Aller (1995). "Anaerobic methane oxidation on the Amazon shelf." Geochim. Cosmochim. Acta 59(18): 3707-3715.

Boetius, A., K. Ravenschiag, et al. (2000). "A marine microbial consortium apparently mediating anaerobic oxidation of methane." Nature 407(6804): 623-626.

Bryant, M. P., E. A. Wolin, et al. (1967). "Methanobacillus omelianskii, a symbiotic association of two species of bacteria." Arch. Microbiol. 59: 20-31.

Carman, G. J., and Hardwick, P. (1983). "Geology and regional setting of the Kuparuk oil field, Alaska." American Association of Petroleum Geologists Bulletin 67(6): 1014-1031.

Chandler, D. P., F. J. Brockman, et al. (1998). "Phylogenetic diversity of Archaea and Bacteria in a deep subsurface paleosol." Microbial. Ecol. 36(1): 37-50.

Chandler, D. P., S. M. Li, et al. (1997). "A molecular comparison of culturable aerobic heterotrophic bacteria and 16S rDNA clones derived from a deep subsurface sediment." FEMS Microbiol. Ecol. 23(2): 131-144.

Chapelle, F. H., K. ONeill, et al. (2002). "A hydrogen-based subsurface microbial community dominated by methanogens." Nature 415(6869): 312-315.

Coleman, D. D., J. B. Risatti, et al. (1981). "Fractionation of carbon and hydrogen isotopes by methane oxidizing bacteria." Geochim. Cosmochim. Acta 45: 10331037.

Collett, T. S. (1993). "Natural gas hydrates of the Prudhoe Bay and Kuparuk River Area, North Slope, Alaska." The American Association of Petroleum Geologists Bulletin 77(5): 793-812.

Collett, T. S. (1993). Natural gas production from arctic gas hydrates. The Future of Energy Gases: USGS Professional Paper 1570. D. G. Howell. Washington, USGPO: 299-311.

Collett, T. S. (1997). "Gas hydrate resources of northern Alaska." Bulletin of Canadian Petroleum Geology 45(3): 317-338.

Collett, T. S., K. J. Bird, et al. (1988). Geologic interrelations relative to gas hydrates within the North Slope of Alaska. Menlo Park, CA, U.S. Geological Survey.

Collett, T. S., K. A. Kvenvolden, et al. (1990). "Characterization of hydrocarbon gas within the stratigraphic interval of gas-hydrate stability on the North Slope of Alaska, U.S.A." Applied Geochemistry 5: 279-287.

Colwell, F. S. (2001). Constraints on the distribution of microorganisms in subsurface environments. Subsurface Microbiology and Biogeochemistry. M. Fletcher. New York, Wiley-Liss, Inc: 71-95.

Conrad, R. (1999). "Contribution of hydrogen to methane production and control of hydrogen concentrations in methanogenic soils and sediments." FEMS Microbiol. Ecol. 28(3): 193-202.

60 of 69 
Cragg, B. A. (1994). Bacterial profiles in deep sediment layers from the Lau Basin (Site 834). Proc. Scientific Results, ODP, Leg 153, Lau Basin. J. Hawkins. Texas A\&M University, College Station, Odp: 147-150.

Cragg, B. A., K. M. Law, et al. (1999). "Bacterial profiles in deep sediments of the Alboran Sea, western Mediterranean, Sites 976-978." Proceedings of the Ocean Drilling Program: Scientific Results 161: 433-438.

Cragg, B. A. and R. J. Parkes (1994). Bacterial profiles in hydrothermally active deep sediment layers from Middle Valley (NE Pacific), Sites 857 and 858. Proc. Scientific Results, ODP Leg 139, Middle Valley, Juan de Fuca Ridge. M. J. Mottl: 509-516.

Cragg, B. A., R. J. Parkes, et al. (1996). "Bacterial populations and processes in sediments containing gas hydrates (ODP Leg 146: Cascadia Margin)." Earth Planet Sci. Lett. 139: 497-508.

Cragg, B. A., R. J. Parkes, et al. (1995). The impact of fluid and gas venting on bacterial populations and processes in sediments from the Cascadia Margin accretionary system (Sites 888-892) and the geochemical consequences. Proc. ODP, Sci. Results, 146 (Pt 1): College Station, TX (Ocean Drilling Programm). E. Suess: 399-411.

Cragg, B. A., R. J. Parkes, et al. (1992). Bacterial biomass and activity in the deep sediment layers of the Japan Sea, Hole 798B. Proc., scientific results, ODP, Legs

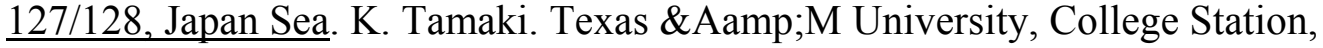
Odp: 761-776.

Cragg, B. A., P. A. Rochelle, et al. (1996). "Bacterial populations and processes in sediments containing gas hydrates (ODP Leg 146: Cascadia Margin)." Earth Planet. Sci. Lett. 139(3-4): 497-507.

Cragg, B. A., J. W. T. Wimpenny, et al. (1990). Bacterial biomass and activity profiles within deep sediment layers. Proc., scientific reports, ODP, Leg 112, Peru continental margin. E. Suess. UK distributors, IPOD Committee, NERC, Swindon, ODP Texas \&Aamp;M University College Station: 607-619.

Crozier, R. H., P.-M. Agapov, et al. (1999). "Towards complete biodiversity assessment: an evaluation of the subterranean bacterial communities in the Oklo region of the sole surviving natural nuclear reactor." FEMS Microbiol. Ecol. 28: 325-334.

Dallimore, S. R. and T. S. Collett (1995). "Intrapermafrost gas hydrates from a deep core in the Mackenzie River Delta, Northwest Territories, Canada." Geology 23(6): 527-530.

Das, D. K. and V. Srivastava (1991). Application of a finite element model to hydrate

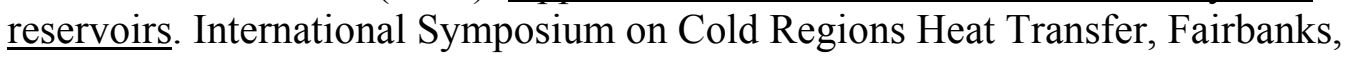
AK.

deBoer, R. B., J. J. H. C. Houbolt, et al. (1985). "Formation of gas hydrates in permeable medium." Geologie en Mijnbouw 64: 245-249.

\section{1 of 69}


Devol, A. H. and S. I. Ahmed (1981). "Are high rates of sulphate reduction associated with anaerobic oxidation of methane?" Nature 291: 407-408.

D'Hondt, S., S. Rutherford, et al. (2002). "Metabolic activity of subsurface life in deepsea sediments." Science 295(5562): 2067-2070.

Ekendahl, S. and K. Pedersen (1994). "Carbon transformations by attached bacterial populations in granitic groundwater from deep crystalline bed-rock of the Stripa research mine." Microbiology 140: 1565-1573.

Elvert, M. and E. Suess (1999). "Anaerobic methane oxidation associated with marine gas hydrates: superlight $C$-isotopes from saturated and unsaturated $C_{20}$ and $C_{25}$ irregular isoprenoids." Naturwissnechaften 86: 295-300.

Elvert, M., M. J. Whiticar, et al. (2000). "Archaea mediating anaerobic methane oxidation in deep-sea sediments at cold seeps of the eastern Aleutian subduction zone." Org. Geochem. 31(11): 1175-1187.

Emerson, S., C. Stump, P.M. Grootes, M. Stuiver, G.W. Farwell and F.H. Schmidt. (1987). "Estimates of degradable organic carbon in deep sea sediments from 14C concentrations." Nature 329:51-53.

Ershov, E. D. (1998). General geocryology. Cambridge, Cambridge University Press.

Ershov, E. D. and V. Yakushev (1992). "Experimental research on gas hydrate decomposition in frozen rocks." Cold Regions Science and Technology 20: 147156.

Finegold, L. (1996). "Molecular and biophysical aspects of adpatation of life to temperatures below the freezing point." Adv. Space Res. 18(12): 87-95.

Fisk, M. R., S. J. Giovannoni, et al. (1998). "Alteration of oceanic volcanic glass: Textural evidence of microbial activity." Science 281(5379): 978-980.

Fredrickson, J. K. and T. C. Onstott (2001). Biogeochemical and geological significance of subsurface microbiology. Subsurface Microbiology and Biogeochemistry. M. Fletcher. New York, Wiley-Liss, Inc: 3-37.

Friedmann, E. I. (1994). Permafrost as microbial habitat. Viable microorganisms in permafrost. D. A. Gilichinsky. Pushchino, Institute of Soil Science and Photosynthesis, Russian Academy of Science: 21-26.

Friedmann, E. I., M. A. Kappen, et al. (1993). "Long-term productivity in the cryptoendolithic microbal community of the Ross Desert, Anarctica." Microb. Ecol. 25: 51-69.

Fujita, Y., E. G. Ferris, et al. (2000). "Calcium carbonate precipitation by ureolytic subsurface bacteria." Geomicrobiol. J. 17(4): 305-318.

Galimov, E. M. and K. A. Kvenvolden (1983). Concentrations of carbon isotopic compostion of $\mathrm{CH} 4$ an $\mathrm{dCO} 2$ in gas from sediments of the Blake Outer Ridge, Deep Sea Drilling Project Leg 76. Init. Res. DSDP, 76. R. E. Sheridan et al. Washington DC, U.S. Government Printing Office: 403-407.

Getliff, J. M., J. C. Fry, et al. (1992). The potential for bacteria growth in deep sediment layers of the Japan Sea, Hole 798B-Leg 128. Proc. Scientific Results, ODP, Legs 62 of 69 
127/128, Japan. K. Tamaki. Texas A\&M University, College Station, Odp: 755760.

Gilichinsky, D. and S. Wagener (1995). "Microbial life in permafrost: a historical review." Permafrost Periglacial Processes 6: 243-250.

Gilichinsky, D. A. (1997). Permafrost as a microbial habitat: extreme for Earth, favorable in Space. Instruments, Methods, and Missions for the Investigation of

Extraterrestrial Microorganisms. R. B. Hoover, Proc. SPIE: 472-481.

Gilichinsky, D. A., E. Vorobyov, et al. (1992). "Long-term preservation of microbial ecosystems in permafrost." Adv. Space Res. 12: 255-263.

Godsey, C. (2002). "Personal communication. Environmental Protection Agency. (907) 271-6561."

Goel, N., M. Wiggins, et al. (2001). "Analytical modelling of gas recovery from in situ hydrates dissociation." Journal of Petroleum Science and Technology 29: 115127.

Gold, T. (1992). "The deep hot biosphere." Proc. Natl. Acad. Sci. USA 89: 6045-6049.

Gounot, A. M. (2001). Ecology of psychrophilic and psychrotrophic micro-organisms in cold and frozen soils. Permafrost response on Ecomonic Development, Environmental Security and Natural Resource. V. Melnikov. Amsterdam, Kluwer Academic: 543-551.

Grantz, A., Holmes, M.L., and Kososki, B.A. (1975). "Geologic framework of the Alaskan continental terrace in the Chukchi and Beaufort Seas. In: Canada's Continental Margins and Offshore Petroleum Exploration. C.J. Yorath, E.R. Parker, and D.J. Glass (eds.)." Canadian Society of Petroleum Geologists Memoir 4: 669-700.

Grossman, E. L. and S. Desrocher (2001). Microbial sulfur cycling in terrestrial subsurface environments. Subsurface Microbiology and Biogeochemistry. M. Fletcher. New York, Wiley-Liss, Inc: 219-248.

Gyrc, G. (1988). "Geology and exploration of the National Petroleum Reserve in Alaska, 1974 to 1982." U.S. Geological Survey Professional Paper 1399: 940p.

Hansen, L. B., K. Finster, et al. (1998). "Anaerobic methane oxidation in sulfate depleted sediments: effects of sulfate and molybdate additions." Aquat. Microb. Ecol. 14(2): 195-204.

Haveman, S. A. and k. Pedersen (2002). "Distribution of culturable microoganisms in Fennoscandian Shield groundwater." FEMS Microbiol. Ecol. 39: 129-137.

Hinrichs, K. U., E. F. DeLong, et al. (1999). "Methane-consuming archaebacteria in marine sediments." Nature 398(6730): 802-805.

Hoehler, T. M., M. J. Alperin, et al. (1994). "Field and laboratory studies of methane oxidation in an anoxic marine sediment: evidence for a methanogen-sulfate reducer consortium." Global Biogeochem. Cycles 8(4): 451-463.

\section{3 of 69}


Holder, G. D., P. F. Angert, et al. (1982). "A Thermodynamic Evaluation of Thermal Recovery of Gas from Hydrates in the Earth." Journal of Petroleum Technology May: 1127-1132.

Huber, H., R. Huber, et al. (1994). "Search for hyperthermophilic microorganisms in fluids obtained from the KTB pump test." Sci. Drill. 4: 127-129.

Inagaki, F., Y. Sakihama, et al. (2002). "Molecular phylogenetic analyses of reversetranscribed bacterial rRNA obtained from deep-sea cold seep sediments." Environ. Microbiol. 4(5): 277-286.

Ingebritsen, A. E., W. E. Sanford, et al. (2000). "Recent studies on bacterial populations and processes in subseafloor sediments: A review." Hydrology J. 8: 11-28.

Islam, M. R. (1994). "A New Recovery Technique for Gas Production from Alaskan Gas Hydrates." Journal of petroleum Science and Engineering 11: 267-281.

Iversen, N. and T. H. Blackburn (1981). "Seasonal rates of methane oxidation in anoxic marine sediments." Appl. Environ. Microbiol. 41: 1295-1300.

Iversen, N. and B. B. Jørgensen (1985). "Anaerobic methane oxidation at the sulfatemethane transition in marine sediments from the Kattegat and Skagerrak (Denmark)." Limnol. Oceanogr. 30: 944-955.

Iverson, N., R. S. Oremland, et al. (1987). "Big Soda Lake (Nevada). 3. Pelagic methanogenesis and anaerobic methane oxidation." Limnol. Oceanogr. 32: 804814.

Judge, A. S. (1988). "Mapping the distribution and properties of natural gas hydrates in Canada (abs.)." Proceedings of the American Chemical Society Third Chemical Congress of the North American Continent, Toronto, Canada(abstract number 29).

Judge, A. S., and Majorowicz, J.A. (1992). "Geothermal conditions for gas hydrate stability in the Beaufort-Mackenzie area - The global change aspect." Global and Planetary Change 98(2/3): 251-263.

Kamath, A., S. P. Godbole, et al. (1987). "Evaluation of the stability of gas hydrates in northern Alaska." Cold Regions Science and Technology 14: 107-119.

Kamath, V. A., G. D. Holder, et al. (1984). "Three Phase Interfacial Heat Transfer During the Dissociation of Propane Hydrates." Chemical Engineering Science 39(10): 1435-1442.

Kamath, V. A., P. N. Mutalik, et al. (1991). "Experimental Study of Brine Injection and Depressurization Methods for Dissociation of Gas Hydrates." SPE Formation Evaluation December: 477-484.

Kim, H. C., P. R. Bishnoi, et al. (1987). "Kinetics of Methane Hydrate Decomposition." Chemical Engineering Science 42(7): 1645-1653.

Klauda, J. B. and S. I. Sandler (2001). "Modeling gas hydrate phase equilibria in laboratory and natural porous media." Ind. Eng. Chem. 40: 4197-4208.

\section{4 of 69}


Kotelnikova, S., A. J. L. Macario, et al. (1998). "Methanobacterium subterraneum, a new species of Archaea isolated from deep groundwater at the Åspö Hard Rock Laboratory, Sweden." Int. J. Syst. Bacteriol. 48: 357-367.

Kotelnikova, S. and K. Pedersen (1998). "Distribution and activity of methanogens and homoacetogens in deep granitic aquifers at Åspö Hard Rock Laboratory, Sweden." FEMS Microbiol. Ecol. 26(2): 121-134.

Krumholz, L. R., S. H. Harris, et al. (1999). "Characterization of two subsurface $\mathrm{H}_{2-}$ utilizing bacteria, Desulfomicrobium hypogeium sp. nov. and Acetobacterium psammolithicum sp. nov., and their ecological roles." Appl. Environ. Microbiol. 65(6): 2300-2306.

Krumholz, L. R., J. P. McKinley, et al. (1997). "Confined subsurface microbial communities in Cretaceous rock." Nature 386(6620): 64-66.

Kukla, A. (2002). Alaska Department of Environmental Conservation. Personal communication. (907) 269-7523.

Kuuskraa, V. A., E. Hammershaimb, et al. (1983). Handbook of gas hydrate properties and occurence, U.S. Department of Energy.

Kuuskraa, V. A., E. Hammershaimb, et al. (1983). Conceptual Models for Gas Hydrates. Phase 1. Technical Directive 6. Final Report., Morgantown Energy Technology Center.

Kvenvolden, K. A. (1993). A primer on gas hydrates. The Future of Energy Gases: USGS Professional Paper 1570. D. G. Howell. Washington, USGPO: 279-291.

Kvenvolden, K. A. (1995). "Natural gas hydrate occurrence and issues." Sea Technol. 36: 69-74.

Kvenvolden, K. A. (1995). "A review of the geochemistry of methane in natural gas hydrate." Org. Geochem. 23(11-12): 997-1008.

Lanoil, B. D., R. Sassen, et al. (2001). "Bacteria and Archaea Physically Associated with Gulf of Mexico Gas Hydrates." Appl. Environ. Microbiol. 67(11): 5143-5153.

Leitz, F. and B. Boegli (2001). Evaluation of the Port Hueneme Demonstration Plant: An analysis of 1 MGD reverse osmosis, nanofiltration, and electrodialysis reversal plants run under essentially identical conditions, U.S. Department of the Interior Bureau of Reclamation.

Lerand, M. (1973). "Beaufort Sea. In: Future petroleum provinces of Canada - Their geology and potential. R.G. McCrossen (ed.)." Canadian Society of Petroleum Geologists Memoir 1: 315-386.

Li, L. N., C. Kato, et al. (1999). "Bacterial diversity in deep-sea sediments from different depths." Biodivers. Conserv. 8(5): 659-677.

LopezGarcia, P., A. LopezLopez, et al. (2001). "Diversity of free-living prokaryotes from a deep-sea site at the Antarctic Polar Front." FEMS Microbiol. Ecol. 36(2-3): 193202.

\section{5 of 69}


Lovley, D. R. (2001). Reduction of iron and humics in subsurface environments. Subsurface Microbiology and Biogeochemistry. M. Fletcher. New York, WileyLiss, Inc: 193-217.

Makogon, Y. F. (1981). Hydrates of Natural Gas, PennWell Publishing Company, Tulsa, Oklahoma.

Marchesi, J. R., A. J. Weightman, et al. (2001). "Methanogen and bacterial diversity and distribution in deep gas hydrate sediments from the Cascadia Margin as revealed by $16 \mathrm{~S}$ rRNA molecular analysis." FEMS Microbiol. Ecol. 34(3): 221-228.

Martens, C. S. and R. A. Berner (1974). "Methane production in the interstitial waters of sulfate depleted marine sediments." Science 185: 1167-1169.

Martens, C. S. and R. A. Berner (1977). "Interstitial water chemistry of anoxic Long Island Sound sediments. 1. Dissolved gases." Limnol. Oceanogr. 22: 10-25.

Morita, R. Y. and C. E. ZoBell (1955). "Occurrence of bacteria in pelagic sediments collected during the Mid-Pacific Expedition." Deep Sea Res. 3: 66-73.

Motamedi, M. and K. Pedersen (1998). "Desulfovibrio aespoeensis sp. nov., a mesophilic sulfate-reducing bacterium for deep groundwater at Åspö Hard Rock Laboratory, Sweden." Int. J. Syst. Bacteriol. 48: 311-315.

Murase, J. and M. Kimura (1994). "Methane production and its fate in paddy fields .7. electron accepters responsible for anaerobic methane oxidation." Soil Sci. Plant Nutr. 40(4): 647-654.

Murase, J. and M. Kimura (1994). "Methane production and its fate in paddy soils. IV. Sources of microogansims and substrates responsible for anaerobic $\mathrm{CH}_{4}$ oxdidation in subsoil." Soil. Sci. Plant Nutr. 40: 57-61.

Nauhaus, K., A. Boetius, et al. (2002). "In vitro demonstration of anaerobic oxidation of methane coupled to sulphate reduction in sediment from a marine gas hydrate area." Environ. Microbiol. 4(5): 296-305.

Onstott, T. C., T. J. Phelps, et al. (1999). "Observations pertaining to the origin and ecology of microorganisms recovered from the deep sufsurface of Taylorsville Basin, Virginia." Geomicrobiol. J. 14: 353-383.

Orphan, V. J., K.-U. Hinrichs, et al. (2001). "Comparative analysis of methane-oxidizing archaea and sulfate-reducing bacteria in anoxic marine sediments." Appl. Environ. Microbiol. 67: 1922-1934.

Orphan, V. J., C. H. House, et al. (2001). "Methane-consuming archaea revealed by directly coupled isotopic and phylogenetic analysis." Science 293(5529): 484487.

Orphan, V. J., L. T. Taylor, et al. (2000). "Culture-dependent and culture-independent characterization of microbial assemblages associated with high-temperature petroleum reservoirs." Appl. Environ. Microbiol. 66(2): 700-711.

Pancost, R. D., J. S. S. Damste, et al. (2000). "Biomarker evidence for widespread anaerobic methane oxidation in Mediterranean sediments by a consortium of methanogenic archaea and bacteria." Appl. Environ. Microbiol. 66(3): 1126-1132.

\section{6 of 69}


Panganiban, A. T., T. E. Patt, et al. (1979). "Oxidation of methane in the absence of oxygen in lake water semples." Appl. Environ. Microbiol. 37: 303-309.

Parkes, R. J., S. J. Bale, et al. (1995). "A combined ecological and physiological approach to studying sulphate reduction within deep marine sediment layers." $\underline{\mathrm{J}}$. Microbiol. Methods 23: 235-249.

Parkes, R. J., B. A. Cragg, et al. (1994). "Deep bacterial biosphere in Pacific Ocean sediments." Nature 371(6496): 410-413.

Parkes, R. J., B. A. Cragg, et al. (2000). "Recent studies on bacterial populations and processes in subseafloor sediments: A review." Hydrogeol. J. 8(1): 11-28.

Patching, J. W. and D. Eardly (1997). "Bacterial biomass and activity in the deep waters of the eastern Atlantic - evidence of a barophilic community." Deep Sea Res. Pt. I Oceanog. Res. 44(9-10): 1655-1670.

Patil, S. L. (2002). Overview of Gas Hydrate Production Technology. SPE-AAPG Western Regional Meeting, Anchorage, Alaska.

Pedersen, K. (1997). "Microbial life in deep basaltic aquifers." FEMS Microbiol. Rev. 20: $399-414$.

Pedersen, K. (2000). "Exploration of deep intraterrestrial microbial life: current perspectives." FEMS Microbiol. Lett. 185: 9-16.

Pedersen, K. (2001). Diversity and activity of microorganisms in deep igneous rock aquifers of the Fennoscandian Shield. Subsurface Microgeobiology and Biogeochemistry. M. Fletcher. New York, Wiley-Liss: 97-139.

Pedersen, K. and S. Ekendahl (1992). "Incorporation of CO2 and introduced organic compounds by bacterial populations in groundwater from the deep crystalline bedrock of the Stripa mine." J. Gen. Microbiol. 138: 369-376.

Peters, K. E., and Fowler, M.G. (2002). "Applications of petroleum geochemistry to exploration and reservoir management." Organic Geochemistry 33: 5-36.

Petsch, S. T., T. I. Eglinton, et al. (2001). "C-14-dead living biomass: Evidence for microbial assimilation of ancient organic carbon during shale weathering." Science 292(5519): 1127-1131.

Popp, B. N., F. J. Sansone, et al. (1995). "Determination of concentration and carbon isotopic composition of dissolved methane in sediments and nearshore waters." Anal. Chem. 67: 405-411.

Reeburgh, W. S. (1967). "An improved interstitial water sampler." Limnol. Oceanogr. 12: 163-165.

Reeburgh, W. S. (1977). "Methane consumption in Cariaco Trench waters and sediments." Earth Plant. Sci. Lett. 28: 337-344.

Reeburgh, W. S. (1980). "Anaerobic methane oxidation: rate depth distributions in Skan Bay sediments." Earth Planet. Sci. Letters 47: 345-352.

Reeburgh, W. S. (1982). A major sink and flux control for methane in marine sediments: anaerobic consumption. The Dynamics of the Ocean Floor. F. T. Manheim. Lexington, MA, D.C. Heath and Co.: 203-218.

67 of 69 
Reeburgh, W. S. and D. T. Heggie (1977). "Microbial methane consumption reactions and their effect on methane distributions in freshwater and marine environments." Limnol. Oceanogr. 22:1-9.

Rivkina, E., D. Gilichinsky, et al. (1998). "Biogeochemical activity of anaerobic microorganisms from buried permafrost sediments." Geomicrobiol. J. 15(3): 187193.

Rivkina, E. M., E. I. Friedmann, et al. (2000). "Metabolic activity of permafrost bacteria below the freezing point." Appl. Environ. Microbiol. 66(8): 3230-3233.

Rochelle, P. A., B. Cragg, et al. (1994). "Effects of sample handling on estimation of bacterial diversity in marine sediments by $16 \mathrm{~S}$ rRNA gene sequence analysis." FEMS Microbiol. Ecol. 15: 215-225.

Sassen, R., D. A. DeFreitas, et al. (1999). "Thermogenic gas hydrates and hydrocarbon gases in complex chemosynthetic communities, Gulf of Mexico continental slope." Org. Geochem. 30(7): 485-497.

Sassen, R., I. R. MacDonald, et al. (1994). "Organic geochemistry of sediments from chemsynthetic communities, Gulf of Mexico slope." Geo.-Mar. Lett. 14: 110-119.

Sassen, R., S. T. Sweet, et al. (1999). "Geology and geochemistry of gas hydrates, central Gulf of Mexico continental slope." Trans. Gulf Coast Assoc. Geol. Soc. 49: 462468.

Shi, T., R. H. Reeves, et al. (1997). "Characterization of viable bacteria from Siberian permafrost by 16S rDNA sequencing." Microbial. Ecol. 33(3): 169-179.

Sira, J. H., S. L. Patil, et al. (1990). Study of Hydrate Dissociation by Methanol and Glycol Injection. 65th Annual Technical Conference and Exhibition of the Society of Petroleum Engineers, New Orleans, LA.

Sloan, E. D. (1990). Chapter 7: Hydrates in the Earth. Clathrate Hydrates of Natural Gases. New York, Marcel Dekker.

Sorensen, K. B., K. Finster, et al. (2001). "Thermodynamic and kinetic requirements in anaerobic methane oxidizing consortia exclude hydrogen, acetate, and methanol as possible electron shuttles." Microbial Ecol. 42(1): 1-10.

Stetter, K. O. (1996). "Hyperthermophilic procaryotes." FEMS Microbiol. Rev. 18: 145148.

Stevens, T. O. and J. P. McKinley (1995). "Lithoautotrophic microbial ecosystems in deep basalt aquifers." Science 270: 450-454.

Stevens, T. O. and J. P. McKinley (2000). "Abiotic controls on $\mathrm{H}_{2}$ production from basalt-water reactions and implications for aquifer biogeochemistry." Environ. Sci. Technol. 34(5): 826-831.

Stroes-Gascoyne, S. and F. P. Sargent (1998). "The Canadian approach to microbial studies in nuclera waste management and disposal." J. Contam. Hydrol. 35: 175 190.

\section{8 of 69}


Thomsen, T. R., K. Finster, et al. (2001). "Biogeochemical and molecular signatures of anaerobic methane oxidation in a marine sediment." Appl. Environ. Microbiol. 67(4): 1646-1656.

Thorseth, I. H., H. Furnes, et al. (1995). "Textural and chemical effects of bacterial activity on basaltic galss: an experimental approach." Chem. Geol. 119: 139-160.

Thorseth, I. H., T. Torsvik, et al. (1995). "Microbes play and important role in the alteration of oceanic crust." Chem. Geol. 126: 137-146.

Ussler, W. and C. K. Paull (1995). "Effects of ion exclusion and isotopic fractionation on pore water geochemistry during gas hydrate formation and decomposition." GeoMarine Letters 15: 37-44.

Valentine, D. L. and W. S. Reeburgh (2000). "New perspectives on anaerobic methane oxidation." Environ. Microbiol. 2(5): 477-484.

Vetriani, C., H. W. Jannasch, et al. (1999). "Population structure and phylogenetic characterization of marine benthic Archaea in deep-sea sediments." Appl. Environ. Microbiol. 65(10): 4375-4384.

Vorobyova, E., N. Minkovsky, et al. (2001). Micro-organisms and biomarkers in permafrost. Permafrost response on Ecomonic Development, Environmental Security and Natural Resources. V. Melnikov. Amsterdam, Kluwer Academic: 527-541.

Vorobyova, E., V. Soina, et al. (1997). "The deep cold biosphere: facts and hypothesis." FEMS Microbiol. Rev. 20: 277-290.

Waseda, A. (1998). "Organic carbon content, bacterial methanogenesis, and accumulation processes of gas hydrates in marine sediments." Geochem. J. 32(3): 143-157.

Wellsbury, P., K. Goodman, et al. (1997). "Deep marine biosphere fuelled by increasing organic matter availability during burial and heating." Nature 388(6642): 573576.

Wellsbury, P., K. Goodman, et al. (2000). "The geomicrobiology of deep marine sediments from Blake Ridge containing methane hydrate (Sites 994, 995, and 997)." Proc. Ocean Drill. Prog.: Sci. Res. 164: 379-391.

Wilson, G. S., P. Braddock, et al. (1998). "Coring for microbial records of Antarctic climate." Antarct. J U.S. 1996 Review 31: 83-86.

Wittebolle, R. J. (1985). A laboratory facility for testing sediments containing gas hydrates. 4th International Offshore Mechanics and Arctic Engineering Symposium, Dallas, Texas.

Wittebolle, R. J. and D. C. Sego Analysis of a production well through sediments containing gas hydrates.

Yousif, M. H., H. H. Abass, et al. (1991). "Experimental and Theoretical Investigation of Methane-Gas-Hydrate Dissociation in Porous Media." SPE Reservoir Engineering February: 69-76.

\section{9 of 69}




\section{Appendix E - HOT ICE No. 1 Site/Rig Photos}

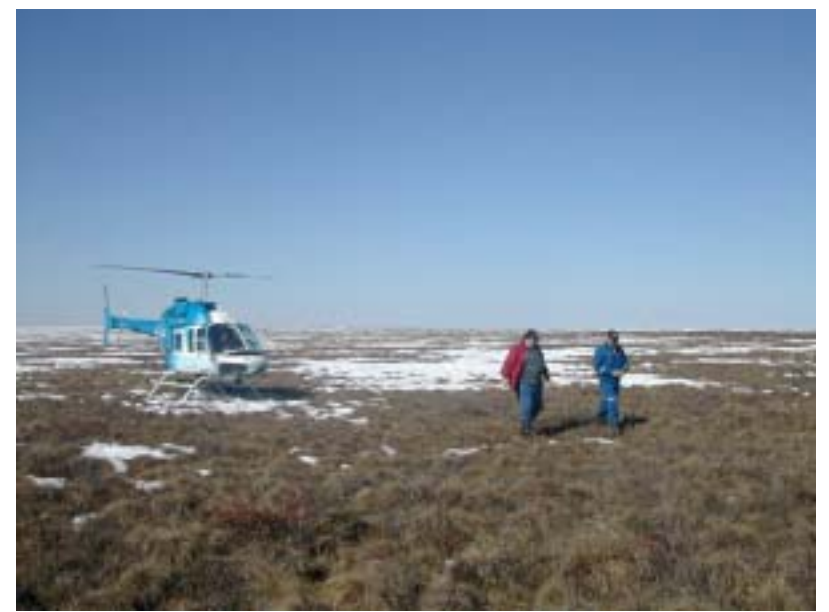

Figure E-1. HOT ICE Well \#2 Site

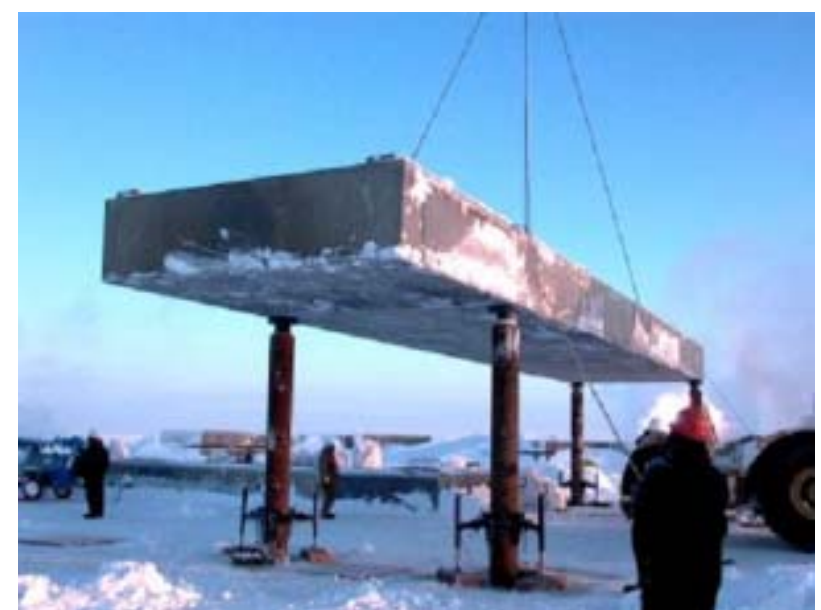

Figure E-3. Setting the First Platform Module

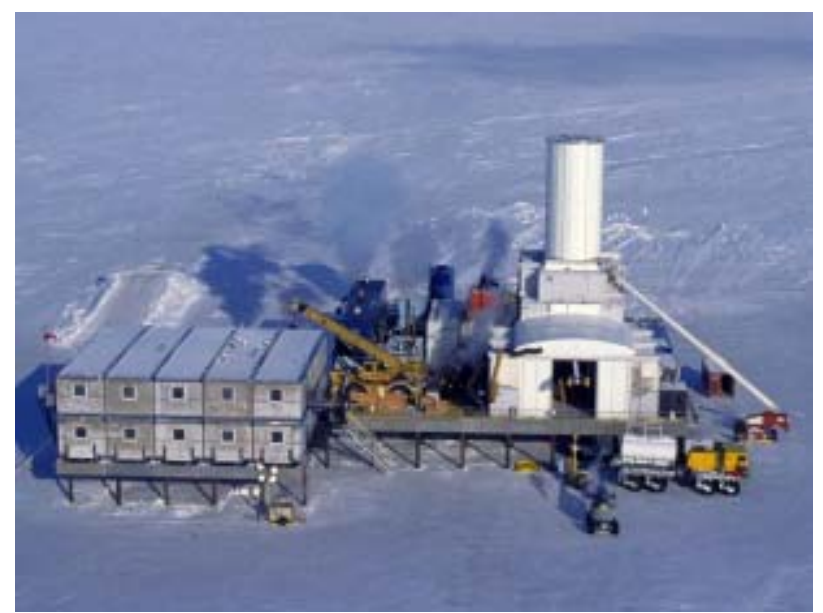

Figure E-5. Complete Camp Ready for Drilling

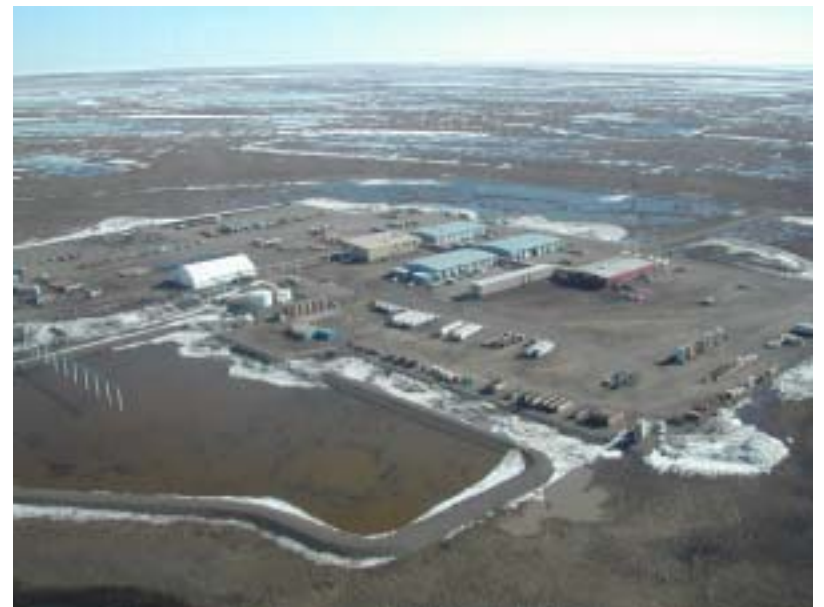

Figure E-2. Base Camp

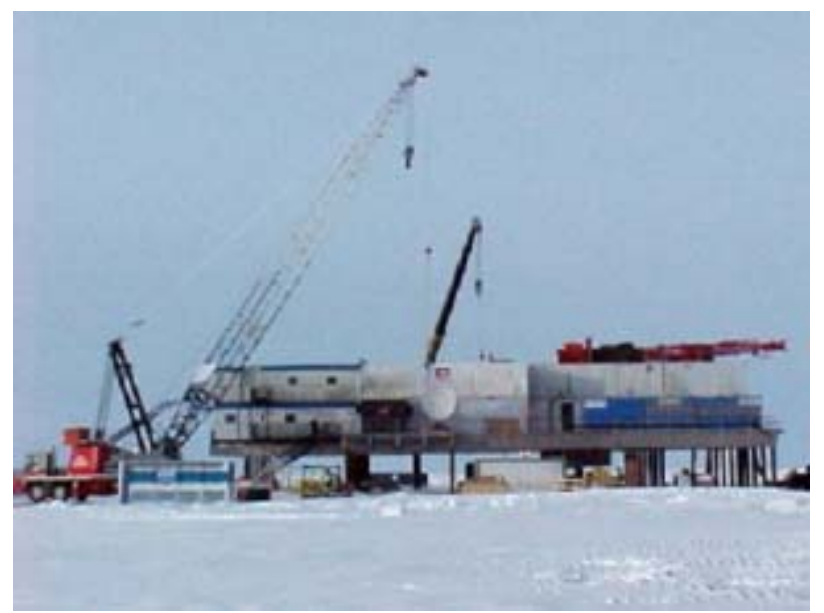

Figure E-4. Assembling the Platform

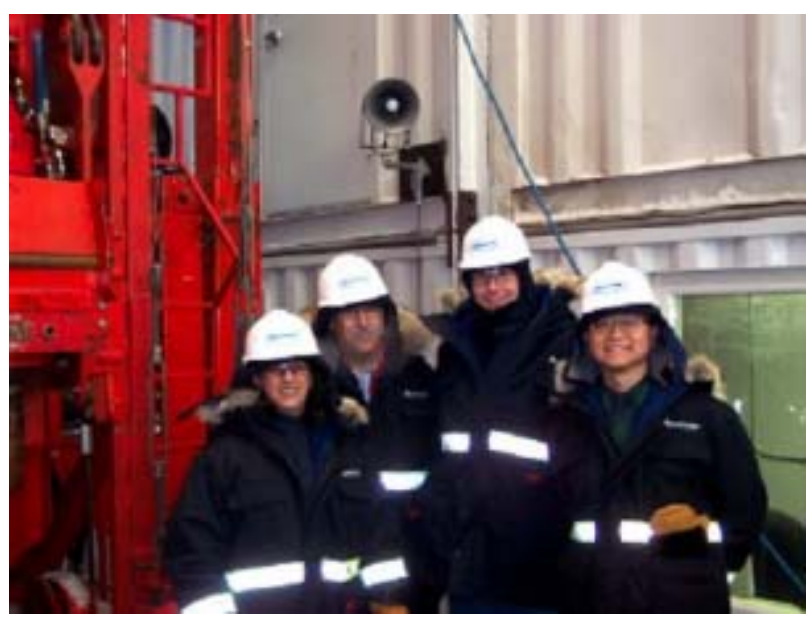

Figure E-6. Team Members on the Rig Floor 


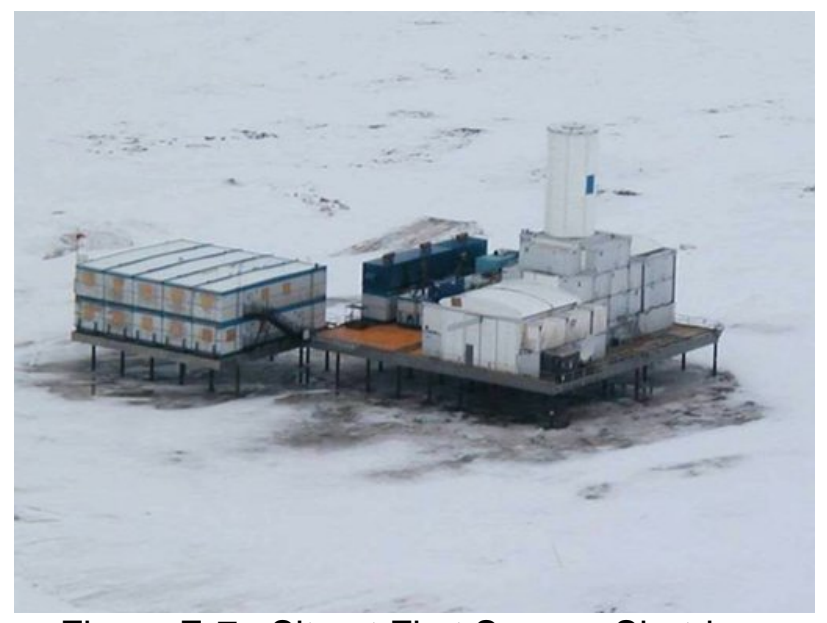

Figure E-7. Site at First Season Shutdown

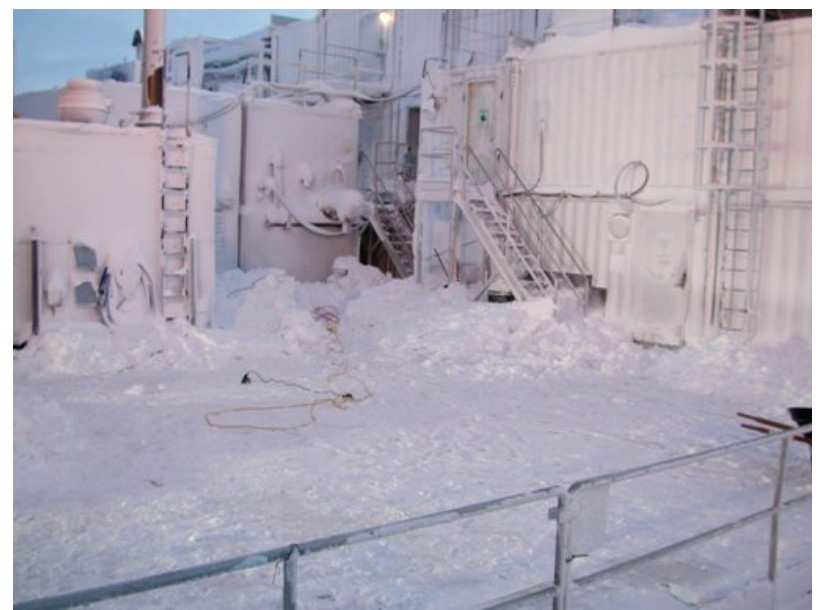

Figure E-9. Beginning of Second Season

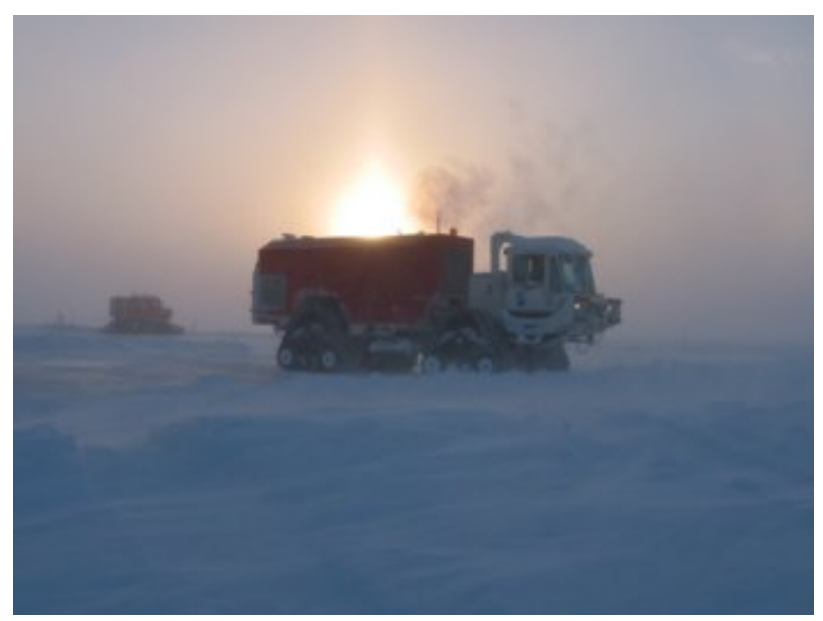

Figure E-11. VSP Thumper Truck

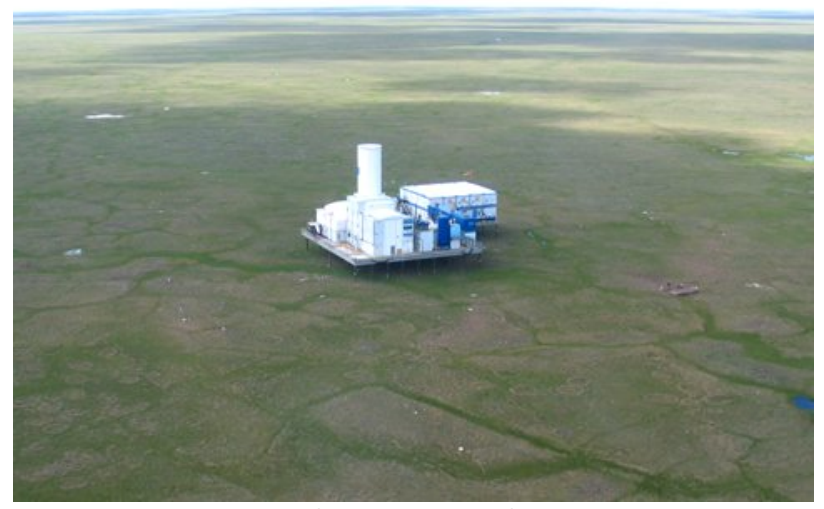

Figure E-8. Site during Summer 2003

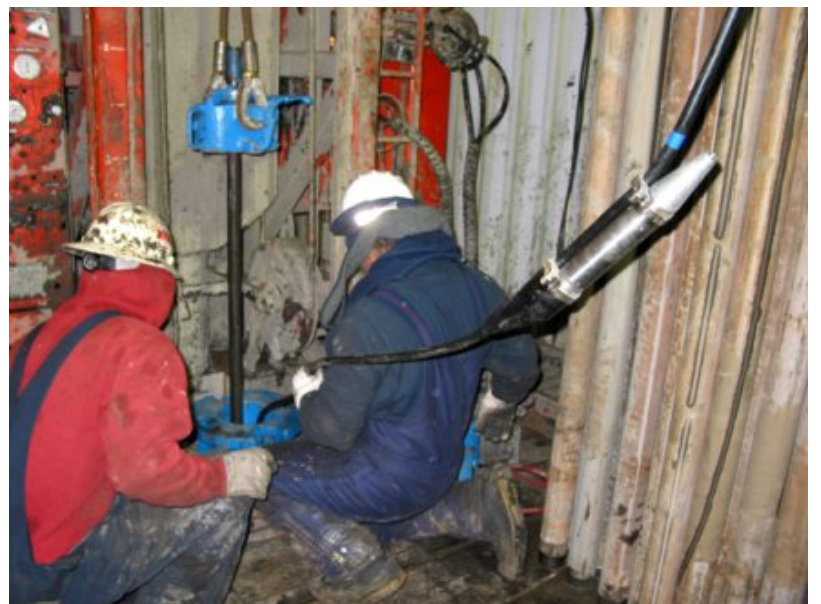

Figure E-10. Deploying VSP Array into Well

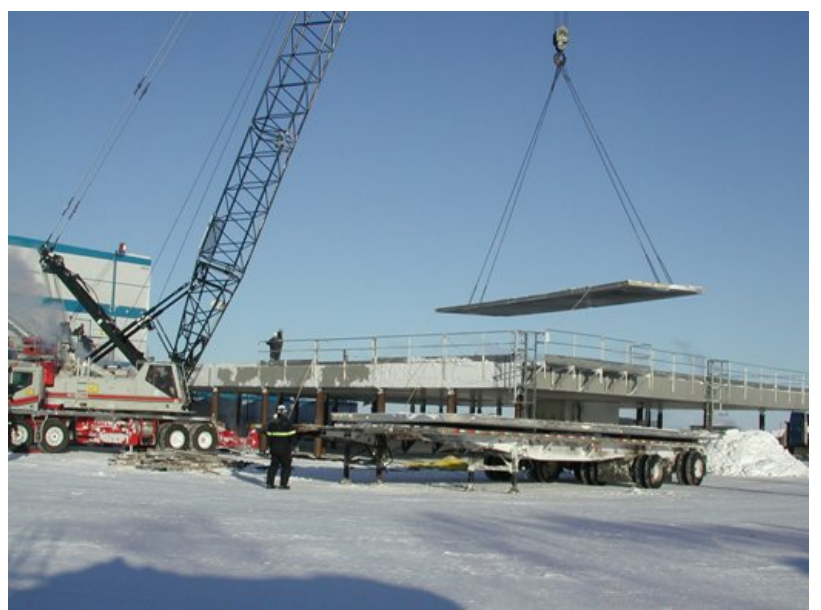

Figure E-12. Disassembling the Platform 


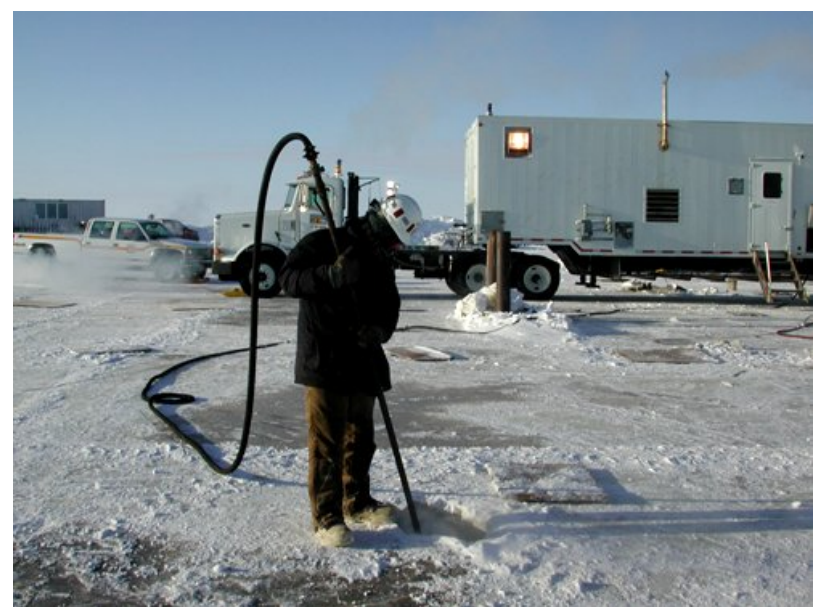

Figure E-13. Vacuuming Platform Leg Holes

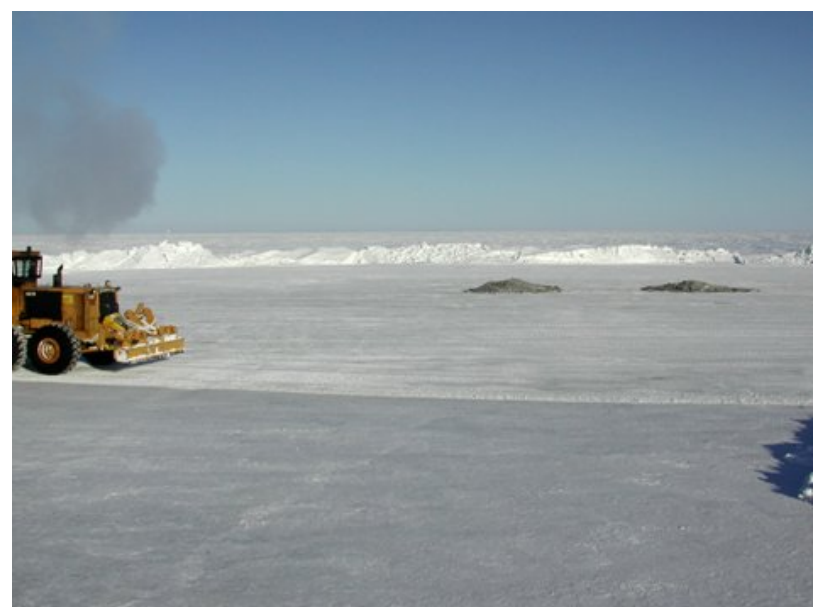

Figure E-14. Site after Demobilization and Remediation 


\title{
Appendix F
}

\author{
AAPG HEDBERG CONFERENCE \\ "Gas Hydrates: Energy Resource Potential and Associated Geologic Hazards" \\ September 12-16, 2004, Vancouver, BC, Canada \\ HOT ICE Well \#1 - \\ Well Planning, Operations and Results of the First \\ Dedicated Gas-Hydrate Well in the Alaskan Arctic
}

Thomas E. Williams, Maurer Technology Inc.

Bill Liddell, Ali Kadaster and Tommy Thompson, Anadarko Petroleum Corp.

Drilling of a dedicated gas-hydrate well, Hot Ice \#1, was completed in the first quarter of 2004. The well is located south of the Kuparuk River field, approximately 60 miles west of Deadhorse, Alaska. This well was constructed as part of a cost-shared partnership between the U.S. Department of Energy's Office of Fossil Energy, Anadarko Petroleum, Maurer Technology, and Noble Engineering and Development.

Objectives of this gas-hydrate project were to analyze existing geological and geophysical data and obtain new field data required to predict hydrate occurrences; test the best methods and tools for drilling and recovering hydrates; and to plan, design, and implement a program to safely and economically drill and produce gas from hydrates in Alaska.

Although the well did not encounter hydrates, several innovative technologies were successfully demonstrated including the first Arctic Drilling Platform, designed and constructed by Anadarko.

This paper addresses well planning, drilling operations, the coring program, and results derived from the first dedicated gas-hydrate well in the Alaskan Arctic. A discussion of lessons learned is also presented. Potential future studies are identified that are needed before the next hydrate well is undertaken. It is hoped that this information will contribute to safe hydrate drilling operations in future applications and will assist the industry in addressing technical and logistical obstacles for the eventual commercial production of methane hydrates. 

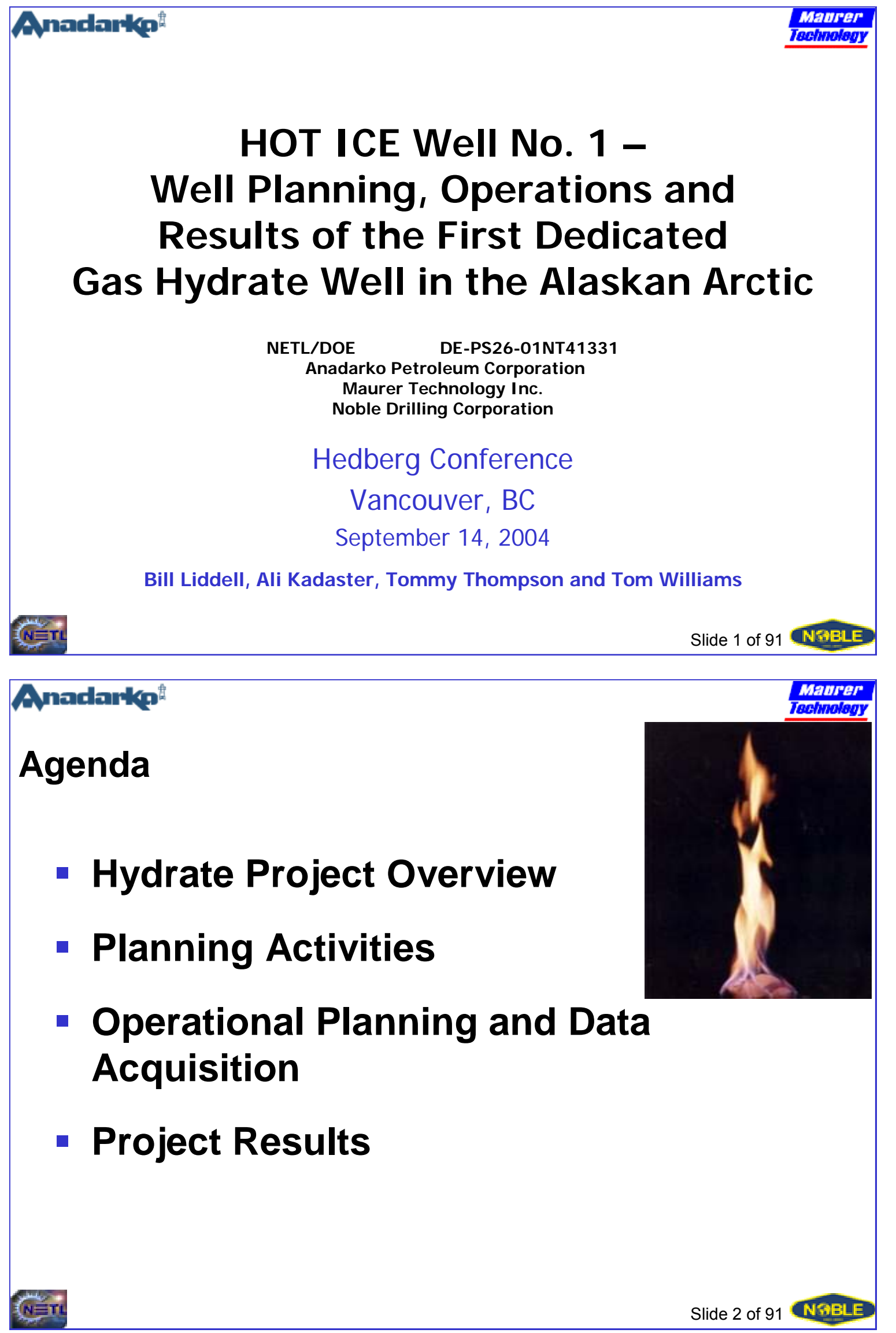


\section{Objectives}

Primary objectives

- Drill, core and test for hydrates on Anadarko acreage in Alaska

- Design, build and field test mobile core lab to measure hydrate filled sediments

- Design and test drilling methodology to core permafrost, coal seams and hydrates with minimal damage

- Characterize hydrate-filled sediments and reservoir at large

- Secondary objectives

- Develop process to operate outside narrow weather window

- Test Arctic platform

- Test light-weight rig

- Test ability to operate "roadless"

\section{Final Published Reports}

Final Report includes all well planning activities and project findings, plus supplemental reports:

- Hydrate Core Drilling Tests (Topical Report)

- Appendix A: Hydrate Test Coring Apparatus: Report on the Tests Conducted at Maurer's Drilling Research Center (U. of Oklahoma)

- Appendix B: Hydrate Test Log

- Drilling and Coring Operations (Topical Report)

- Low impact operations using the Arctic Platform

- Appendix A: Daily Drilling Reports for 2002-2003 Drilling Season

- Appendix B: Daily Drilling Reports for 2003-2004 Drilling Season

- Appendix C: Tundra Platform Leg Tests (UAA)

- Well Logging Operations (Topical Report)

- Appendix A: Summary Open-Hole and Lithologic Log for Hot Ice No. 1 Well 


\section{Final Published Reports (cont.)}

\section{Core and Fluid Analysis (Topical Report)}

- Appendix A: On-Site Geologic Core Analysis Using a Portable X-Ray Computed Tomographic System (LBNL and J oint Oceanographic Inst.)

- Appendix B: Coring for Methane Hydrate in Shallow Sands of the Sagavanirktok Formation, North Slope, Alaska - Geologic Description (PTS Labs and CorePro)

- Appendix C: Supplemental NMR Measurement Results

- Appendix D: NMR Measurements of Permafrost: Unfrozen Water Assay, Growth Habit of Ice, and Hydraulic Permeability of Sediments (Schlumberger and APC)

- Appendix E: An Application Used for Correcting Thermal Gradients Below Permafrost Using an Empirical Diffusion Model (Anadarko and U. Oklahoma)

- Appendix F: Core Recovery Studies (LBNL)

- Appendix G: Coalbed Methane Studies (USGS)

- Appendix H: Dissociation Rates of Methane Hydrates at Elevated Pressures (USGS)

\section{Final Published Reports (cont.)}

\section{D Vertical Seismic Profile Survey (Topical Report)}

\section{Well Completion Procedures}

Well Testing Procedures

- Hydrate Reservoir Characterization and Modeling (Topical Report)

- Appendix A: Geological Exhibits

- Appendix B: On-Site Geologic Core Analysis at Hot Ice No. 1 Using a Portable XRay Computed Tomographic System (LBNL)

- Appendix C: Investigating Methane Hydrate in Sediments Using X-Ray Computed Tomography (LBNL)

- Appendix D: Preliminary Results for Simulation of Gas Production from North Slope Hydrate Deposits (LBNL)

\section{Lessons Learned and Economic Projections}

\section{Environmental Evaluation Report for the Hot I ce Prospect (APC)}

- Final Report Appendix A: Research on Water Generated During the Production of Gas Hydrates (UAA) 


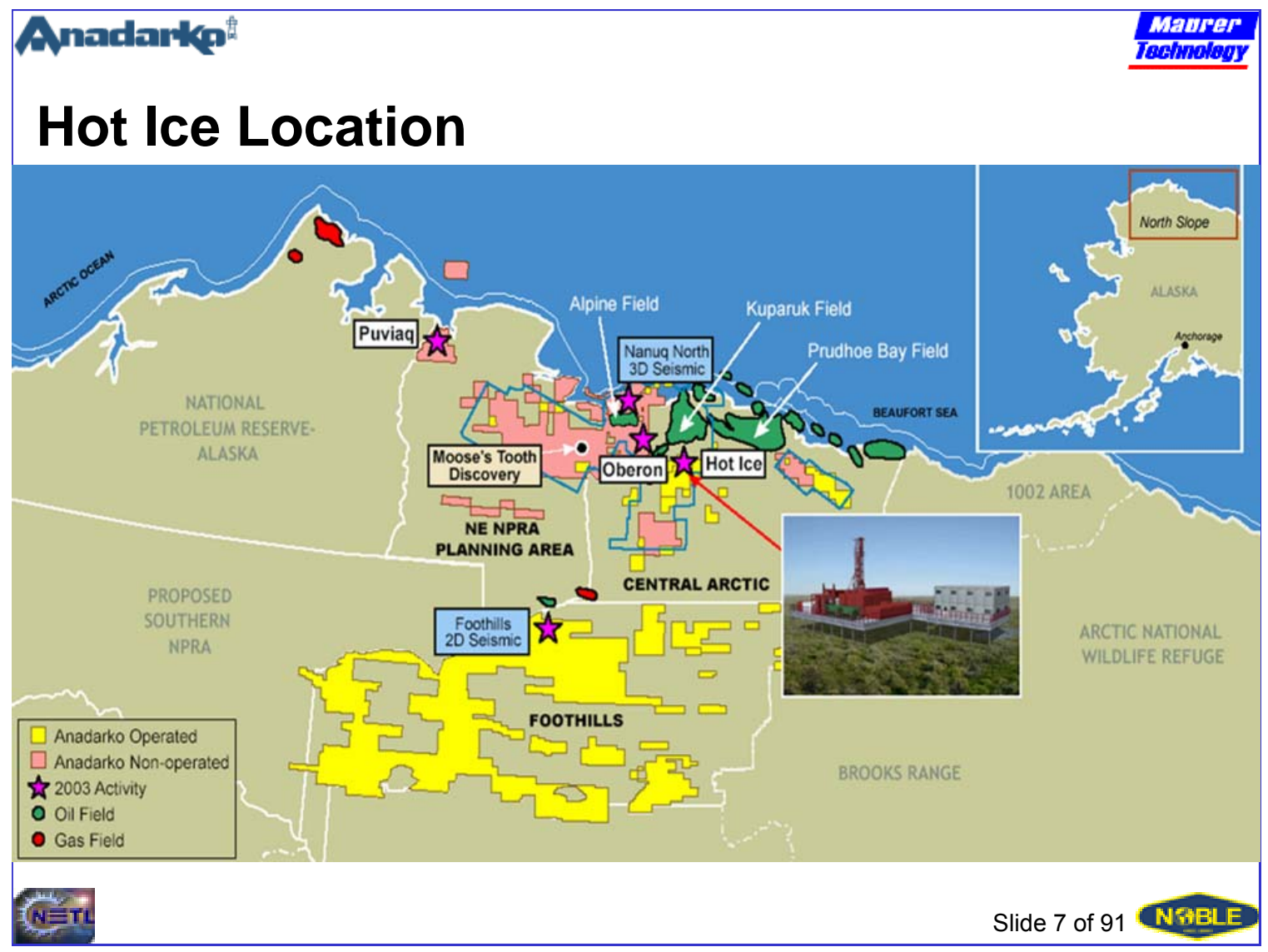

\section{Anadarkpt \\ Progression of Operations

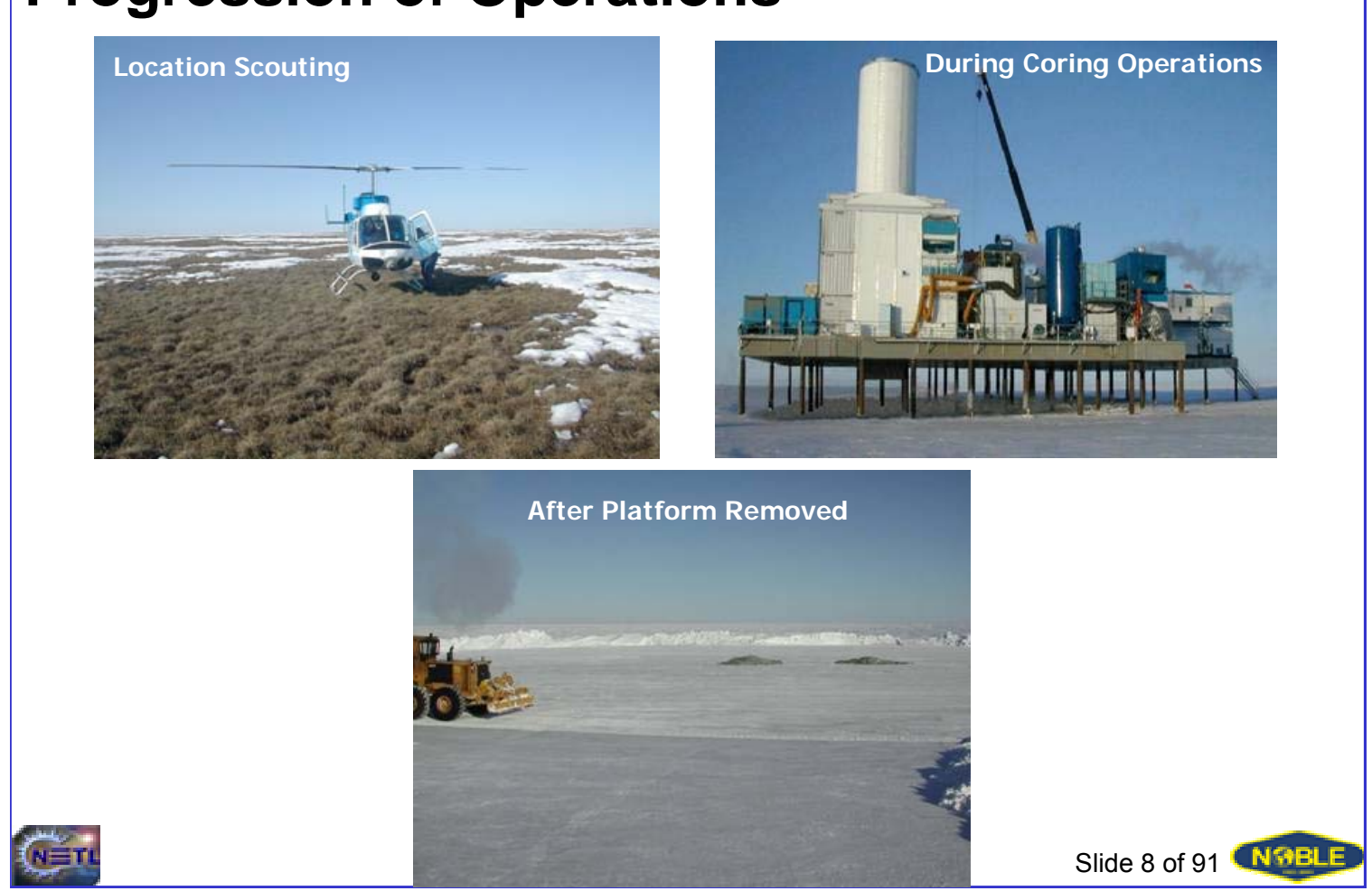



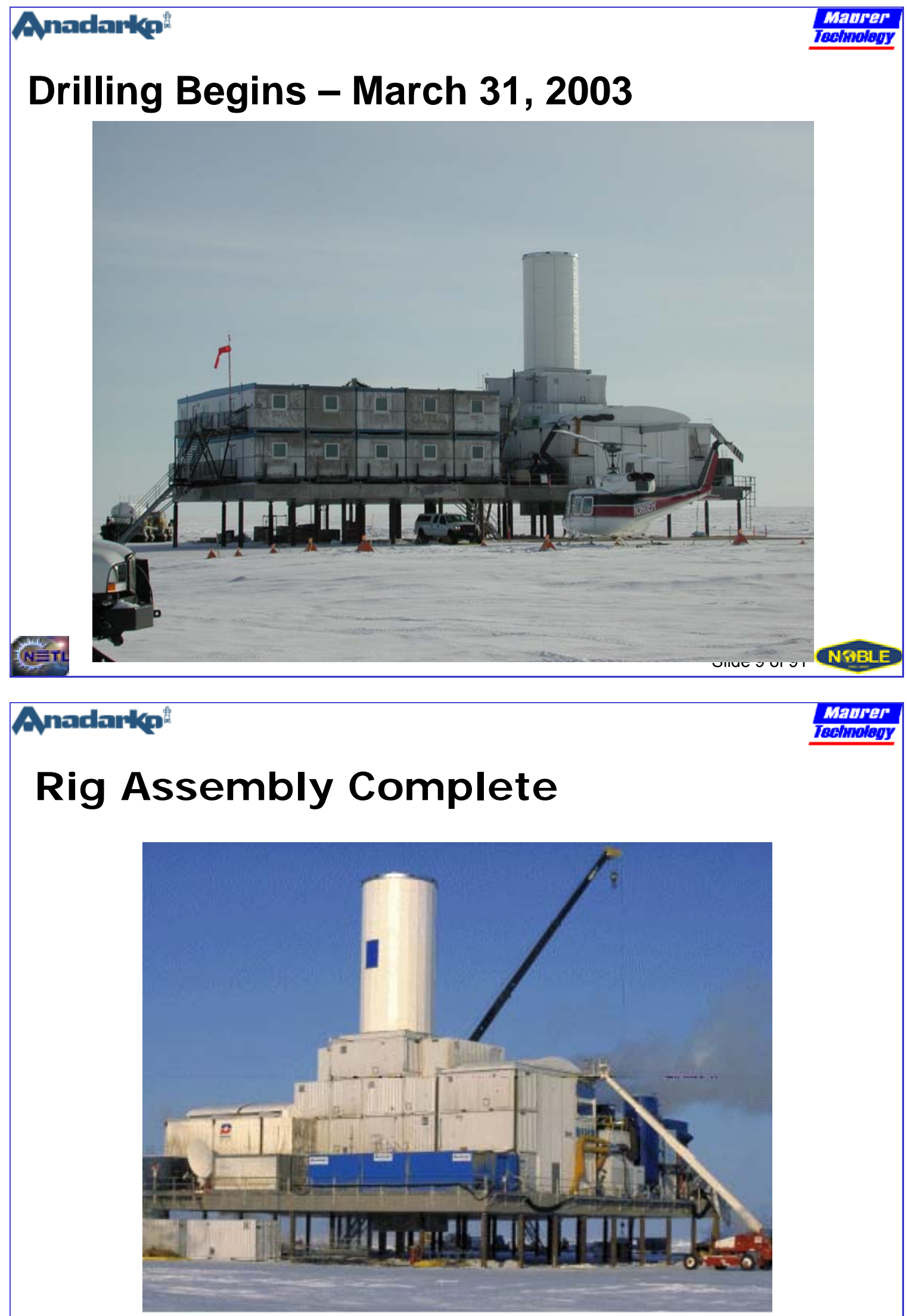

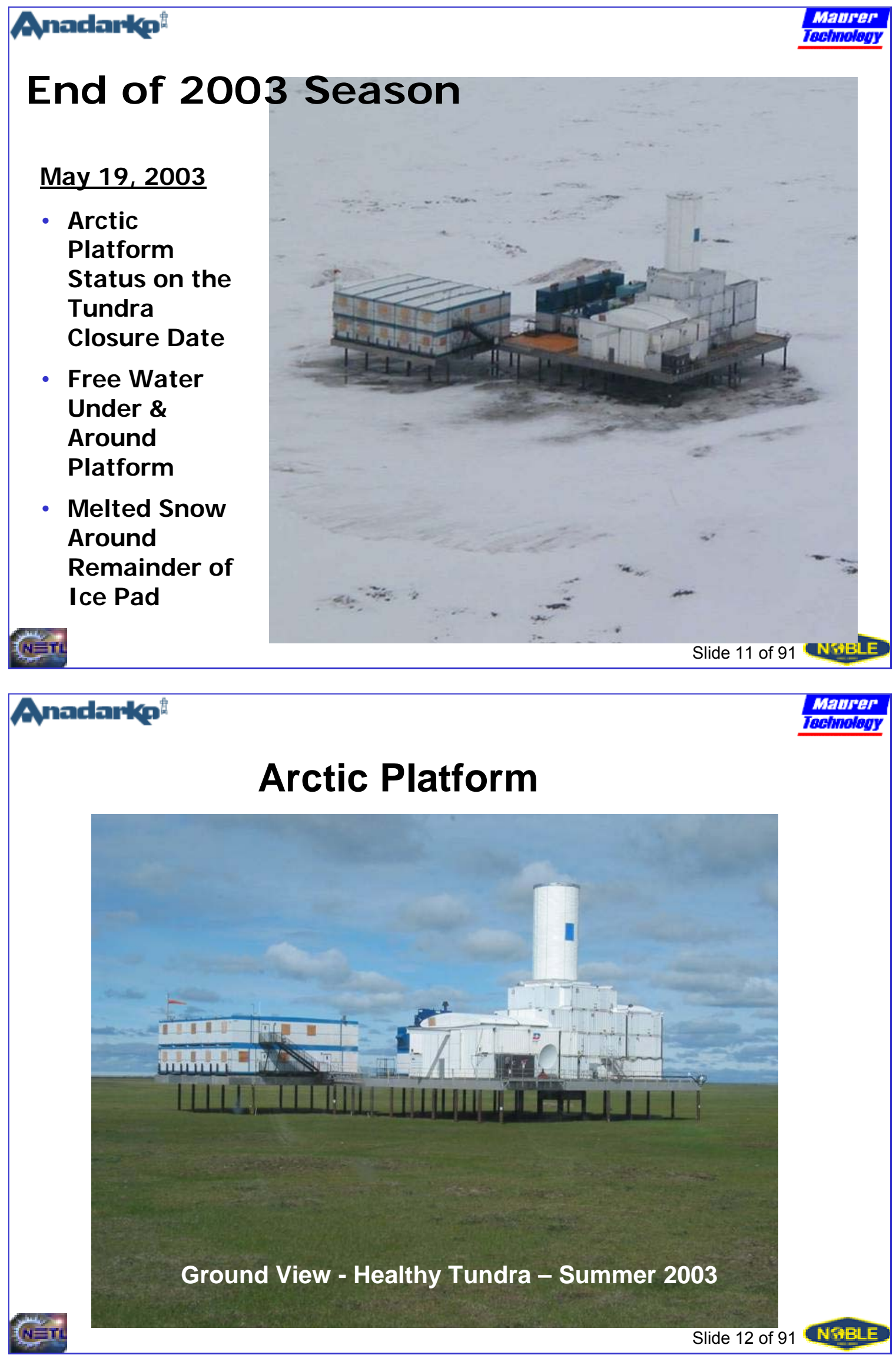

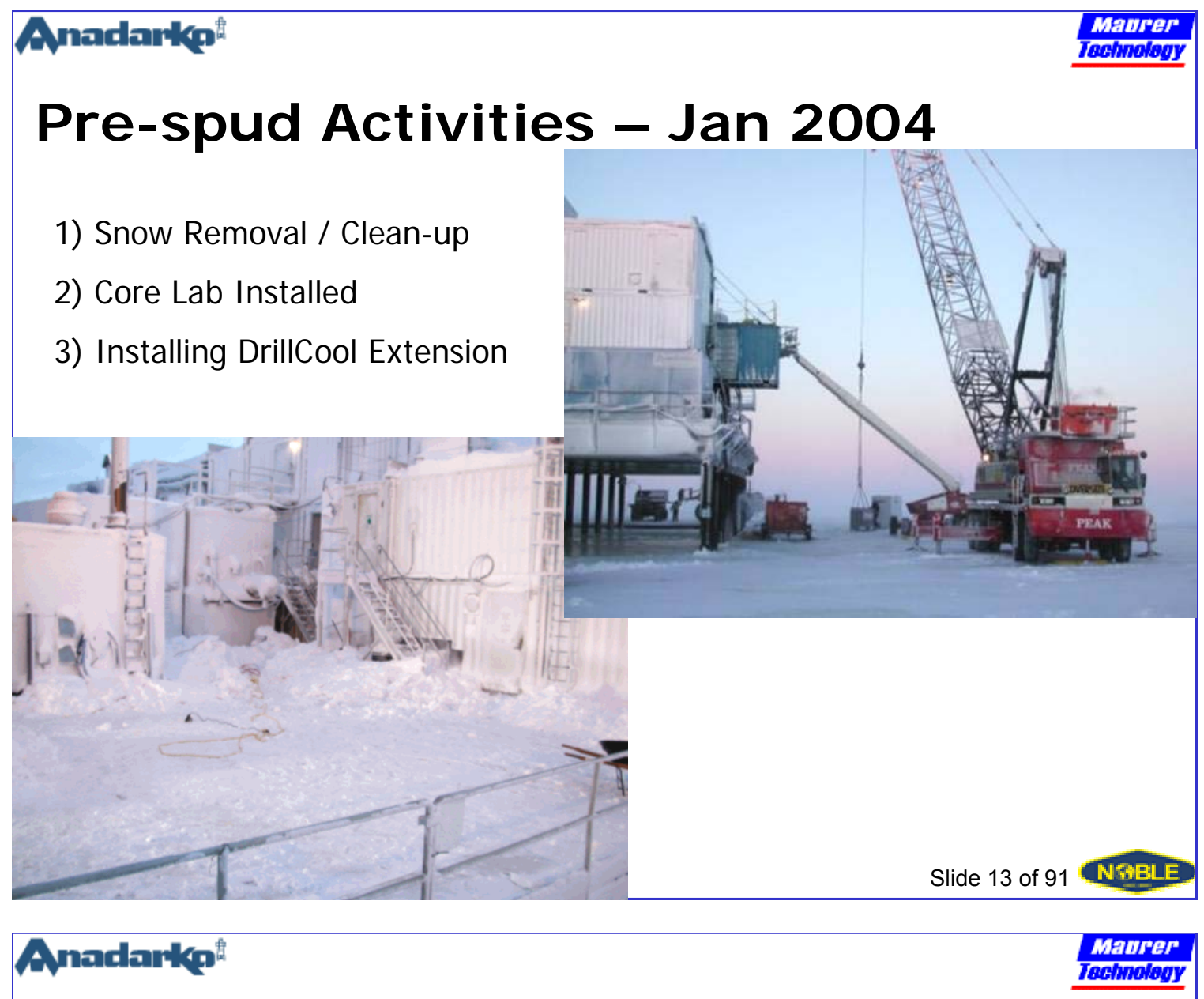

\section{Topsides Removal - Starting 2-18-04}

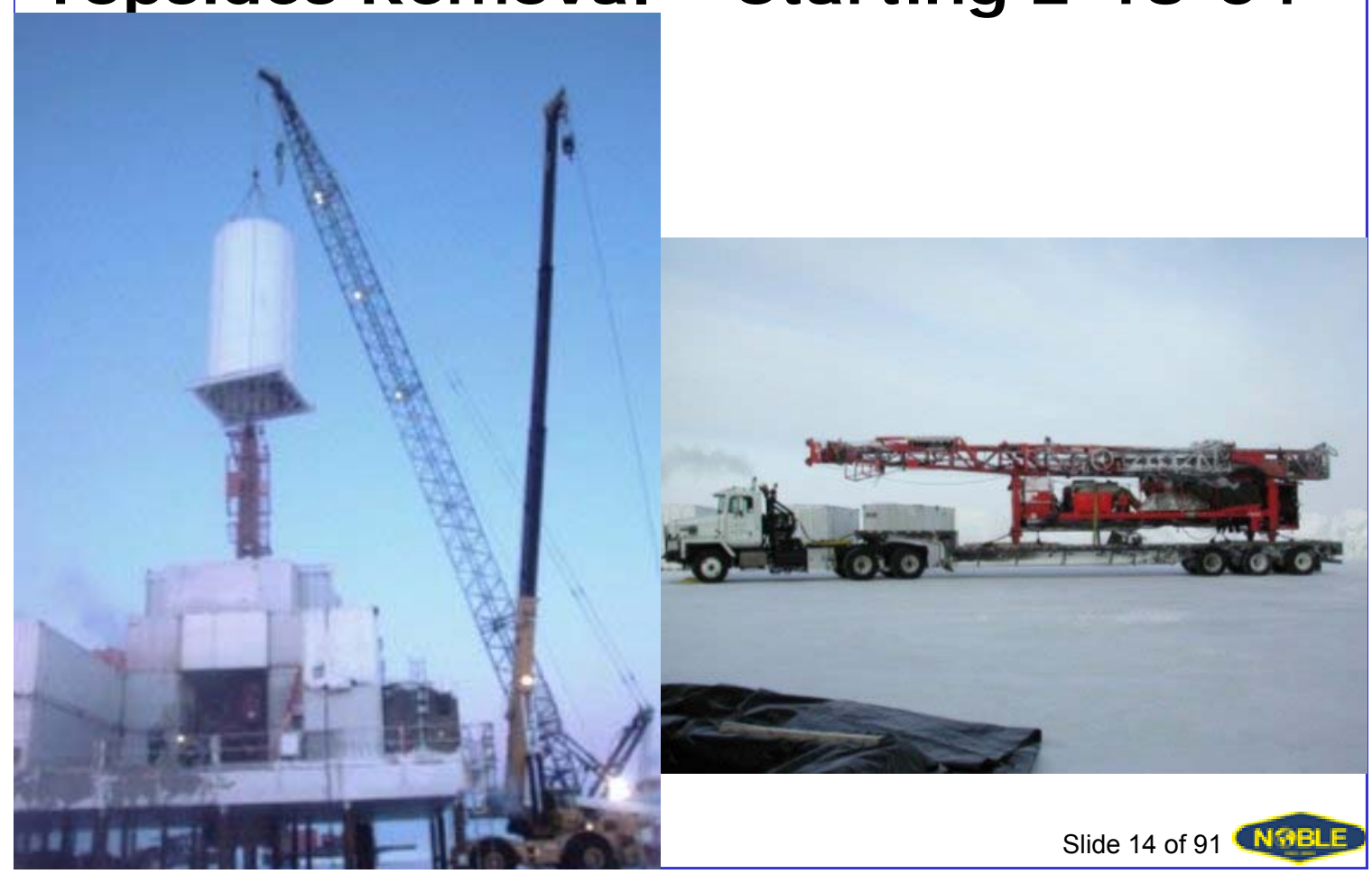



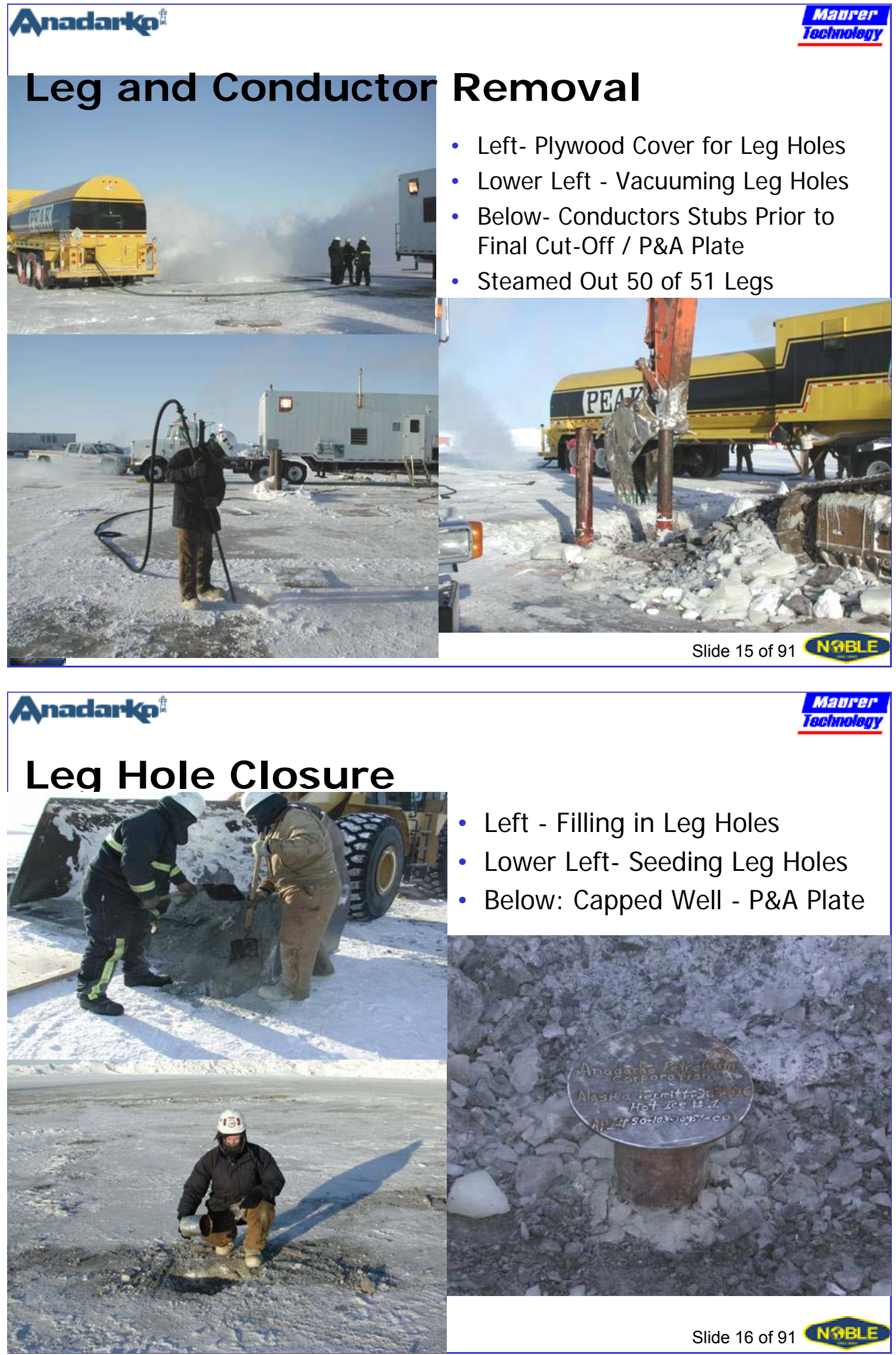

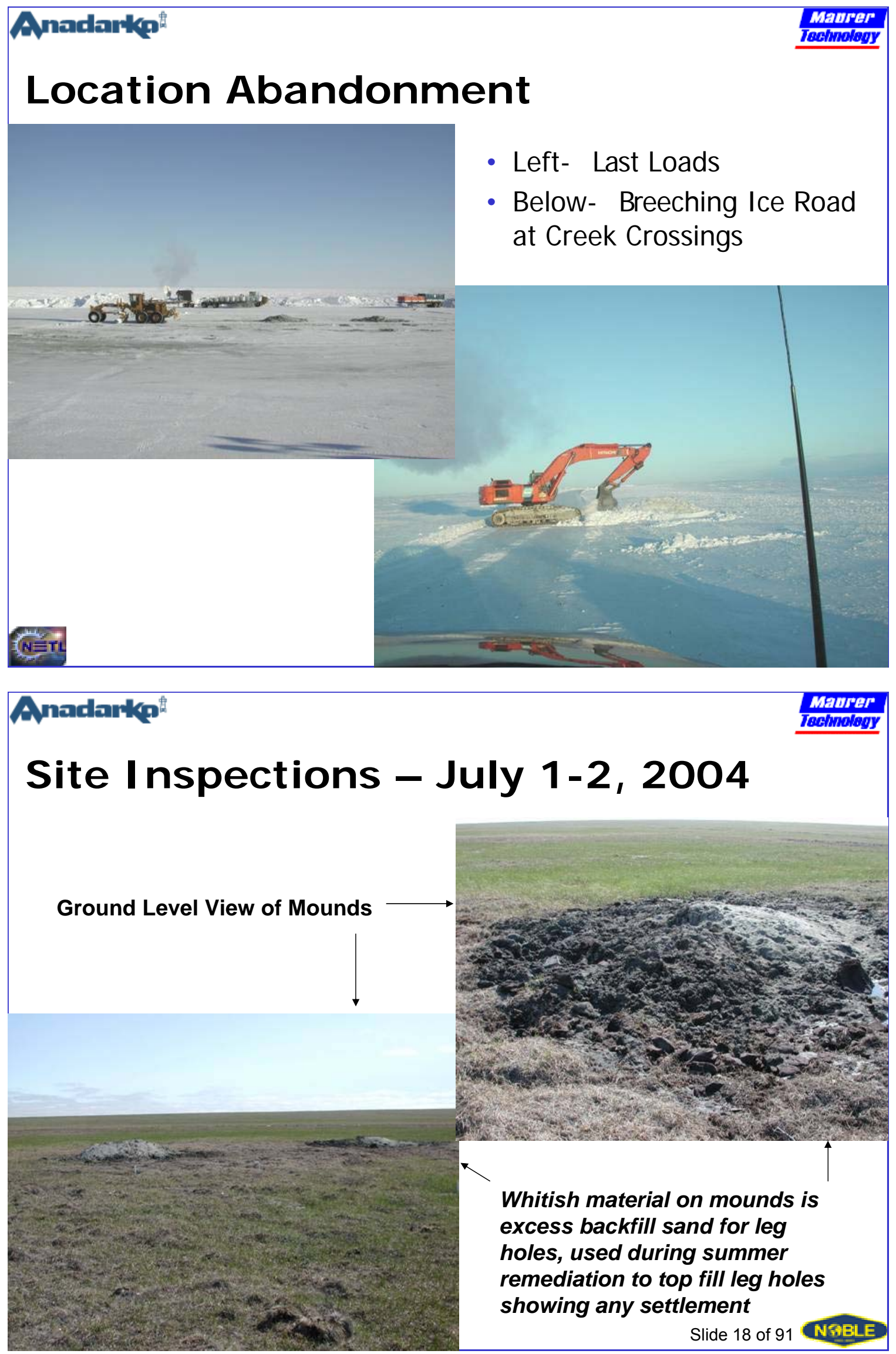


\section{Anadarkp ${ }^{\mathbb{R}}$ \\ Site I nspections - J uly 1-2, 2004}

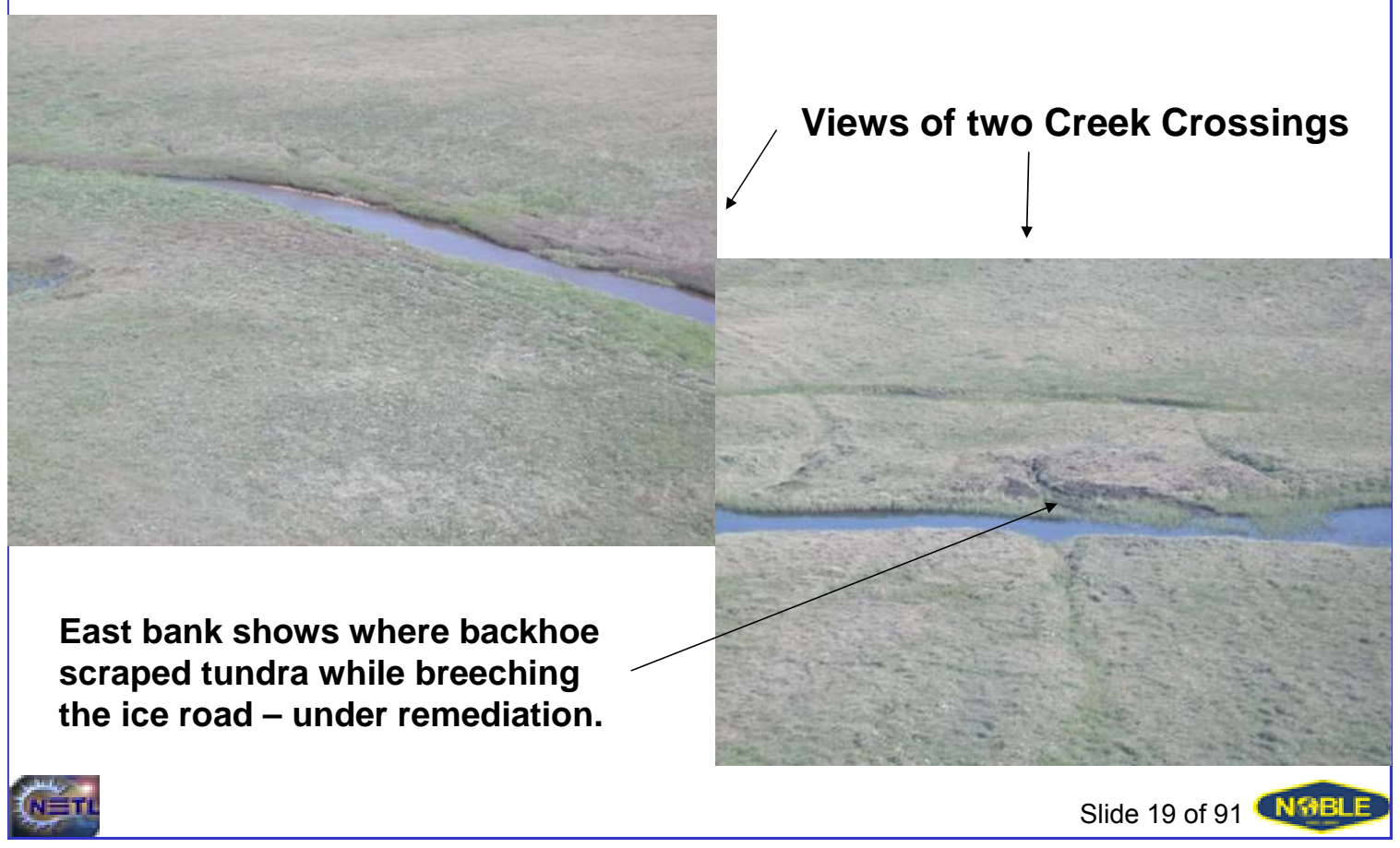

Anadarkgt matrer

\section{Site I nspections - J uly 1-2, 2004}

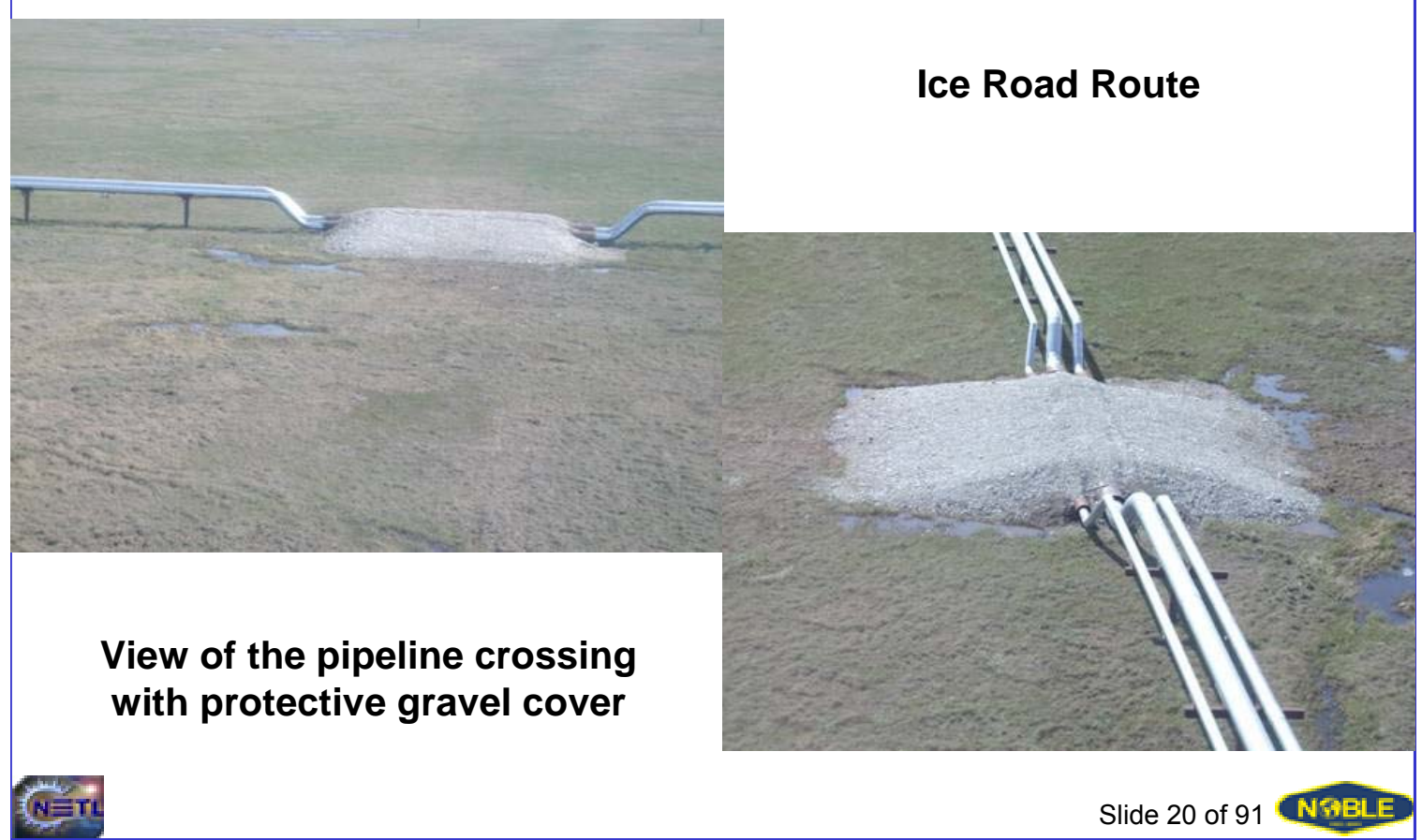




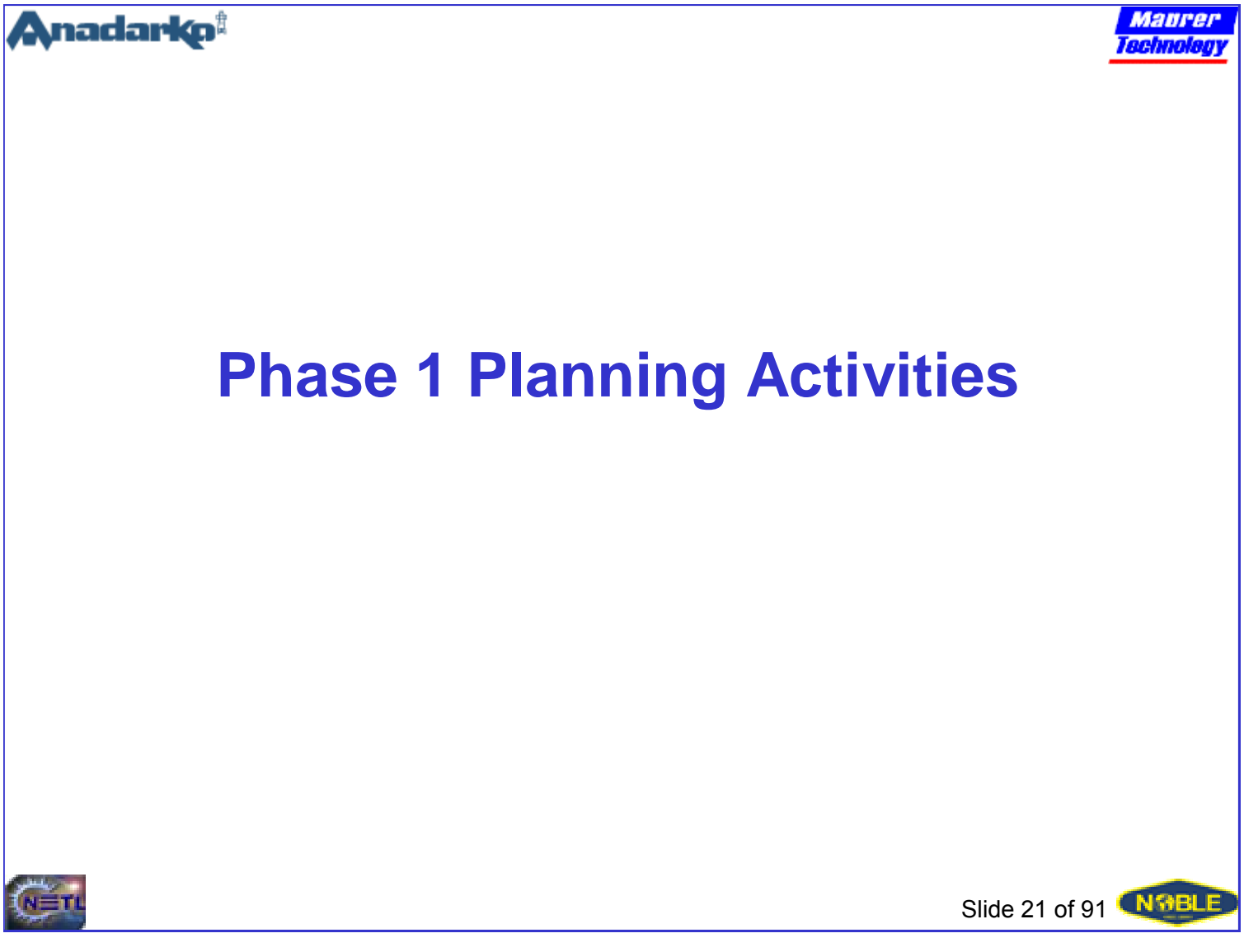

Anadarkpt

\section{Phase I}

- Identify best area for potential hydrate accumulation

- Performed regional geological and geophysical assessment to determine best opportunity for hydrates on $100 \%$ APC acreage

- Reviewed all available well logs and data

- Develop refined scope of work for Phase II

- Logistical/Well Planning

- Developed comprehensive budget 


\section{Planning Activities}

- Full-scale geological and geophysical review of the area

- Well log correlation sections

- Seismic maps and sections showing stratigraphic and lithologic units within the gas hydrate stability zone

- Reservoir modeling report

- Well Data for control wells used for site selection

- Permitting Plan

- Well Plan

- Drilling procedure/acquisition of necessary equipment

- Cost Estimate

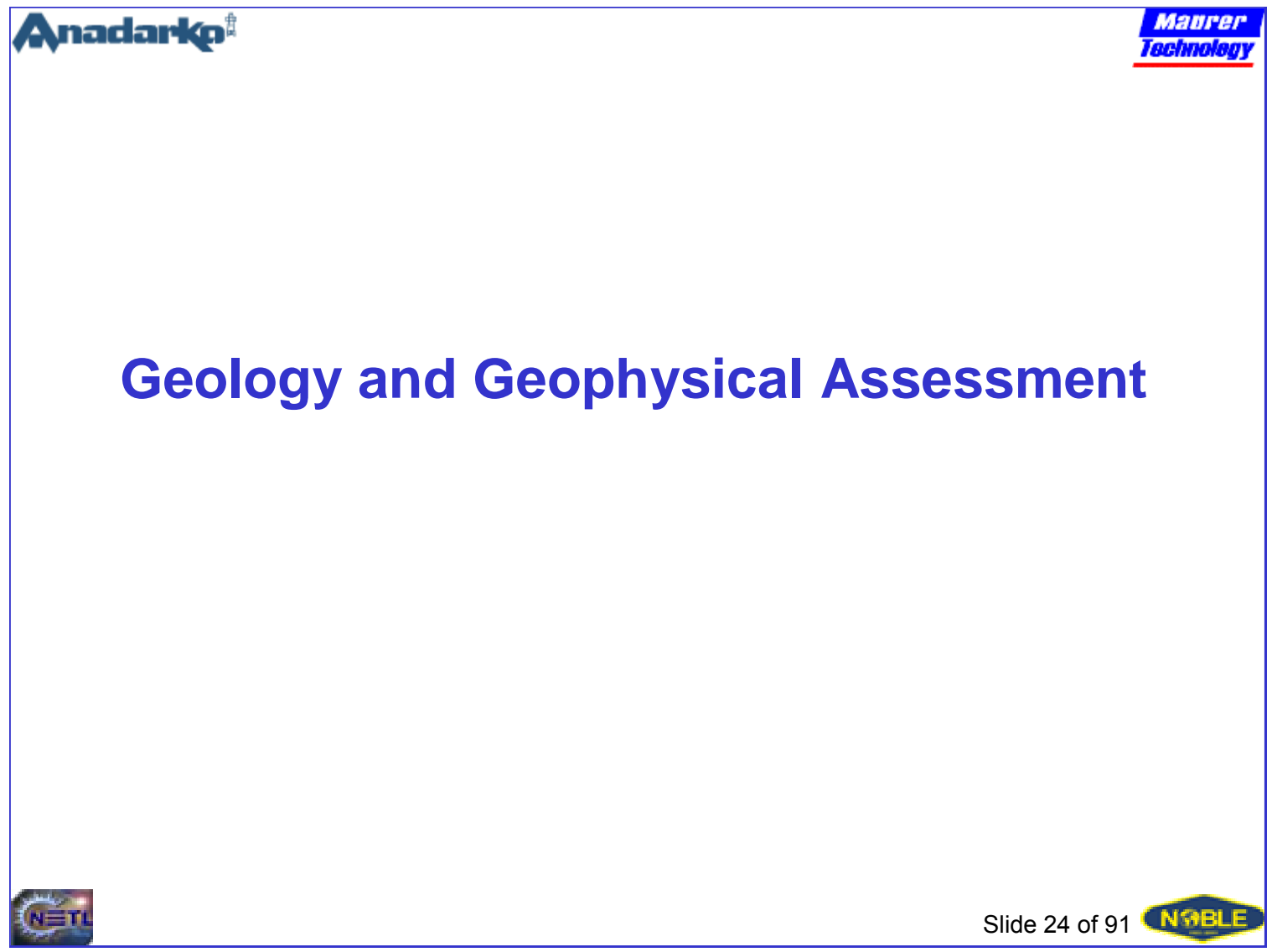


Anadarkipl

\section{Lower Paleocene Paleogeography}

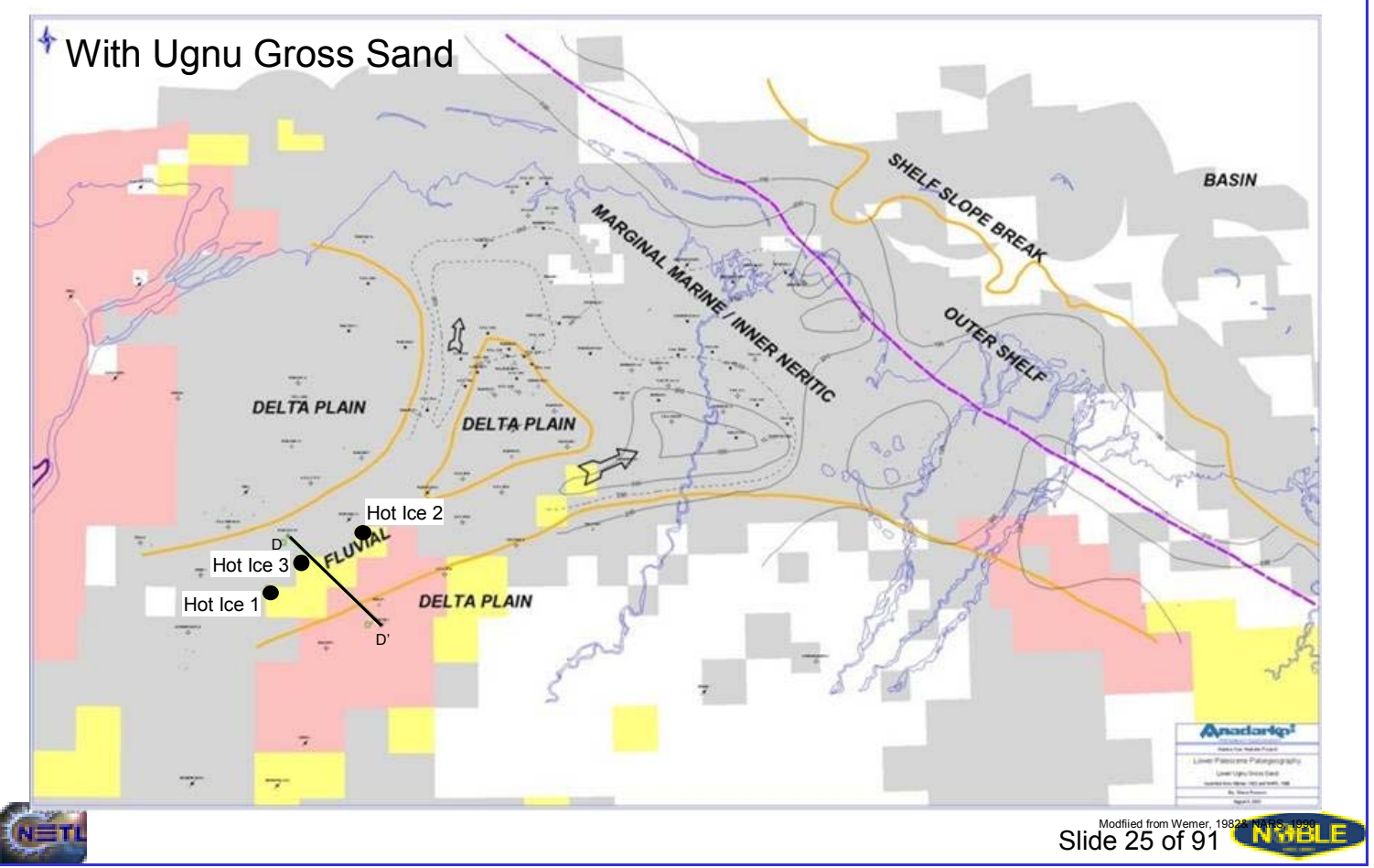

\section{Anadarkp}

\section{Ugnu and West Sak Net Sand}

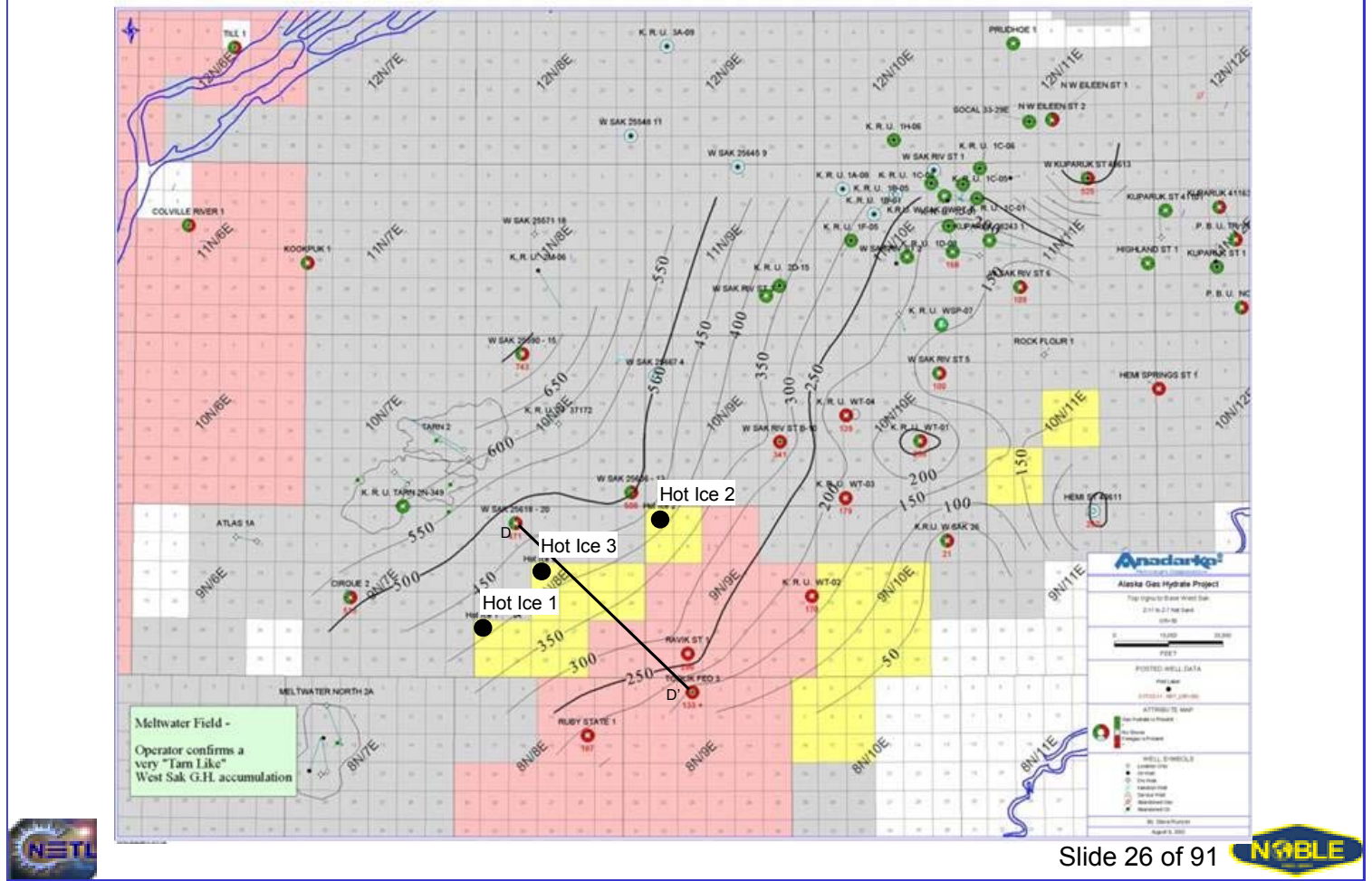


Anadarktp

\section{Ugnu / West Sak Lithology}
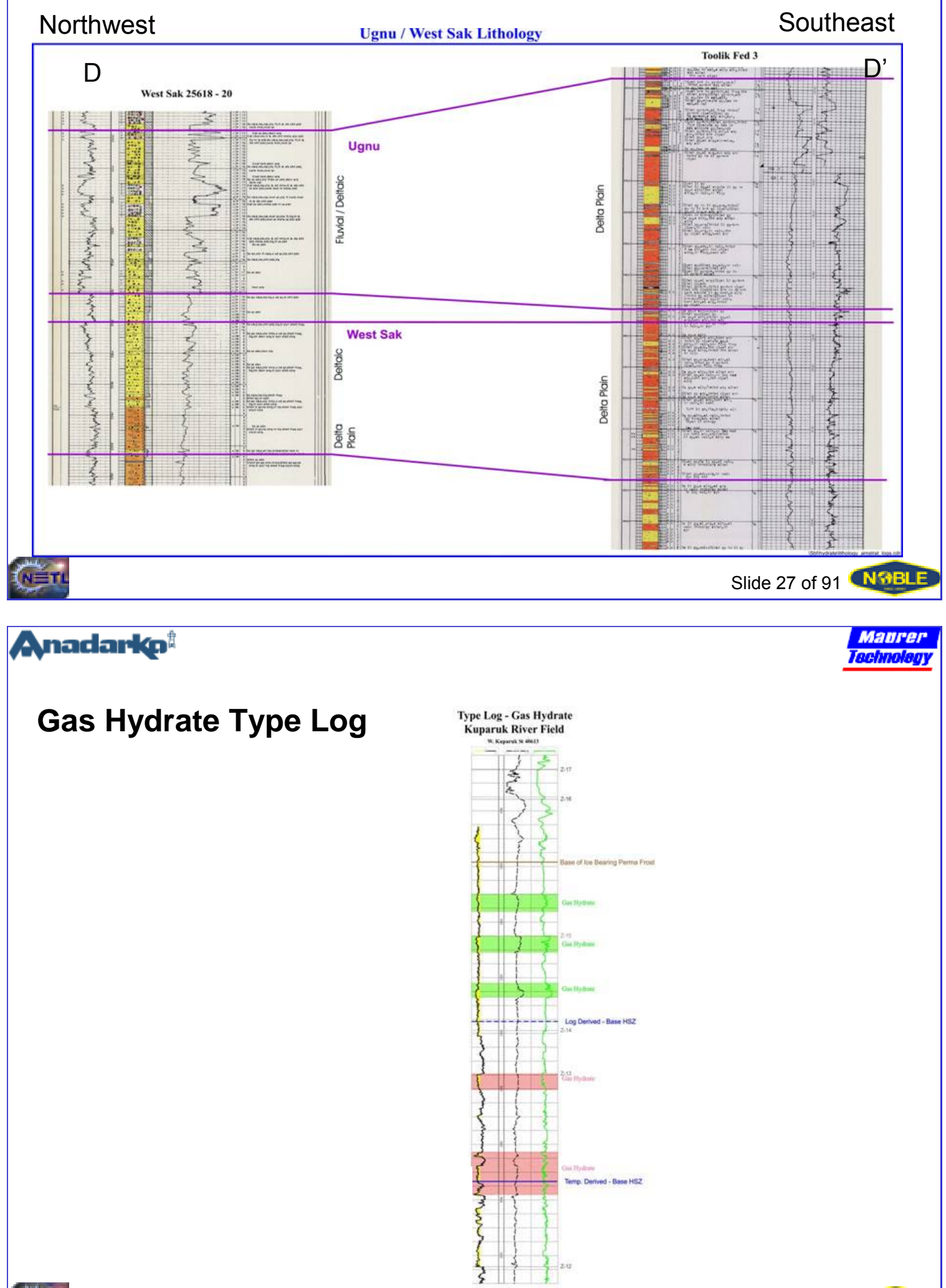
Anadarkip

\section{Hydrate Stability Zone Thickness}

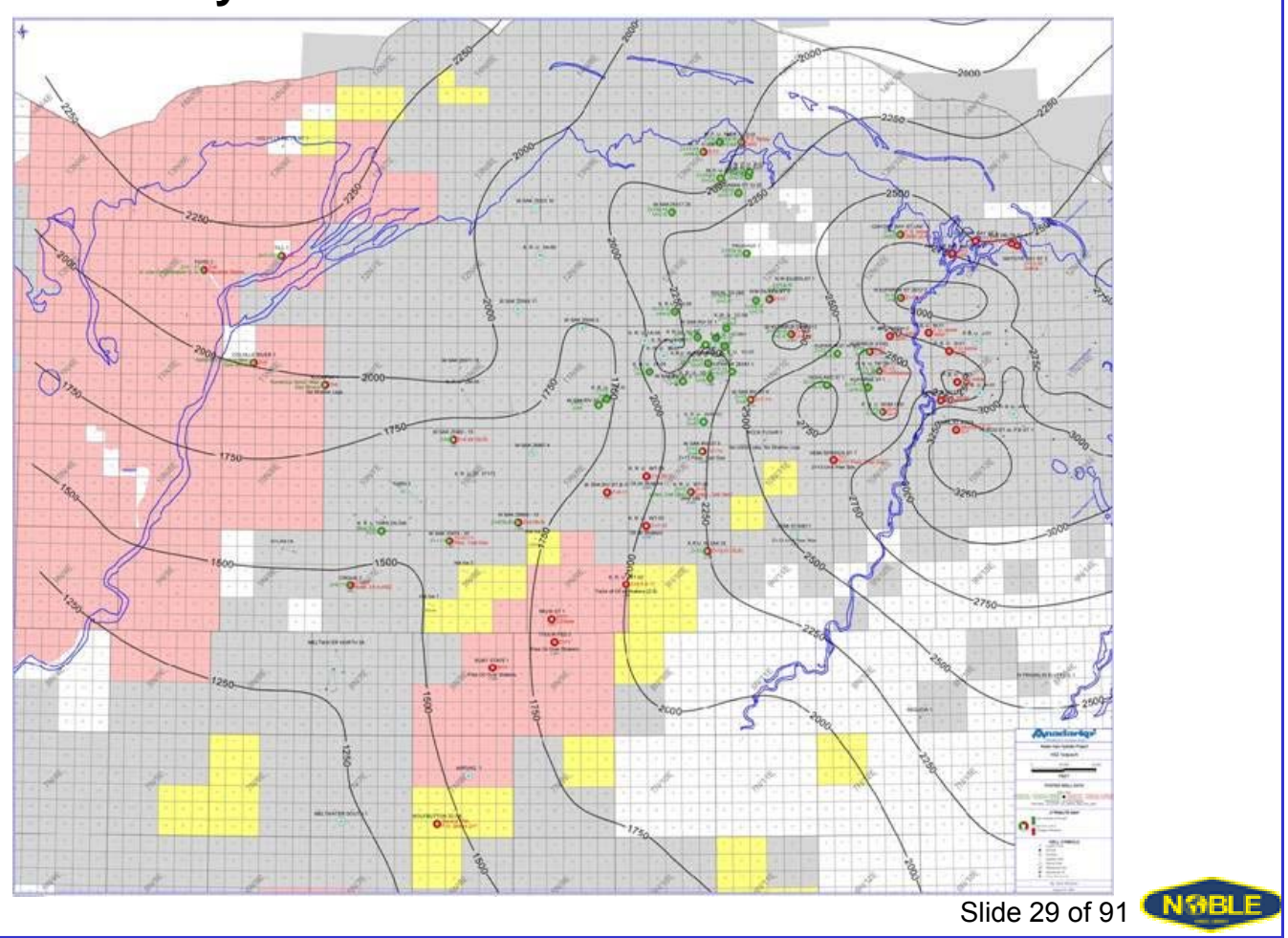

Anadarkp ${ }^{\mathbb{2}}$

\section{Generalized Cross Section}

\section{Southwest}

Northeast

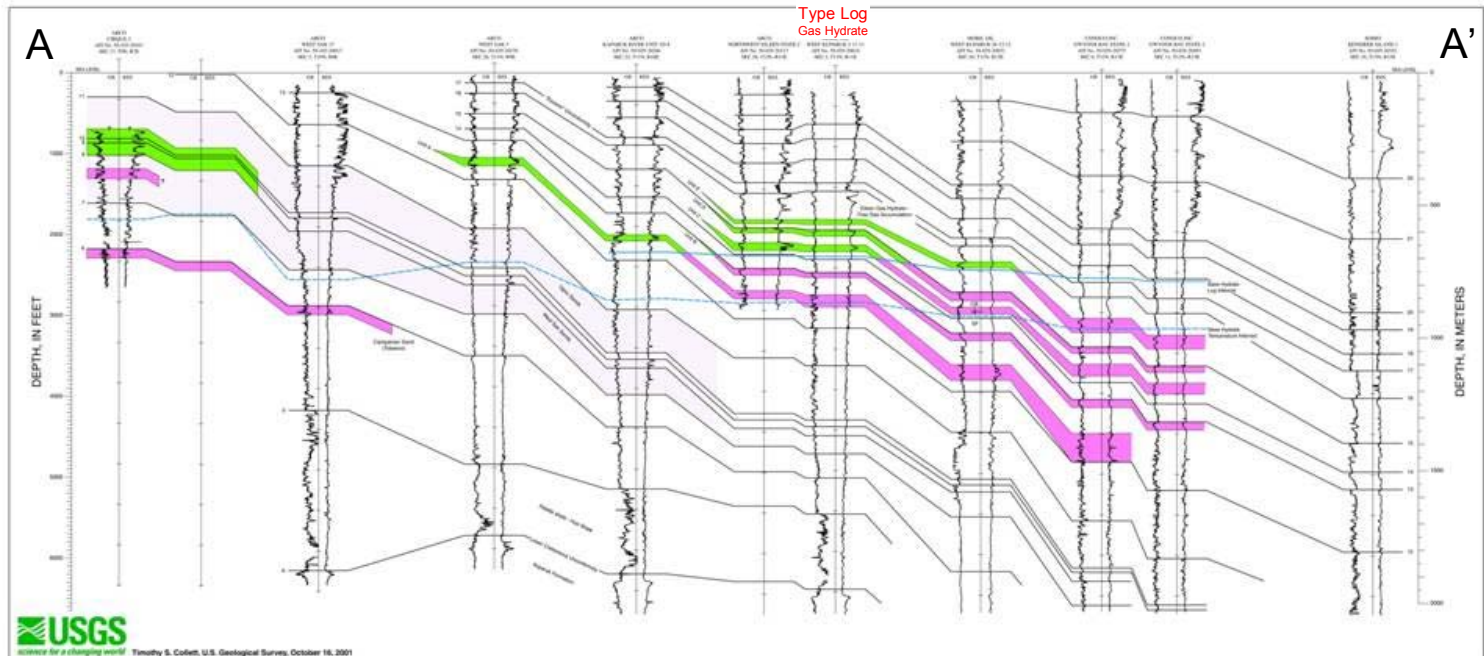




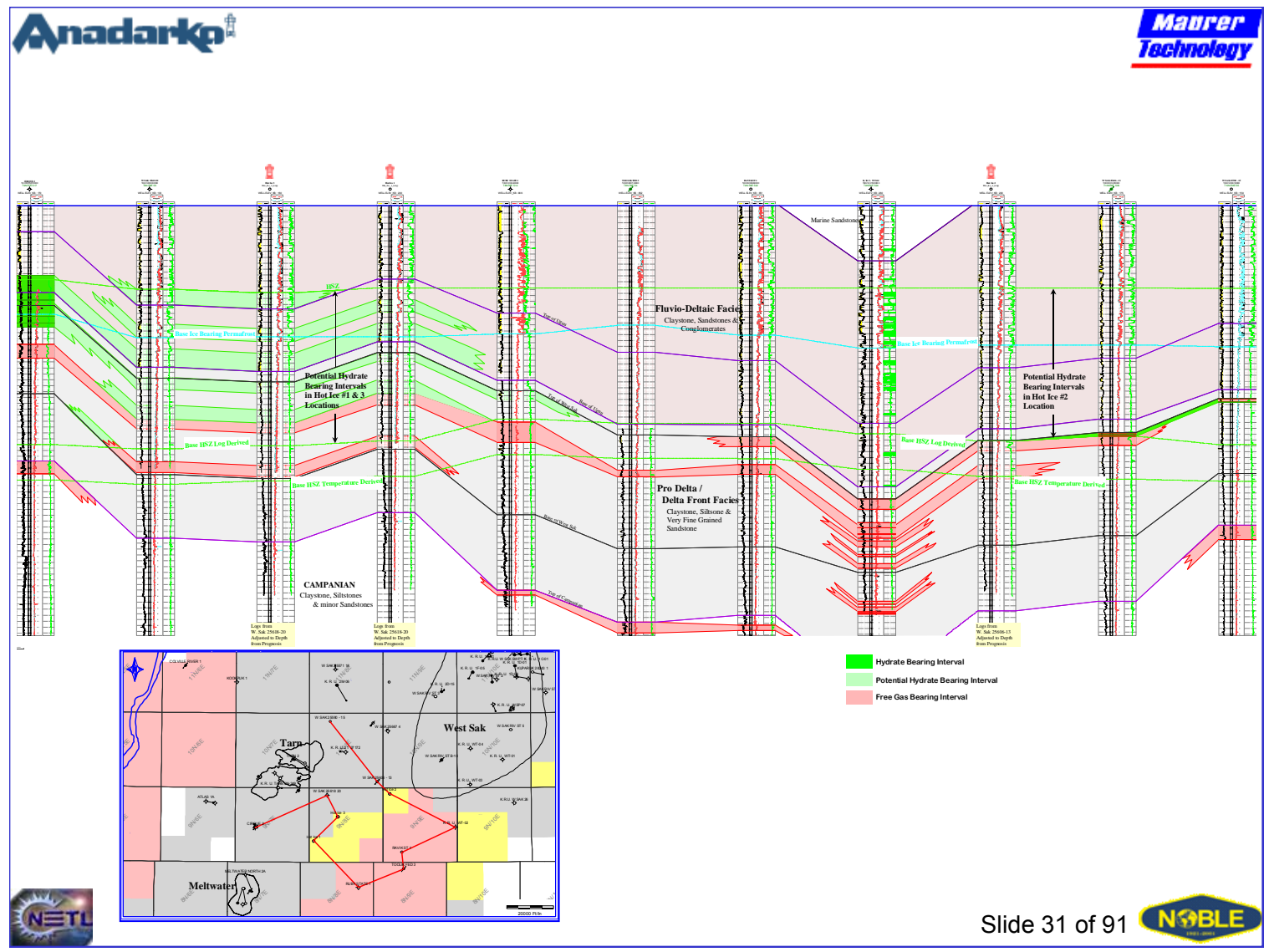

Anadarkpt

\section{Location map for Line 82-36}

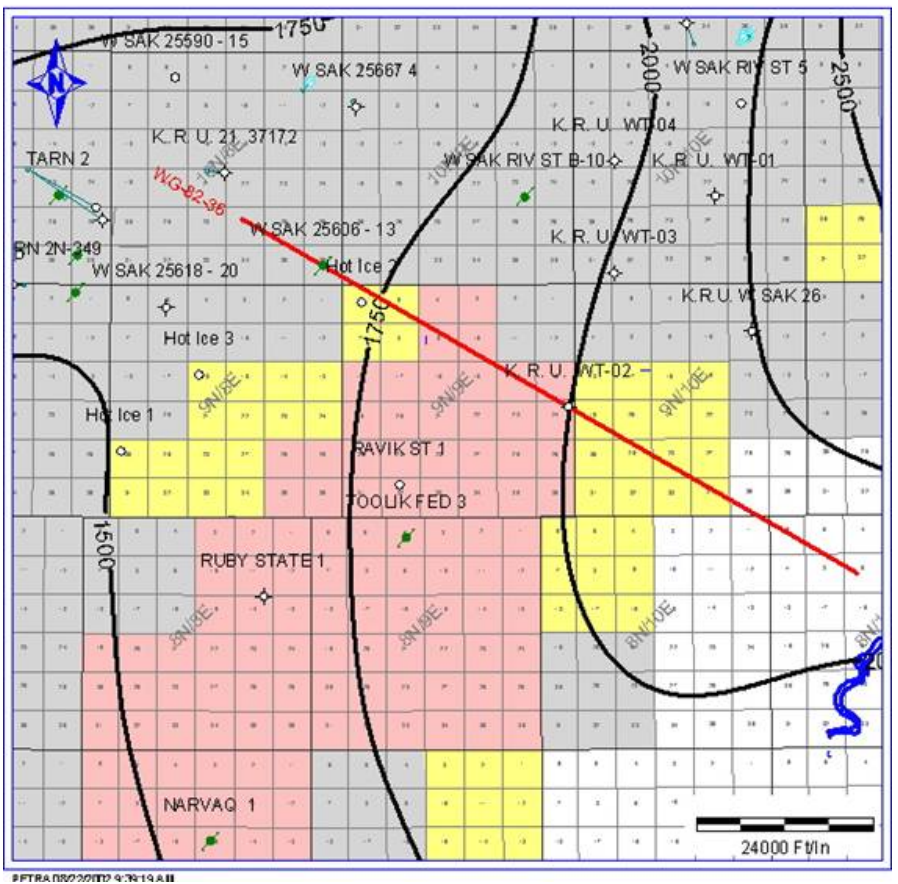

Hydrate Stability Zone Thickness Contours 

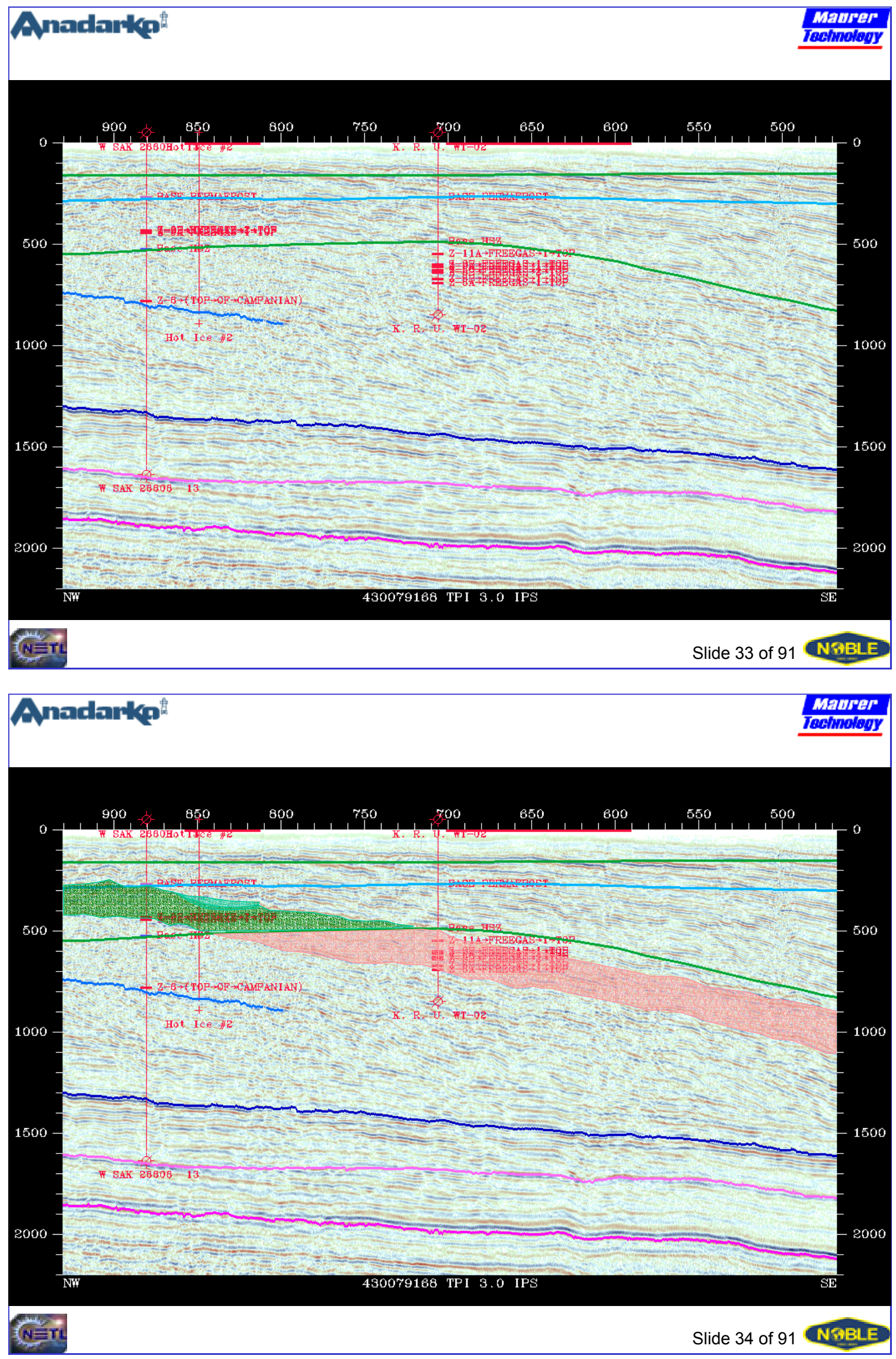

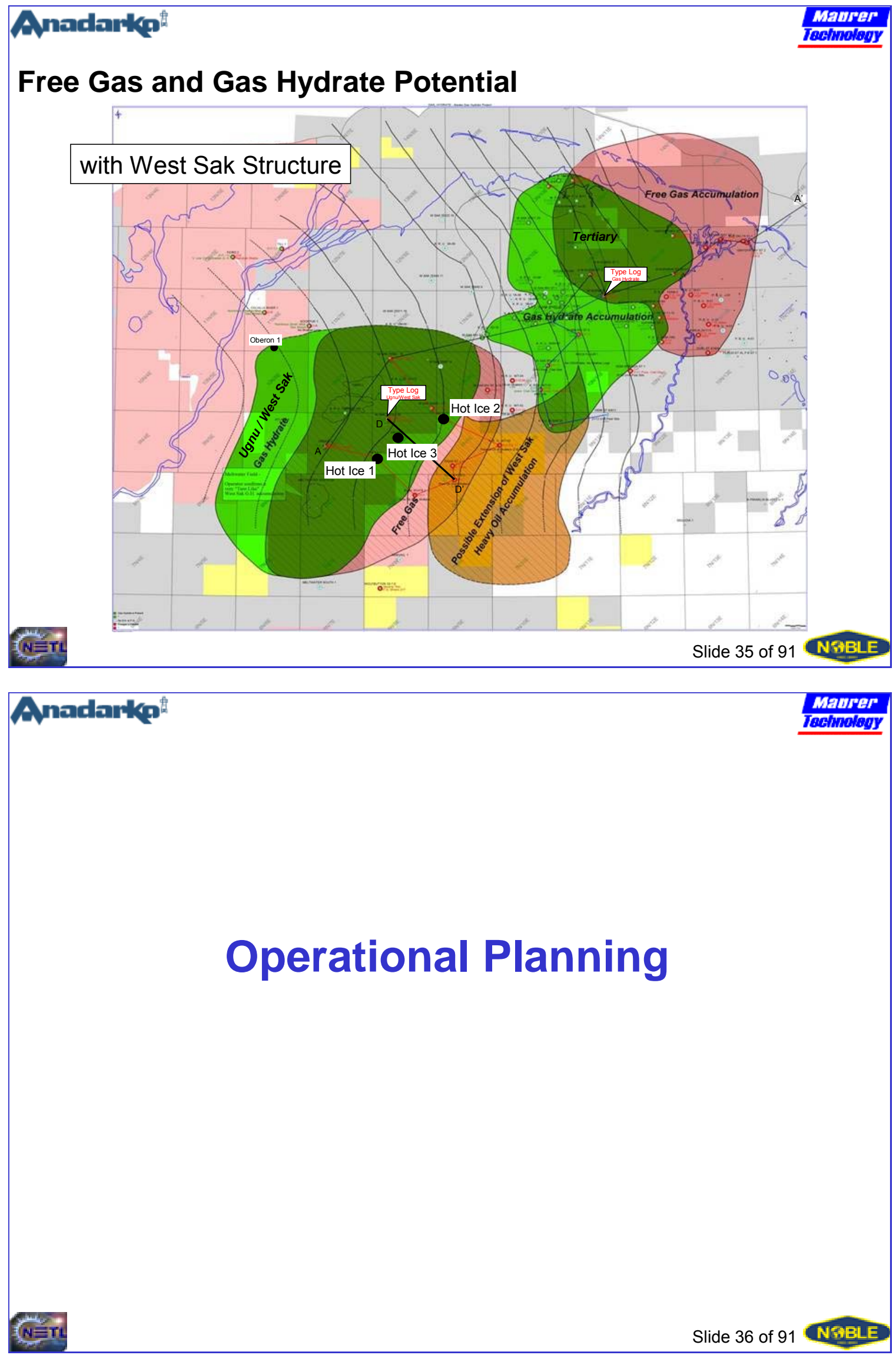


\section{Operational Activities}

\section{Develop an operational plan}

- Permitting activities

- Drilling/coring program

- Logistics

- Create a diagnostic evaluation plan

- Mobile Core Lab

- Logging program

- Completion and testing program

\section{Drilling Planning}

- Test muds, coring operations, etc. prior to actual operations

- Develop procedures

- Coordinate logistics 

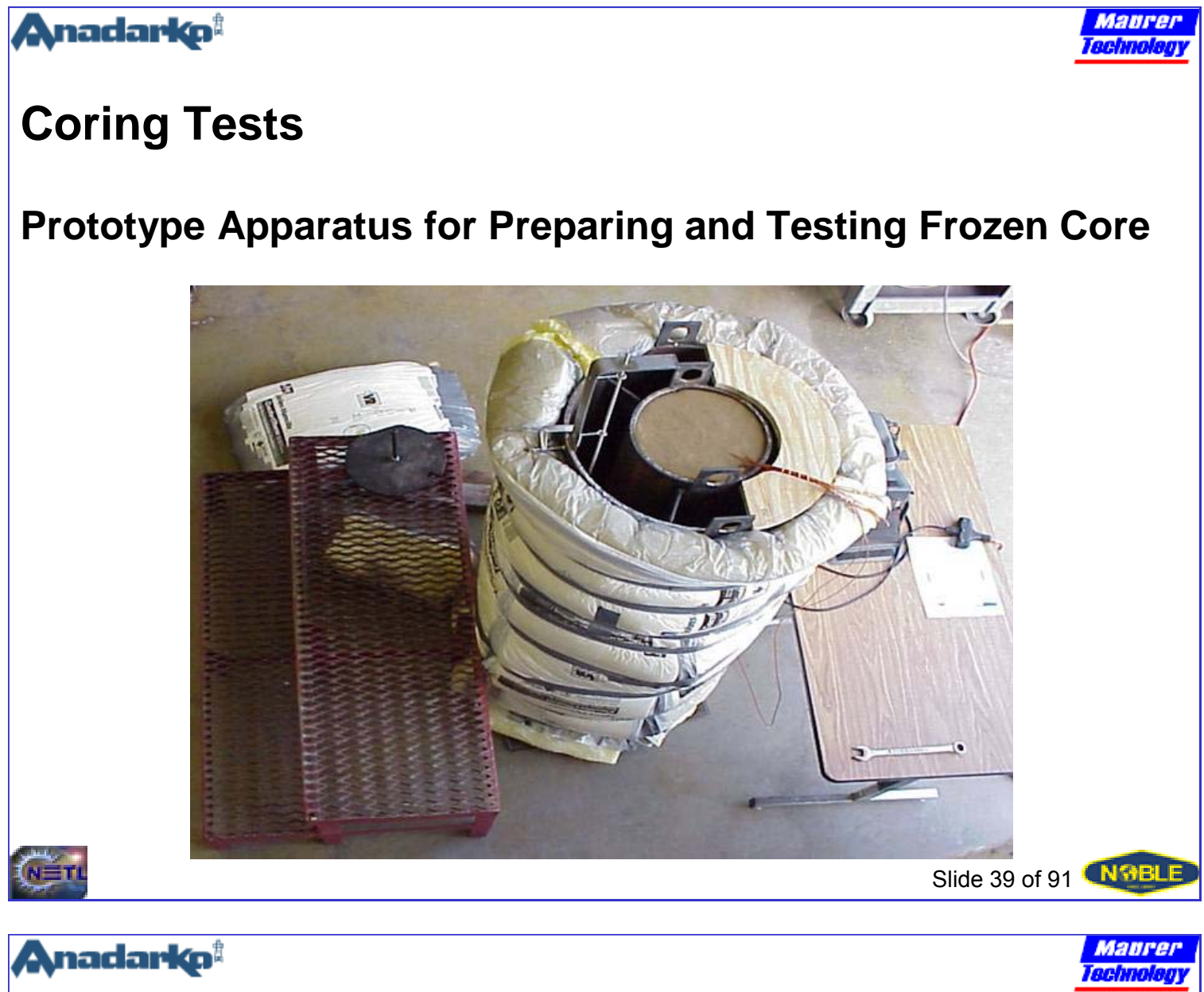

\section{Frozen Core Placement in Well to Be Cored}
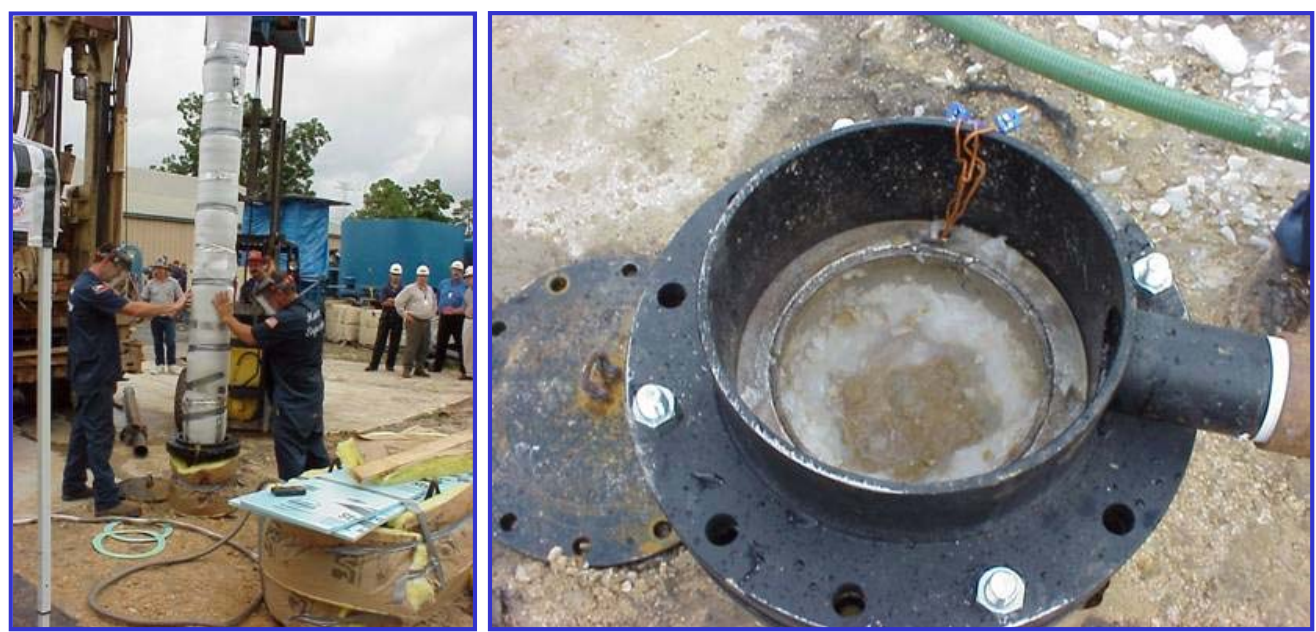


\section{Coring Test Operations}
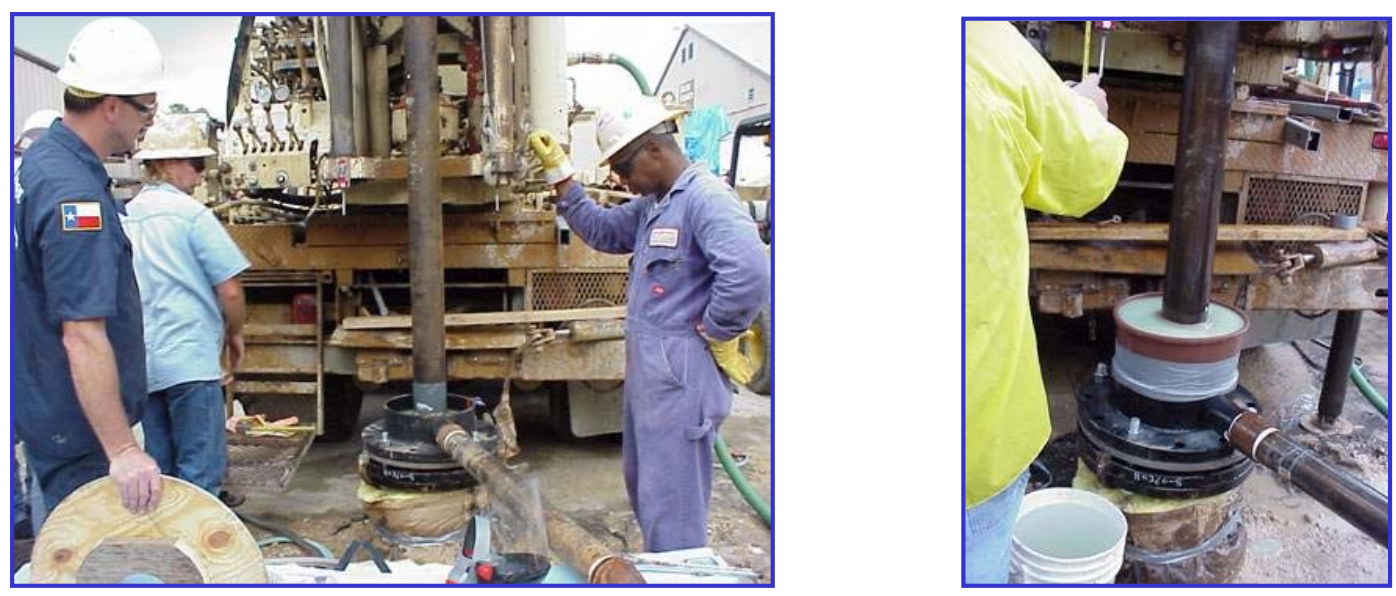

\section{Recovered Frozen Core}
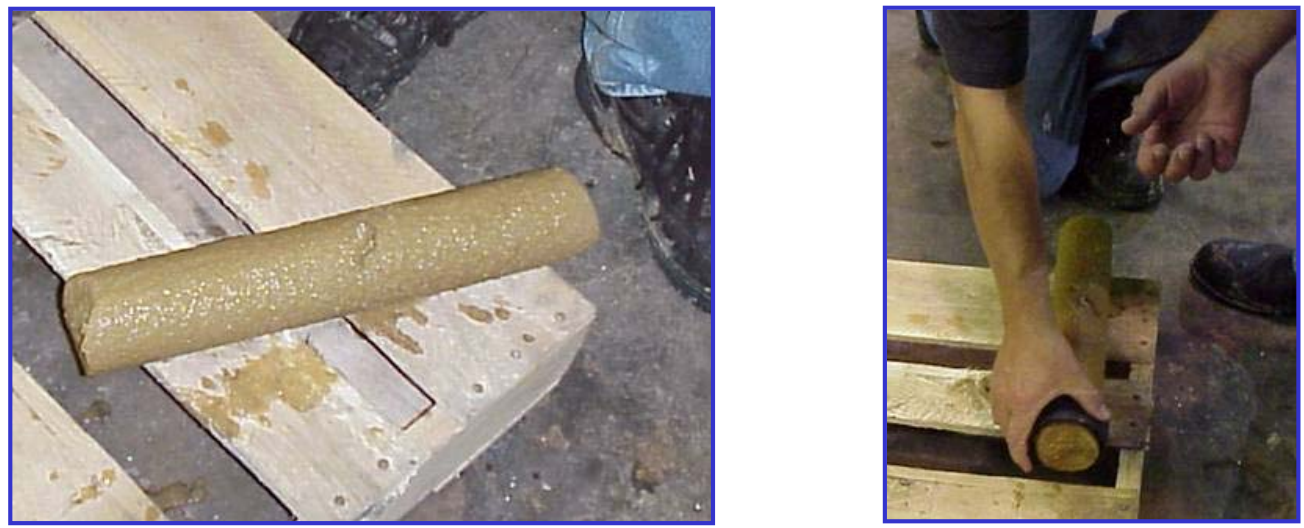


\section{Drilling Scope}

- Use Dynatec 1500 UDR slim hole rig

- Obtain continuous 3.3" diameter core

- Monitor the drilling effort via a live data feed

- Control Fluid Temperature (-5 C)/Monitor DH Temperature

- Utilize Sandia data logger to provide mud temperature, pressure and inclination
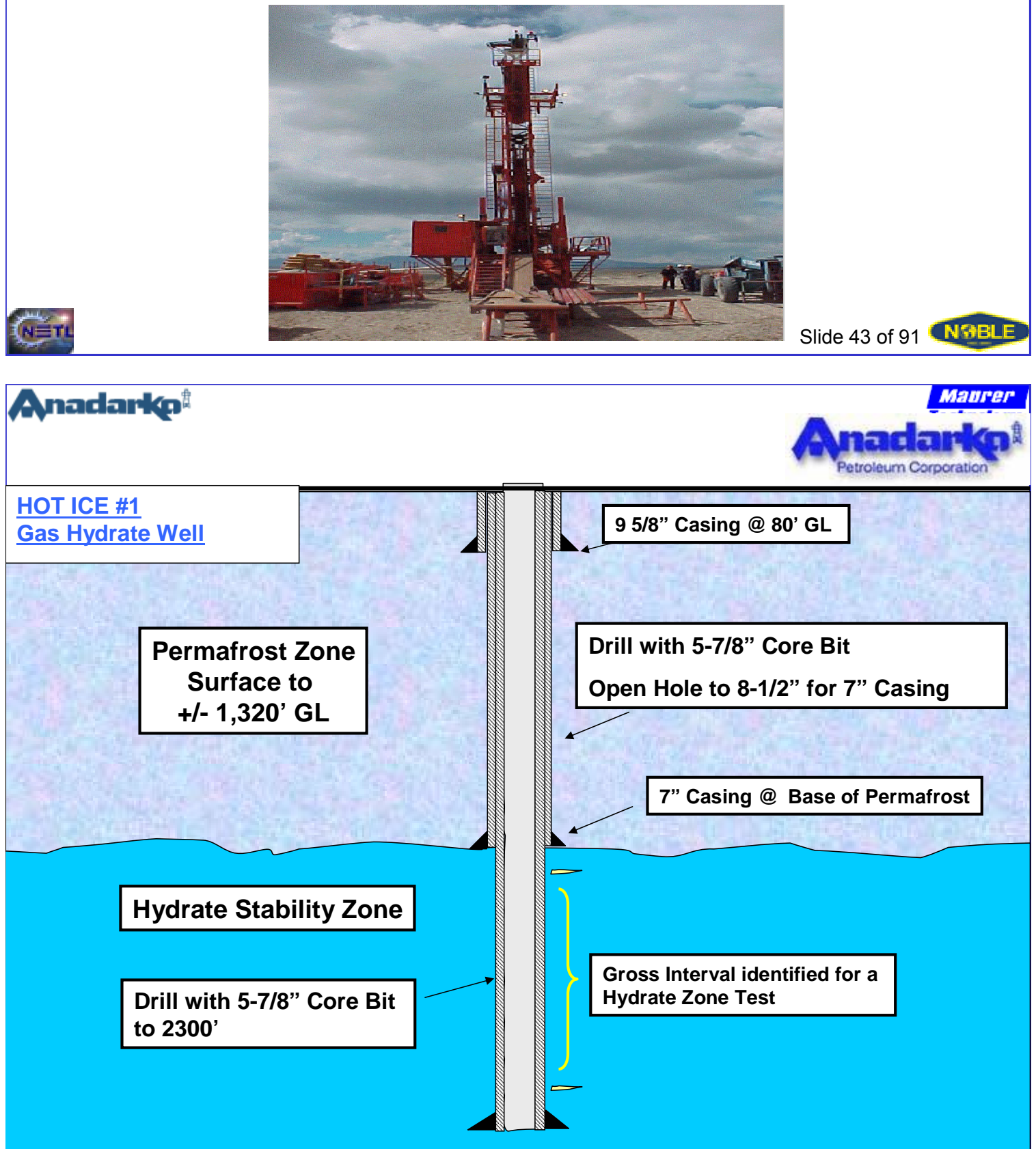


\section{Drilling Options}

- Conventional: Drilling well off of ice pad

- Testing period limited

- Unconventional: Drilling well off of Arctic Platform

- Flexibility for extended well test

- A second well could be drilled quicker and cheaper

\section{Arctic Platform Overview}

- Desire to pilot test the Arctic Platform on the Methane Hydrate project:

- Purpose was to demonstrate the APC technology to regulatory agencies and the industry partners

- Provides opportunity to extend drilling season

- Could significantly drive down costs of exploration in frontier areas

- Minimize environmental impact 


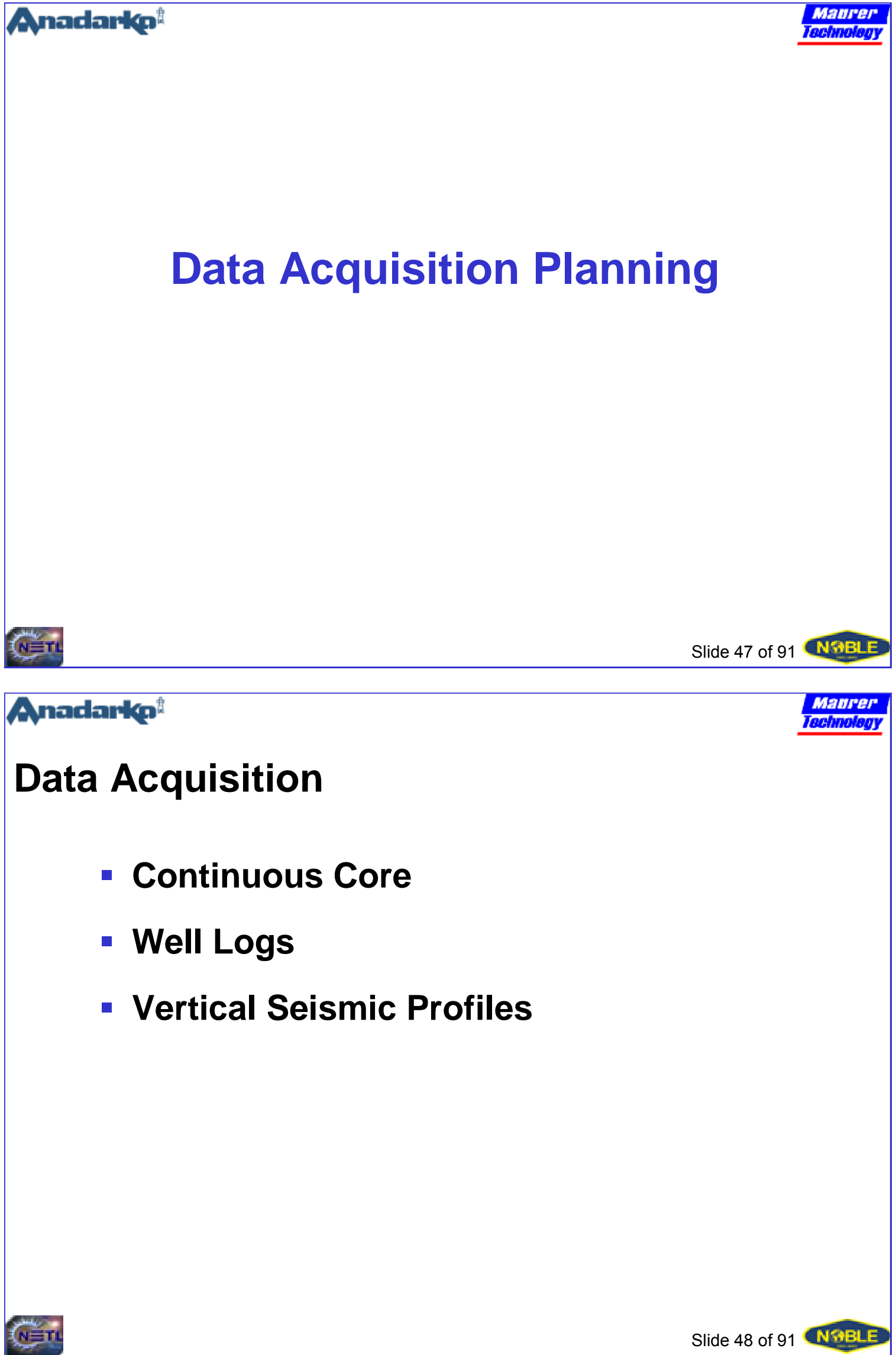




\section{Well Logging}

- Array Induction

- Dipole Sonic

- Density

- Neutron Porosity

- Spectral Gamma

- CMR (Surface)

\section{Mobile Core Lab}

- A state-of-the-art, winterized, mobile core characterization laboratory

- Capable of measuring large volume of core in a costeffective manner in arctic conditions.

- First comprehensive on-site gas hydrate analytical laboratory.

- First of its kind to work in Arctic

- Can process core on site

- Will be able to do conventional analysis as well as special analysis for hydrates 


\section{Anadarkp \\ Hydrate Measurement Considerations}

- Cores are unstable, i.e. they decompose into methane, water and sand.

- Core must be maintained at subzero $C^{\circ}$ during handling and measurement.

- Cores must simultaneously be pressurized and cooled to in-situ conditions for measurements and preservation.

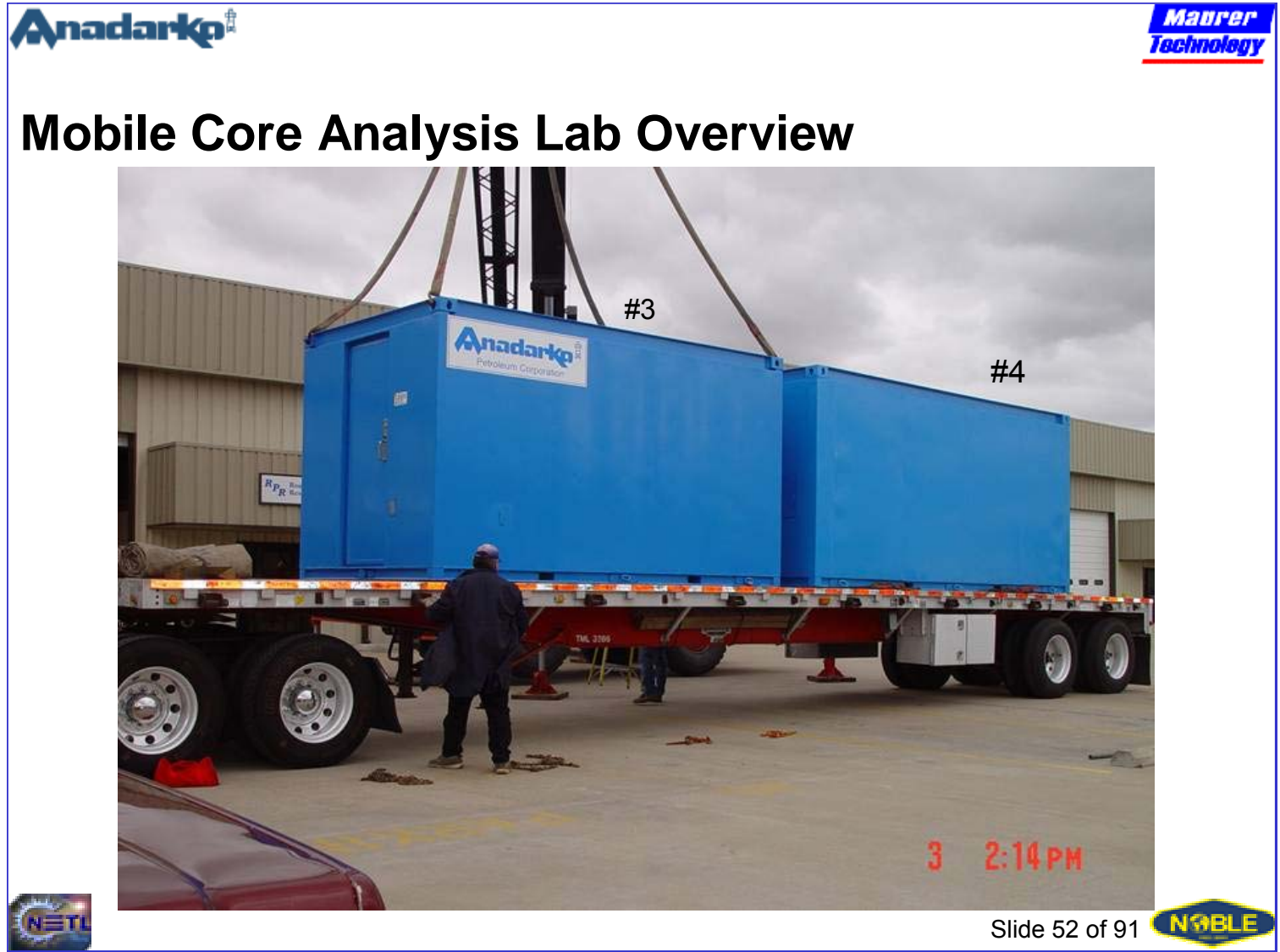



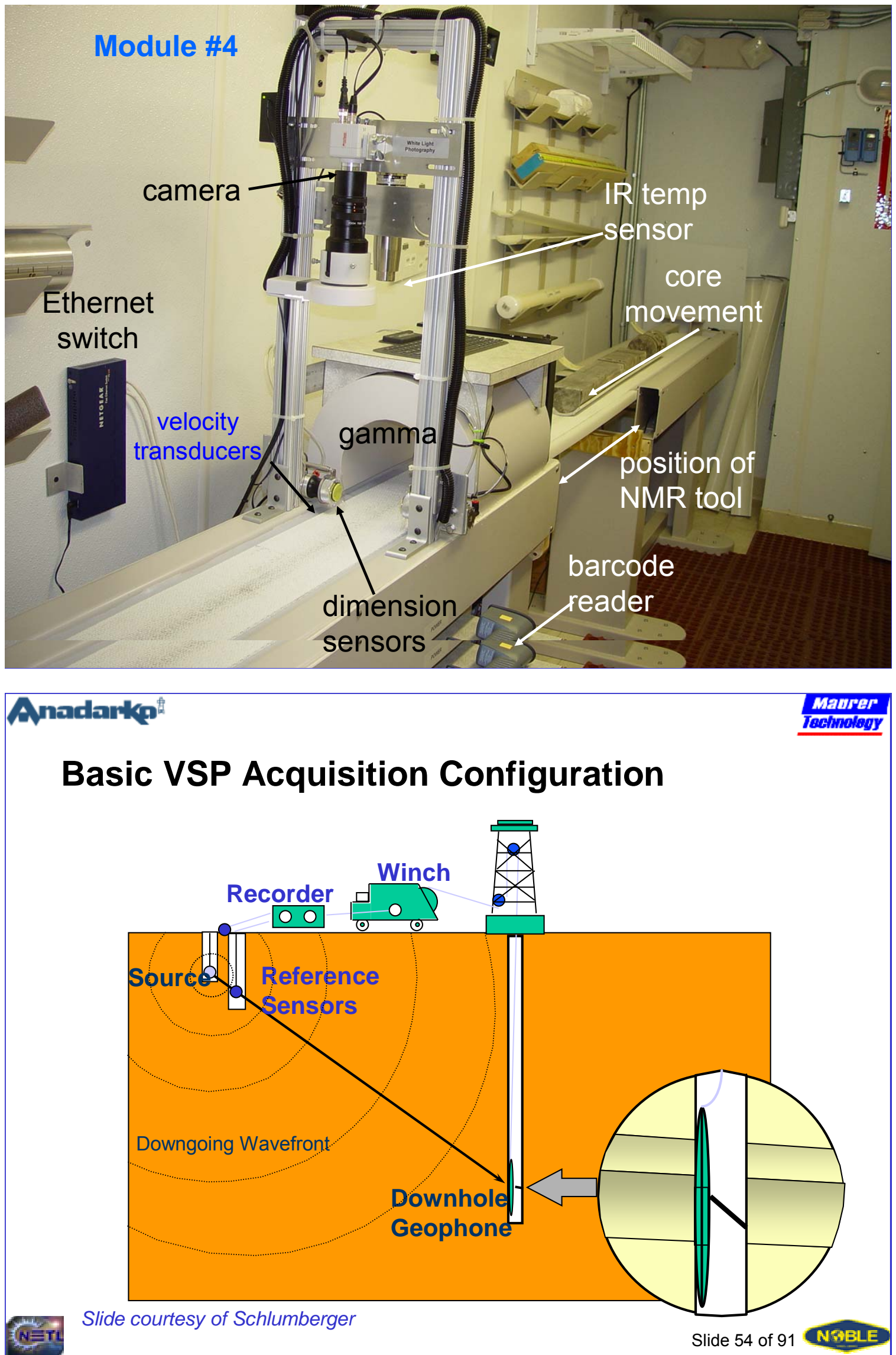


\section{D VSP Survey Information}

- Source point interval: $120-175 \mathrm{ft}$ using an adaptive circular pattern

- Seismic source: Single AHV4 Vibroseis $(62,000 \mathrm{lb})$

- $2 \times 8-220 \mathrm{~Hz} 10 \mathrm{sec}$ linear sweeps, $0.2 \mathrm{sec}$ cosine taper

- Number of surface shot points $=1,185$

- Receiver array depth (ft RKB): $294.35 \mathrm{ft}-2,269.15 \mathrm{ft} @ 25 \mathrm{ft}$ intervals

- Receiver arrays: $3^{\text {rd }}$ generation cable 80-006, Phones: $15 \mathrm{~Hz}$ OYO SMC1850, 3C pods

- 284,400 traces recorded

- Maximum (well to source) offset recorded $=2,750 \mathrm{ft}$

- Well information: Casing: 7", 26\#, Well nominally vertical, cased to $1,358 \mathrm{ft}$, open hole to 2,300 ft. TD

\section{Well Completion and Testing Planning}



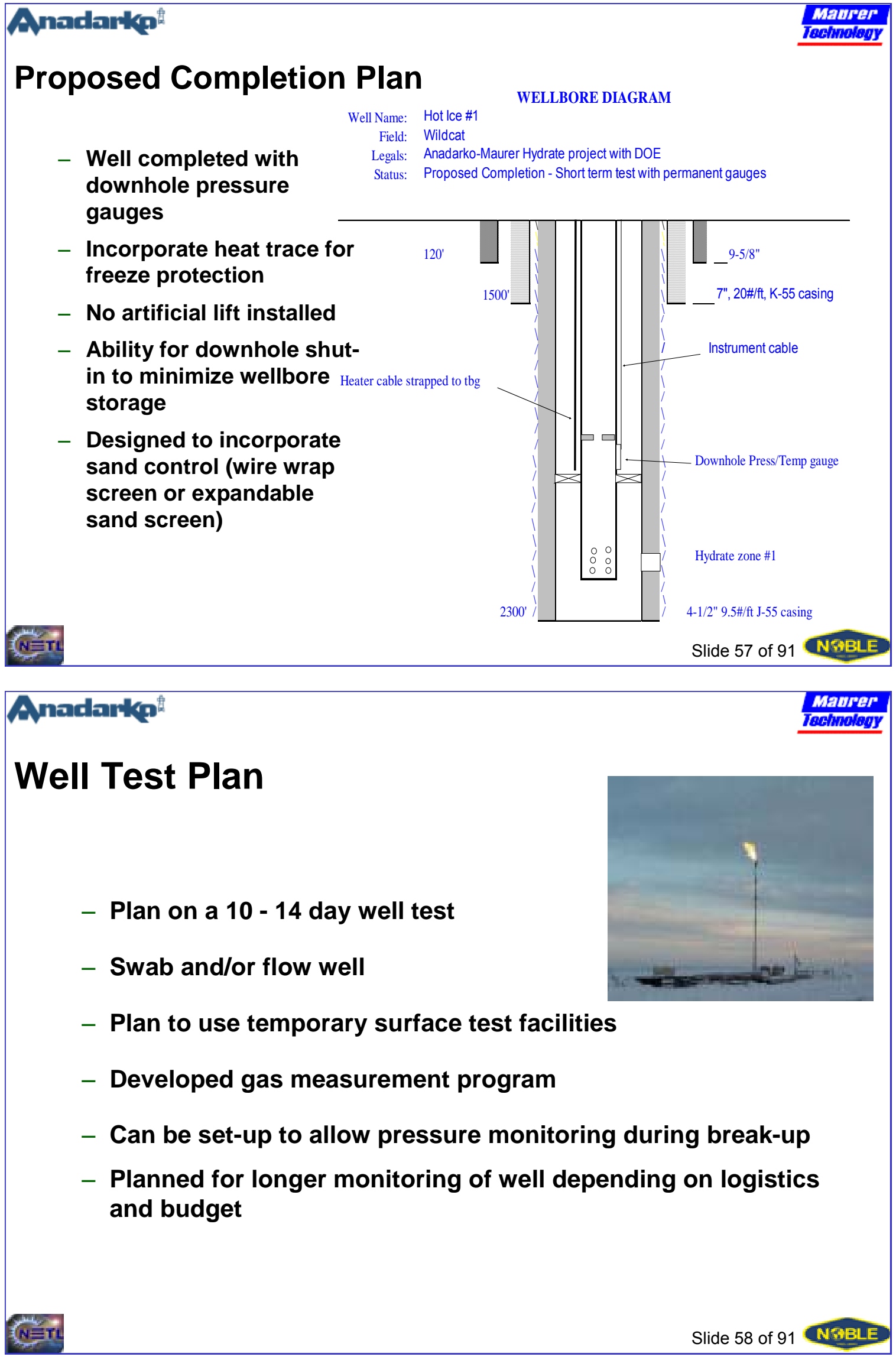

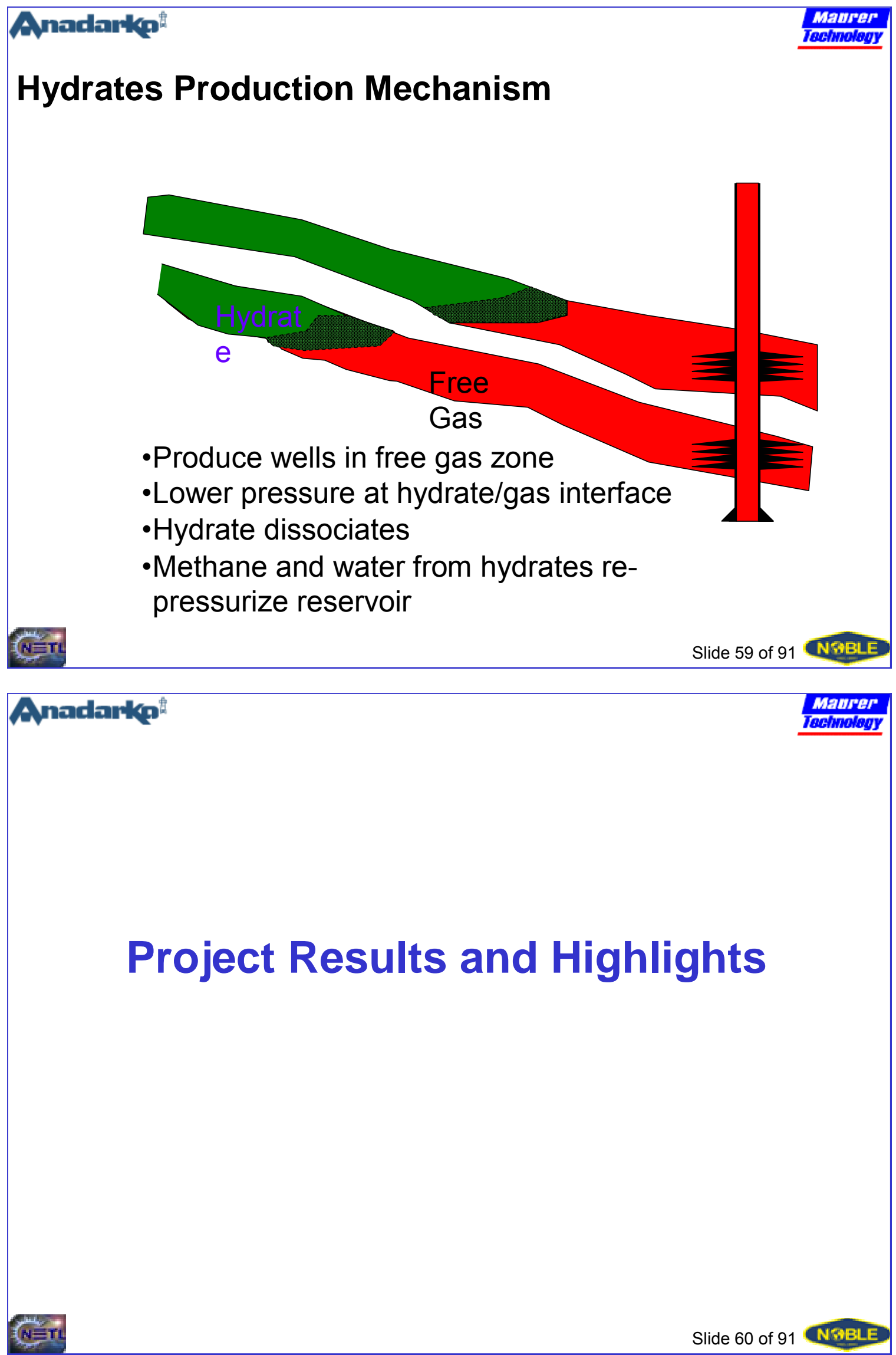


\section{Phase II}

- Drill, core, log and test one well

- Perform core analysis of hydrates on site

- Drilling and completion operations planned to be carried out without use of ice roads

- Plan to test extended season drilling concept via Arctic Exploration platform

- Pending logistics and budget, monitor pressure and temperature throughout summer months

\section{Project Overview}

- Completed Drilling Operations

- Drilled and continuously cored through the hydrate stability zone to 2300'

- Encountered free gas and movable water in porous sands - but no hydrates

- Well successfully plugged and abandoned

- Completion and testing plans

- Did not complete well as no hydrates were found

- Data gathering objectives

- Analyzed core on site

- Logged well

- Conducted massive 3D VSP

- Evaluated shallow seismic data 


\section{Operational Overview}

\section{HOT ICE \#1 Operations Review}

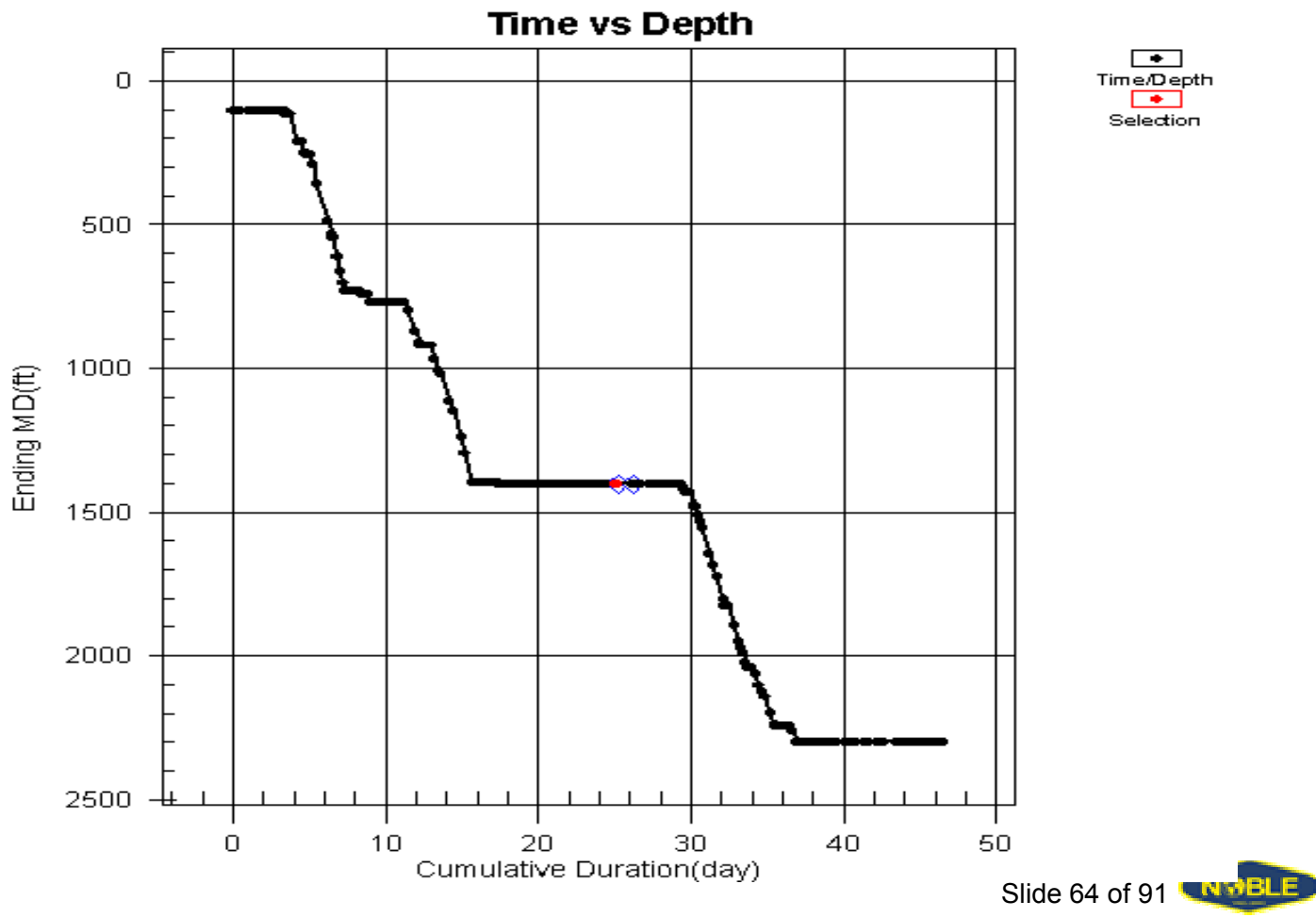


Anadarkipl

\section{Hot Ice Operations Review}

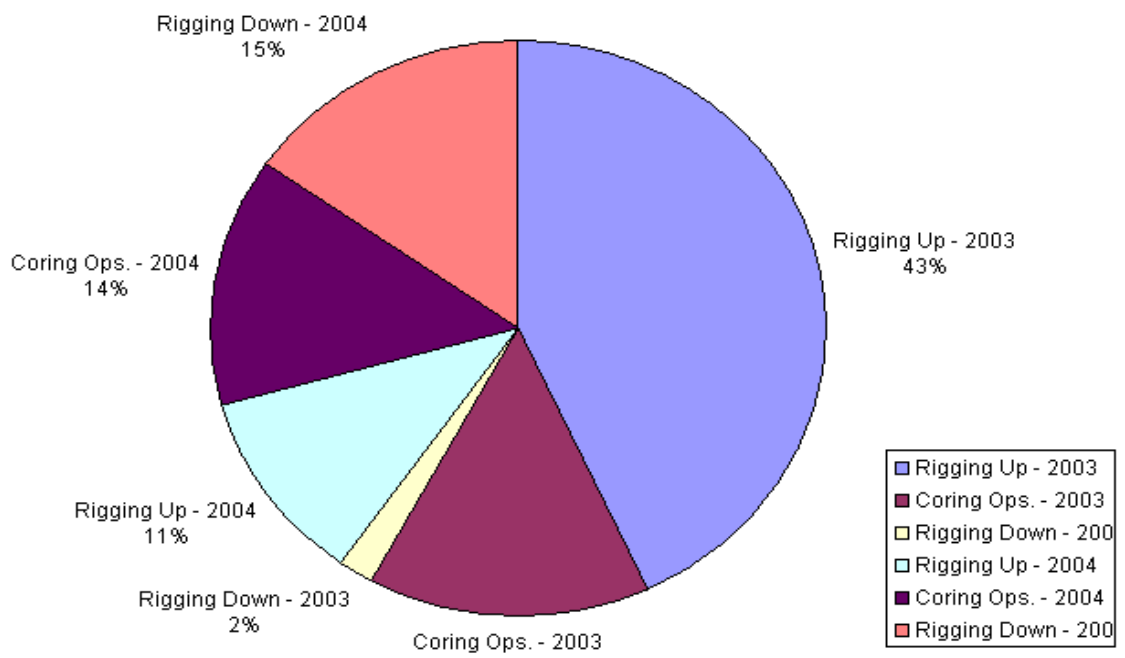

-Gross Operational Days in 2003: 106 Days (Net Field Days: 89)

-Gross Operational Days in 2004: 67 Days (Net Field Days: 54 )

-Cumulative Days of Operation : Gross 173 / Net: 143 Days

\section{Noble "DrillGraph" MM Temp Data}

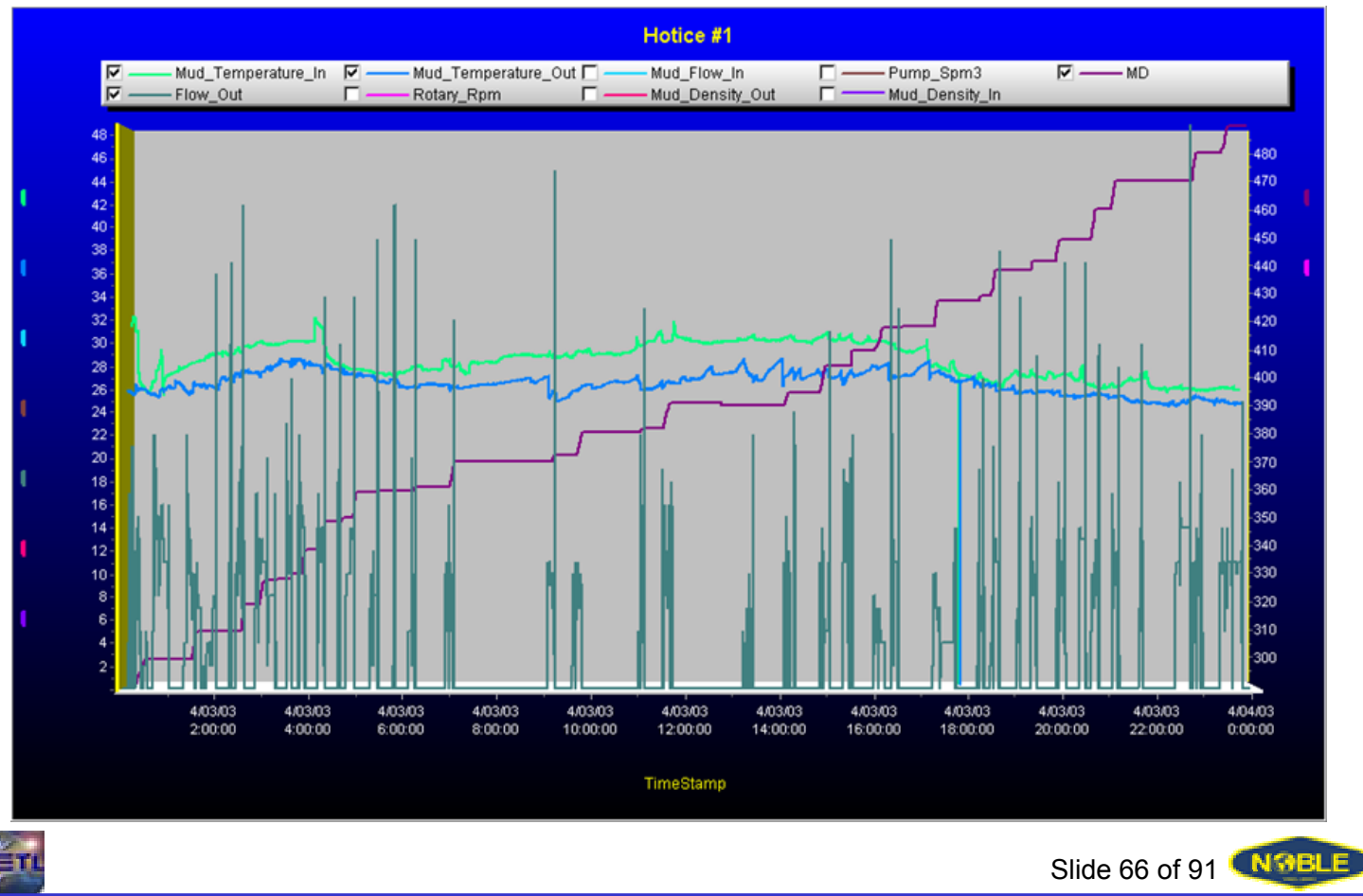



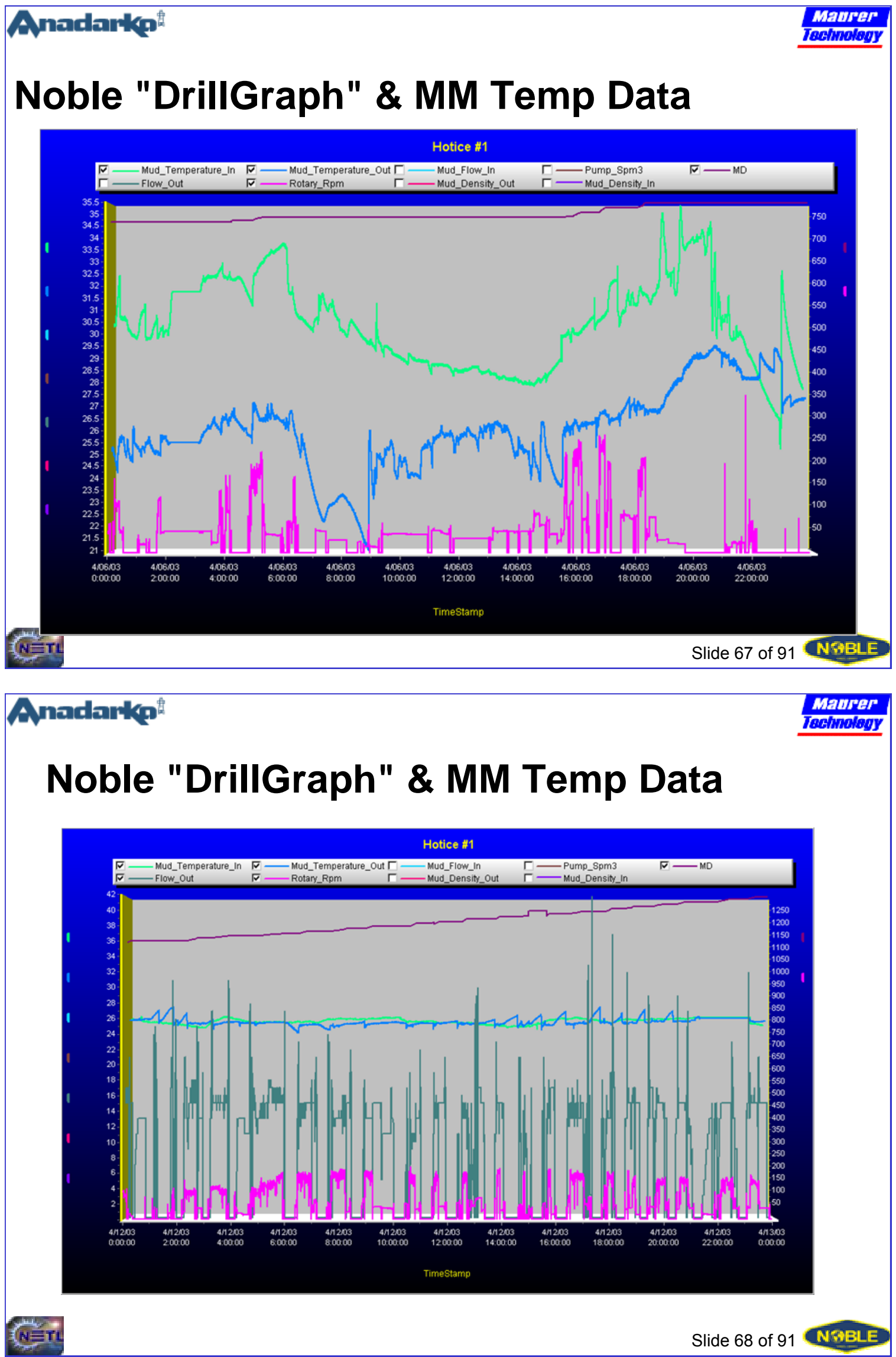


\section{Core Data}

\section{General Lithology}
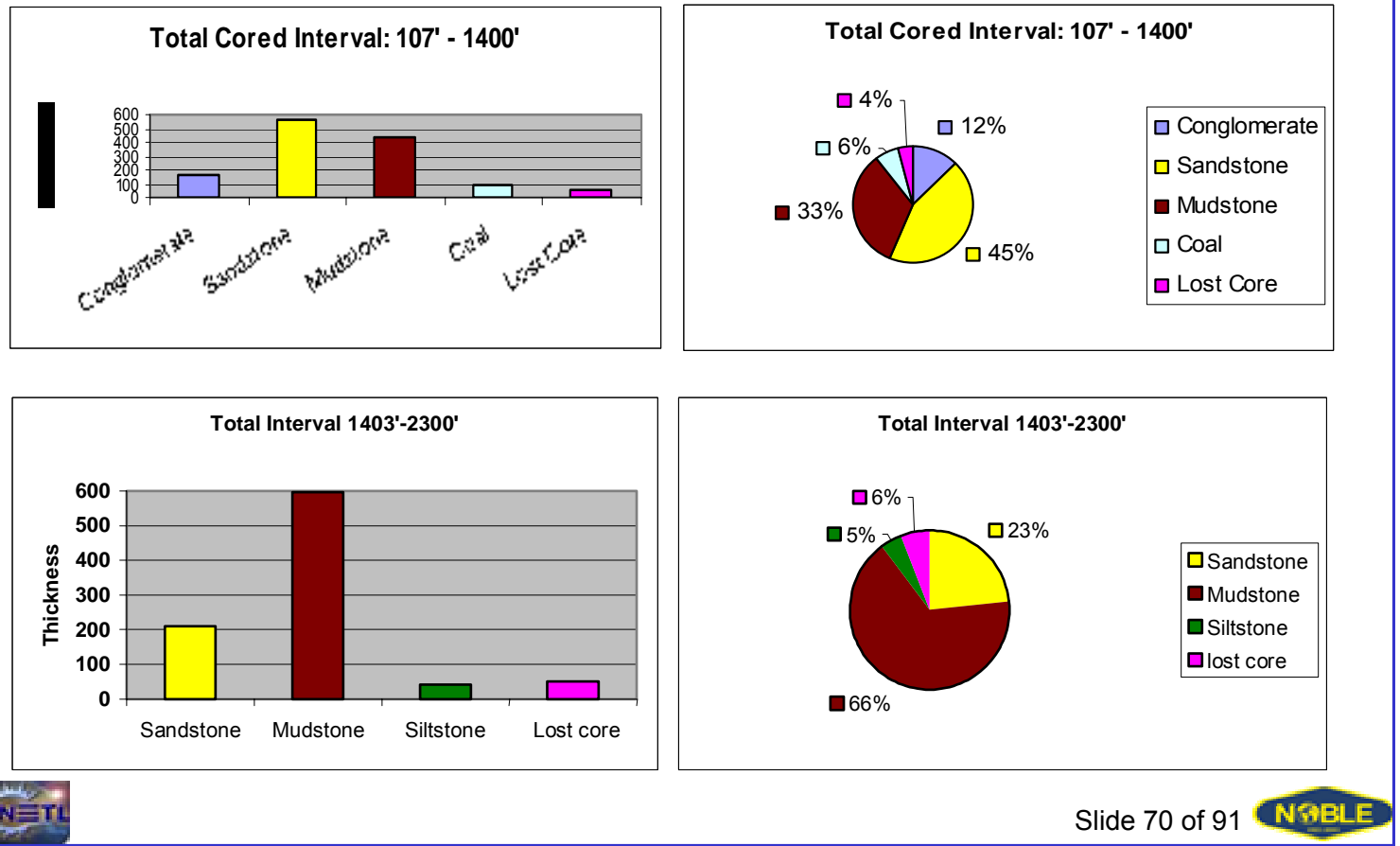


\section{Ugnu Sands}

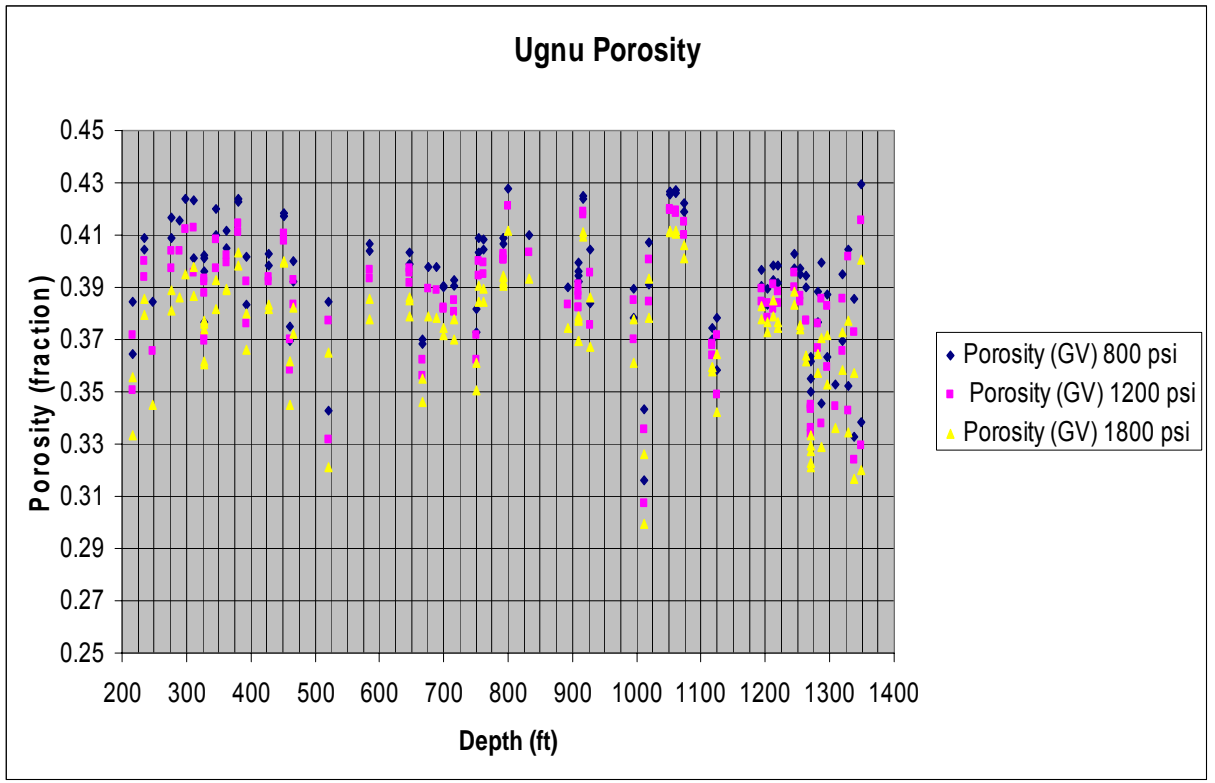

\section{Ugnu Sands}

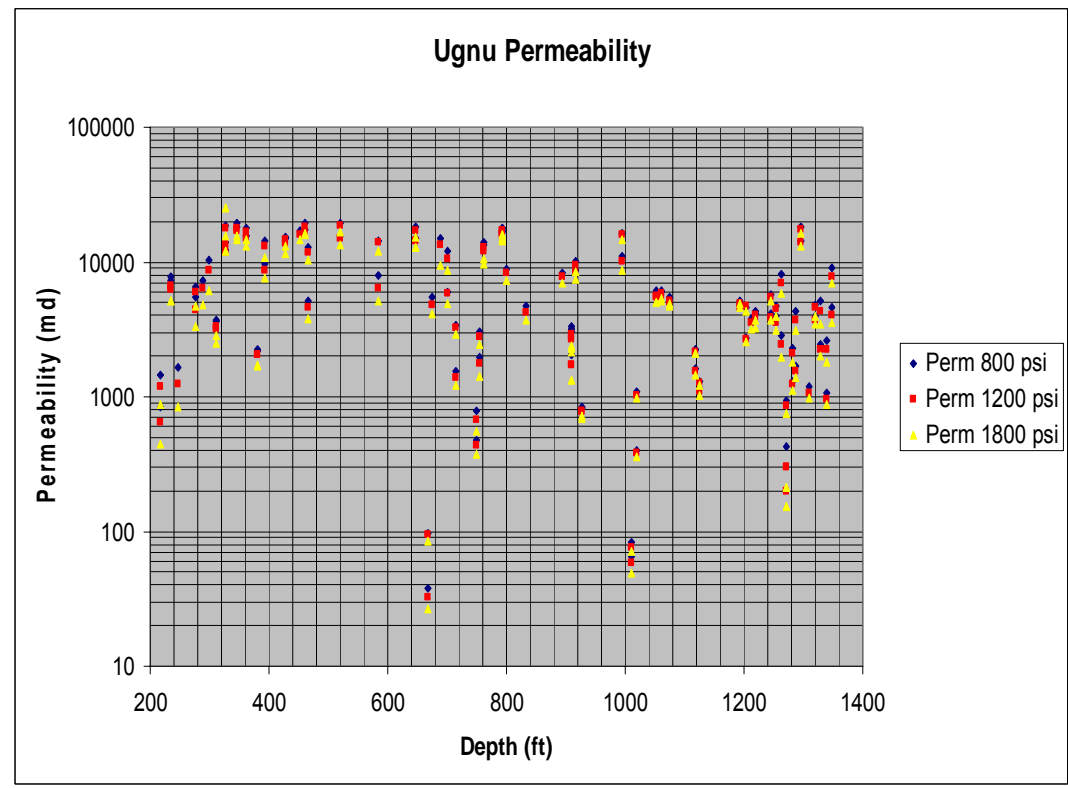


Anadarkpti

\section{West Sak Sands}

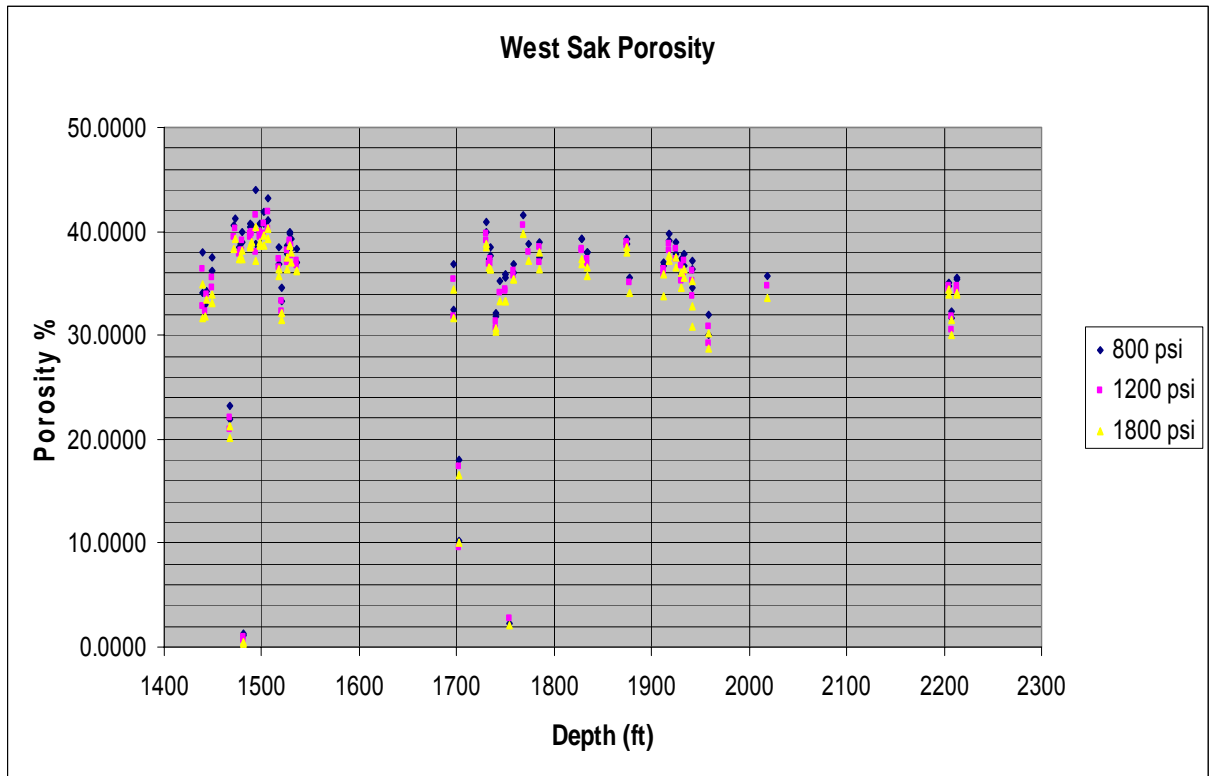

\section{West Sak Sands}

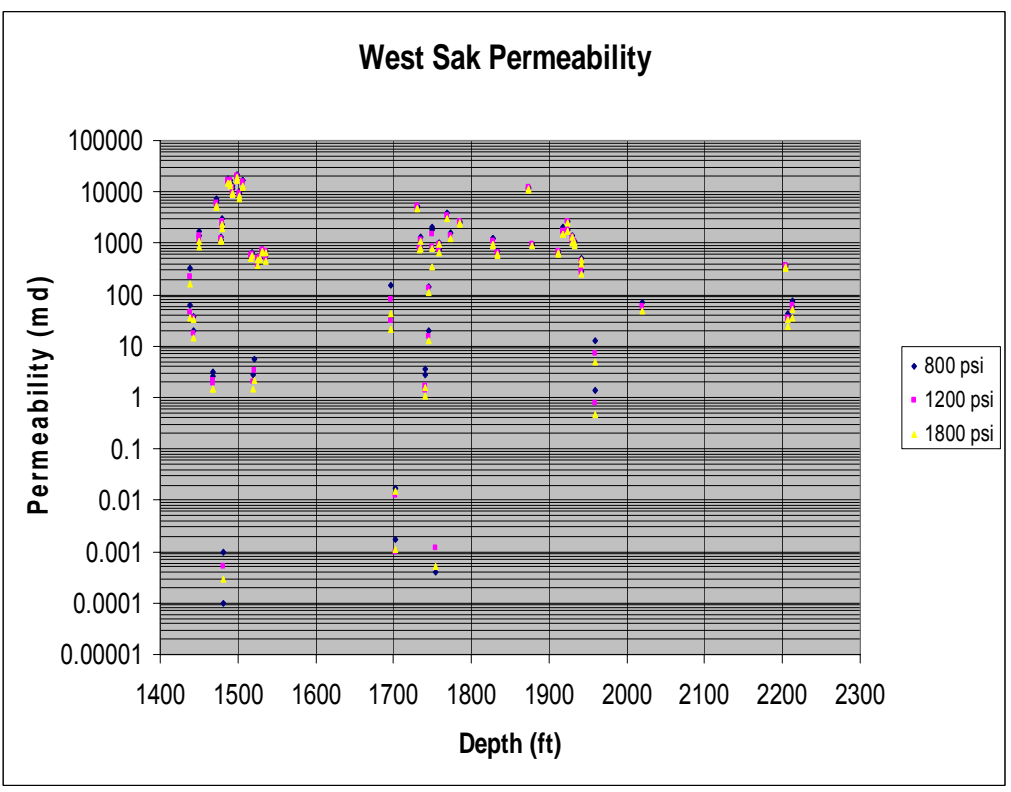




\section{Anomalous Hard Zones}

- Five Thin Zones Cored

$-1481 \mathrm{ft}$

$-1754 \mathrm{ft}$

$-1756 \mathrm{ft}$

$-1827 \mathrm{ft}$

$-2247 \mathrm{ft}$

- 1-2 ft Thick

- Visible on Logs

\section{Anomalous Hard Zones}

\begin{tabular}{|l|l|l|l|l|}
\hline Sample & Phi \% & $\begin{array}{l}\text { Resistivity } \\
\text { Rw }=23 \\
20 \mathrm{C}\end{array}$ & $\begin{array}{l}\mathrm{Vp} \\
\mathrm{km} / \mathrm{sec}\end{array}$ & $\begin{array}{l}\mathrm{Vs} \\
\mathrm{km} / \mathrm{sec}\end{array}$ \\
\hline $\begin{array}{l}\text { Typical } \\
\text { Sand }\end{array}$ & 38. & 1.5 & 2.1 & 1.1 \\
\hline 1482 & 1.1 & 254 & 4.9 & 2.4 \\
\hline 1702 & 18. & 16 & 4.5 & 1.9 \\
\hline 1754 & 2.2 & 63 & 4.5 & 1.6 \\
\hline
\end{tabular}




\section{Log Data Results}

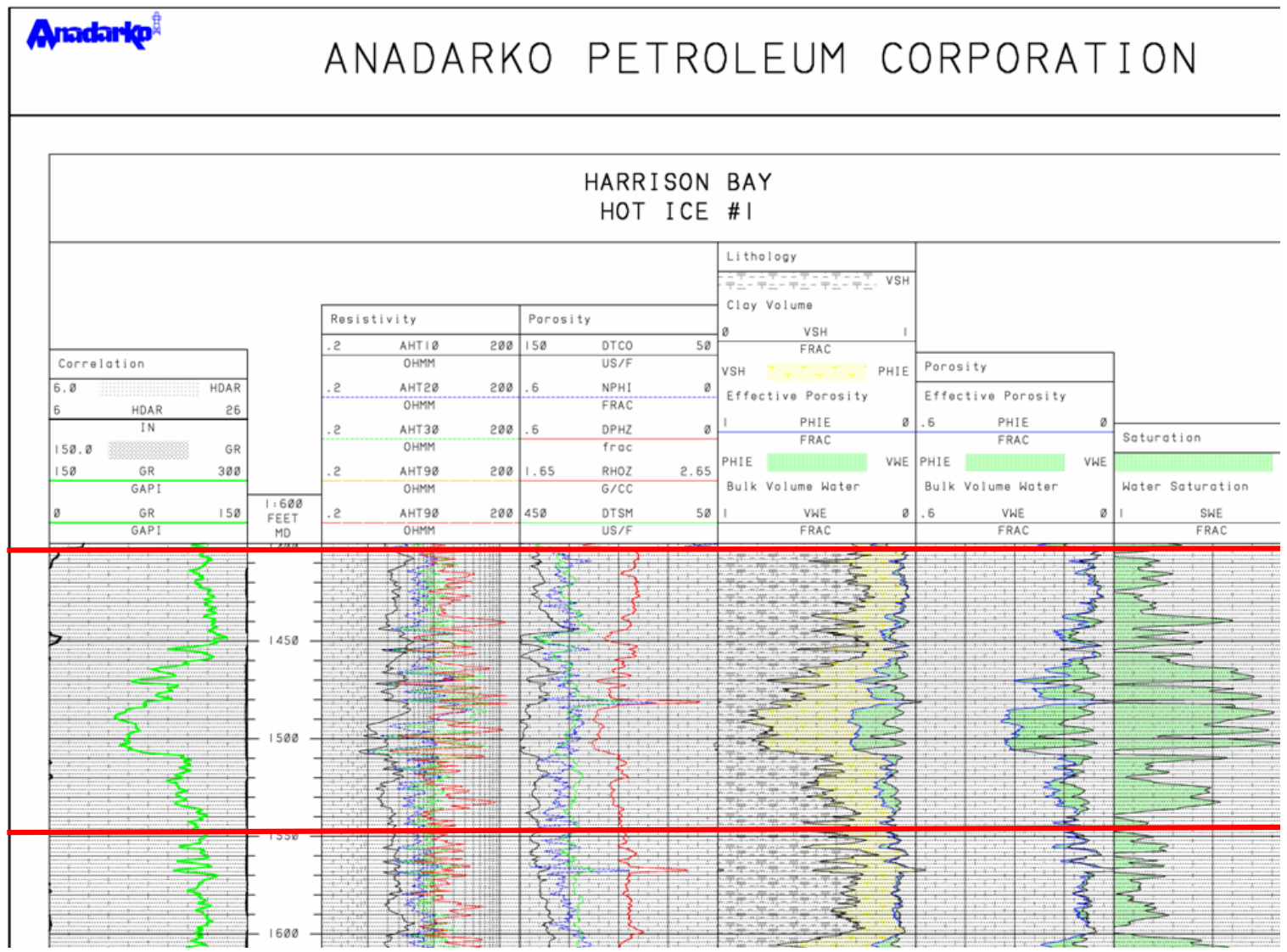

41 of 60

Anadarko Petroleum Corp. Maurer Technology Inc. 


\section{Geological Interpretation}

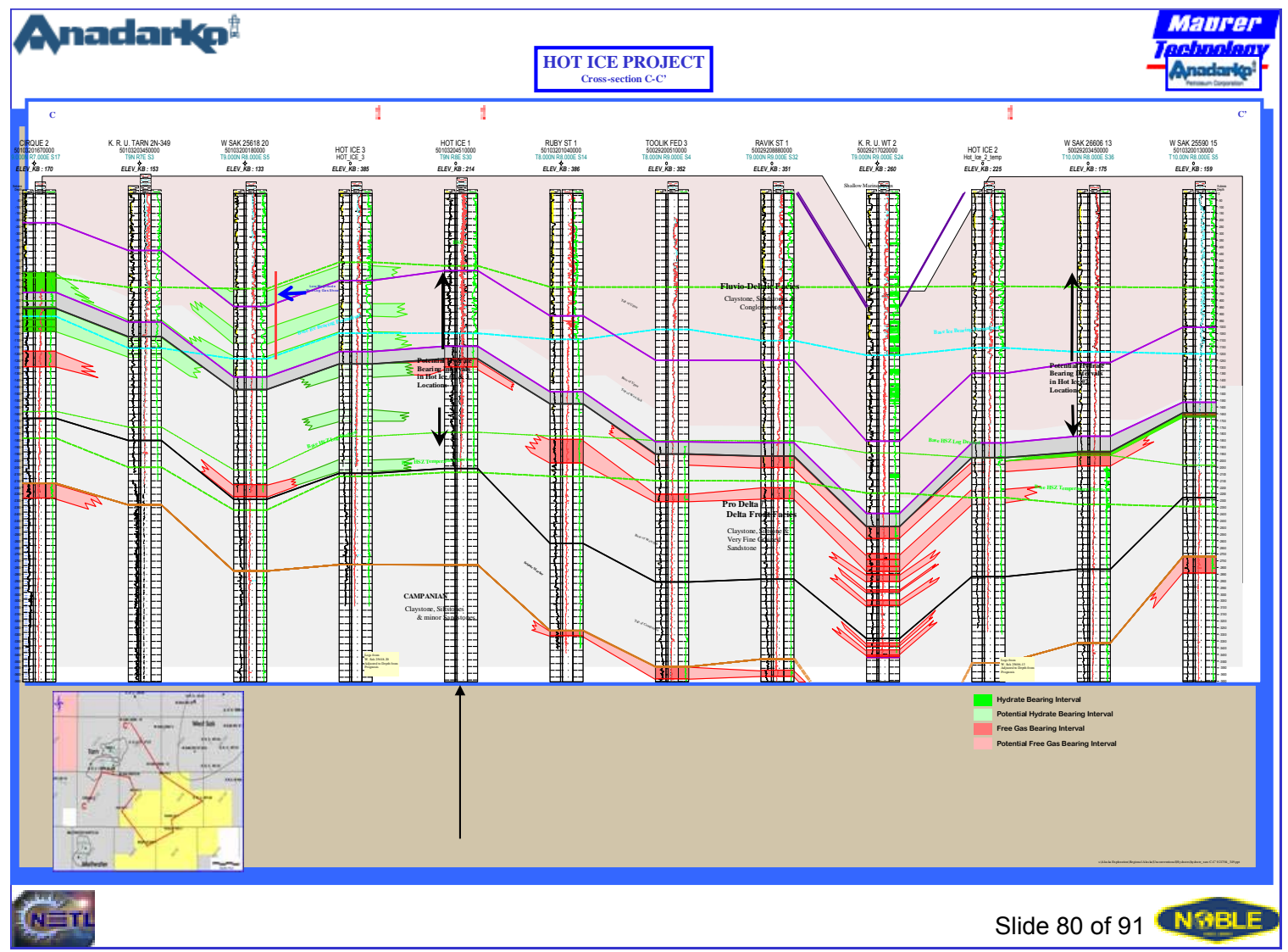



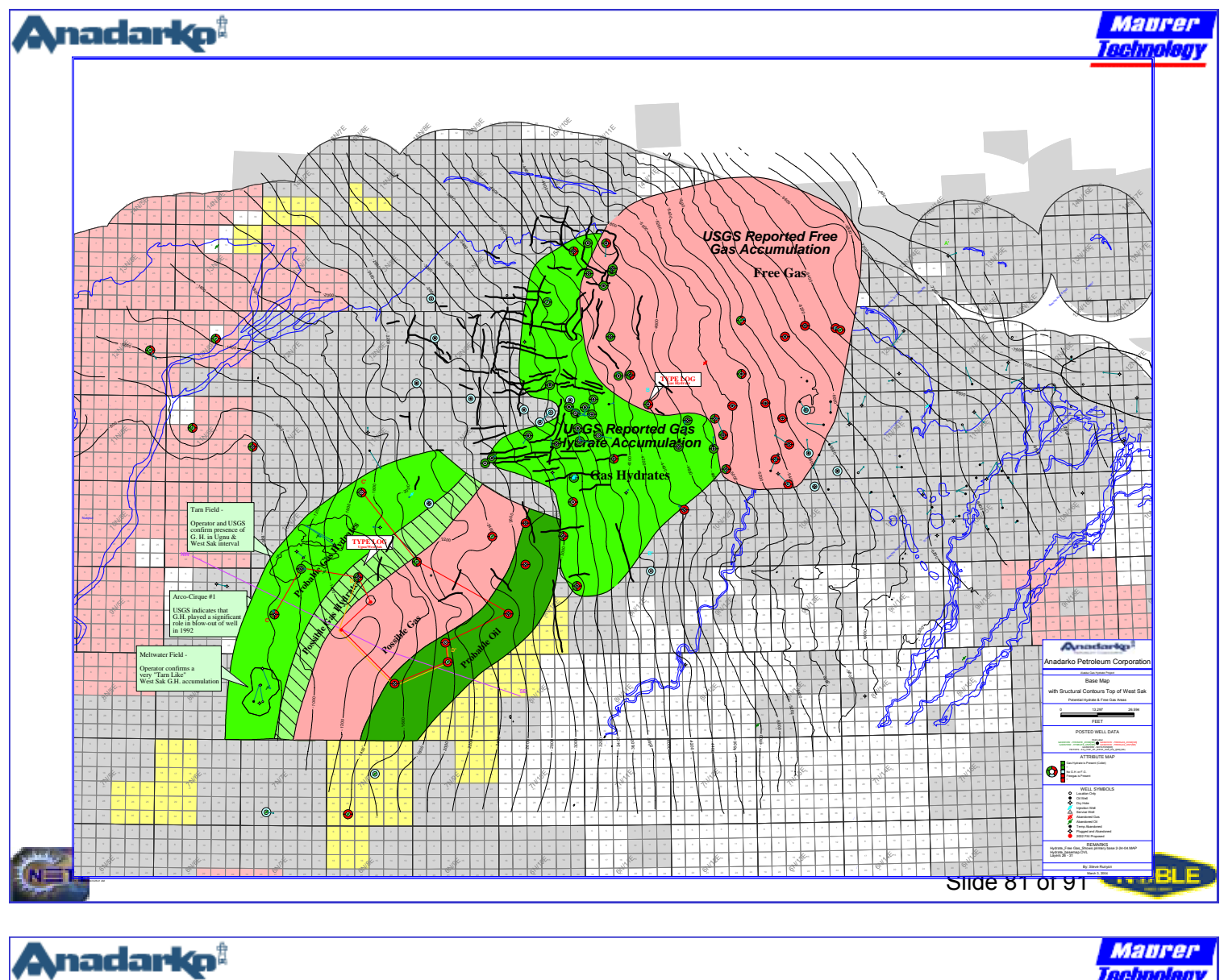

\section{Seismic Data Interpretation}




\section{D Seismic at Hot Ice well}

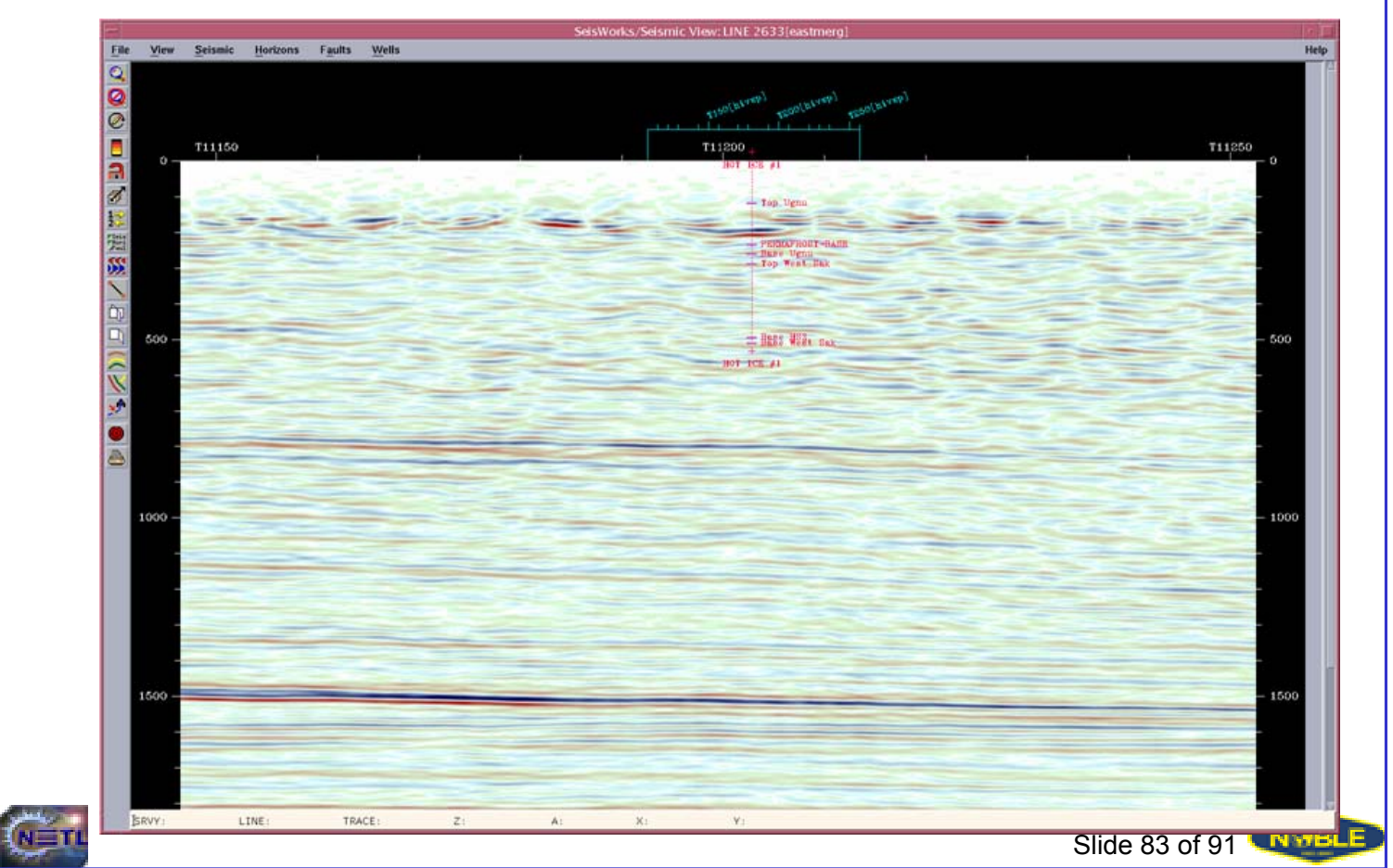

Anadarkip

\section{D Seismic and VSP at Hot Ice well}

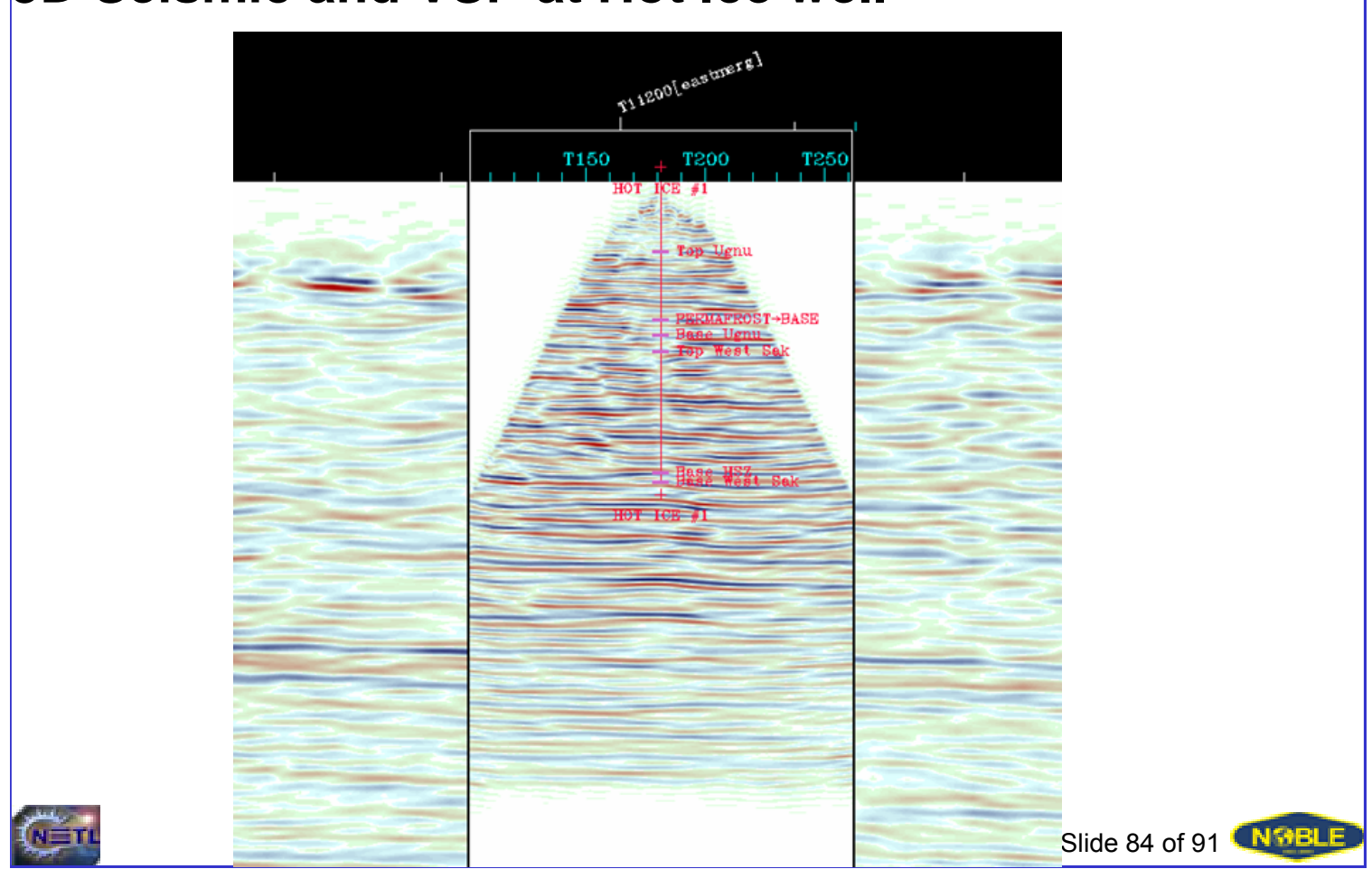



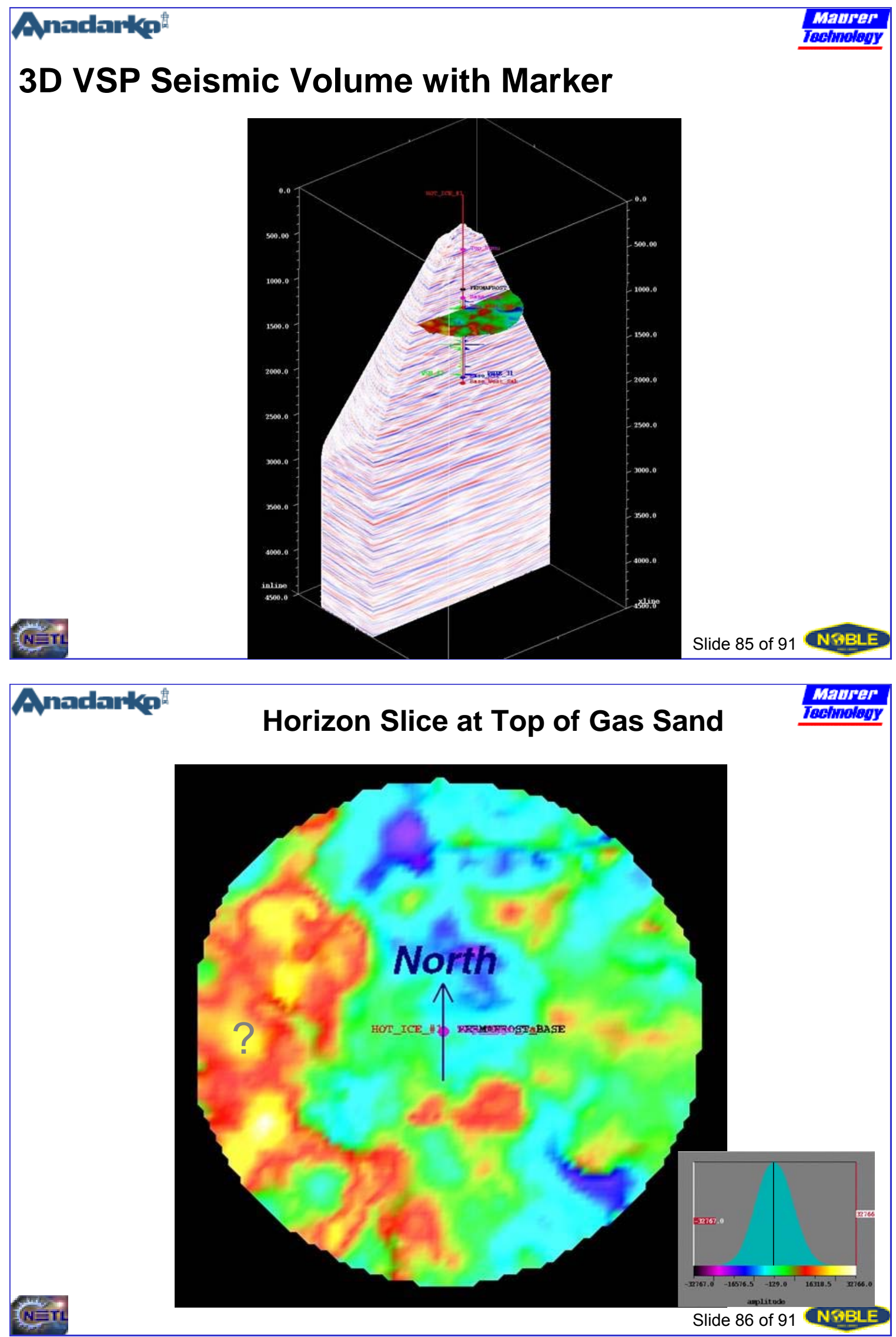


\section{Anadarkp ${ }^{\mathrm{t}}$ \\ Project Highlights}

- Concept of early access/occupation successfully demonstrated

- Low/minimal/virtually zero negative impact has been demonstrated.

- Drill/auger piling holes using a rolligon successfully demonstrated

- No access roads were required

- Ice 'trails' and ice 'work areas' were used to eliminate repetitive low impact environmental stress from low impact vehicles/rolligons and tracked vehicles

-The ability to haul heavier loads by rolligons without negative impact was demonstrated.

Arctic Platform and On-site Lab were demonstrated

- Leaving facility on location, loaded w/ equipment, demonstrated $\mathrm{w} /$ minimum/no impact on surrounding wildlife and flora

Negligible movement of legs throughout project (<.48 inches)

NA=T 50 of 51 legs removed by heating - (1 cut below grade)

\section{Project Highlights}

- Geological model used to predict potential hydrate-bearing strata was proven correct

- Ability to test and characterize the whole core on site was demonstrated

- Equipment developed for making hydrate-specific measurements

- (Lab and equipment now being provided by OU)

- Demonstration of LBNL CT for non-destructive core analysis

- Ability to quickly make Petrophysical measurements on core plugs at reservoir conditions was demonstrated 


\section{Project Highlights}

Rig and coring tools proved to be a safe and effective drilling system

- $93 \%$ of continuous core was recovered

- Successful use of a Rotating Head while Coring

Developed a custom Slimhole Dynamic Kill well control model

Data and video transmitted in real time

\section{Project Highlights}

- Real-time coal desorption tests conducted on coal core samples by USGS in 2003. Contrary to prediction, no coal found in 2004 drilling.

- Conducted massive shallow VSP on North Slope

- Successfully obtained open-hole logs throughout wellbore 


\section{Acknowledgments}

We gratefully acknowledge the many contributors to this project:

University of Oklahoma

Craig Woodard and the University of Alaska, Anchorage

Steve Kirby and Tim Collett with the United States Geological Survey

Robert Kleinberg, Doug Griffin with Schlumberger

Berry Freifeld and George Moridis with Lawrence Berkeley Labs

Pacific North West National Lab

Sandia National Lab

Ocean Drilling Program, JOI - Frank Rack

Anadarko Team - Tommy Thompson, Ali Kadaster, Donn McGuire, Steve Runyon, Richard Sigal, Bill Liddell and Jonathon Kwan

Paulsson Geophysical Services, PGS on-shore

Frances Toro and John Rogers, DOE NETL 


\title{
AAPG HEDBERG CONFERENCE \\ "Gas Hydrates: Energy Resource Potential and Associated Geologic Hazards" September 12-16, 2004, Vancouver, BC, Canada \\ Integration of VSP seismic data with core and well log data to investigate lateral variations of potential hydrate-bearing sands, Alaska North Slope
}

\author{
Donn McGuire and Steve Runyon, Anadarko Petroleum Corp., Tom Williams, Maurer \\ Technology, and Richard Sigal, University of Oklahoma
}

\begin{abstract}
In the winter seasons of 2003 and 2004, Anadarko Petroleum, Maurer Technology and Noble Drilling, in a cooperative effort with the U.S. Department of Energy's Office of Fossil Energy (contract DE-FC26-01NT41331), drilled an exploratory well on the Alaska North Slope to investigate the occurrence, subsurface distribution and producibility of methane hydrates. The well was continuously cored from surface to total depth in order to sample the entire thickness of the permafrost and hydrate-stability zone. An on-site mobile core laboratory was designed and fabricated to measure rock properties at the well site in nearly in-situ conditions. Geophysical measurements of the core included compressional and shear velocities and density.
\end{abstract}

A 3D vertical seismic profile (VSP) survey was recorded in February 2004 for the purpose of using high-frequency seismic data to identify and delineate lateral variations in the subsurface within the hydrate-stability zone. The VSP consisted of 1185 surface source points and 80 levels of three-component geophones at 25-ft intervals in the wellbore, resulting in a 3D survey of over 284,000 traces. Surface vibrators were used to create input signals with a frequency range from 8 to $220 \mathrm{~Hz}$ at each surface position.

The results of the VSP processing indicated useable frequencies (less than $-30 \mathrm{~dB}$ down from maximum) over $200 \mathrm{~Hz}$ were retained, and good quality, laterally consistent reflection events were imaged.

The processed VSP seismic data were correlated with the well log and core data to provide an integrated characterization of the Ugnu and West Sak sands within the hydrate-stability zone. Lateral variations in amplitude and reflectivity of the 3D VSP data were identified and investigated for evidence of changes in lithology or in hydrate/free-gas pore content. 


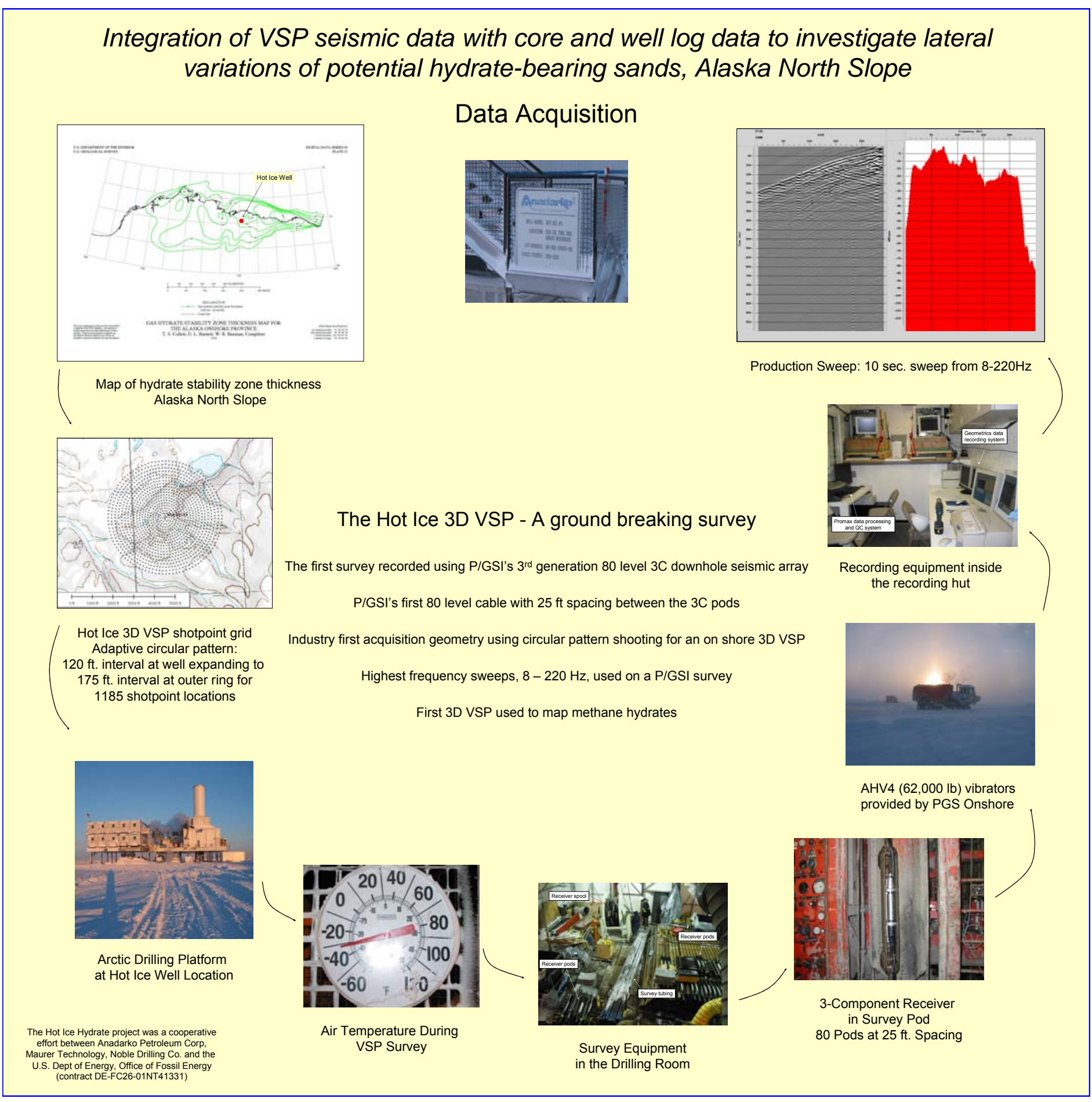




\section{D VSP Survey - Data Processing}

\begin{tabular}{|l|}
\multicolumn{1}{|c|}{ Processing Steps } \\
A) Receiver geometry \\
B) 3-component orientation \\
C) First break picks \\
D) Wavefield separation \\
E) Statics correction \\
F) Deconvolution \\
G) Amplitude recovery \\
H) Velocity computation \\
I) Prestack depth migration \\
\hline
\end{tabular}

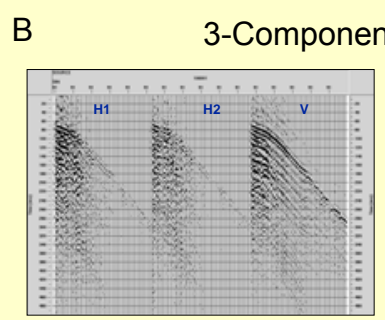

Before Rotation to $\mathrm{XYZ}$ (shotpoint due North)
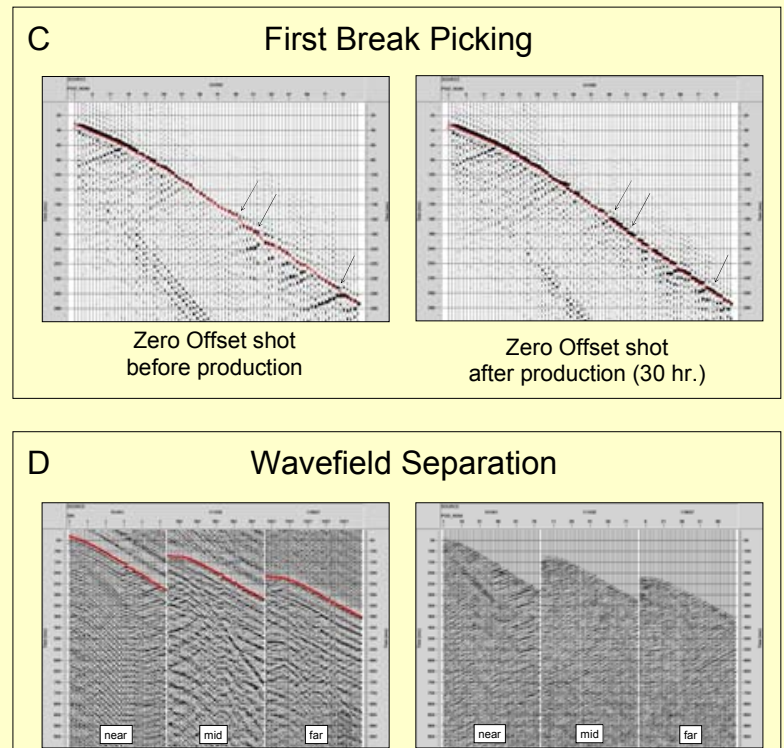

Raw data with AGC

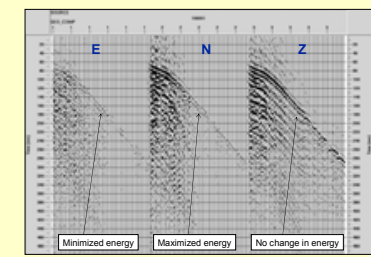

After Rotation to $\mathrm{XYZ}$ (shotpoint due North)
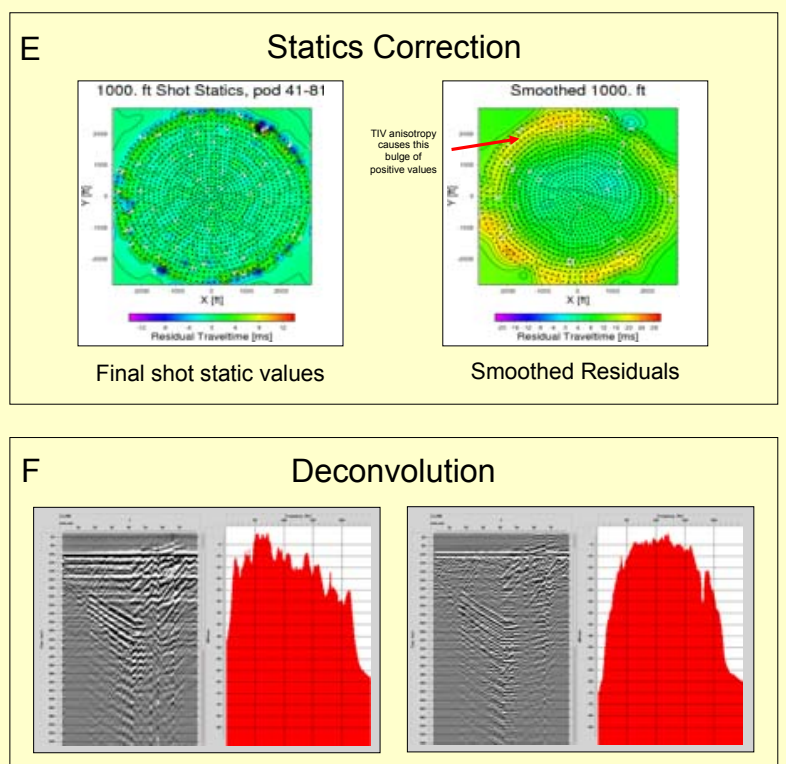

Raw wavefield at zero offset

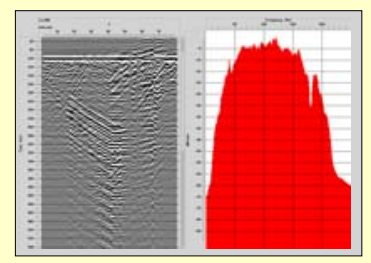

Wavelet inversion at zero offset
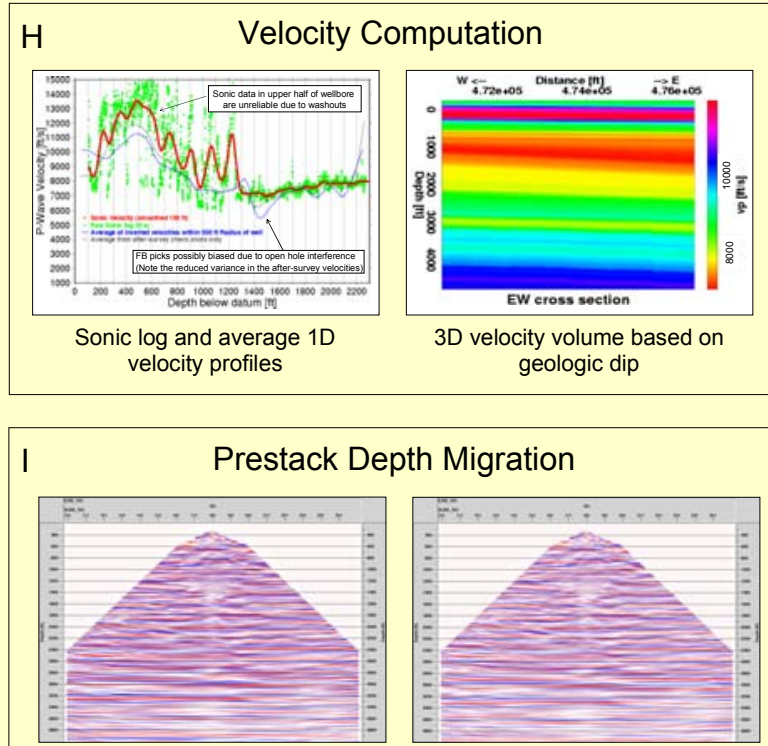

W - E slice, normalized stack 1D model

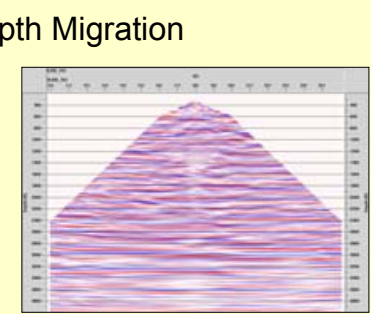

W - E slice, normalized stack 3D model 


\section{D VSP Survey - Results}

Well logs from Hot Ice No.1

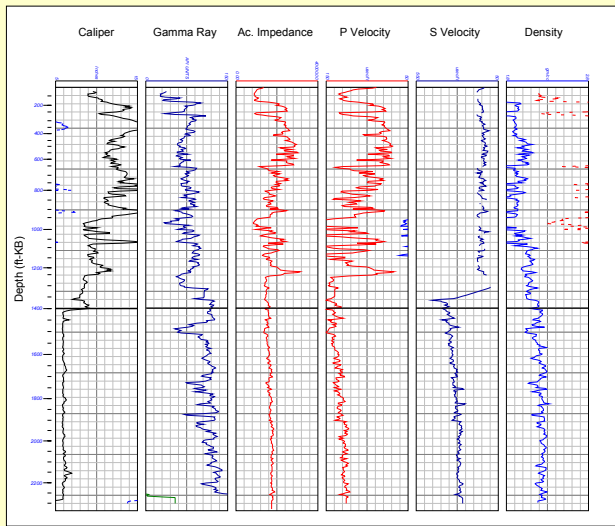

Data above $1400 \mathrm{ft}$ are unreliable due to hole washout
Synthetic seismograms from Vp, Vs and Density logs

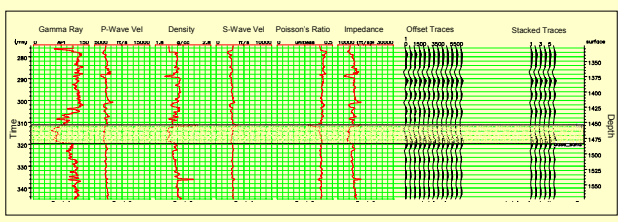

In situ sand should have little reflectivity at the top and a weak to moderate peak at the base on stacked zero phase data

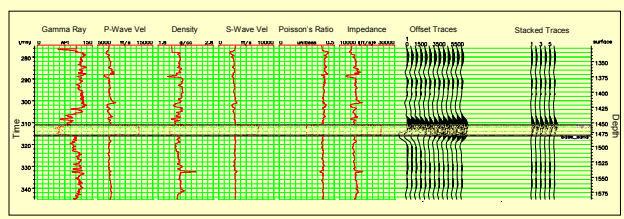

Hydrate-bearing sand should have a strong peak at the top and no reflectivity at the base on stacked, zero phase data

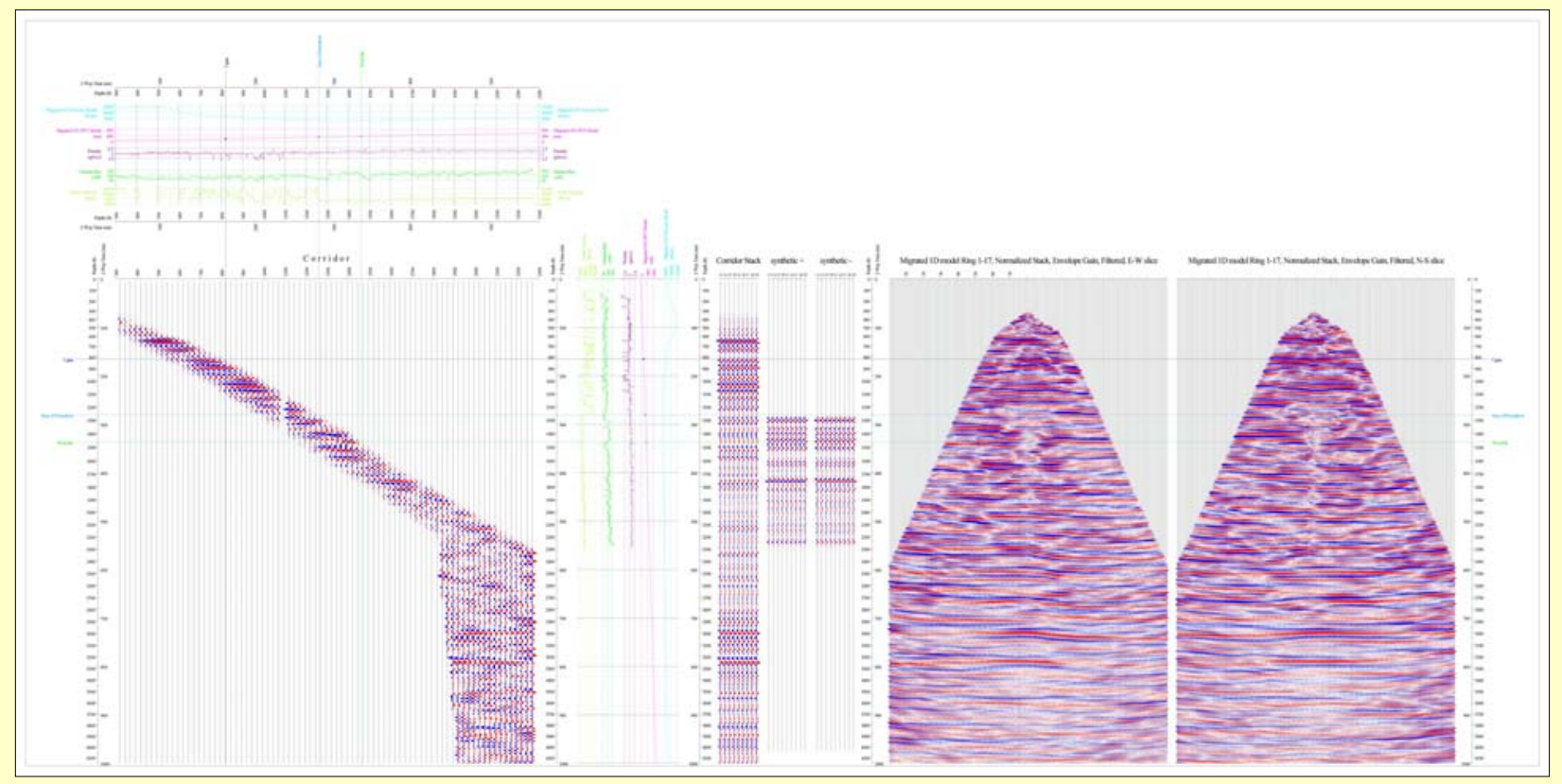

VSP "L" plot showing the correlation between well data, VSP corridor plot, synthetic seismograms and migrated VSP profiles at the well location 


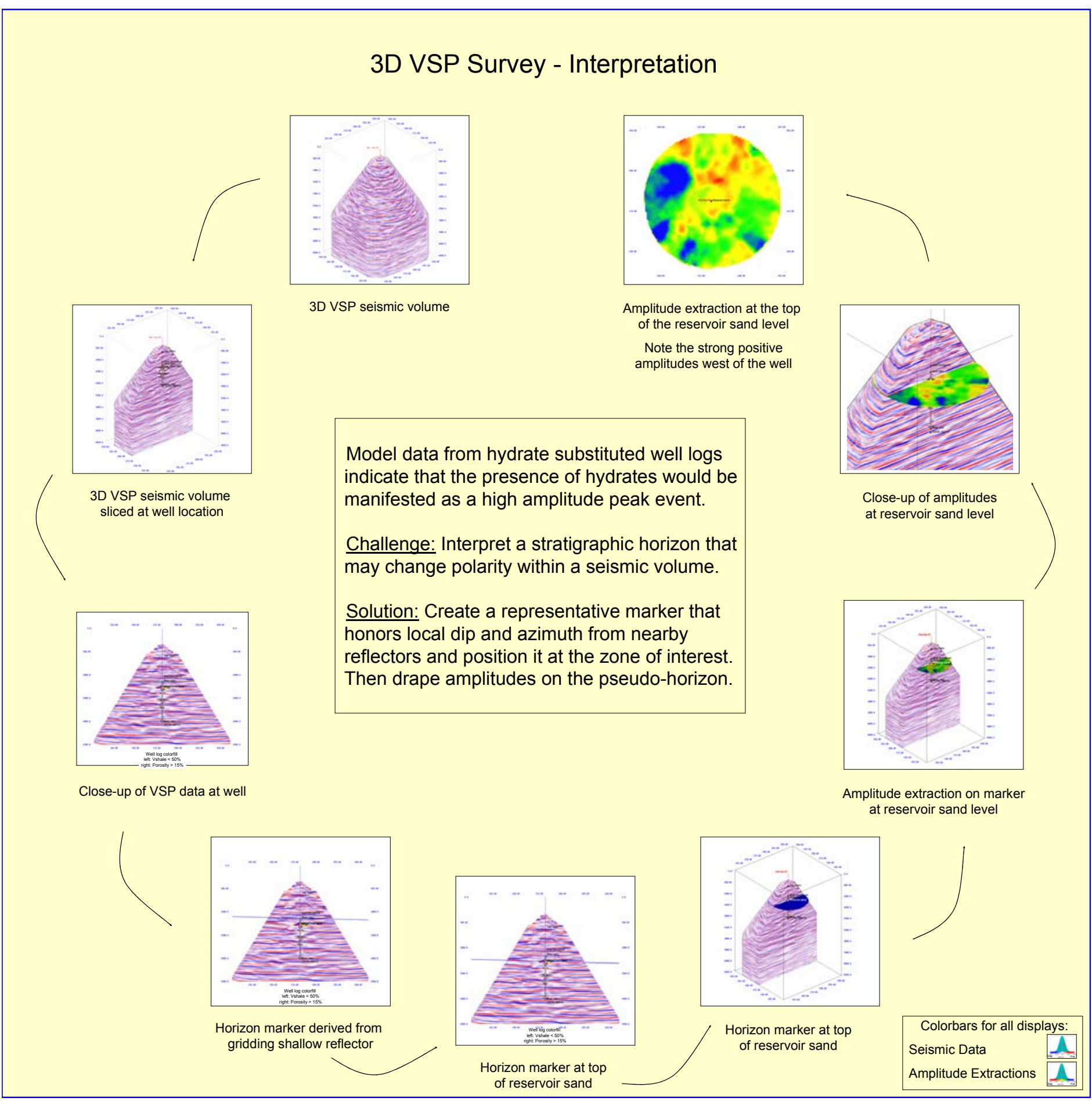




\title{
AAPG HEDBERG CONFERENCE \\ "Gas Hydrates: Energy Resource Potential and Associated Geologic Hazards" September 12-16, 2004, Vancouver, BC, Canada \\ Characterization of Potential Hydrate Bearing Reservoirs in the Ugnu and West Sak Formations of Alaska's North Slope
}

\author{
Richard Sigal, Chandra Rai, and Carl Sondergeld, University of Oklahoma \\ Jim Ebanks and William Zogg, PTS Labs \\ Robert Kleinberg, Schlumberger
}

During the winter operations seasons of 2003 and 2004, Anadarko Petroleum, in cooperation with Maurer Technology and Noble Corporation and with support of the US Department of Energy, drilled and cored a shallow well, Hot Ice 1, located at 30-T9N-R8E, Umiat Meridian, on the North Slope of Alaska. The well location is on an Anadarko Lease that is located about 5 miles down dip from the established hydrate occurrences in the Cirque well and in wells in the Tarn Field. Primary goals of the operation were to recover and characterize hydrate-bearing core and potential hydrate and shallow gas reservoir rocks, and to test several technologies designed to improve the economic viability of North Slope exploration. These technologies included a lightweight continuous coring system, an Arctic Platform, and an on-site mobile core characterization lab. Anadarko Petroleum worked with Rock Properties Resources to design and build the mobile lab that contained both standard core characterization capacity and equipment specially designed to measure properties of hydrate-containing sediments. The lab has the capacity to make measurements on plugs at below freezing temperatures, under specified confining and pore pressures. This lab was operated on the drill site by a team from Corpro and PTS. All measurements discussed in this paper were recorded in the portable lab on the drilling platform or in Deadhorse.

The Hot Ice No. 1 well was drilled from the surface to $2300 \mathrm{ft}$. There was almost $100 \%$ core recovery from the bottom of surface casing at $107 \mathrm{ft}$ to TD at $2300 \mathrm{ft}$ from the surface. Based on the best estimate of the bottom of the methane hydrate stability zone, core was recovered over its complete range. Approximately $565 \mathrm{ft}$ of good sandstone reservoir rock were recovered in the Ugnu formation and approximately $215 \mathrm{ft}$ were recovered in the West Sak. There were gas shows in the bottom part of the Ugnu and throughout the West Sak. No hydrate-bearing zones were identified either in the recovered core or on the well logs.

The whole core was described by the well-site geologists who produced a detailed lithology log and core description. Core photographs and a gamma ray log were also recorded for the whole length of the core. During 2003 operations, a CMR logging tool located in the mobile lab made an NMR measurement on a 6-inch section from each 40-inch length of core. The tool was donated for use by Schlumberger and operated by a Schlumberger team (Robert Kleinberg and Doug Griffin). This measurement provided an estimate of the amount of unfrozen brine in the "frozen rocks" from the permafrost section. The median value for the unfrozen porosity in the permafrost zone was 0.051 . For the rocks in this section this corresponds to about $13 \%$ of the pore space being filled with unfrozen brine. All whole core measurements were recorded in a lab module maintained at a temperature below the freezing point of water.

One-inch plugs were cut from all the potential reservoir rock identified by the well site geologists. Thick sections had several plugs cut. At some stage all the plugs were cleaned and dried. After this porosity, permeability, and grain density were measured. The other procedures on the plugs followed two paths depending on if they came from the "permafrost zone" or from the deeper section. For samples from the permafrost zone, velocity and resistivity were 
measured on recovered state samples at subfreezing temperatures. Thermal conductivity was also measured on some. NMR measurements were performed on a few frozen plugs and on thawed plugs, and some resaturated samples. For samples taken from unfrozen formations, the complete suite of measurements was done after cleaning and drying.

With the exception of the deepest sands in the West Sak and some anomalous thin tight zones, all sands recovered were unconsolidated high-porosity, high-permeability formations. At 800 psi the Ugnu sands had an average porosity of $39.3 \%$ and geometrical mean permeability of 3.7 Darcys. Their average grain density was $2.64 \mathrm{~g} / \mathrm{cc}$. West Sak sands had an average porosity of $35.5 \%$, geometrical mean permeability of 0.3 Darcys and average grain density of 2.69.

There were several 1-2 ft thick cemented sand zones recovered from the West Sak. These zones had only a few percent porosity and almost no measurable permeability. On a well log they appear as very resistive with a high velocity. In shallow sections of wells these are usually the only logs available. Given the presence of gas in the Hot lce 1 well, if those logs along with a mud log had been the only data available, the tight sand zones would probably have been identified as hydrates. Although this does not imply that mapped hydrate zones are tight sands, it does add a note of caution to identifying hydrates from old well information.

Plug NMR measurements in the Ugnu present some interesting unanswered questions. There are significant differences between thawed measurements and resaturated measurements on the same samples. As of yet no completely satisfactory model to explain the differences has been found. Observed relaxation times for the samples are somewhat more rapid than usually observed for rocks with such high permeability. Finally the NMR measurements do not produce a good permeability estimator.

The NMR measurements on the West Sak samples are higher what would be expected. This may be due to the fact that measurements were made only after resaturation. For these samples a very good permeability estimator could be developed. The formula differed from the default formula by a factor of three so that the West Sak samples have a relaxation rate 1.7 times that of the samples used to develop the default formula.

In summary, the methane hydrate-stability zone below the Hot Ice No. 1 location has thick sections of sandstones that would make excellent reservoir rocks for either shallow gas or hydrates. The Ugnu contains more sand sections than the West Sak formation and the Ugnu is slightly more porous and significantly more permeable. 


\section{Characterization of Potential Hydrate Bearing Reservoirs in the Ugnu and West Sak Formations of Alaska's North Slope.}

Richard Sigal, Chandra Rai, and Carl Sondergeld, University of Oklahoma

Jim Ebanks and William Zogg, PTS Labs

Robert Kleinberg, Schlumberger
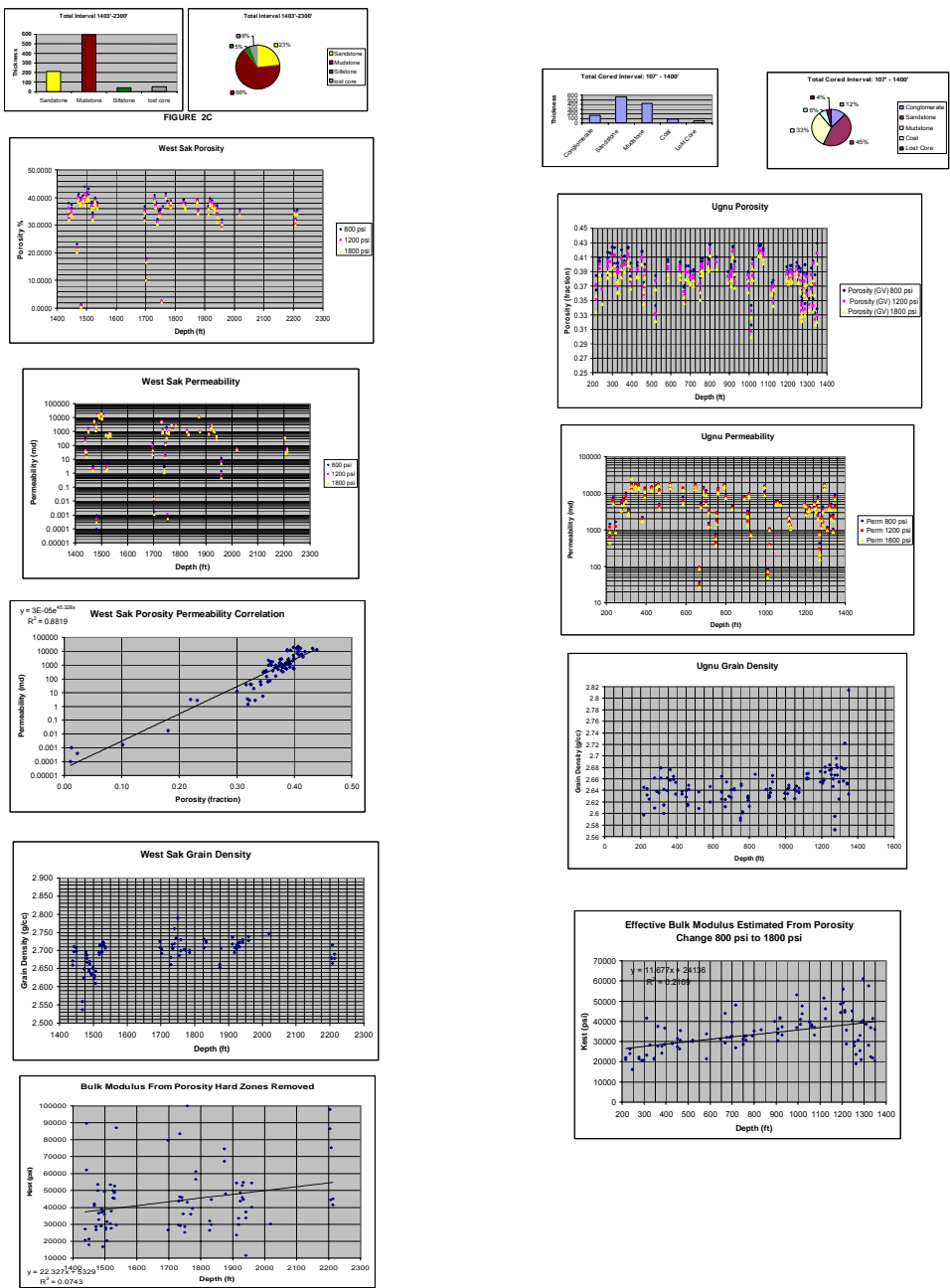
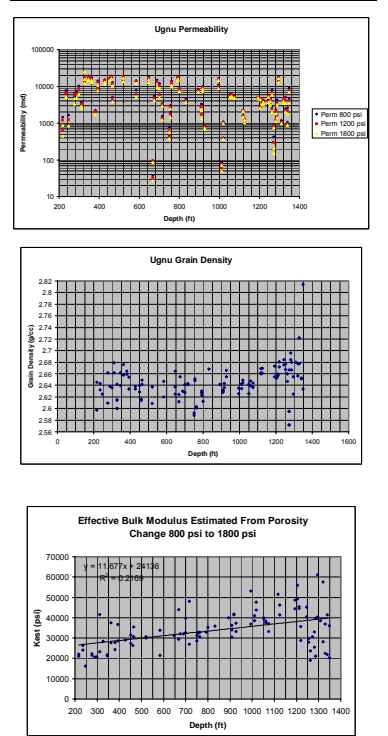

Ugnu NMR Rock Types
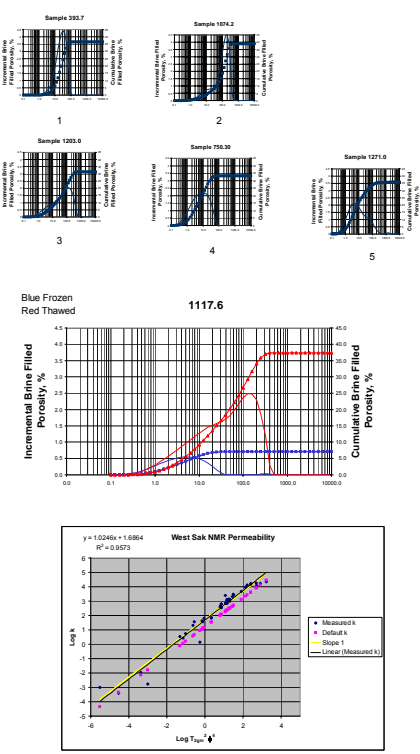


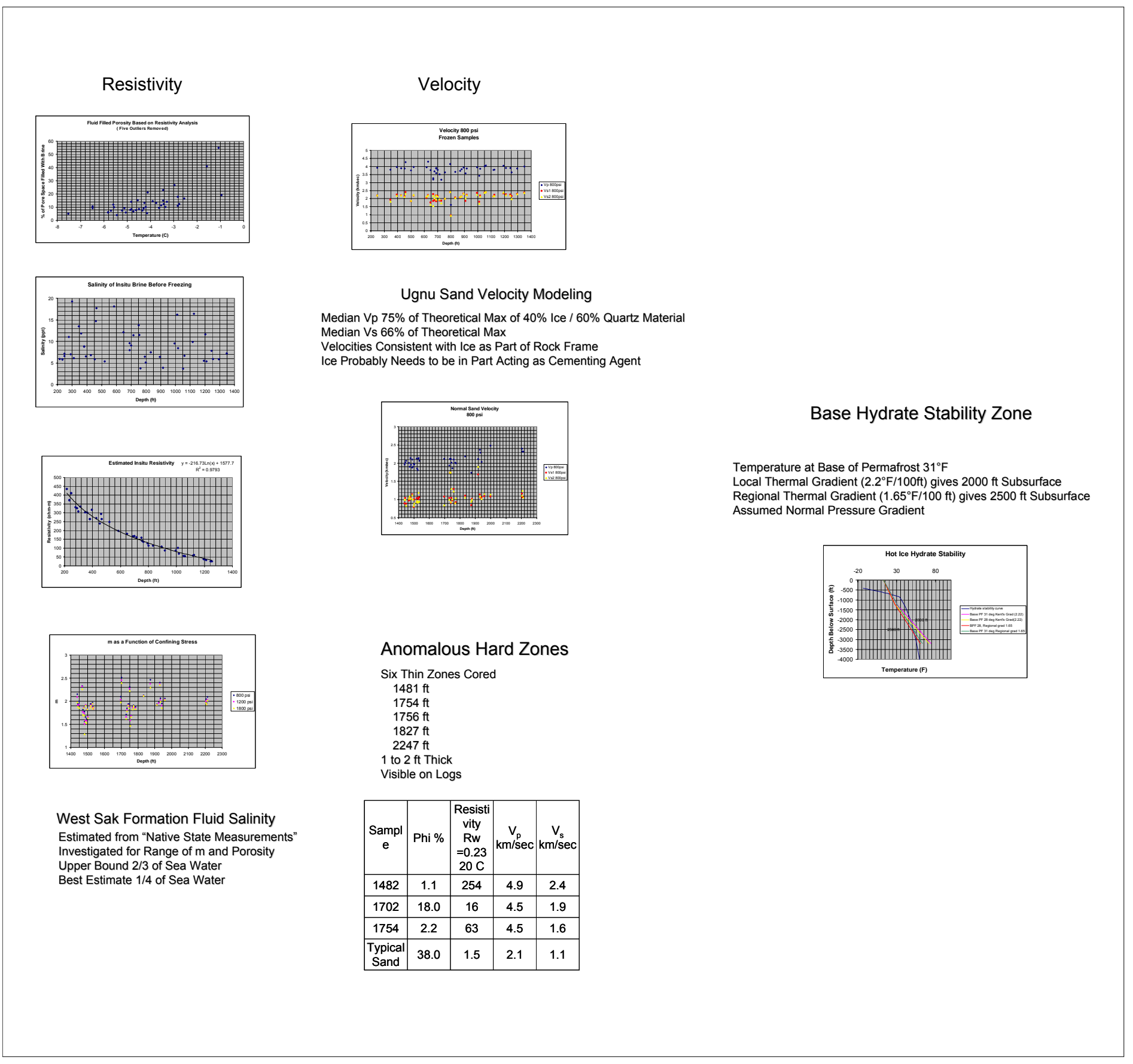




\section{Mobile Core Lab \\ North Slope Configuration}
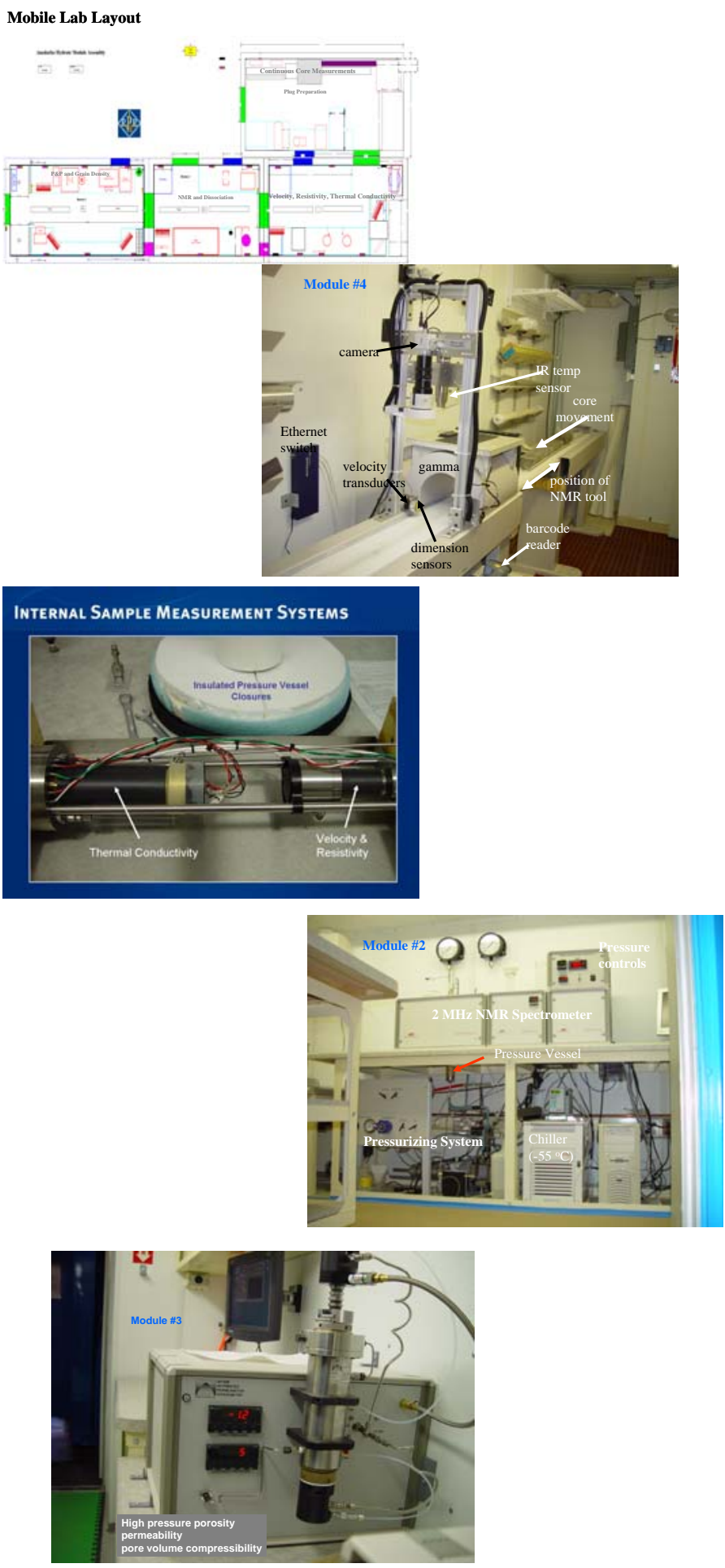
